$\underline{\text { PNL-2133 }}$

UC-71

\title{
An Assessment of the Risk of Transporting Gasoline by Truck
}

R. E. Rhoads

Project coordinator

November 1978

Prepared for the U.S. Department of Energy under Contract EY-76-C-06-1830

Pacific Northwest Laboratory Operated for the U.S. Department of Energy by Battelle Memorial Institute 


\title{
NOTICE
}

This report was prepared as an account of work sponsored by the United States Covernment. Neither the United States nor the Department of Energy, nor any of their employees, nor any of their contractors, subcontractors, or their employees, makes any warranty, express or implied, or assumes any legal liability or responsibility for the accuracy, completeness or usefuiness of any information, apparatus, product or process disclosed, or represents that its use would not infringe privately owned rights.

The views, opinions and conclusions contained in this report are those of the contractor and do not necessarily represent those of the United States Government or the United States Department of Energy.

\author{
PACIFIC NORTHWEST LABORATORY \\ operated by \\ BATTELLE \\ for the \\ UNITED STATES DEPARTMENT OF ENERGY \\ Under Contract EY-76-C-06-1830
}

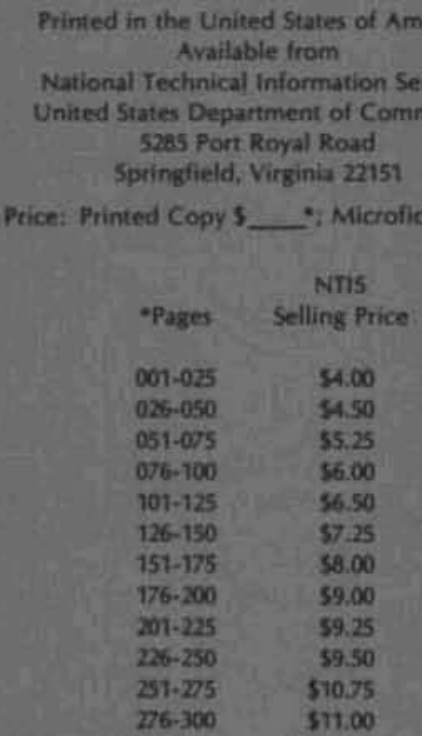


Technical Contributors

J. L. Buelt

G. W. Dawson

T. W. Horst

P. L. Peterson

B. A. Ross

November 1978

Prepared for the U.S. Department of Energy under Contract EY-76-C-06-1830

Pacific Northwest Laboratory

Richland, WA 99352 
$-$ 


\section{CONTENTS}

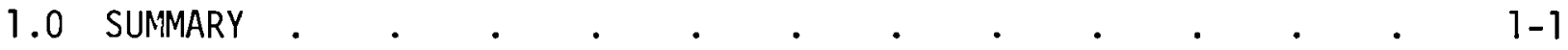

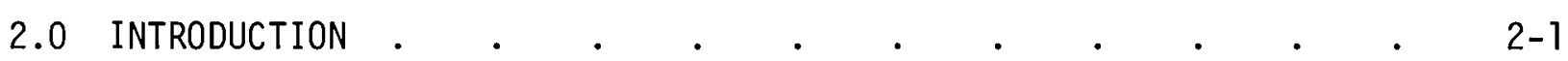

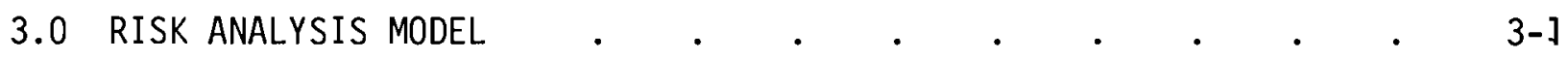

3.1 RISK MODEL DESCRIPTION .

3.1.1 System Description . . . . . . . . 3-3

3.1.2 Release Sequence Identification . . . . . . 3-4

3.1.3 Release Sequence Evaluation . . . . . . 3-4

3.1.4 Risk Calculation and Assessment . . . . . 3-7

4.0 SHIPPING SYSTEM DESCRIPTION .

4.1 GASOLINE SHIPPING REQUIREMENTS $\quad$. $\quad$. . . . . . . . 4-1

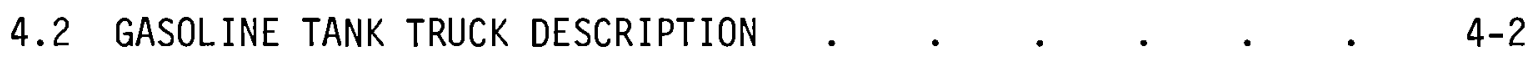

5.0 TRANSPORTATION ACCIDENT ENVIRONMENT $\quad$. . . . . . . . . . 5-1

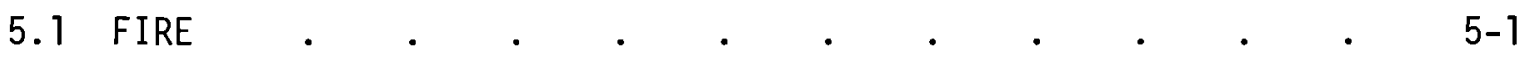

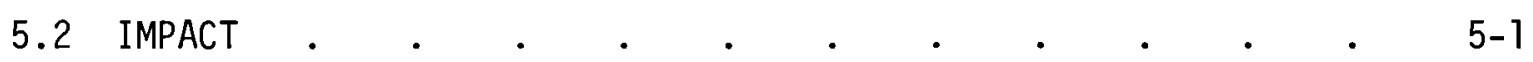

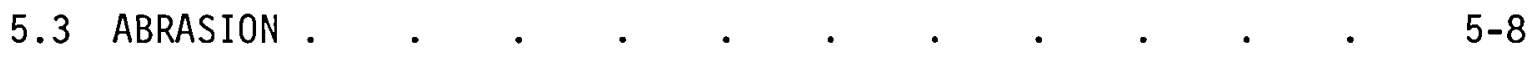

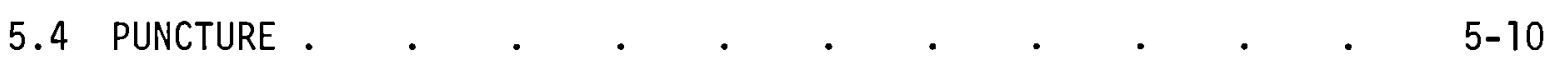

6.0 GASOLINE TANK TRUCK FAILURE THRESHOLDS . . . . . . . . . 6-1

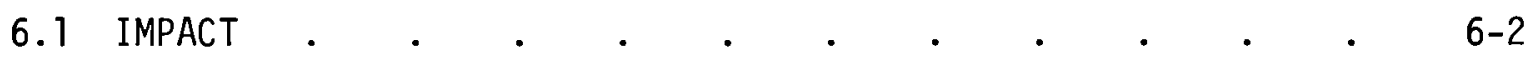

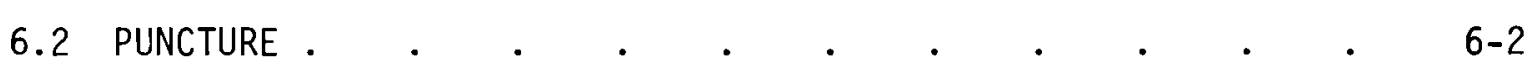

6.3 ABRASION .

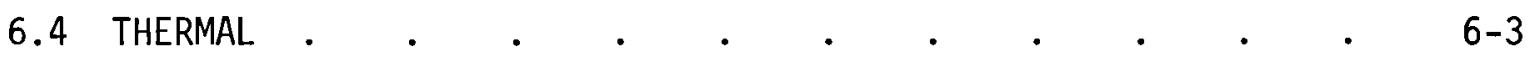

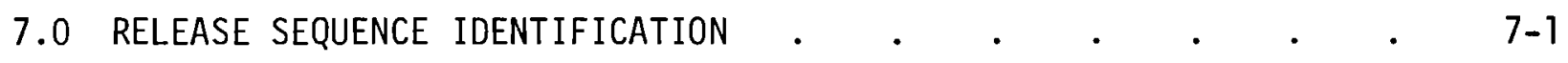

7.1 FAULT TREE CONSTRUCTION . . . . . . . . . . . . . . 
7.2 FAULT TREE FOR SHIPMENT OF GASOLINE BY TRUCK . . . 7-3

7.3 RELEASE SEQUENCES • • • • • • • • • • •

8.0 RELEASE SEQUENCE EVALUATION . . . . . . . . . . . . . . . .

8.1 BASIC EVENT PROBABILITIES . . . . . . . . . 8-2

8.2 RELEASE SEQUENCE PROBABILITIES .

8.3 RELEASE FRACTIONS . $. \quad . \quad$.

9.0 EVALUATION OF THE CONSEQUENCES OF GASOLINE RELEASES . . . . .

9.1 CONSEQUENCES OF GASOLINE POOL FIRES . . . . . . . . . 9-1

9.2 CONSEQUENCES FROM THE FORMATION OF GASOLINE VAPOR CLOUDS • 9-8

9.3 CONSEQUENCES OF TANK TRUCK EXPLOSIONS • • • • • • • $\quad$ • 9-10

10.0 THE RISK OF SHIPPING GASOLINE BY TRUCK . . . . . . . . 10-1

10.1 RISK EVALUATION FOR GASOLINE SHIPMENTS . . . . . . 10-1

10.2 RISK SENSITIVITY EVALUATIONS . . . . . . . . 10-6

APPENDIX A - GASOLINE TANK TRUCK DESCRIPTION AND OPERATING PROCEDURES . A-1

APPENDIX B - PHYSICAL PROPERTIES OF GASOLINE . . . . . . . . B B-1

APPENDIX C - ATMOSPHERIC DIFFUSION OF GASOLINE VAPORS FROM AN EVAPORATING $\mathrm{POOL}$. $. \quad . \quad . \quad . \quad . \quad . \quad . \quad . \quad . \quad . \quad . \quad C-1$

APPENDIX D - CALCULATION OF GASOLINE TANK TRUCK FAILURE THRESHOLDS . D-1

APPENDIX E - CHARACTERISTICS OF GASOLINE FIRES . . . . . . . E-1

APPENDIX $F$ - ESTIMATE OF DAMAGE FROM GASOLINE TANK TRUCK EXPLOSIONS • F-1

APPENDIX G - ESTIMATE OF SECONDARY FIRES INITIATED BY GASOLINE POOL FIRES G-1 


\section{FIGURES}

1.1 Risk Spectrum for Gasoline Shipments by Truck in 1980 . . . 1-3

3.1 Model to Calculate the Risk of Shipping Hazardous Material . . 3-2

3.2 Information Required to Describe Transport System . . . 3-5

4.1 Tractor/Semitrailer Used for Gasoline Shipments in the Eastern U.S. 4-3

4.2 Tank Truck/Tank Trailer Used for Gasoline Shipments in the Western U.S. . . . . . . . . . . . . . . $4-3$

5.1 Expected Duration of Fires for Accidents Involving a Truck with Nonflammable Cargo . . . . . . . . . . . 5-2

5.2 The Expected Maximum Velocity Change Given a Truck Subjected to a

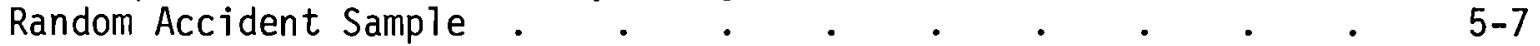

5.3 The Expected Maximum Kinetic Energy Change Ratio Given a Truck Subjected to a Random Accident Sample . . . . . . . . $5-8$

5.4 DOT Hazardous Materials Incident Report . . . . . . . 5-11

7.1 Gasoline Truck Transportation Fault Tree . . . . . . 7-4

8.1 Remaining Steps in the Risk Evaluation . . . . . . . . 8-1

9.1 Gasoline Transportation Accident Consequence Model . . 9-2

9.2 Probability Distribution for Fatalities in a Building Fire. . 9 9-5

9.3 Estimated Total Number of Vehicle Occupants Involved in Heavy Truck Accidents Plotted as a Function of Accident Frequency a 9-9

10.1 Risk Spectrum for Release of Gasoline from Tank Truck Accidents in $1980 . \quad . \quad . \quad . \quad . \quad . \quad . \quad . \quad . \quad . \quad$. $\quad . \quad 10-2$

10.2 Accident Fatalities Not Associated with Hazardous Nature of Cargo 10-3

10.3 Sensitivity of Risk to Probability of Failure from Puncture 'Forces 10-8

10.4 Sensitivity of Risk to Assumption of the Probability of an Explosion, Given a Release . . . . . . . . . 10-8

10.5 Sensitivity of Risk to Number of Vehicle Occupant Fatalities in a Fire $. \quad . \quad . \quad . \quad . \quad . \quad . \quad . \quad . \quad . \quad .10-9$ 
10.6 Effect on Risk of Strengthening Tank or Installing Fire Suppression System .

A.1 DOT Specification MC-306 Tank Truck and Trailer Used for Gasoline Shipments in the Western U.S:

A.2 Gasoline Trailer Tank Outlet Valve for Western Shipping System - A-4

A.3 Outlet Valve Showing Internal Valve Mechanism . . . . A-5

A.4 Gasoline Tank Truck Outlet Assembly . . . . . . . A-5

A.5 Tank Top Showing Manway Cover and Protective Rails . . . A-7

A.6 Photograph of Manway Cover . . . . . . . . . . A-7

A.7 Schematic Drawing of Manway Cover Showing Pressure and Vacuum Relief Devices

A.8 MC-306 Semitrailer Used for Gasoline Shipments in the Eastern U.S. A-9

A.9 Outlet Valve Assembly for 4-Compartment Semitrailer . . . A-10

B.1 Vapor Pressure of Gasoline . . . . . . . . . . B-2

D. 1 Buckling Mechanism of a Thin-walled Tube Under Axial Compression D-2

D.2 End View of Tank Truck After Overturn Accident . . . . D-5

D.3 Relative Angle of Contact Required for Puncture . . . . D-7

D.4 Shear Force Required to Puncture Tank as a Function of Probe Diameter. . . . . . . . . • . . D-8

D.5 Energy to Shear Tank Skin as a Function of Probe Diameter . . D-9

D.6 Total Energy for Puncture as a Function of Probe Diameter . . D-10

D.7 Deformed Configuration of a Tank Overturning with Forward Velocity Showing Primary Wear Areas . . . . . . D-12

D.8 Side View of Tank Truck After Overturn Accident . . . . D-13

E.1 Safe Separation Distance from a Hydrocarbon Fire . . . . E-2

E.2 Flame Angle as a Function of Windspeed and $M / T_{b} \cdot$. . . E-2

E.3 Radiant Exposures to Cause Various Flesh Burns . . . . E-3 
E.4 Radiation from 10-ft Diameter JP5 Fires versus Radiometer Leve1

Above Ground . . . . . . . . . . E E-4

E.5 Radiant Flux as a Function of Distance from JP5 Fire . . . . E-5

E.6 Variation of Radiant Heat Flux with Downwind Distance from a 55-ft Radius Gasoline Pool Fire . . . . . . . . . . E-6

E-7 Radiant Exposures to Ignite Various Materials . . . . . E- $\bar{i}$

F.1 Explosion Pressures over the Explosive Range of Gasoline . . F-3

F.2 Assumed Burning Process for Calculation of Equivalent Heat of Combustion of Gasoline . $. \quad . \quad . \quad . \quad . \quad$.

F.3 Effective Heats of Combustion of Gasoline . . . . . . . F-5

F.4 Explosion Damage Limits versus Scaled Range . . . . . . . F-6

F.5 Probable Total Destruction, Serious Structural Damage and Missile Damage Limits for Gasol ine and Air Mixtures . . . . . . F-6

G.1 Assumed Gasoline Pool Shapes and Safe Separation Distance for Various Windspeeds for a Gasoline Pool Fire on a City Street . G-2

G.2 Residential Area Models Used to Estimate Secondary Fires from Gasoline Spills

G.3 Industrial Area Model Used to Estimate Secondary Fires from Gasoline Spills . . . . . . . . . . . . .

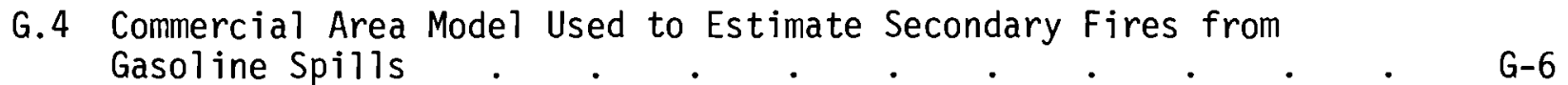

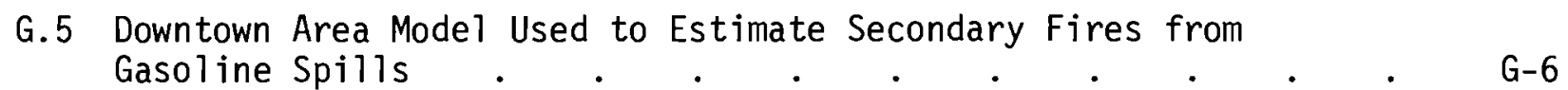

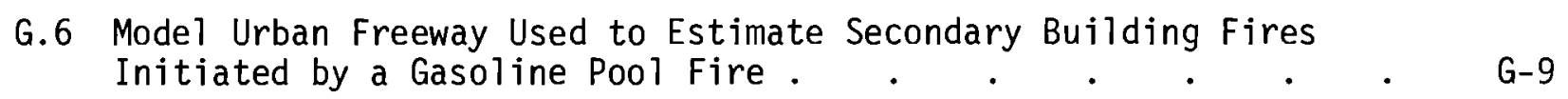

G.7 Assumed Gasoline Pool Shape for a Spill on an Urban Freeway G-10 


\section{$\underline{\text { TABLES }}$}

1.1 Comparison of Gasoline Transportation Risks with Individual Risk from Various Accidents and Natural Disasters . . . . 1-4

5.1 Distribution of Collision Accidents . . . . . . 5-3

5.2 Distritubion of Collision Accident Data by Revised Categories . 5-4

5.3 Distribution of Revised Categories by Type of Vehicle - Collision Only Accidents . . . . . . . . . . 5-5

5.4 Collision Accident Distribution by Direction of Acceleration Vector on Cargo Container. . . . . . . . . . . 5-6

5.5 Fraction of Roads Constructed of Various Materials . . . 5-9

5.6 Truck Accidents as a Function of Pre-accident Speed . . . 5-9

5.7 Summary of DOT Hazardous Material Incident Reports for Bulk Liquid Carriers . . . . . . . . . . 5-13

5.8 Percentage of Bulk Liquid Tank Failures Resulting from Puncture Forces. . . . . . . . . . . 5-13

6.1 Minimum Velocities Predicted at Failure . . . . . 6 6-2

6.2 Minimum Velocity to Fail Tank Skin by Abrasion . . . . 6-3

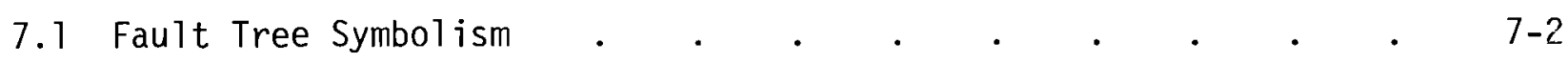

7.2 Listing of Basic Events for Gasoline Truck Transportation Fault Tree 7-10

7.3 Listing of Gate Logic Rectangle Labels for Gasoline Truck Transportation Fault Tree . . . . . . . . . 7-12

7.4 Listing of gasoline Truck Transportation Fault Tree Release

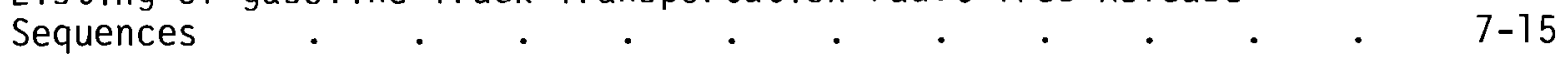

8.1 Release Sequence Probabilities . . . . . . . . 8-18

8.2 Release Fractions for Gasoline Tank Truck Failures . . . 8-21

9.1 Summary of NFPA Data on Building Fire Deaths for 1974 . . . 9-4

9.2 Estimated Probability of $n$ Deaths from $j$ Secondary Building Fires 9-5 
9.3 Estimated Probability of $n$ or more Deaths from Secondary Fires

Given that a Gasoline Release Has Occurred . . . . . 9-7

9.4 Distribution of Heavy Truck Accidents by Number of Vehicles Involved 9-7

9.5 Estimated Number of People Involved in Heavy Truck Accidents . 9-8

9.6 Estimated Probability, Given a Release, of $n$ or More Deaths of Vehicle Occupants from Exposure to a Gasoline Pool Fire . . 9-9

9.7 Number of Occupants per Building and Accident Locations Used to Estimate Fatalities from Tank Truck Explosions in Urban Areas . 9-11

9.8 Estimated Probability, Given a Release, that $n$ or More Fatalities Will Occur in Adjacent Buildings from a Gasoline Tank Explosion .

9.9 Estimated Probability Distribution for Fatalities of Vehicle Occupatns from Explosion, Given a Release . . . . . 9-13

10.1 Traffic Fatalities in Heavy Truck Accidents . . . . . . 10-4

10.2 Comparison of Gasoline Transportation Risks with Individual Risk from Various Accidents and Natural Disasters . . . . 10-5

10.3 Summary of Bureau of Motor Carrier Safety Data for 1975 on Accidents Involving Tank Trucks Carrying Gasoline and Similar Flammable Liquids

10.4. Sensitivity of the Expected Number of Fatalities from Gasoline Releases to the Value of Various System Parameters . . . 10-7

A.1 Truck and Trailer Tank Dimensions for Western Shipping System . A-3

B.1 Physical Properties of Gasoline . . . . . . . . B-1

C. 1 Formulas for the Determination of $\sigma_{z}$ and $\sigma_{y}$. . . . . C $C-2$

C.2 Volume Fraction at Downwind Pool Edge . . . . . . . C-3

C.3 Health Hazard. . . . . . . . . . . . C-3

C.4 Instantaneous Flammability Hazard . . . . . . . . C-4

C.5 Vertical Mixing Confined to a Shallow Layer. . . . . C-5

D.1 Snow Plow Skid Plate Wear Data . . . . . . . . D-15

G.1 Flame Angle and Safe Separation Distance as a Function of Windspeed for Gasoline Pool Fires. . . . . . . . . . G-3 
G.2 Model Urban Area Land Development . . . . . . . . . G-4

G.3 Probability of Various Windspeeds . . . . . . . . . G-4

G.4 Probability of Secondary Building Fires from a Gasoline Pool Fire on a City Street - 3000-gal Spil1 . . . . . . . . . G-7

G.5 Probability of Secondary Building Fires from a Gasoline Pool Fire on a City Street - 4200-gal Spill . . . . . . .

G.6 Probability of Secondary Building Fires from a Gasoline Pool Fire on a City Street - 8400 gal Spill . . . . . . .

G.7 Probability of Secondary Building Fires Initiated by a Gasoline Pool Fire on an Urban Freeway - 3000-gal Spill . . . . G G-10

G.8 Probability of Secondary Building Fires Initiated by a Gasoline Pool Fire on an Urban Freeway - 4200-gal Spill . . . . . G-11

G.9 Probability of Secondary Building Fires Initiated by a Gasoline Pool Fire on an Urban Freeway - 8400-gal Spill . . . . 


\subsection{SUMMARY}

This report is the fourth in a series of assessments of the risk of transporting energy materials. The report presents the risk of shipping gasoline by truck. The risk assessment methodology used in this study was developed in the first report in this series. (1) The methodology is summarized in Section 3. The methodology is presented in the form of a risk assessment model which is constructed for ease of periodic updating of the data base so that the risk may be reevaluated as additional data become available.

The report is sectioned to correspond to specific analys is steps identified in the model. The transport system and accident environment are described in Sections 4 through 6 . Release sequences are postulated in Section 7 and evaluated in Sections 8 through 10 to determine both the likelihood and possible consequences of a release. Supportive data and analyses are given in the appendices.

The risk assessment results are related to the year 1980 to allow a direct comparison with other reports in this series. For the assessment, certain assumptions about the gasoline shipping industry were made. These assumptions included:

- All gasoline is shipped to a bulk distribution terminal by pipeline and/ or barge and from the distribution terminal to the retail outlet by truck.

- All shipments to the retail outlet are made in tank trucks or tank trailers designed to meet Department of Transportation specification MC-306.

- The amount of gasoline shipped corresponds to the gasoline consumption goal in the President's Energy Plan. (2)

Based on these assumptions and available data, the following industry characteristics for 1980 were calculated:

- Total gasoline shipped by truck in $1980-1.14 \times 10^{11}$ gallons.

- Average shipment quantity - 8,400 gallons.

- Average shipment distance - 50 miles.

- Total shipping distance $-6.7 \times 10^{8}$ miles. 
Based on these shipping assumptions and the current accident rate of $2.5 \times 10^{-6}$ per mile, it is estimated that gasoline tank trucks will be involved in 1,781 accidents in 1980. It is further estimated that 110 of the accidents, or about one in 15 will result in a release of 3,000 gallons of gasoline or more from the tank truck. About one in four of the releases are expected to result in a large fire. The estimated number of fatalities from the gasoline releases in 1980 is 29 . Twelve of these fatalities are estimated to be drivers of gasoline tank trucks, and the other 17 are occupants of other vehicles involved in the accident. Fatalities of other members of the public were found to occur infrequently. An additional 26 persons are expected to be fatally injured from the accident forces, regardless of the hazardous nature of the cargo. These total fatality figures (55) were compared to data from the Bureau of Motor Carrier Safety (BMCS). BMCS data would predict 43 deaths from a similar number of gasoline tank truck accidents. The calculated results are therefore in substantial agreement with available data. In addition to validating the results of the analysis, this comparison incicates the usefulness of the analys is approach used in extending the information from available data sources to calculate total shipping system risks and to predict the occurrence of less frequent, but potentially higher consequence accidents.

The risk spectrum for shipment of gasoline by truck is presented in Figure 1.1. The risk spectrum is a plot of the expected frequency (in events/yr) of events versus the number of fatalities that are predicted from those events. For example, the curve shows that for the 1980's shipping levels used in the analysis, about 25 accidents resulting in one or more fatalities from the release of gasoline in an accident are predicted to occur each year. Accidents that produce ten or more fatalities are estimated to occur at a rate of $2.2 \times 10^{-2}$ per year, or one accident in about 45 years. The risk curve shows that a number of events resulting in less than two deaths/event can be expected each year from gasoline releases, but that larger consequence events occur relatively infrequently. There does not appear to be a significant possibility of very large consequence events from gasoline 


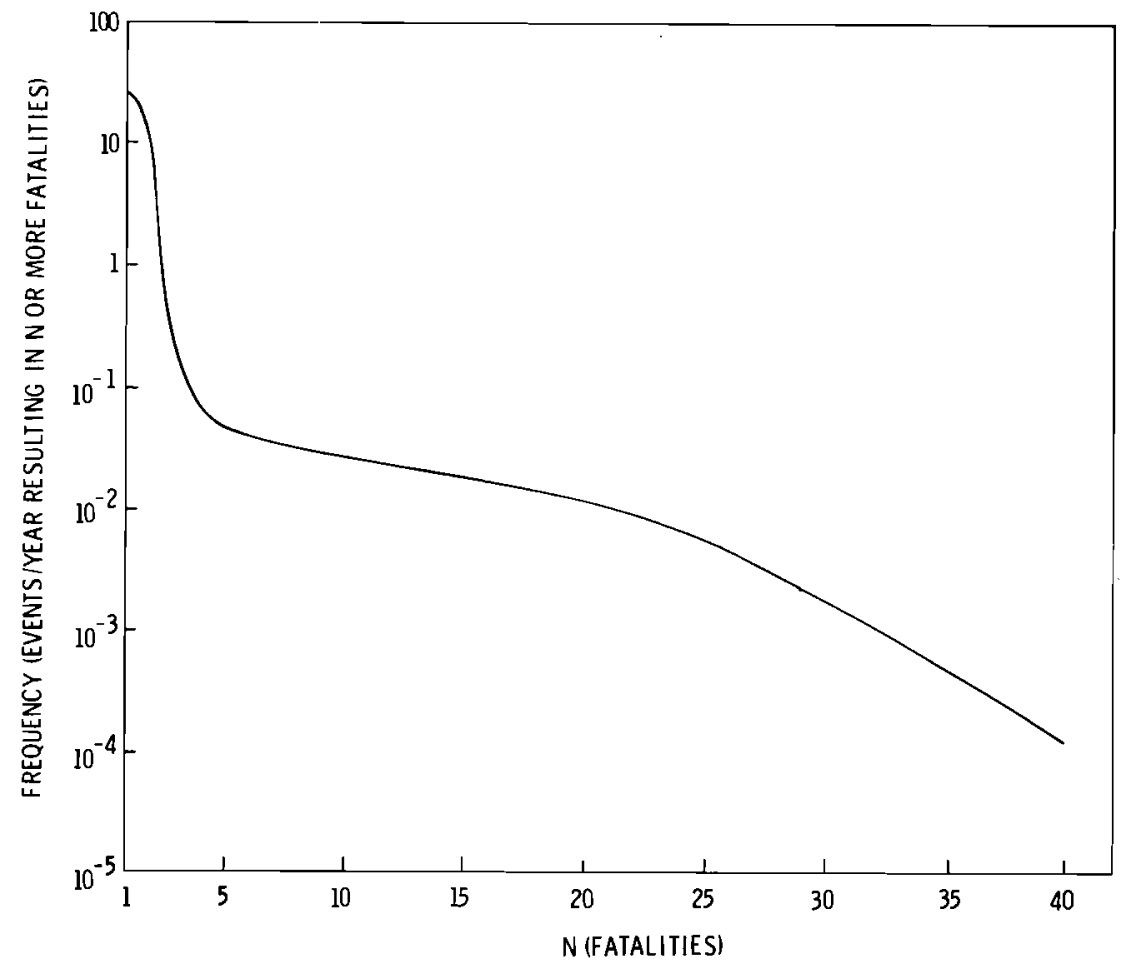

FIGURE 1.1. Risk Spectrum for Gasoline Shipments by Truck in 1980

tank truck accidents. The gasoline shipping risks are compared to other risks in society in Table 1.1. The table illustrates that the risk to any individual in society from gasoline shipments is comparable to the risk from lightning or tornadoes.

Sensitivity studies were performed to determine the most important contributors to the risk. It was found that tank wall failures from puncture, impact and abrasion combine to produce over $90 \%$ of the gasoline releases. An accurate description fo the puncture environment experienced by a large truck in an accident was not available. The uncertainty in the analysis would be reduced by development of such a description. The sensitivity studies also showed that the expected number of fatalities from gasoline releases in 1980 is directly proportional to the assumed number of occupants killed by fire in vehicles involved in an accident. 
TABLE 1.1. Comparison of Gasoline Transportation Risks with Individual Risk from Various Accidents and Natural Disasters(a)

Accident Type

A11 Accidents

Motor Vehicle Accident

A11 Industrial Accidents(b)

Falls

Drowning

Fires

Poisoning

Airplane Crashes

Railway Accidents

Lightning (d)

Tornadoes (e)

Gasoline Tank Truck Accidents

\section{Total Fatalities Individual Risk per Year}

115,821

1 in 2,000

55,511

1 in 4,000

14,100

1 in $6,000^{(c)}$

16,506

1 in 13,000

7,152

1 in 29,000

6,503

1 in 32,000

5,335

1 in 40,000

1,668

1 in 130,000

789

1 in 250,000

160

1 in 2,000,000

90

1 in $2,300,000$

29

1 in $7,400,000$

(a) Data are from reference 3 unless otherwise indicated.

(b) Reference 4

(c) Only workers included in population at risk

(d) Reference 5

(e) Reference 4. Average value for several years

Two possible methods for reducing the risk from gasoline releases in tank truck accidents were investigated. The first involved making the tank ten times more resistant to failure by puncture, impact and abrasion. This reduced the expected number of fatalities to nine per year. The second method involved installation of an accident-activated fire suppression system on all tank trucks. Potentially this could reduce the expected number of fatalities to less than one per year. A detailed cost-benefit analysis would be required to determine the merits of these systems.

Judgments about the acceptability of the risks from shipping gasoline by truck are beyond the scope of this analysis, but the information presented here can provide input to such decisions. The analysis has shown that the risk from gasoline shipments is less than many other commonly-accepted risks 
in society. There is a clear and substantial benefit to society from the use of the gasoline that is shipped because gasoline provides about $75 \%$ of the energy consumed in the U.S. for transportation. The risks and benefits are also spread evenly throughout society, so that the population exposed to risk is essentially the same as the population receiving the benefits. It should also be noted that any analysis of this type is generally conservative; i.e., the calculated risk is usually somewhat higher than the actual risk might be if it could be measured. This results because many assumptions and simplifications must be made to make the analysis tractable. Every attempt has been made to make these assumptions as realistic as possible, but lacking information, a generally conservative assumption was made. Sensitivity studies were used to test the effect of key assumptions on the analysis results. It is felt that the results presented are the most realistic possible using existing information.

\section{REFERENCES}

1. T. I. Sweeney, R. J. Hall et al., An Assessment of the Risk of Transporting Plutonium Oxide and Liquid Plutonium Nitrate by Truck. BNWL-1846, Battelle, Pacific Northwest Laboratories, Richland, WA, 1975.

2. National Energy Plan. Executive Office of the President, Energy Policy and Planning, Washington, DC, April 1977.

3. U.S. Bureau of the Census, Statistical Abstract of the United States: 1975. U.S. Department of Commerce, Washington, DC, p. 66, 1975.

4. Accident Facts 1973. National Safety Counci1, Chicago, IL, 1974.

5. Reactor Safety Study. WASH-1400, U.S. Nuclear Regulatory Commission, Washington, DC, p. 3, October 1975. 


\subsection{INTRODUCTION}

To insure the health and safety of the general public, industry and government agencies are continually improving their level of understanding of the safety-related aspects of transporting energy materials.

Research programs are one method of improving the level of understanding. Such a research program is being conducted by Pacific Northwest Laboratory ${ }^{(a)}$ for the Transportation Branch of the Division of Environmental Control Technology in the Department of Energy. The objective of this continuing program is to develop a methodology for quantitatively assessing the safety of transporting energy materials and to apply it to current and future shipping systems. Risk analysis was the technique selected for this assessment. Through analysis of risk, consequences of postulated releases of energy materials during transport can be put into perspective by viewing the events relative to their expected frequency of occurrence.

Risk, as used in the context of this report, is the product of the magnitude of a possible loss and the expected frequency of occurrence of the loss. There are two measures of the risk that are of importance in a risk assessment. The first is the total risk, obtained by summing the risk associated with each particular loss. In order to perform the summation, all risks have to be expressed with respect to the same time interval (e.g., per year). Although the total risk is an important measure, it gives only the loss that would be expected on the average during the reference time interval. The range of losses which could be experienced is not discernable. For example, the risk associated with an accident that occurs once a year and results in one fatality is the same (i.e., one fatality/year) as that from an accident which occurs once in ten years but results in ten fatalities. In a plot of the expected frequency of $\mathrm{N}$ or more fatalities as a function of $\mathrm{N}$, these two accidents would appear as discrete points. The second measure of risk is a curve called a risk spectrum, which is generated by connecting such points. The risks associated with two

\footnotetext{
(a)Operated by Battelle Memorial Institute
} 
activities are similar only if they have the same total risk (risk magnitude) and the same risk spectrum. Both risk measures are used in this report.

The risk assessment methodology used in this report was initially applied to the shipment of plutonium (1) by truck and has subsequently been applied to the shipment of plutonium by rail $^{(2)}$ and air, (3) and uranium hexafluoride by truck and rail. (4) A review of the methodology is presented in this report. This report presents the results of the first application of this methodology to transportation of a fossil energy material. The truck shipment of gasoline was selected as the first fossil energy material risk assessment for several reasons:

- Transportation annually accounts for $25 \%$ of the energy consumption in the U.S. About three quarters of the transportation energy is supplied by gasoline.

- Gasoline represents about one third of all hazardous materials shipments made by truck.

- Information was available or could be derived concerning the accident environment that a gasoline truck would experience.

- The risks and benefits from truck transportation of gasoline are spread evenly throughout society.

- Although much information was available concerning the truck shipment of gasoline and accidents involving these trucks, the risk to which society is exposed from these shipments was not known. 


\section{REFERENCES}

1. T. I. McSweeney, R. J. Hall et al., An Assessment of the Risk of Transporting Plutonium 0xide and Liquid Plutonium Nitrate by Truck. BNWL-1846, Battelle, Pacific Northwest Laboratories, Richland, WA, August 1975.

2. R. J. Hall et al., An Assessment of the Risk of Transporting Plutonium Dioxide and Liquid Plutonium Nitrate by Train. BNWL-1996, Battelle, Pacific Northwest Laboratories, Richland, WA, January 1977.

3. T. I. McSweeney, J. F. Johnson, An Assessment of the Risk of Transporting Plutonium Dioxide by Cargo Aircraft. BNWL-2030, Battelle, Pacific Northwest Laboratories, Richland, WA, June 1977.

4. C. A. Geffen, J. F. Johnson et a1. An Assessment of the Risk of Transporting Uranium Hexafluoride by Truck and Train. PNL-2211, Pacific Northwest Laboratory, Richland, WA, August 1978. 


\subsection{RISK ANALYSIS MODEL}

Risk, as used throughout this report, is defined as the product of the likelihood of occurrence of an event and the consequences of that event. The risk model described in this section has been developed from methodologies used in prior risk assessments. A detailed description of the risk model used in this report is provided in Reference 1. The model was developed to evaluate the risk of transporting radioactive materials. By generalizing some of the component designations, it has been applied here to shipments of gasoline.

\subsection{RISK MODEL DESCRIPTION}

The risk assessment model provides a systematic method for handling the data required to analyze the safety of the transport environment. The components of the assessment model are shown in Figure 3.1. The following paragraphs provide a more detailed description of the components shown in this figure.

The model uses one fundamental equation:

$$
R=\sum_{i} R_{i} \cdot
$$

The total system risk $R$ is the sum of the risks of all accidental releases as denoted by the subscript $i$. Only accidental releases are considered in the model. The risk of an individual release is the product of the consequences of the release and the probability of its occurrence. This equation could be expanded into a single, long, complex equation. In the current formulation of the model, each term in Equation (1) is expanded into two expressions which have more physical significance. The expanded equation for $R_{i}$ is:

$$
R_{i}=\left(A F_{R_{i}} \times P_{R_{i}}\right) \times \sum_{q}\left(C_{E_{i, q}} \times P_{E_{q}}\right)
$$




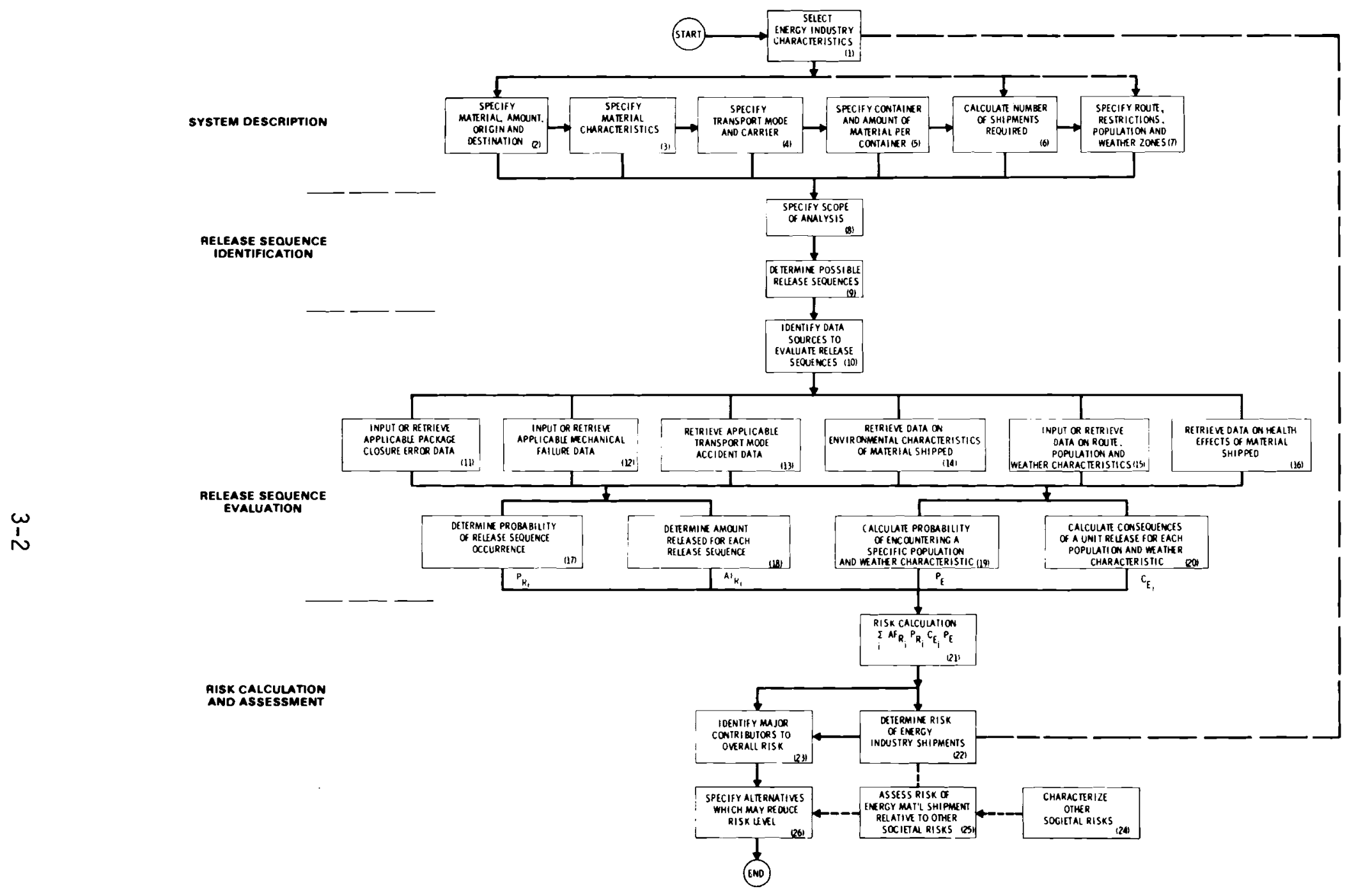

FIGURE 3.1. Model to Calculate the Risk of Shipping Hazardous Material 
The first factor, $A F_{R_{j}}$, is the product of the amount of material present in a shipment times the fraction of that material lost to the environment in the $i^{\text {th }}$ release sequence. This factor can be thought of as a source for the $i^{\text {th }}$ chain of events or failures which end with a release of radioactive material. The second factor, $P_{R_{j}}$, is the probability that the release sequence wil1 happen during transport. The first expression, $A F_{R_{j}} \times P_{R_{j}}$, can be thought of as a probabilistic source term for each identified release sequence.

The factor $C_{E_{j}, q}$ in the second part of Equation 2 is the consequences of a unit release. The subscript $q$ is added to show that the factor is a function of the specific weather conditions existing at the time of the release and the population exposed to the release. The final factor, $P_{E_{q}}$, is the probability of encountering a particular set of weather conditions within a specific population zone. The expression $\sum_{\mathrm{q}}\left(\mathrm{C}_{\mathrm{E}_{\mathrm{i}}, \mathrm{q}} \times \mathrm{P}_{\mathrm{E}_{\mathrm{q}}}\right)$ can be thought of as the consequences of a unit release of material (unit source term) under probabilistically weighted weather conditions and population distributions.

Equation 2 is the pivotal equation in the risk mode1. Two preparatory steps are needed before the terms can be evaluated. These are the system description and the release sequence identification steps. Following these two steps is the release sequence evaluation step which utilizes Equations 1 and 2. The final step is to evaluate or assess the significance of the risk level determined for the transport system being evaluated. The relationship between the four steps is shown in Figure 3.1. The steps are briefly discussed in the following four subsections.

\subsubsection{System Description}

As shown in Figure 3.1, the system description step has seven components:

1) Select Industry Characteristics

2) Specify Material Amount, Origin and Destination

3) Specify Material Characteristics

4) Specify Transport Mode and Carrier

5) Specify Container and Amount of Material per Container

6) Calculate Number of Shipments Required

7) Specify Route, Restrictions, Population and Weather Zones. 
Figure 3.2 shows the type of information called for by these components to describe the gasoline shipping system.

\subsubsection{Release Sequence Identification}

The second step in the risk assessment is identification of release sequences. This requires, first, component 8, Specify Scope of Analysis, which completes the information required to initiate work in component 9 , Determine Possible Release Sequences. The relationship of these two components to the rest of the model is shown in Figure 3.1. Component 8 sets the scope of the risk assessment by selecting the factors that will be considered in the analysis. For the present analysis, primary consideration is given to the risks from failure sequences resulting from transportation accidents. The possible release sequences within the scope of the assessment are identified in component 9 by use of fault tree analysis; a method that works backwards from a release through the chains of events or failures required to breach the barriers between the material and man's environment.

\subsubsection{Release Sequence Evaluation}

The release sequence evaluation step considers each release sequence identified in the previous step and determines the factors in Equation 2. The assembly of this data will be described in the following subsections entitled Source Term Evaluation and Environmental Consequences Evaluation.

Source Term Evaluation. The release sequence factors in Equation 2, denoted by the subscript "R", represent the probability that material wi11 be released and the amount of material released. The evaluation of these factors requires the input of four data bases, shown in Figure 3.1 as components 11-14. These data bases are:

- Input or Retrieve Applicable Package Closure Error Data (11)

- Input or Retrieve Applicable Mechanical Failure Data (12)

- Retrieve Applicable Transport Mode Accident Data (13)

- Retrieve Data on Environmental Characteristics of Material Shipped (14).

With the information from components 11 to 14 , the model evaluates the probability and magnitude of the release (components 17 and 18 in Figure 3.1). 


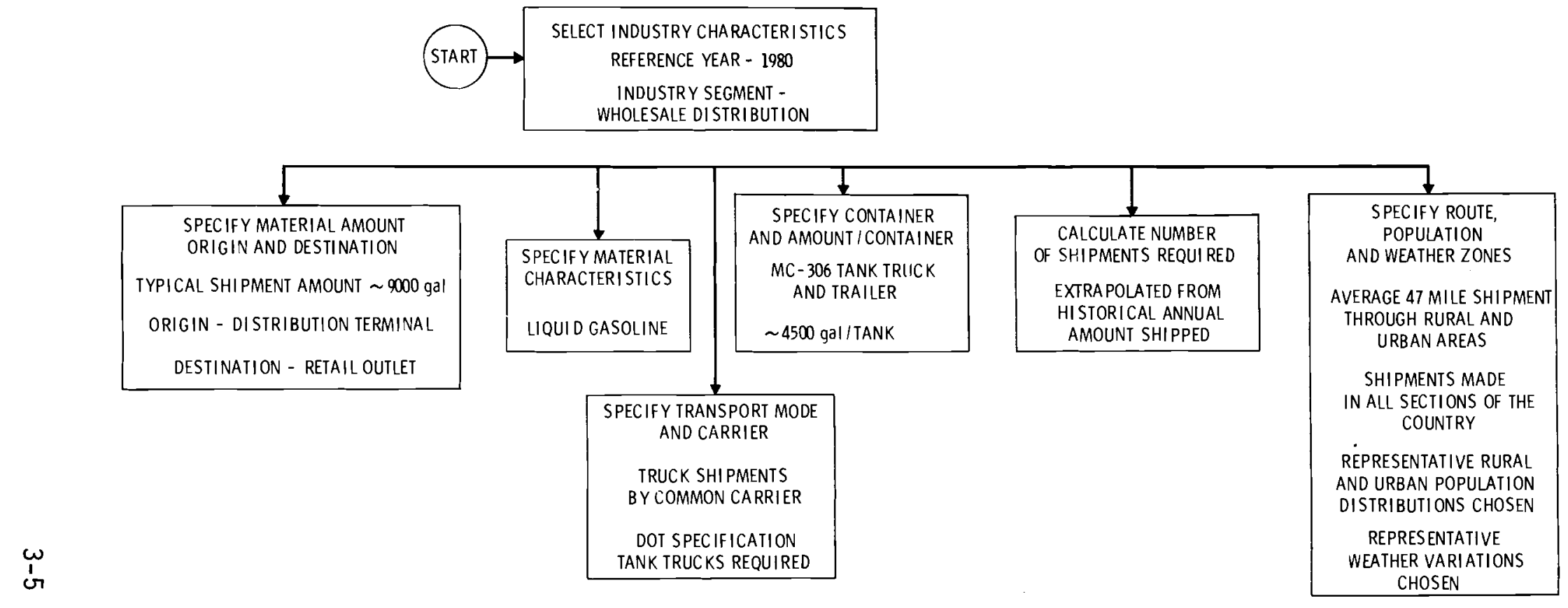

FIGURE 3.2. Information Required to Describe Transport System 
The $F_{R_{j}}$ factors of source term expression used for various release sequences and environmental conditions are discussed in Section 9.

Environmental Consequences Evaluation. The environmental terms in Equation 2 are denoted by a subscript $E$. The factor $P_{E}$ represents the probability that a given set of weather and population density characteristics will be encountered. The factor $C_{E_{j}}$ represents the consequences of a unit release from an accident when it occurs in the region characterized by the weather and population density used to determine $P_{E}$. The consequences of the release are expressed as health effects using commonly accepted methods. The evaluation of the two factors in Equation 2 requires the input from three data bases, shown in Figure 3.1 as components 14 to 16 . These data bases are:

- Retrieve Data on Dispersal Characteristics of Material Shipped (14)

- Input or Retrieve Data on Route, Population and Weather Characteristics (15)

- Retrieve Data on Health Effects of Material Shipped (16).

The model uses relevant information from components 14 to 16 to evaluate the probability of experiencing a given set of weather conditions and population characteristics. These evaluations are shown as components 19 and 20 in Figure 3.1. The $P_{E}$ term in Equation 2 is the probability associated with the weather and population characteristics. The expanded form of this term is given:

$$
P_{E_{j, k, 1}}=P_{j / k} \times P_{k} \times P_{1}
$$

The subscripts $j, k$ and 1 refer to the multiplicity of environmental conditions which could exist at the location of the accident. The variable $P_{j / k}$ is the probability of experiencing the $j^{\text {th }}$ atmospheric stability classification when the $k^{\text {th }}$ windspeed exists. The variable $P_{k}$ is the probability of encountering the $k^{\text {th }}$ windspeed category. The variable $P_{1}$ is the probability of encountering a specified population distribution. 
This data completes the description of the four terms in the risk equation. Once all of these variables are specified, the risk calculation and assessment step, the last step, can be completed.

\subsubsection{Risk Calculation and Assessment}

The final step in the risk assessment is to sum and evaluate the risks associated with all the applicable release sequences. As shown in Figure 3.1, this final step consists of six components numbered 21 to 26 :

- Risk Calculation (21)

- Determine Risk of Hazardous Material Shipments (22)

- Identify Major Contributors to Overall Risk (23)

- Characterize Other Accepted Societal Risks (24)

- Assess Risk of Shipments Relative to Other Societal Risks (25)

- Specify Alternatives Which May Reduce Risk Level (26).

In this report, the risk of transporting gasoline by truck will be calculated and then compared with other accidental risks. Such comparisons place the risks of shipping gasoline in perspective.

\section{REFERENCE}

1. T. I. McSweeney, R. J. Hall et al., An Assessment of the Risk of Transporting Plutonium 0xide and Liquid Plutonium Nitrate by Truck. BNWL-1846, Battelle, Pacific Northwest Laboratories, Richland, WA, August 1975. 
$-$ 


\subsection{SHIPPING SYSTEM DESCRIPTION}

Gasoline is typically transported from the refinery to a distribution terminal by pipeline and/or barge. Large tank trucks are then used to ship the gasoline from the distribution terminal to the retail outlets. This is the transportation step considered in this analysis. Distribution terminals and retail outlets are located throughout the U.S. The number of terminals and retail outlets in a given area is roughly proportional to the population in that area. The distance from a distribution terminal to the retail outlets is usually less than 100 miles. The risks from gasoline transportation are therefore spread relatively evenly throughout the U.S. population and it was not necessary to look at specific shipping and receiving locations as in previous studies.

The analysis is based on the year 1980 to permit comparison with previous studies for other energy commodities. This section presents a projection of the gasoline shipping requirements in the reference year and a brief description of the tank trucks used.

\subsection{GASOLINE SHIPPING REQUIREMENTS}

The National Energy Plan provides for a target consumption of $1.14 \times 10^{11}$ gallons of gasoline in $1980 .^{(1)}$ Interstate Commerce Commission (ICC) statistics ${ }^{(2)}$ show that the average gasoline shipment by truck contains 8400 gallons. Contacts with transportation experts from several major petroleum refining companies indicate that the average loaded shipping distance for a gasoline tank truck is 50 miles. Therefore the total number of gasoline tank truck shipments in 1980 is estimated to be $1.36 \times 10^{7}$, with tank trucks being loaded $6.79 \times 10^{8} \mathrm{miles} /$ year. These projections are summarized in Table 4.1. 
TABLE 4.1. Assumed Gasoline Shipping Information for 1980

$\begin{array}{ll}\text { Projected Gasoline Sales } & 1.14 \times 10^{11} \text { gallons } \\ \text { Average Shipment Quantity } & 8,400 \text { gallons } \\ \text { Average Shipment Distance } & 50 \mathrm{miles} \\ \text { Total Number of Shipments } & 1.36 \times 10^{7} \\ \text { Truck Miles loaded/year } & 6.79 \times 10^{8}\end{array}$

\subsection{GASOLINE TANK TRUCK DESCRIPTION}

Gasoline is classified as a flammable liquid and its transportation is regulated under the hazardous materials transportation regulations of the U.S. Department of Transportation. These regulations are contained in Sections 100-199 of Title 49 of the U.S. Code of Federal Regulations. The regulations specify packaging, shipping and handling requirements for all hazardous materials. The regulations permit the use of several DOT specification tank trucks for gasoline transport but conversations with tank truck manufacturers and trucking companies that haul gasoline indicate that DOT specification MC-306 is in predominant use by the gasoline shippirig industry.

Two basic configurations of this shipping system are in current use. Shippers in the eastern portion of the U.S. generally use the tractor/semitrailer configuration shown in Figure 4.1 Western operators typically use the tank truck/tank trailer combination shown in Figure 4.2. The tanks in both configurations have an eliptical cross section and are constructed of aluminum alloy 5454. The tank wall thickness for the semitrailer configuration is 0.25 inches in the belly and 0.188 inches in the sides and top. The smaller tanks in the western configuration have a 0.188 -inch wall thickness in the belly and 0.154 inches in the sides and top. The tanks have internal baffles for stiffening and may be divided into several compartments. For this analysis it was assumed that each tank in the western configuration is a single compartment and that the semitrailer is divided into two compartments. 


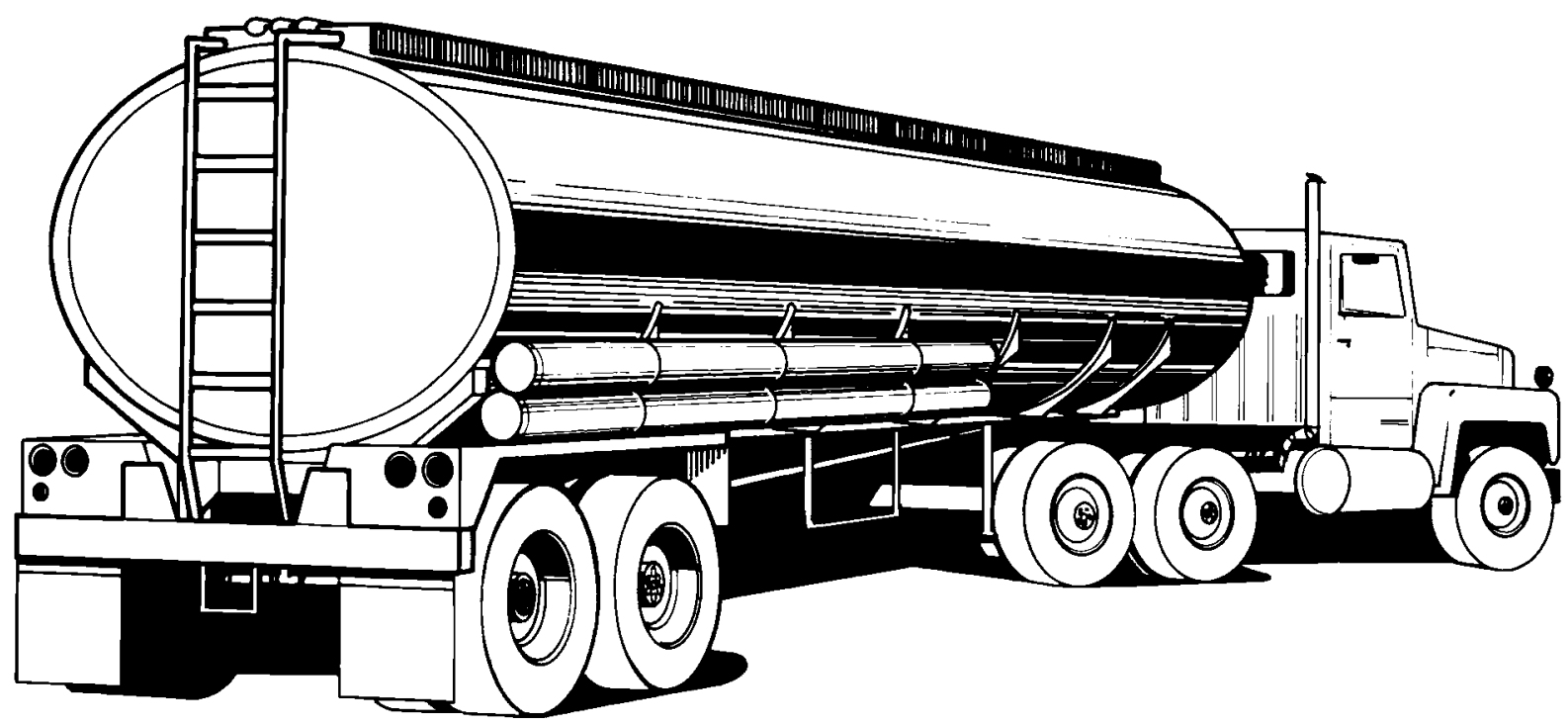

FIGURE 4.1. Tractor/Semitrailer Used for Gasoline Shipments in the Eastern U.S.

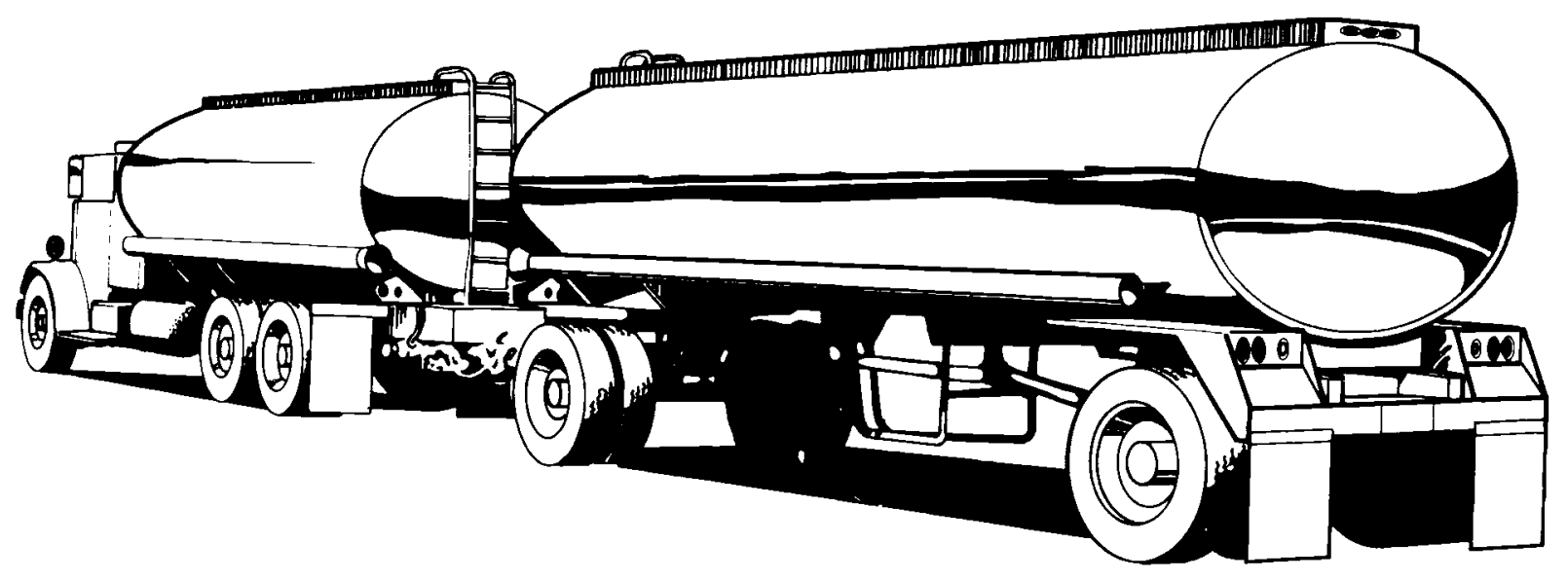

FIGURE 4.2. Tank Truck/Tank Trailer Used for Gasoline Shipments in the Western U.S. 
Each tank compartment is fitted with a manway cover and an outlet valve. The manway cover also contains a relief valve that vents to the atmosphere when the tank pressure exceeds 1 psig. Another relief valve in the cover vents at 9 psig. This analys is assumes that all compartments are loaded through the manway cover and unloaded through the outlet valve with the manway cover opened for venting. It should be noted, however that about $25 \%$ of the tank trucks currently in use are equipped for bottom loading and unloading. A more detailed description of the reference tank trucks is presented in Appendix A.

\section{REFERENCES}

1. The National Energy Plan. Executive Office of the President, Energy Policy and Planning, Washington, DC. April 1977.

2. Freight Commodity Statistics, Motor Carriers of Property, Year Ended December 31, 1972. Interstate Commerce Commission, Bureau of Accounts, Washington, DC. 


\subsection{TRANSPORTATION ACCIDENT ENVIRONMENT}

Transportation accident related failure of a gasoline tank truck and release of the contents occur when the forces generated in an accident exceed the mechanical strength of some component of the tank. This section discusses the forces or stresses that might be generated in a truck accident environment and their likelihood of occurrence. Section 6.0 discusses the mechanical strength of a gasoline tank. The use of the information in Sections 5.0 and 6.0 to estimate the likelihood of gasoline release in a tank truck accident is demonstrated in Section 8.0 .

For the purposes of this study, the stresses present in a truck accident environment have been divided into four categories: fire, impact, abrasion and puncture. Other stresses, such as crush and immersion, were judged to be unimportant contributors to the likelihood of gasoline tank failures. The four significant accident stresses are discussed individually below.

\subsection{FIRE}

Information on the fire environment is extracted from Reference 1. Only fires that do not involve the cargo are considered, since the intent is to establish the likelihood of tank failure. Fire can be expected to occur in $1.6 \%$ of all truck accidents. (2) The mean fire temperature is $1850^{\circ} \mathrm{F}$. Fire durations may vary from a few minutes to several hours. The expected duration of fires in truck accidents is shown in Figure 5.1.

\subsection{IMPACT}

The impact environment for an accident involving a large container such as a gasoline tank truck is taken from information from A. W. Dennis, Sandia Laboratories (June 23, 1976). The statistical information provided by Sandia was developed from Bureau of Motor Carrier Safety (BMCS) data. The impact accident environment information was developed from the statistical data base using a Monte Carlo computer simulation. 


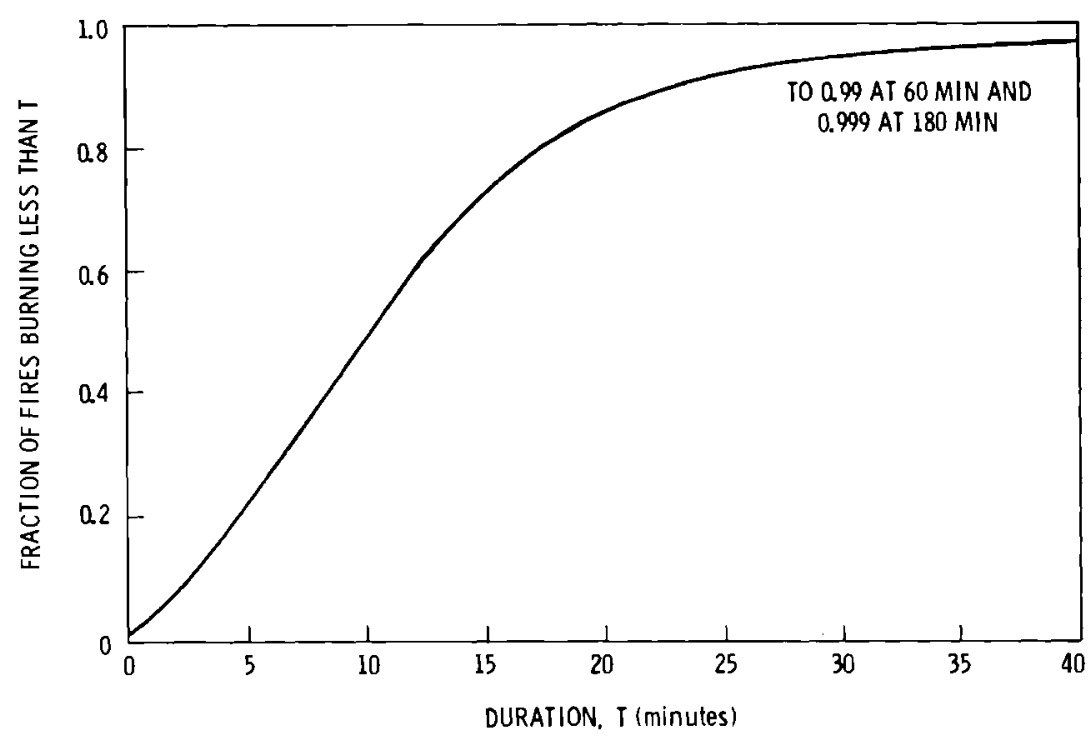

FIGURE 5.1. Expected Duration of Fires for Accidents Involving a Truck with Nonflammable Cargo (extracted from Reference 1)

The statistical information from A. W. Dennis is presented in Tables 5.1 through 5.4. Table 5.1 contains the basic BMCS accident distribution data. The data has been broken down into two sets, collision accidents and noncollision accidents. Collision accidents involve a primary impact with another vehicle, a train, a fixed object or a pedestrian, animal or bicycle. Noncollision accidents involve fire (before or without impact), running off the road, overturning and other accidents of this type. Noncollision accidents may include impacts with roadside ditches, banks, the roadway and other roadside features.

Table 5.2 presents the basic data in revised categories. The revised categories were established to simplify further analysis. Collisions with trucks, motor buses and streetcars were combined into a single category collisions with trucks. Collisions with fixed objects, unreported objects and other objects were also combined into a single category. The collision rollaway and noncollision rollaway categories were combined. A new category, overturn/run off road was established to include accidents where either the primary cargo damage was due to overturning or running off the road or the collision effects on the cargo were considered to be slight. Collisions 
TABLE 5.1. Distribution of Collision Accidents (BMCS Data 1969 through 1972) (A. W. Dennis, Sandia Laboratories)

Accident Classification Number of Accidents Fraction of Total

a. Collision with:

Pedestrian

$\begin{array}{rr}1,520 & 0.0085 \\ 28,101 & 0.1569 \\ 87,268 & 0.4873 \\ 787 & 0.0044 \\ 1,049 & 0.0059 \\ 1,027 & 0.0057 \\ 9 & 0.0001\end{array}$

Animal/Animal Drawn Vehicle

1,344

0.0075

Bicycle

182

0.0010

Fixed Object

25,934

0.1448

Unreported Object

216

0.0012

Other Object

270

0.0015

Rol laway

2,096

0.0117

b. Noncollision:

0.8365

Overturn on Road

5,065

0.0283

Ran off Road

11,976

0.0663

Other

12,259

0.0685

Rol laway

67

$\underline{0.0004}$

0.1635

SUM

179,070

1.0000

with pedestrians, animals. etc. were included in this category since it was felt that damage to the vehicle in this type of accident would result from overturning or running off the road as a result of attempts at evasive action. 
TABLE 5.2. Distribution of Collision Accident Data by Revised Categories (A. W. Denriis, Sandia Laboratories)

Accident Classification Number of Accidents Fraction of Total

a. Collision-only:

Truck

Property

28,897

0.1614

Motor Bus

Street Car

Passenger Auto

87,268

0.4873

Railroad Train

1,027

0.0057

Object

26,420

0.1476

Fixed Object

Unreported Object

Other Object

b. Collision \& Noncollision:

35,458

0.1980

Overturn/Ran off Road

Pedestrian

Other Vehicle

Animal/Animal Drawn

Vehicle

Bicycle

Rollaway (collision)

Overturn on Road

Ran off Road

Other

Rollaway (Noncollision)

SUM

179,070

1.0000

In Table 5.3, the collision-only accidents have been divided by the type of vehicle involved in the collision (another truck, car, train) and by the type of collision (head-on, end-on, etc.). The distribution of each type accident derived for use in the computer calculations is shown in the table. The information in Table 5.3 was used to develop Table 5.4. The 
TABLE 5.3. Distribution of Revised Categories by Type of Vehicle Collision Only Accidents (A. W. Dennis, Sandia Laboratories)

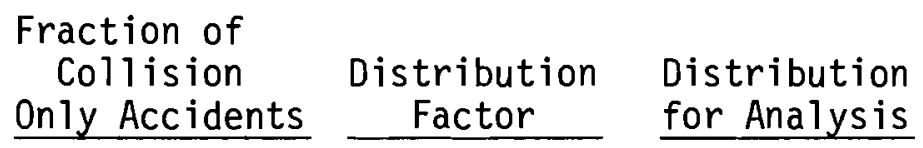

a. Truck

Head-on

End-on \# ${ }^{(a)}$ into $\# 2$ (b)

End-on \#2 into \#1

Side-on \#1 into \#2

Side-on \#2 into \#1

0.2012

0.0405

0.0081

0.4255

0.0856

0.4004

0.0806

0.0427

0.0086

0.0910

0.0183

b. Auto

0.6076

Head-on

0.0538

0.0327

End-on \#1 into \#2

0.3695

0.2245

End-on \#2 into \#1

0.3032

0.1842

Side-on \#1 into \#2

0.0742

0.0451

side-on \#2 into \#1

0.1993

0.1211

c. Railroad Train

0.0072

Struck by Train

0.7500

0.0054

Ran into Train

0.2500

0.0018

d. Object

0.1840

Auto

0.8400

0.1546

Railroad Train

0.1600

0.0294

(a) Vehicle \#1 is the truck being studied.

(b) Vehicle \#2 is the other vehicle involved in the accident.

fraction of all collisions resulting in the cargo container being accelerated along its axis, decelerated along its axis or accelerated perpendicular to its axis is presented in this table. 
TABLE 5.4. Collision Accident Distribution by Direction of Acceleration Vector on Cargo Container (A. W. Dennis, Sandia Laboratories)

Direction of Acceleration Vector on Cargo Container

a. The Cask is Decelerated along its Axis

Head-on, Truck

End-on \#1 (a) into \#2, (b) Truck

Side-on \#1 into \#2, Truck

Head-on, Auto

End-on \#1 into \#2, Auto

Side-on \#1 into \#2, Auto

Ran into Train

Object

b. The Cask is Accelerated along its Axis

End-on \#2 into \#1, Truck

End-on \#2 into \#1, Auto

0.0806

0.1842

0.2648
Distribution

Factors

0.0081

0.0856

0.0086

0.0327

0.2245

0.0451

0.0018

0.1840

0.5904

c. The Cask is Accelerated Perpendicular to its Axis

Side-on \#2 into \#1, Truck

0.0183

Side-on \#2 into \#1, Auto

0.1211

Struck by Train

$\underline{0.0054}$

0.1448

(a) Vehicle \#1 is the truck being studied

(b) Vehicle \#2 is the other vehicle involved in the accident 
The data in Tables 5.1 through 5.4 were used by Sandia Laboratories in a Monte Carlo computer code to estimate the impact environment experienced by a large truck in an accident. The results of this analys is for a truck with a gross weight of 80,000 1bs are presented in Figures 5.2 and 5.3. Figure 5.2 presents the magnitude of the velocity change versus expected frequency of occurrence in a collision accident. Figure 5.3 presents similar results in terms of the expected change in kinetic energy. The kinetic energy change has been normalized to the kinetic energy change that would be experienced in a $30-\mathrm{ft}$ drop onto an unyielding surface.

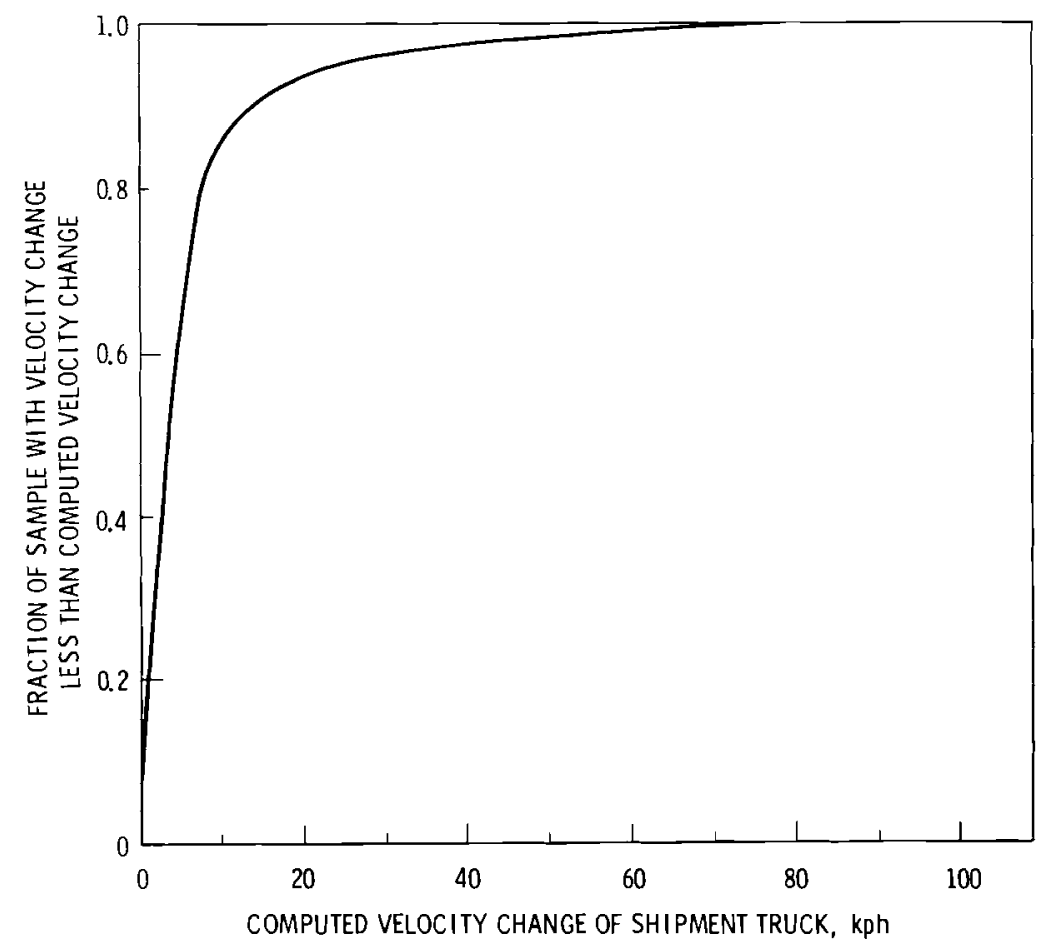

FIGURE 5.2. The Expected Maximum Velocity Change Given a Truck Subjected to a Random Accident Sample (A. W. Dennis, Sandia Laboratories) (Number of Samples - 1,000;

Truck Gross wt. - 80,000 lbs) 


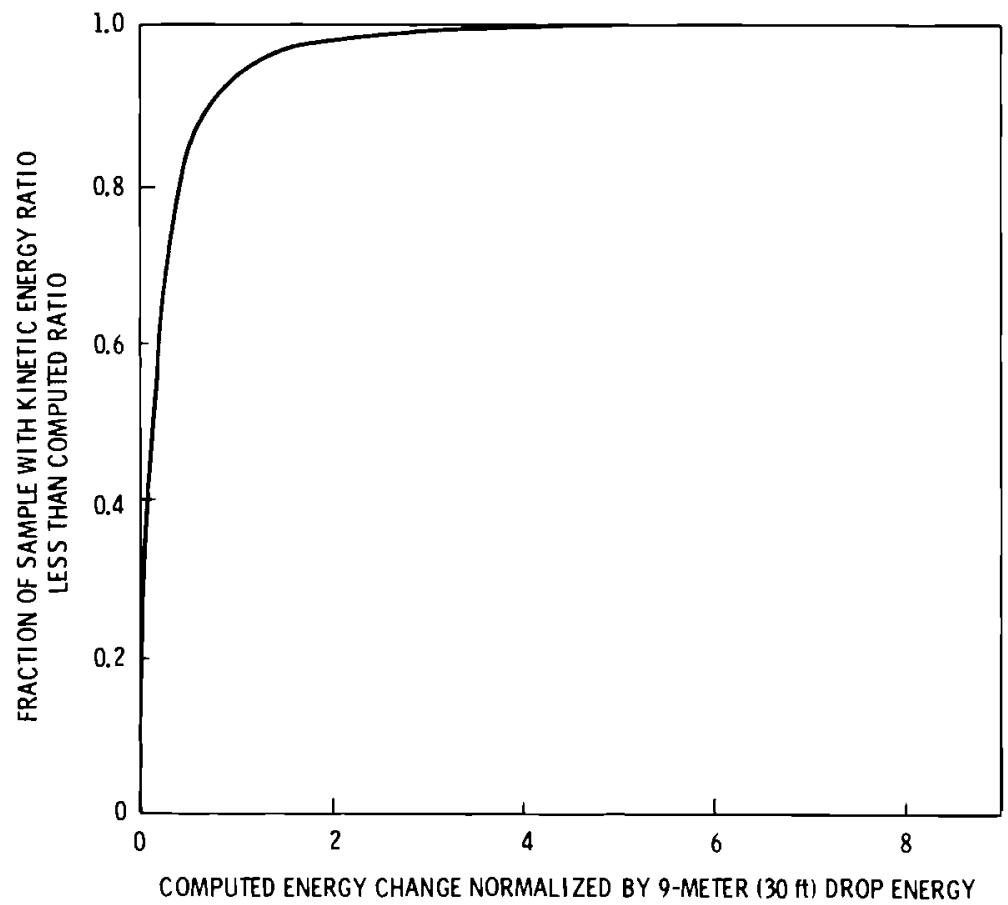

FIGURE 5.3. The Expected Maximum Kinetic Energy Change Ratio Given a Truck Subjected to a Random Accident Sample (A. W. Dennis, Sandia Laboratories) (Number of Samples - 10,000; Truck Gross wt. 80,000 Tbs)

\subsection{ABRASION}

Two factors determine the abrasion environment that a gasoline tank truck could experience in an accident - the type of road surface that an overturned tank might slide along and the speed at which the tank slides along the surface. The fraction of each type of road surface used in this analysis is presented in Table 5.5. These data were obtained from the State of Washington Department of Highways and are assumed to be typical of highways and streets throughout the country. 
TABLE 5.5. Fraction of Roads Constructed of Various Materials Fraction of Total Miles

$\begin{array}{ll}\text { Road Survace } & \\ \text { Asphalt } & 0.45 \\ \text { Bituminous Surface Treatment } & (a) \\ \text { Portland Cement } & 0.43 \\ \text { Gravel } & 0.08 \\ \text { Other } & 0.01 \\ & 0.03\end{array}$

(a) Small gravel and tar

The initial speed of a gasoline truck sliding along an abrasive surface is assumed to be the pre-accident speed for all truck accidents. The data used were taken from Reference 3. These data represent an analysis of 10,838 truck accidents in the state of Texas. The fraction of all truck accidents occurring in each speed range is shown in Table 5.6.

TABLE 5.6. Truck Accidents as a Function of Pre-accident Speed

\begin{tabular}{lc}
\multicolumn{1}{c}{ Speed Range } & Fraction of A11 Accidents \\
\cline { 1 - 1 } Stop & 0.058 \\
$1-10$ & 0.321 \\
$11-20$ & 0.157 \\
$21-30$ & 0.156 \\
$31-40$ & 0.113 \\
$41-50$ & 0.116 \\
$51-60$ & 0.072 \\
$61-70$ & 0.005 \\
Greater than 70 & 0.0005
\end{tabular}




\subsection{PUNCTURE}

A general description of the puncture environment that would be present in a gasoline tank truck accident is not available. Existing information, (2) derived for small containers in an enclosed van, is not applicable to a large container such as a gasoline tank truck or trailer. The role of puncture forces in the failure of gasoline tank trucks in an accident can be inferred from data obtained from the Office of Hazardous Materials of the U.S. Department of Transportation (DOT). The Office of Hazardous Materials collects data on releases of hazardous materials during transportation. The data are collected on the incident report form shown in Figure 5.4. An incident report is required to be made by all carriers of hazardous materials in interstate commerce whenever a release occurs from the package or transport vehicle. The reported release does not have to be the result of a transportation accident.

The data obtained from DOT cover a 5-year period from 1971-1975. The reports include several types of DOT tank truck and trailer specifications. Tanks conforming to some of the specifications in the data are no longer being built for use as hazardous liquid bulk carriers, but the tark wall construction is similar to the gasoline tank trucks currently in use. The DOT provided summary data from Section F (Nature of Packaging Failure) of the incident report. This information is presented in Table 5.7. The categories "tank truck" and "tank trailer" were used when the DOT specification number was not included on the incident report. Most of these vehicles were being used for gasoline shipments at the time of the incident. Releases reported under a general category called "other conditions" (cause code 17) wer? not included in the table. Most of these releases occurred during loading or unloading. Loading and unloading releases were not considered in this study.

Most releases reported in cause codes 10 and 11 (defective or loose fittings, valves or closures) were not the result of an accident and did not usually result in the release of large amounts of material. Small releases such as these, that occurred during routine transport are not considered 


\section{HAZARDOUS MATERIALS INCIDENT REPORT}

INSTRUCTIONS: Submit this report in duplicate to the Secretary, Hazardous Materials Regulations Board, Department of Transportation, Washington, D.C. 20590. (ATTN: Op. Div.). If space provided for any item is inadequate, complete that item under Section $\mathbf{H}$. "Remarks', keying to the entry number being completed. Copies of this form, in limited quantities, may be obtained from the Secretary, Hazardous Materials Regulations Board. Additional copies in this prescribed format may be reproduced and used, if on the same size and kind of paper.

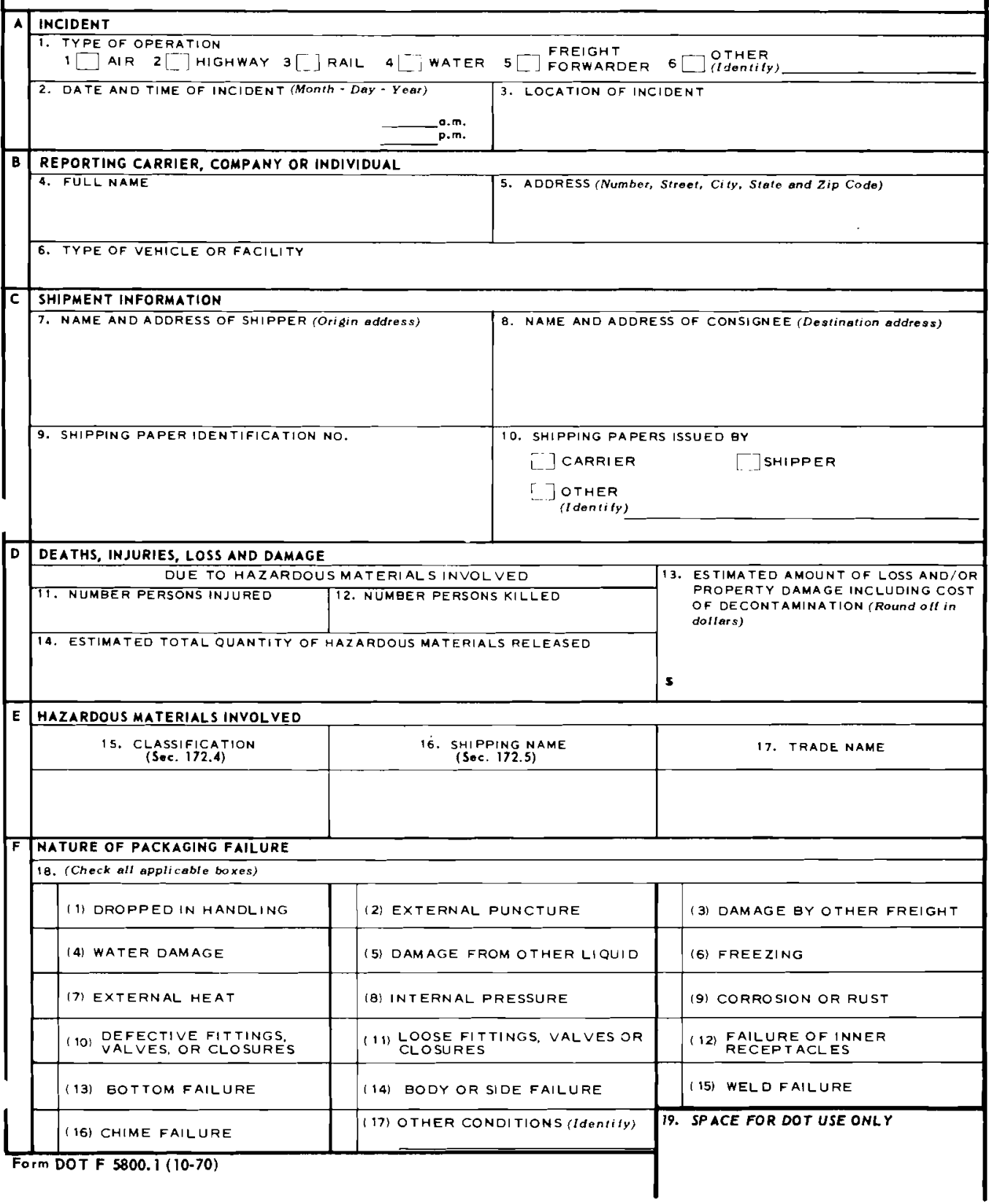

\section{FIGURE 5.4. DOT Hazardous Materials Incident Report}




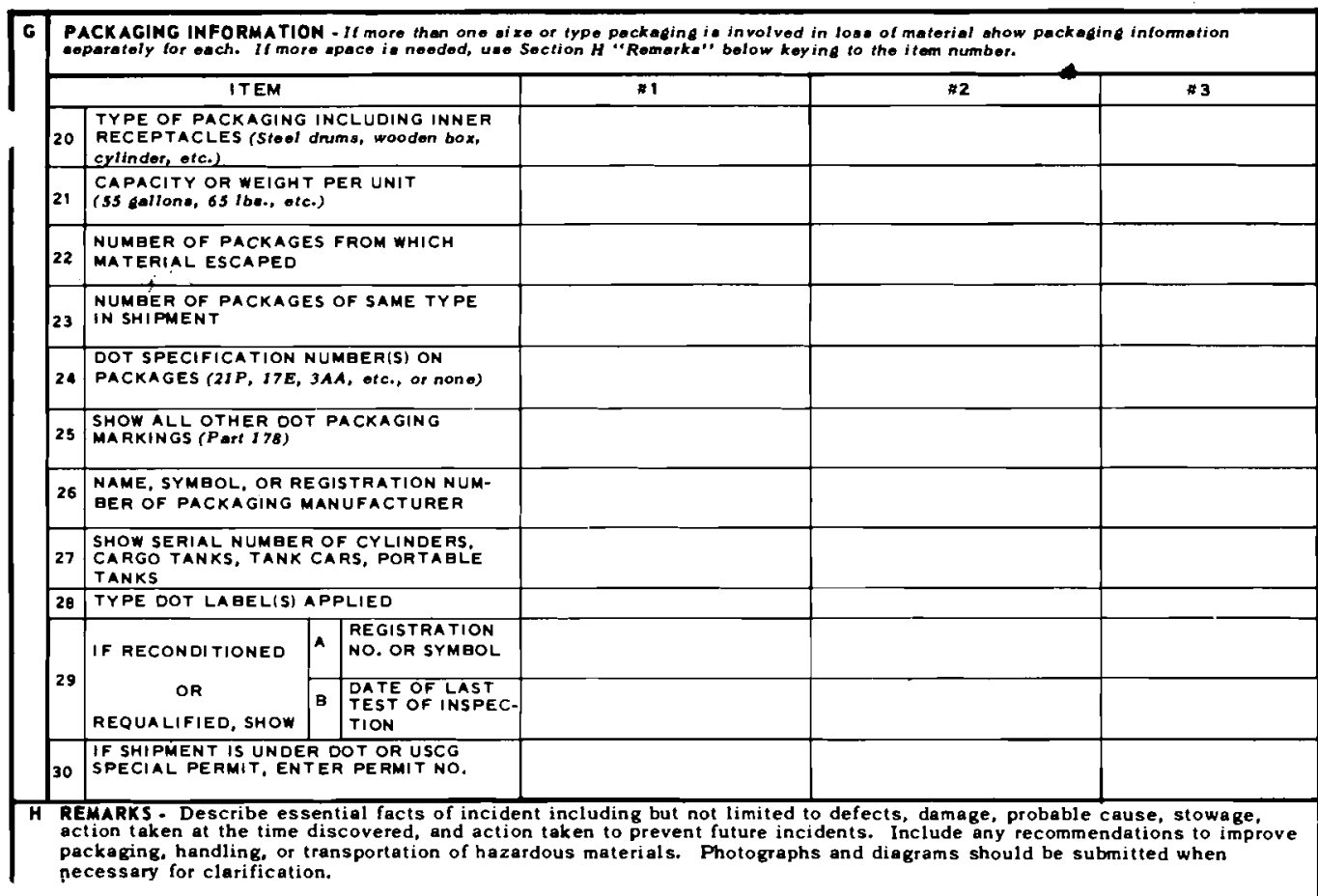

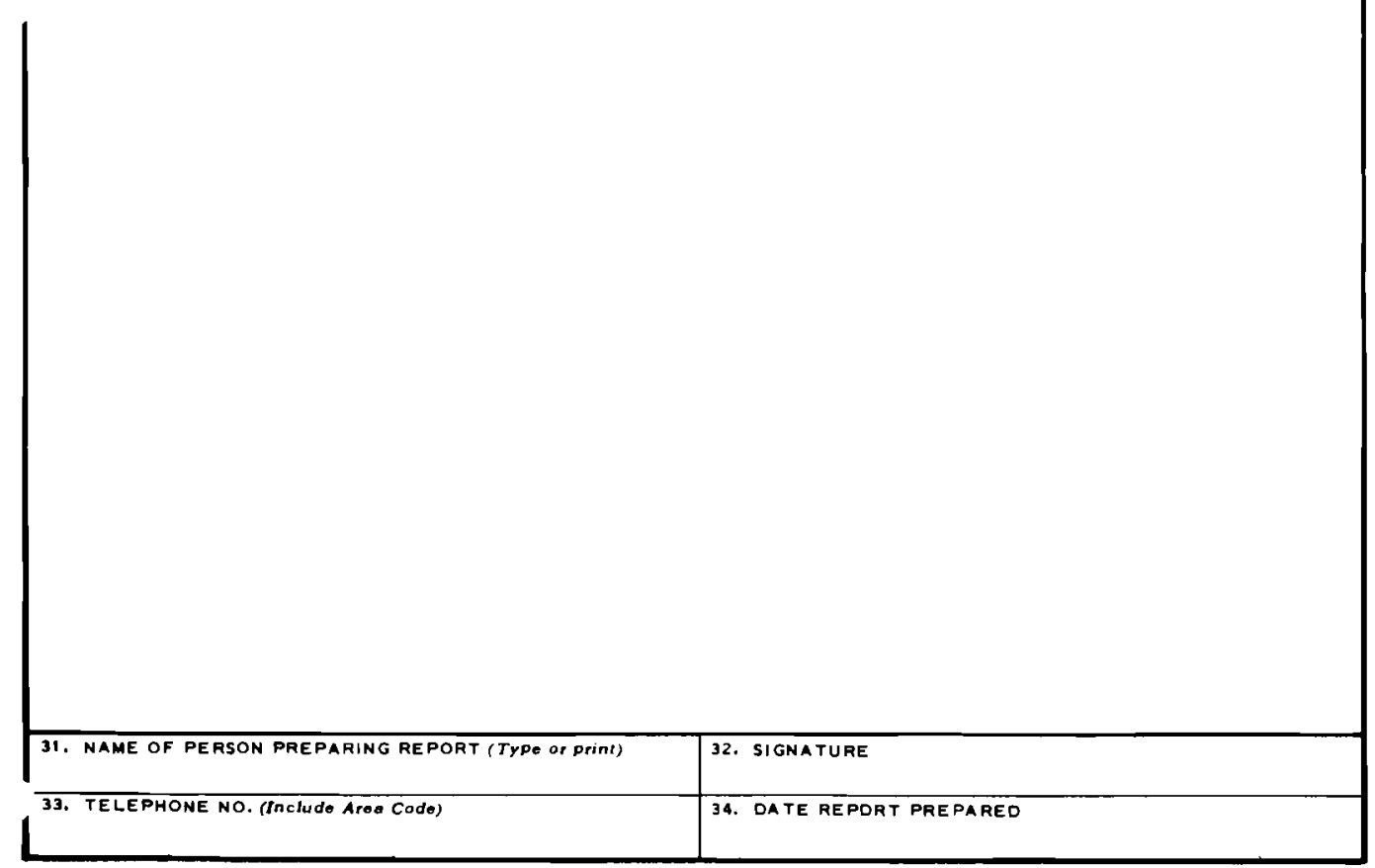

Reverse of Form DOT F 5800.1 (10-70)

\section{FIGURE 5.4. (Cont'd)}


TABLE 5.7. Summary of DOT Hazardous Material Incident

Reports for Bulk Liquid Carriers (1971-1975)

\begin{tabular}{|c|c|c|c|c|c|c|c|c|c|c|c|c|c|c|}
\hline $\begin{array}{c}\text { DOT } \\
\text { Specification }\end{array}$ & & ails & re & $\mathrm{Sat}$ & e & ode & $(\mathrm{Sec}$ & io & $F-$ & ncic & ent & Rep & & \\
\hline & 1 & $\frac{1}{2}$ & & & 6 & $\frac{7}{7}$ & $\frac{1}{8}$ & $\frac{10}{9}$ & 10 & $\frac{11}{11}$ & $\frac{112}{12}$ & $\frac{13}{13}$ & $\frac{1}{14}$ & 15 \\
\hline$M C-300$ & & & & & & & & & 4 & 3 & & & & \\
\hline$M C-301$ & & & & & & & & & 1 & 2 & & & & \\
\hline MC-302 & & 23 & & & 1 & 2 & 1 & & 5 & 1 & & 1 & 1 & 2 \\
\hline$M C-303$ & & 9 & & & & & 2 & & 13 & 8 & & & 4 & 2 \\
\hline$M C-304$ & 1 & 2 & & & 1 & & 5 & & 31 & 15 & & 1 & 6 & 4 \\
\hline$M C-305$ & 1 & 71 & 1 & 1 & 1 & 1 & 6 & & 102 & 82 & 2 & 2 & 7 & 8 \\
\hline$M C-306$ & 4 & 89 & & & 3 & 10 & 13 & 1 & 102 & 78 & 2 & 1 & 13 & 19 \\
\hline$M C-307$ & & 1 & & & & & 2 & & 29 & 16 & 1 & & 2 & 3 \\
\hline Tank Truck & 30 & 84 & 1 & & 5 & 6 & 26 & & 96 & 77 & 4 & 1 & 8 & 7 \\
\hline Tank Trailer & 11 & 79 & 1 & L & 5 & 6 & 29 & $\underline{2}$ & 135 & 75 & 3 & 2 & 3 & 4 \\
\hline Totals & 47 & 358 & 3 & 1 & 16 & 25 & 84 & 3 & 518 & 357 & 12 & 8 & 44 & 49 \\
\hline
\end{tabular}

significant for this study. Table 5.8 presents the revised data used to estimate the fraction of tank failures in accidents that resulted from puncture forces. Failure codes 10 and 11 have been el iminated and all cause codes except puncture have been combined and categorized as "other".

TABLE 5.8. Percentage of Bulk Liquid Tank Failures Resulting from Puncture Forces

\begin{tabular}{|c|c|c|c|}
\hline \multirow[b]{2}{*}{ DOT Tank Specification } & \multicolumn{2}{|c|}{ Failure Cause } & \multirow{2}{*}{$\begin{array}{l}\text { Failures from } \\
\text { Puncture } \\
\end{array}$} \\
\hline & Puncture & Other & \\
\hline$M C-302$ & 23 & 8 & 0.74 \\
\hline$M C-303$ & 9 & 8 & 0.53 \\
\hline$M C-304$ & 2 & 18 & 0.10 \\
\hline MC-305 & 71 & 30 & 0.71 \\
\hline$M C-306$ & 89 & 66 & 0.57 \\
\hline MC-307 & 1 & 8 & 0.11 \\
\hline Tank Truck & 84 & 88 & 0.49 \\
\hline Tank Trailer & 79 & $6 \epsilon$ & $\underline{0.54}$ \\
\hline Totais & 358 & 292 & 0.55 \\
\hline
\end{tabular}




\section{REFERENCES}

1. T. I. McSweeney, R. J. Hall et a1., An Assessment of the Risk of Transporting Plutonium 0xide and Liquid Plutonium Nitrate by Truck. BNWL-1846, Battelle, Pacific Northwest Laboratories, Richland, WA, pp. 5.4-5.5, August 1975.

2. R. K. Clarke, J. T. Foley, W. R. Hartman and D. W. Larson, Severities of Transport Accidents, Vol. II I - Motor Carriers. SLA-74-0001, Sandia Laboratories, Albuquerque, NM, July 1976.

3. R. E. Scott et al., Statistical Analys is of Truck Accident Involvements. The University of Michigan Highway Research Institute, Ann Arbor, MI, December 1971. 


\subsection{GASOLINE TANK TRUCK FAILURE THRESHOLDS}

The previous section describes the accident environment associated with highway transport of gasoline in bulk tankers. A summary of calculated response of the reference gasoline tank vehicles to this accident environment is presented below. Substantiating calculations appear in Appendix D. Response to the most significant stresses imposed in highway accidents is quantified in terms of failure thresholds. A failure threshold is the level of applied thermal or mechanical stresses that produces a release of lading (gasoline) in an accident. Thresholds are related to minimum energy or vehicle velocity required to produce the failure.

The most significant types of accident-imposed stresses are:

- impact

- puncture

- abrasion

- thermal (solar or external fire)

The response of the gasoline tanker to each type of stress associated with the accident environment is calculated independently. No attempt was made to predict the lowered level of failure when the applied stresses act simultaneously or sequentially. The effect of this simplification on the overall risk analysis was determined to be small.

The analytical approach used for prediction of response of the gasoline tanker is, in most cases, rather simplified. Comprehensive analytical treatment is not warranted because of the lack of quantitative information on the truck accident environment. A summary of failure thresholds in response to the individual accident-imposed stresses is found in the subsections below. Failure threshold calculations were performed for both reference shipping systems considered in the study. In most cases, the results did not vary significantly between the systems. Instances where differences were found are indicated in the following sections. 


\subsection{IMPACT}

To simplify the analysis, the failure threshold for impact was calculated by representing the elliptical tank as an axially-loaded cylinder. Cases analyzed were impact against a flat surface in the direction of the longitudinal axis and impact perpendicular to the longitudinal axis against a similar surface. The minimum velocities predicted at failure for each case are shown in Table 6.1.

TABLE 6.1. Minimum Velocities Predicted at Failure

Minimum Velocity (mph)

Axial impact against

a flat barrier

30.6

Side impact into

a flat barrier
18.7

These cases assumed that the failure threshold is reached when the volume of the tank is reduced by a volume equivalent to the head space (10\% for the cases analyzed). The air and gasoline vapor above the liquid gasoline are presumed to vent out the pressure relief devices.

\subsection{PUNCTURE}

Puncture of the relatively thin aluminum skin of the gasoline tank can be expected whenever a fixed probe more than a few inches long contacts the skin during an accident. Because of its ductility, the aluminum skin of the tank will deform about six inches before sheer stresses finally fail the skin around the head of the probe. The minimum length puncture probe required to fail the tank walls is then six inches, although shorter probes could fail the walls in the immediate vicinity of a baffle. The minimum energy between the tank and the probe that would fail the walls was found to be $480 \mathrm{ft}-1 \mathrm{~b}$. The energy required increases with probe diameter. Calculations have shown that probes with energies available in truck accidents will puncture the walls only if they are greater than 0.4 inches in diameter. 


\subsection{ABRASION}

The failure threshold by pure abrasion was derived through experimental data related to now plow skid plates and actual measurements and observations of a tank that had failed by abrasion. The minimum velocities required to fail the skin of the tank by abrasion are shown in Table 6.2. It was determined that the likelihood of abrasive failure on loose gravel or dirt was very low.

TABLE 6.2. Minimum Velocity to Fail Tank Skin by Abrasion

Surface

Asphalt-Concrete

Bituminous Surface Treatment
Minimum Velocity

$26 \mathrm{mph}$

$20 \mathrm{mph}$

\subsection{THERMAL}

The aluminum skin of the tank will melt in a short time if exposed to an $1850^{\circ} \mathrm{F}$ fire. Failure by this mechanism is usually prevented because the liquid gasoline backing the skin conducts the heat away. It was determined that exposure to an $1850^{\circ} \mathrm{F}$ fire for one hour would cause half the contents of the tank to be vaporized and released through the relief valve. It is assumed that some portion of the skin of a half full tank will be backed by liquid gasoline and will fail from exposure to the fire.

It was found that if all the relief valves on the tank failed to function, the tank would fail from overpressurization after a 40-minute exposure to an $1850^{\circ} \mathrm{F}$ fire. 
-

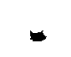




\subsection{RELEASE SEQUENCE IDENTIFICATION}

Gasoline releases from tank truck accidents occur each year in the United States. The statistical accident information available from state and federal agencies does not provide a sufficient basis to identify the mechanisms that caused these tanks to fail in the accident. Possible ways that releases could occur (sequences of events leading to a release or "release sequences") must be identified by a reasoning process. This section describes a formalized procedure for identifying possible release sequences. The first step in the procedure is to develop fault trees using the techniques described in Section 7.1. Section 7.2 presents the fault tree developed for shipment of gasoline by truck. Analysis of the fault tree provides the release sequences. The release sequences identified from the gasoline truck transportation fault tree are presented in Section 7.3.

\subsection{FAULT TREE CONSTRUCTION}

The fault tree analysis technique was developed in the 1960s in the aerospace industry to identify design deficiencies before actual space flight of the equipment. Basically the procedure is to assume a failure and work backwards to identify component failures which could cause or contribute to the failure. The fault tree should be related to individual components for which failure data are available. For instance, in an electronic circuit the basic failure might occur in a resistor. In practice, fault trees seldom are developed to that degree. What occurs instead is development of fault trees in terms of basic system modules. Using the electronic example, one would carry the possible failure back through the fault tree only to the amplifier which contained the resistor. Such a fault tree is called a Top Level Fault Tree since it usually identifies only large systems which could result in a failure. Table 7.1 gives the various fault tree symbols and their meanings.

The methodology applied to transportation of gasoline involves postulating a release of gasoline during transport and then examining the series of events which must have occurred to cause the release. This form of 
reasoning is thought to be much more inclusive than beginning with an initiating event and working toward a release, (i.e., constructing accident scenarios or event trees). When properly applied, the accident scenarios obtained from using the fault tree methodology should be more complete than the alternative method of trying to 1 ist all the accident scenarios without the aid of any formalized reasoning process. The tree constructed using the fault tree methodology is used as the basis for estimating the total release probability.

\section{TABLE 7.1. Fault Tree Symbolism}

The simultaneous occurrence of inputs is required to cause an output.

inputs

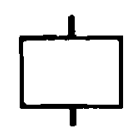

Fault event that results from the logical operation of two or more fault events. It is always the output from a logic gate.

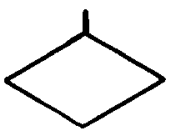

Inferred fault event. Any failure except a primary failure which is not developed further due to lack of information, time or money or due to the low probability of occurrence. It can also be used where other analyses give sufficient information to indicate that further analysis would be redundant.

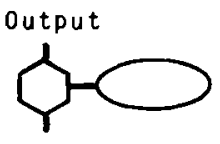

"Inhibit" gate. The condition specified in the oval is required for an input fault event to result in an output event. This condition is frequently a design limit which will not transmit a failure until the design limits have Input been exceeded.

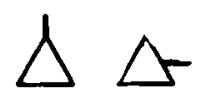

Transfer symbol denoting that failure also impacts on other branches of fault tree. A line at the apex of the triangle represents a "transfer in." A line in the side represents a "transfer out." A number is placed in the triangle to identify transfer locations.

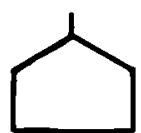

"House" defines an event that must occur, or is expected to occur, due to design and normal operating conditions. 


\subsection{FAULT TREE FOR SHIPMENT OF GASOLINE BY TRUCK}

The fault tree for shipment of gasoline by truck has been developed for routine transport on primary roads and urban ${ }^{(a)}$ streets in the U.S. The effects of sabotage or natural disasters were not included in the analysis. It is assumed for this analysis that all gasoline is shipped in tank trucks and trailers designed to meet DOT specification MC-306. A description of the tank trucks used in the analysis is contained in Appendix $A$.

The fault tree developed for shipment of gasoline in an MC-306 tank truck is shown in Figure 7.1. The tree was drawn using the fault tree graphics code ACORN. (1) A list of identified events that could contribute to a release are shown in Table 7.2 and the input labels for the gate logic rectangles are presented in Table 7.3. The fault events in the tree designated by the circle symbol were not analyzed individualiy because of lack of information or because they were included in other events. They are included in the fault tree only for completeness. The tree was constructed by drawing a separate branch to analyze the failure of each type of tank component - tank walls, outlet valve, relief valve and manway cover that could release gasoline in an accident. Failure of each of these components by impact, puncture, fire, crush and abrasion was examined. The contribution to failure of substandard component manufacture or human errors in operating the components was also considered, as was the effect of one accident stress on the ability of the container to withstand a subsequently-applied stress.

\subsection{RELEASE SEQUENCES}

The fault tree can be thought of as a compact notation for identifying and displaying large numbers of release sequences. For large trees, it is convenient to use computer programs to perform the Boolean algebra that reduces the tree to a series of release sequences or "cut sets." The computer code MFAULT ${ }^{(2)}$ was used for this analysis.

(a) The term urban as used in this report includes the suburban areas surrounding many cities. 


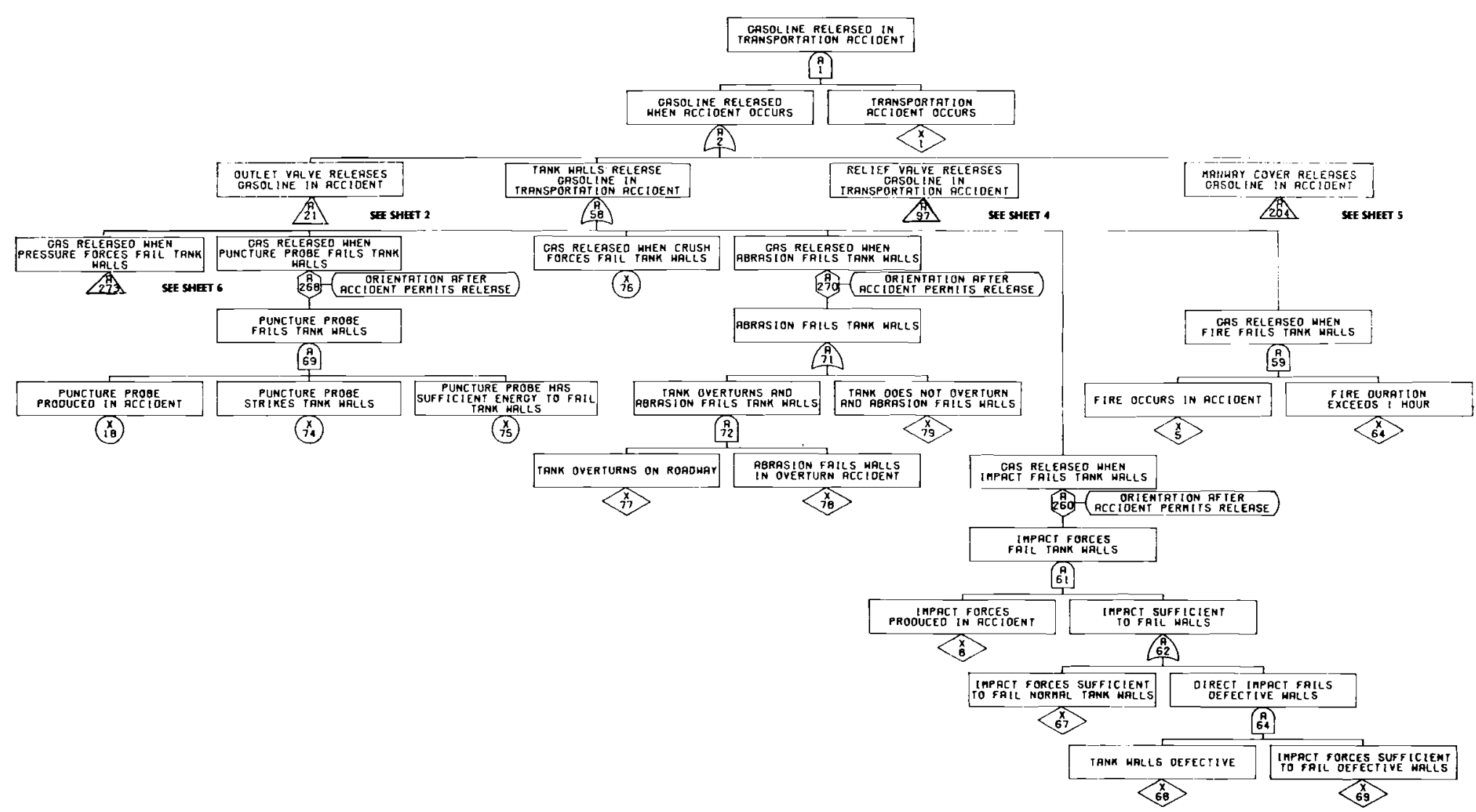

FIGURE 7.1. Gasoline Truck Transportation Fault Tree 


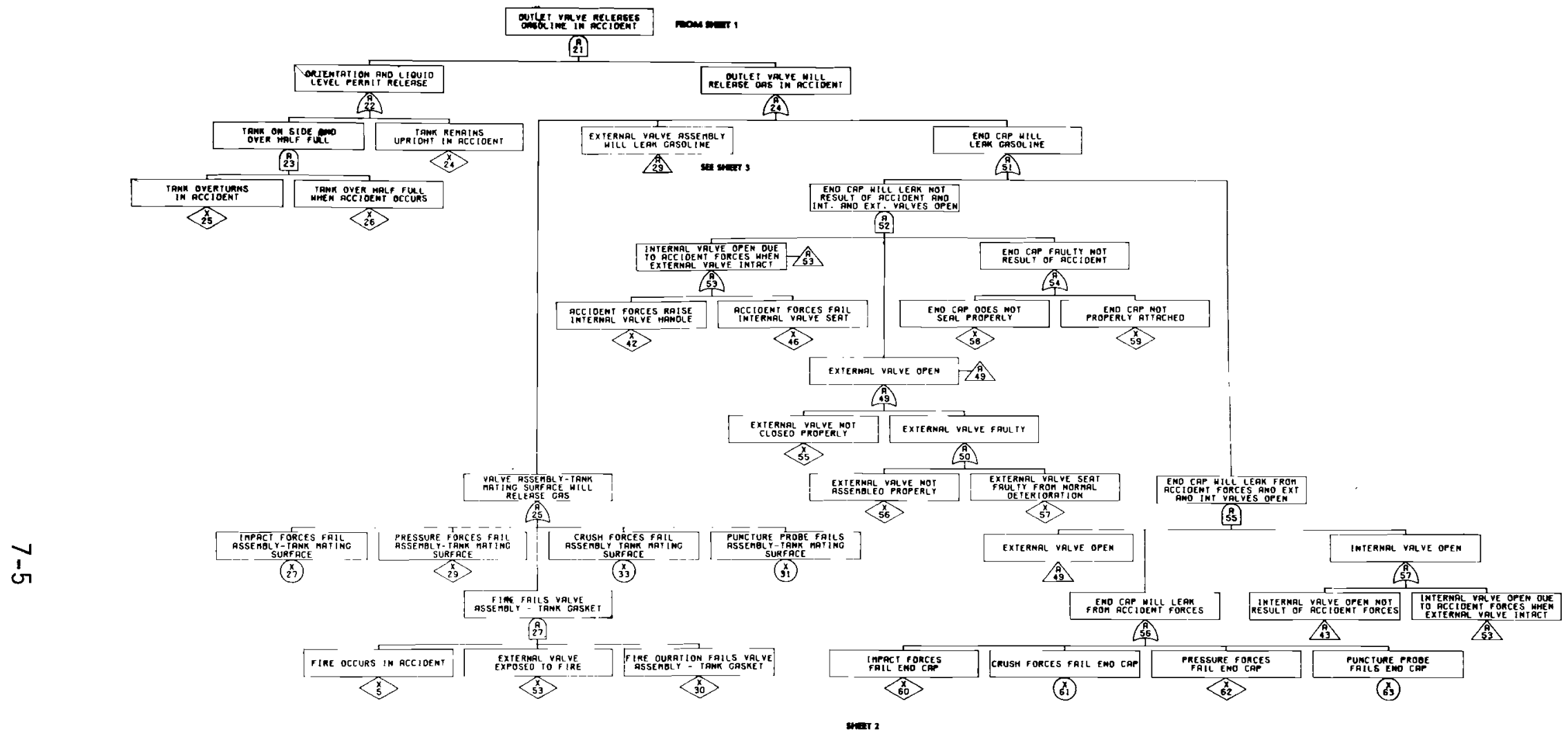

FIGURE 7.1 . (cont'd) 


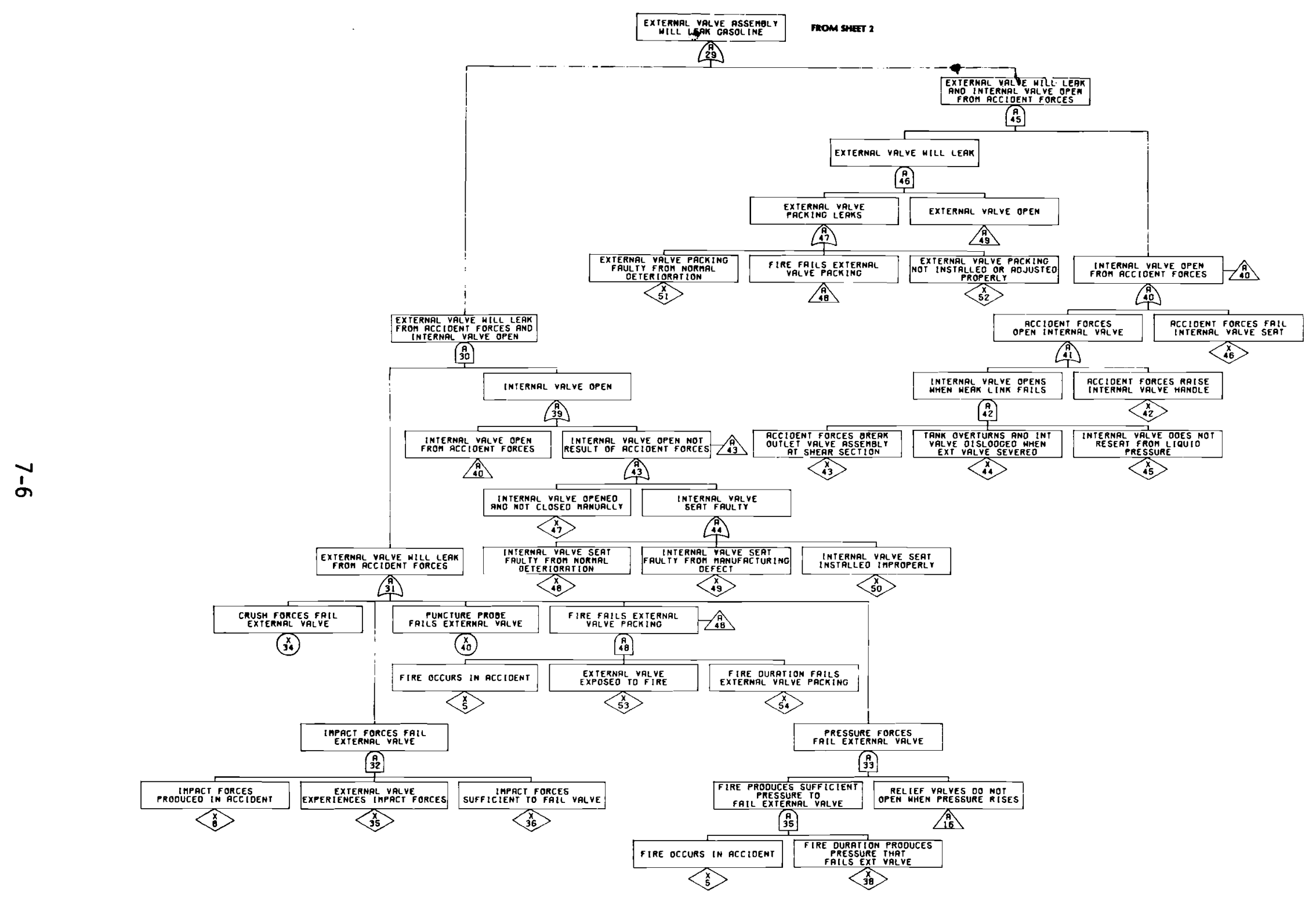

FIGURE 7.1. (cont'd) 


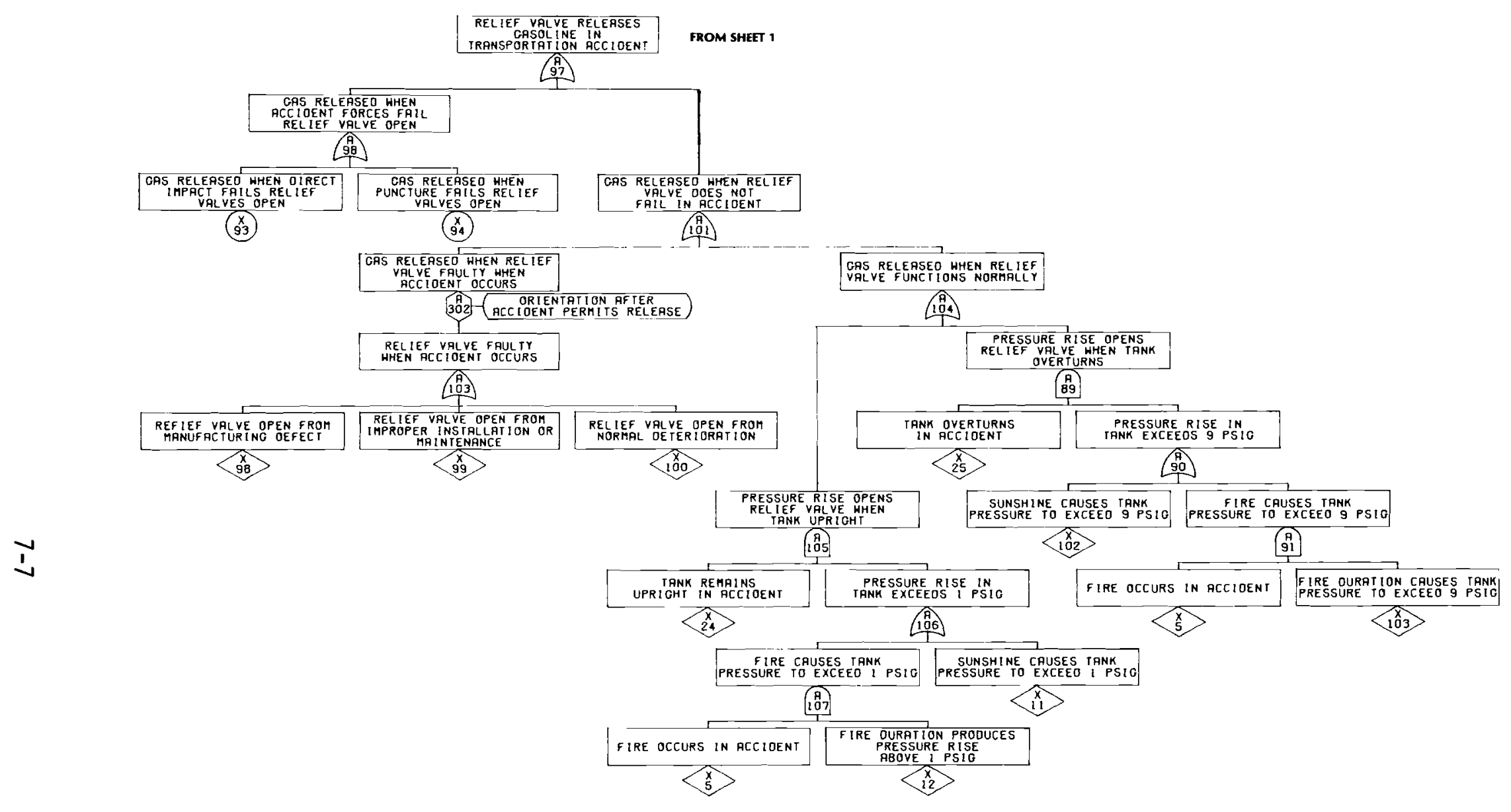

SHEET

FIGURE 7.1 . (cont'd) 


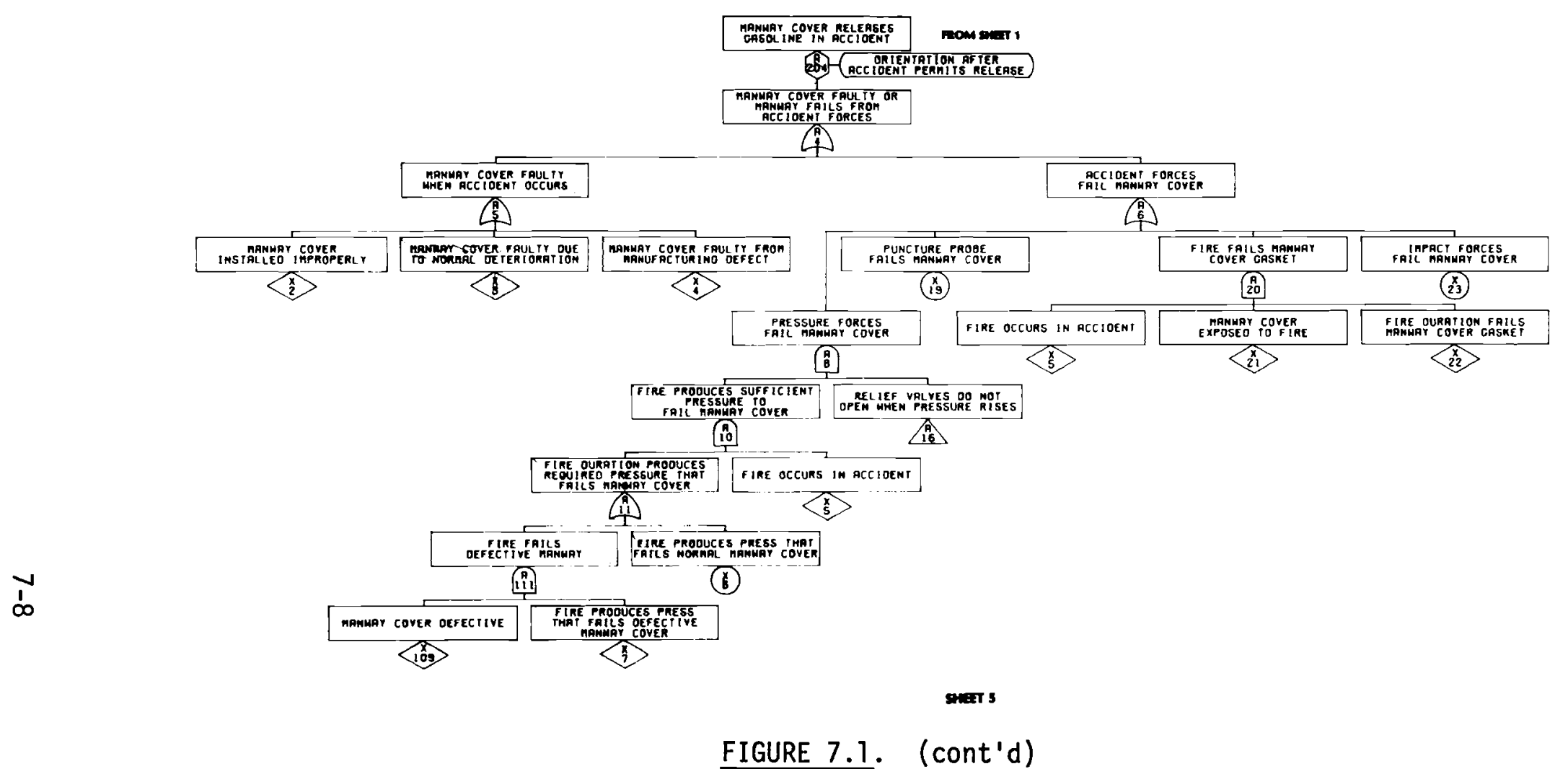

FIGURE 7.1 . (cont'd) 


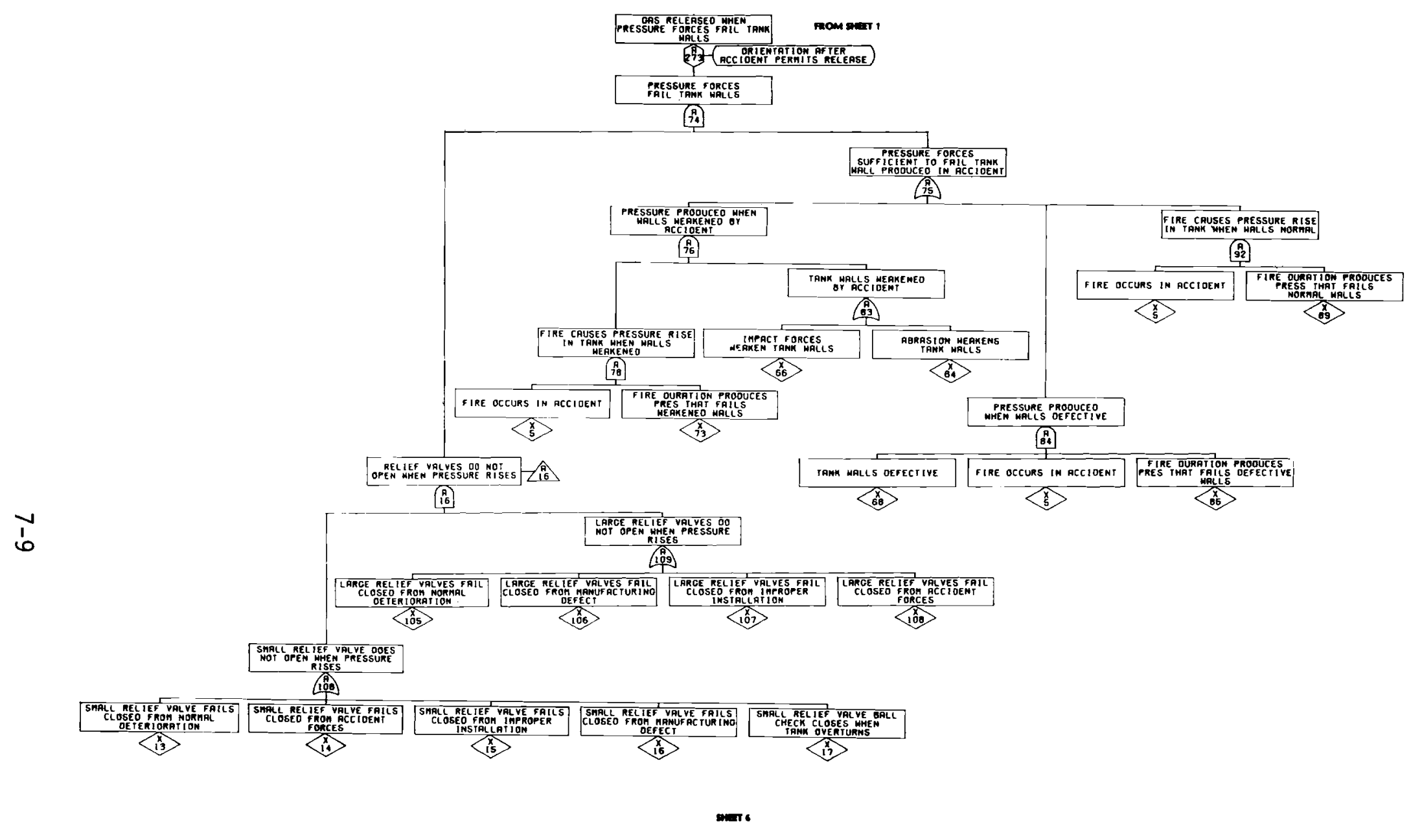

FIGURE 7.1 . (cont'd) 
TABLE 7.2. Listing of Basic Events for Gasoline Truck Transportation Fault Tree

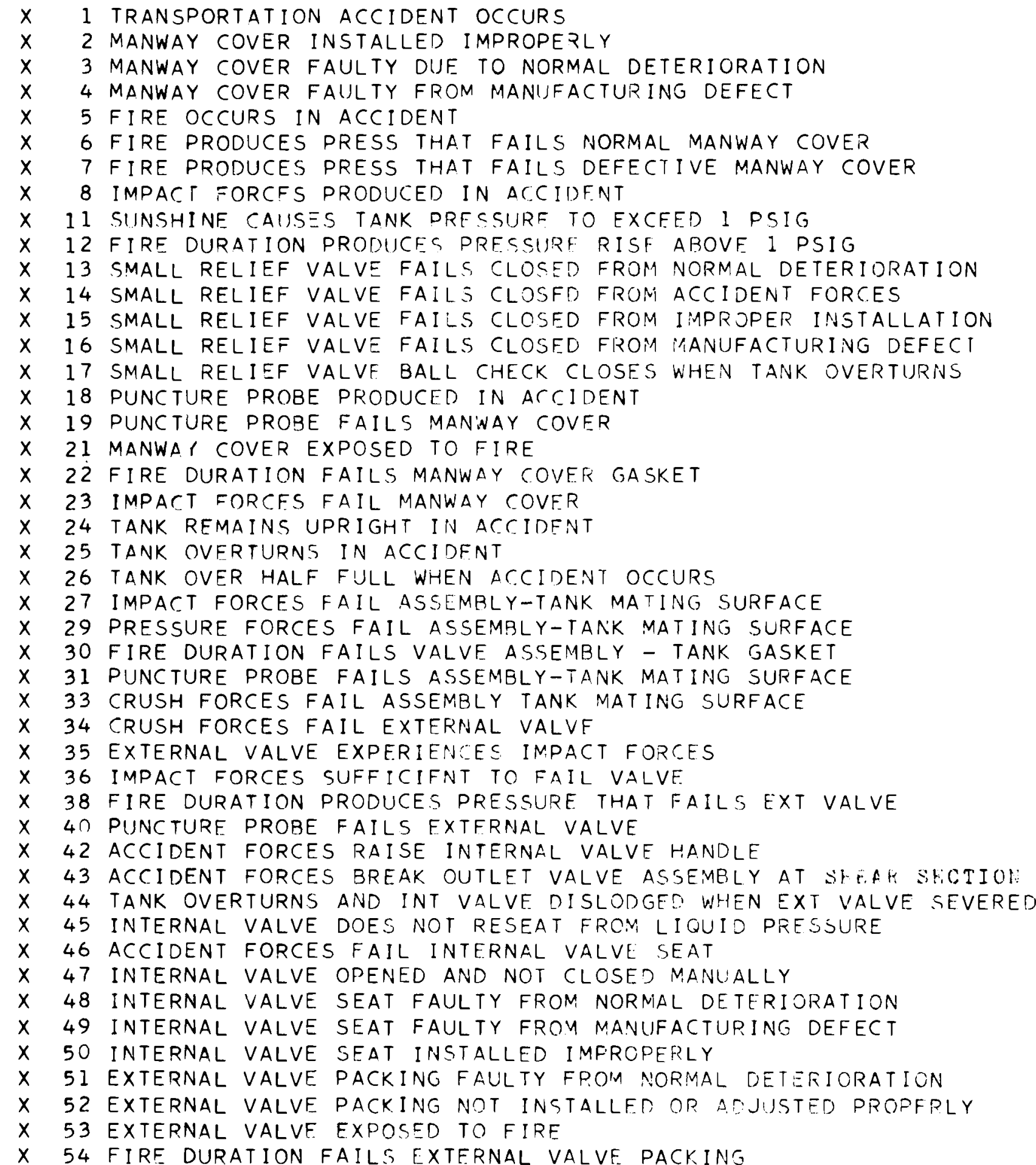




\section{TABLE 7.2. (cont'd)}

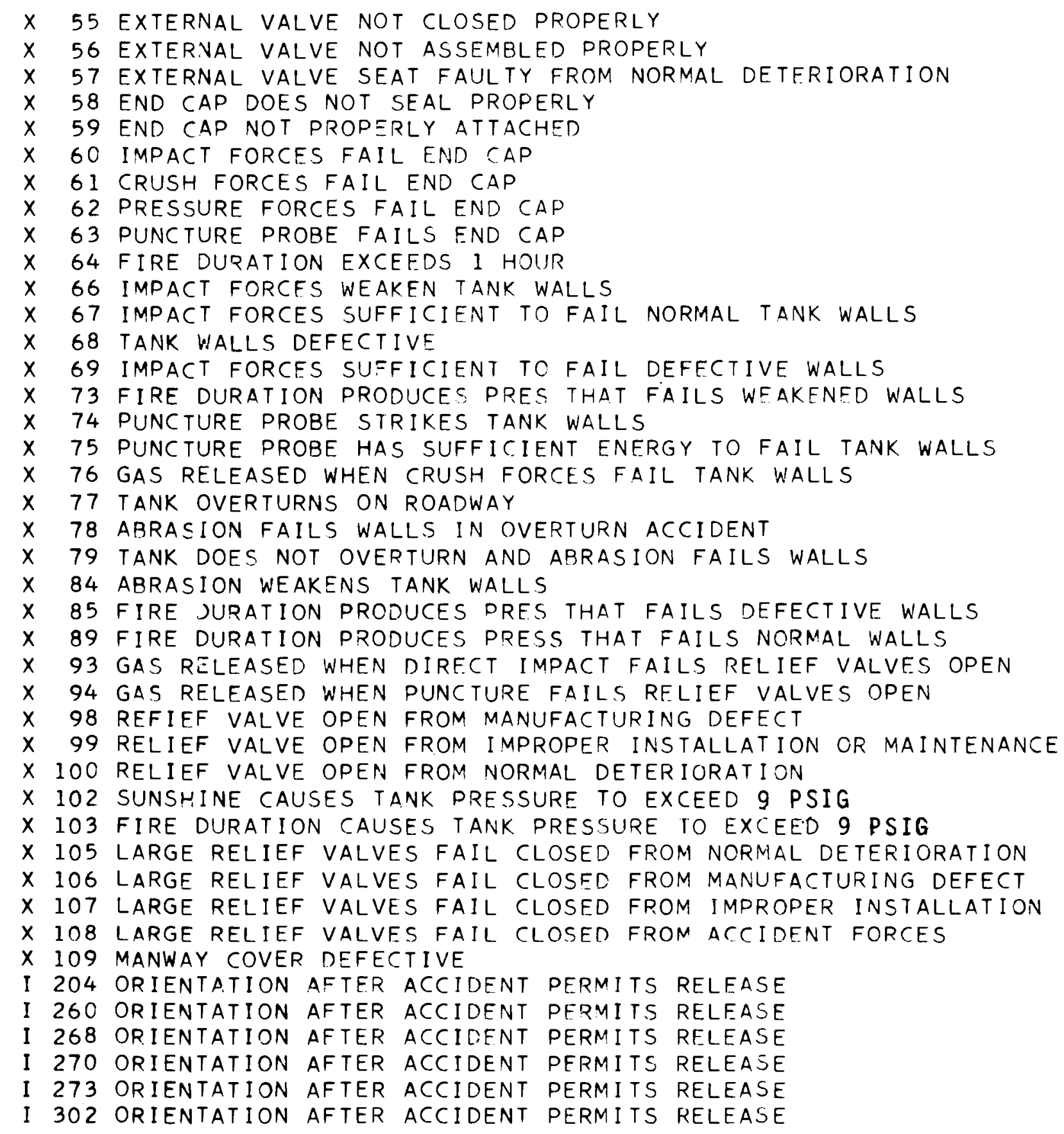


TABLE 7.3. Listing of Gate Logic Rectangle Labels for Gasoline Truck Transportation Fault Tree

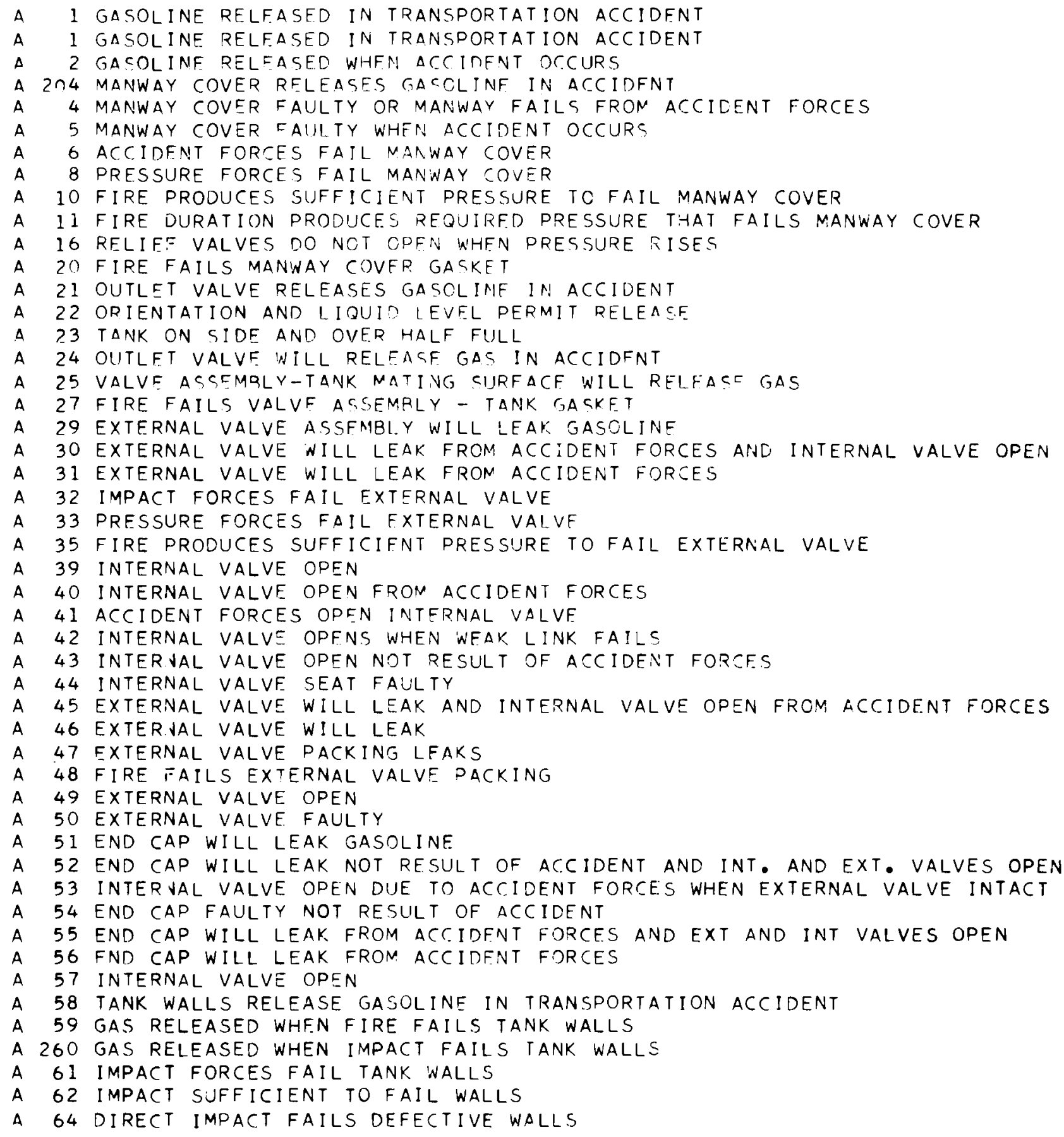




\section{TABLE 7.3. (cont'd)}

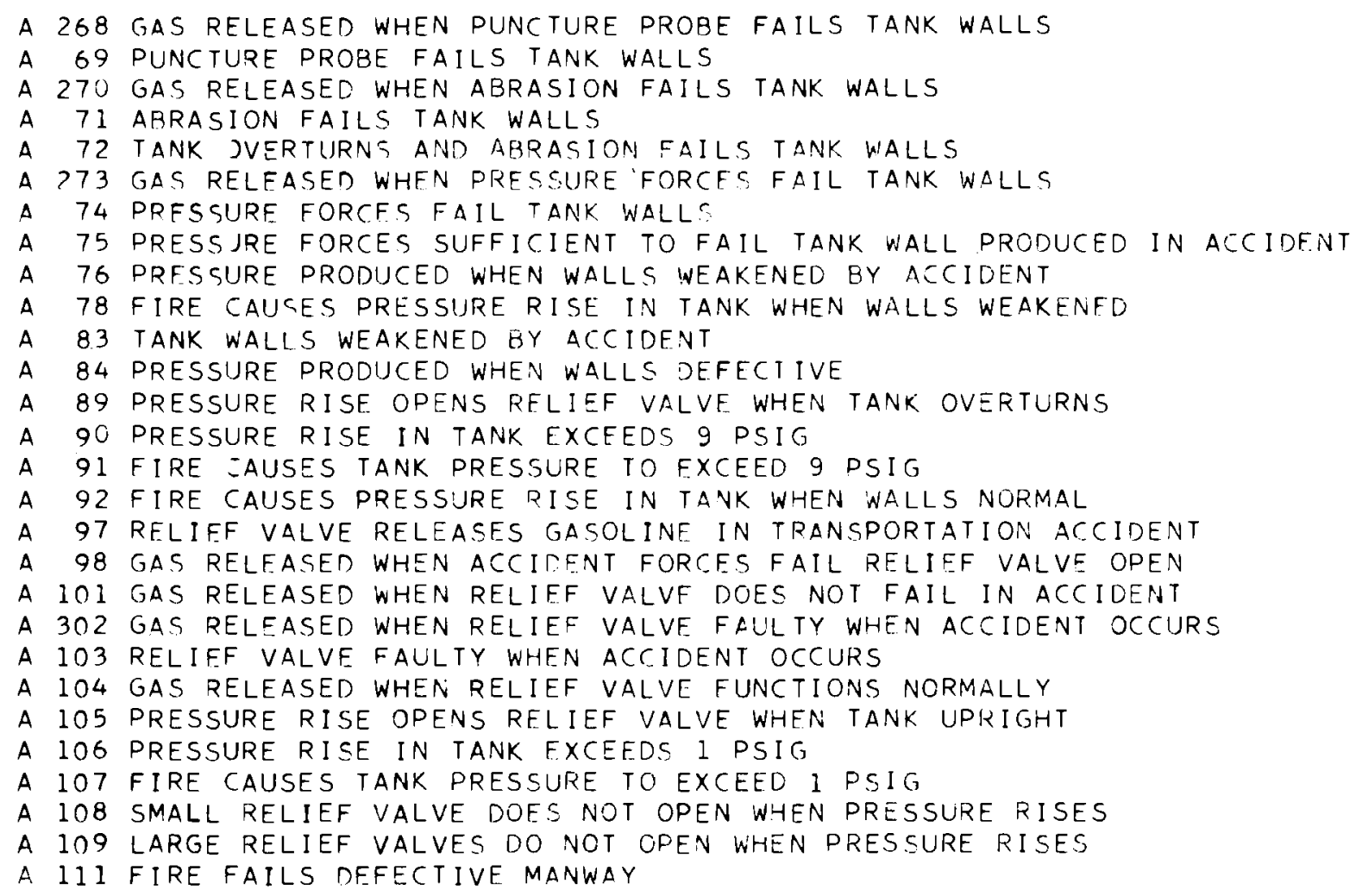

A partial listing of the release sequences identified from the gasoline truck transportation fault tree is presented in Table 7.4. There are a total of over seven hundred possible release sequences in the fault tree. These have been screened for presentation here to eliminate those sequences that have a probability of occurrence of less than once in $10^{12}$ shipments. (see Section 8). All of the release sequences were retained in the actual analysis. 
TABLE 7.4. Listing of Gasoline Truck Transportation Fault Tree Release Sequences

\begin{tabular}{|c|c|c|c|c|c|c|c|c|}
\hline$x$ & 1 & A 69 & 1268 & & & & & \\
\hline$x$ & 1 & $\times 5$ & $\times 64$ & & & & & \\
\hline$x$ & 1 & $\times 2$ & I 204 & & & & & \\
\hline$x$ & 1 & $x$ & 1204 & & & & & \\
\hline$x$ & 1 & $\times 4$ & 1204 & & & & & \\
\hline$x$ & 1 & $\times 79$ & 1270 & & & & & \\
\hline$x$ & 1 & $\times 98$ & 1302 & & & & & \\
\hline$x$ & 1 & $\times 25$ & $\times 102$ & & & & & \\
\hline$x$ & 1 & $\times 24$ & $\times 29$ & & & & & \\
\hline$x$ & 1 & $\times 99$ & I 302 & & & & & \\
\hline$x$ & 1 & $\times 100$ & I 302 & & & & & \\
\hline$x$ & 1 & $\times 11$ & $\times 24$ & & & & & \\
\hline$x$ & 1 & $\times 77$ & $\times 78$ & $\mathrm{I} 270$ & & & & \\
\hline$x$ & 1 & $\times 5$ & $\times 25$ & $\times 103$ & & & & \\
\hline$x$ & 1 & $\times 25$ & $\times 26$ & $\times 29$ & & & & \\
\hline$x$ & 1 & $\times 8$ & $\times 67$ & $\mathrm{I} 260$ & & & & \\
\hline$x$ & 1 & $\times 5$ & $\times 12$ & $\times 24$ & & & & \\
\hline$x$ & 1 & $\times 8$ & $\times 68$ & $\times 69$ & I 260 & & & \\
\hline$x$ & 1 & $\times 5$ & $\times 24$ & $\times 30$ & $\times 53$ & & & \\
\hline$x$ & 1 & $\times 5$ & $\times 21$ & $\times 22$ & I 204 & & & \\
\hline$x$ & 1 & $\times 24$ & $\times 46$ & $\times 56$ & $\times 59$ & & & \\
\hline$x$ & 1 & $\times 24$ & $\times 46$ & $\times 55$ & $\times 59$ & & & \\
\hline$x$ & 1 & $\times 5$ & $\times 25$ & $\times 26$ & $\times 30$ & $\times 53$ & & \\
\hline$x$ & 1 & $\times 8$ & $\times 24$ & $\times 35$ & $\times 36$ & $\times 48$ & & \\
\hline$x$ & 1 & $\times 8$ & $\times 24$ & $\times 35$ & $\times 36$ & $\times 46$ & & \\
\hline$x$ & 1 & $\times 8$ & $\times 24$ & $\times 35$ & $\times 36$ & $\times 42$ & & \\
\hline$x$ & 1 & $\times 5$ & $\times 17$ & $\times 89$ & $\times 108$ & 1273 & & \\
\hline$x$ & 1 & 5 & $\times 24$ & $\times 48$ & $\times 53$ & $\times 54$ & & \\
\hline$x$ & 1 & 5 & $\times 24$ & $\times 46$ & $\times .53$ & $\times 54$ & & \\
\hline$x$ & 1 & 5 & $\times 24$ & $\times 42$ & $\times 53$ & $\times 54$ & & \\
\hline$x$ & 1 & 8 & $\times 24$ & $\times 35$ & $\times 36$ & $\times 47$ & & \\
\hline$x$ & 1 & 8 & $\times 24$ & $\times 35$ & $\times 36$ & $\times 49$ & & \\
\hline$x$ & 1 & 8 & $\times 24$ & $\times 35$ & $\times 36$ & $\times 50$ & & \\
\hline$x$ & 1 & 5 & $\times 24$ & $\times 47$ & $\times 53$ & $\times 54$ & & \\
\hline$x$ & 1 & 5 & $\times 24$ & $\times 49$ & $\approx 53$ & $\times 54$ & & \\
\hline$x$ & 1 & 5 & $\times 24$ & $\times 50$ & $\times 53$ & $\times 54$ & & \\
\hline$x$ & 1 & 8 & $\times 25$ & $\times 26$ & $\times 35$ & $\times 36$ & X. 48 & \\
\hline$x$ & 1 & 8 & $\times 25$ & $\times 26$ & $\times 35$ & $\times 36$ & $\times 46$ & \\
\hline$x$ & 1 & 8 & $\times 25$ & $\times 26$ & $\times 35$ & $\times 36$ & $\times 42$ & \\
\hline$x$ & 1 & $\times 5$ & $\times 25$ & $\times 26$ & $\times 48$ & $\times 53$ & $\times 54$ & \\
\hline$x$ & 1 & $\times 5$ & $\times 25$ & $\times 26$ & $\times 46$ & $\times 53$ & $\times 54$ & \\
\hline$x$ & 1 & 8 & $\times 25$ & $\times 26$ & $\times 35$ & $\times 36$ & $\times 47$ & \\
\hline$x$ & 1 & 8 & $\times 25$ & $\times 26$ & $\times 35$ & $\times 36$ & $\times 49$ & \\
\hline$x$ & 1 & $\times 8$ & $\times 25$ & $\times 26$ & $\times 35$ & $\times 36$ & $\times 50$ & \\
\hline$x$ & 1 & 5 & $\times 25$ & $\times 26$ & $\times 47$ & $\times 53$ & $\times 54$ & \\
\hline$x$ & 1 & 5 & $\times 25$ & $\times 26$ & $\times 49$ & $\times 53$ & $\times 54$ & \\
\hline$x$ & 1 & 5 & $\times 25$ & $\times 26$ & $\times 50$ & $\times 53$ & $\times 54$ & \\
\hline$x$ & 1 & $\times 8$ & $\times 24$ & $\times 35$ & $\times 36$ & $\times 43$ & $\times 44$ & $\times 45$ \\
\hline
\end{tabular}




\section{REFERENCES}

1. J. L. Carter, ACORN a Program for Plotting Fault Trees. BNWL-2144, Battelle, Pacific Northwest Laboratories, Richland, WA, October 1977.

2. P. J. Pelto, W. L. Purcel1, MFAULT: A Computer Program for Analyzing Fault Trees. BNWL-2145, Battelle, Pacific Northwest Laboratories, Richland, WA, November 1977. 


\subsection{RELEASE SEQUENCE EVALUATION}

The previous section presented the fault tree for the shipment of gasoline by truck and listed the more important release sequences. Figure 8.1 illustrates the remaining steps in the risk evaluation and the inputs to these steps. It is necessary to assign a frequency of occurrence and a release fraction to each release sequence. This section presents the information used to evaluate these terms for each release sequence. The release fraction is input to the environmental consequence model in Section 9. The consequence of each release sequence is multiplied by its probability and this product is summed for all release sequences to determine the total risk.

LIST OF RELEASE

SEQUENCES

SECTION 7

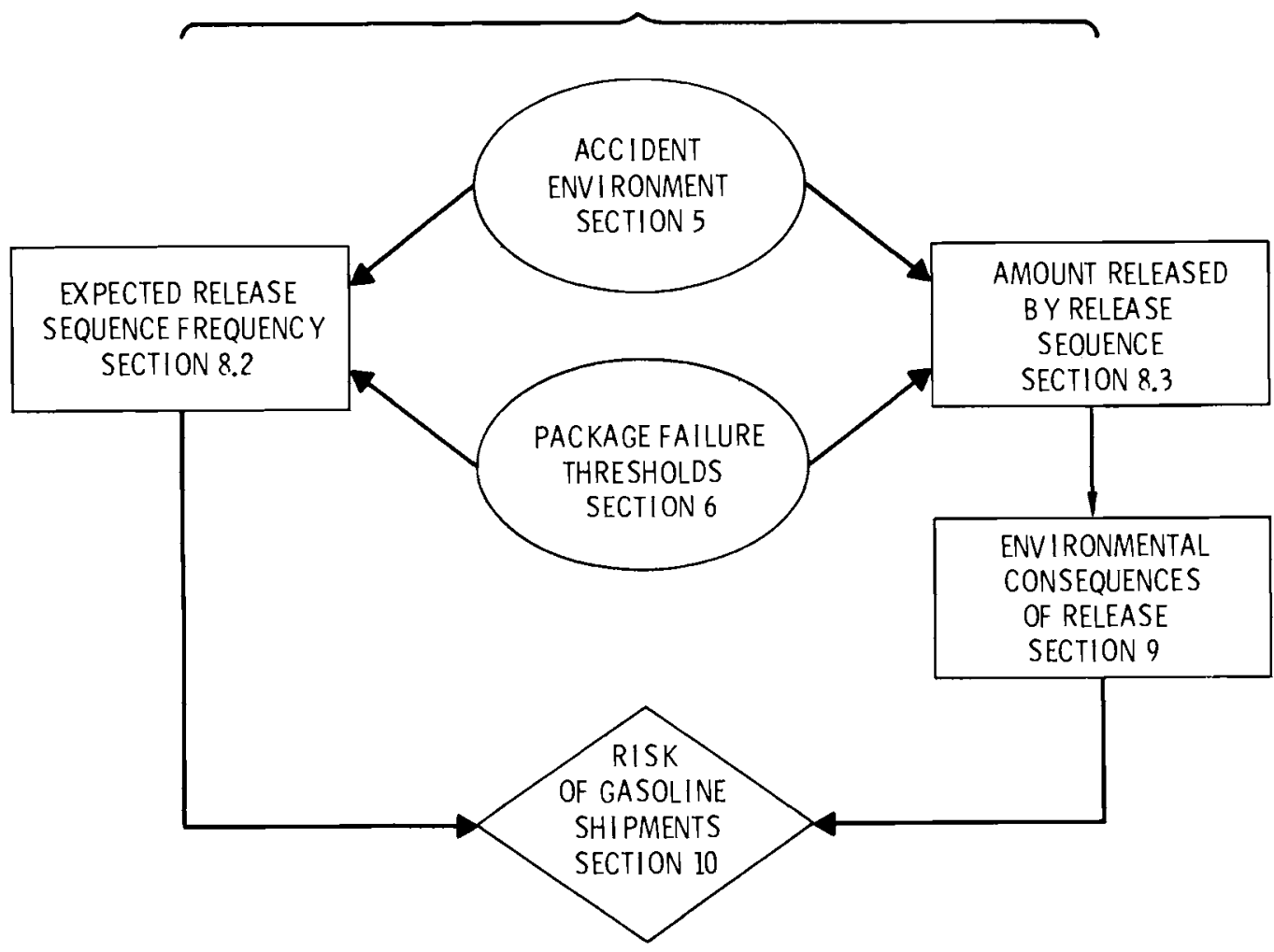

FIGURE 8.1. Remaining Steps in the Risk Evaluation 


\subsection{BASIC EVENT PROBABILITIES}

The expected frequency of each release sequence is obtained by taking the product of the probability of each event in the sequence. The estimates of the event probabilities are presented below. For most of the events, the probability is the same for both reference shipping systems used in the analysis. Where differences exist, the system that would result in the higher probability for that event was used.

Transportation Accident 0ccurs (XI)). The accident frequency for truck transport is one accident every $400,000 \mathrm{miles}$, i.e., a rate of $2.5 \times 10^{-6}$ truck accidents per mile. (1) For a shipping distance of 50 miles, the expected accident frequency is $1.25 \times 10^{-4}$ accidents per shipment. This value is used in the analysis.

Manway Cover Installed Improperly (X2). Manway covers are removed from the tanks periodically for tank cleaning and maintenance. Previous studies (2) have used a probability of $3 \times 10^{-3}$ for human errors in performing a task embedded in a routine procedure. The manway cover is opened each time the product is loaded into or off-loaded from the tank. Most installation errors would be discovered during this process. Therefore, a probability of $3 \times 10^{-4}$ was assigned to this event.

Manway Cover Faulty Due to Normal Deterioration (X3). No data are available for this event. A survey of local trucking companies engaged in gasoline transportation indicated that the manway cover was not a significant maintenance item. This event was therefore assigned a relatively low probability of $10^{-3}$. An analysis was performed to determine the sensitivity of the total release probability to the probability value used for this event. It was found that increasing this event probability by a factor of 10 raised the total release probability by less than 3 percent. This is well within the overall accuracy of the analysis.

Manway Cover Faulty from Manufacturing Defect (X4). A study of error rates in quality control inspections of electrical components gives a probability of 0.003 that a defective component will not be detected. (3) Although not directly applicable to manufacturing defects for manway covers, 
it is assumed that this value is representative of quality control in a variety of manufacturing operations. This value is in agreement with the value of human errors in routine procedures used in event $X 2$.

Fire 0ccurs in Accident (X5). The probability that a fire that does not initially involve the cargo will occur in a truck accident is 0.016 (see Section 5.0).

Fire Produces Pressure That Fails Normal Manway Cover (X6). Failure of the tank by overpressurization is considered in event X89. This event is assigned a probability of zero since it is included in $\times 89$.

Fire Produces Pressure That Fails Defective Manway Cover (X7). It is assumed that a defective manway cover would fail at $1 / 2$ the pressure rise that would fail a normal manway cover. Extrapolating the calculation in Appendix $D$, this would require a 25-minute fire. The probability that a fire in an accident will last 25 minutes or longer is given in Figure 5.1 as 0.1 . An analysis was performed to determine the sensitivity of the total release probability to the probability value used for this event. . It was found that increasing this event probability by a factor of 10 raised the total release probability by less than 0.01 percent. This is well within the overall accuracy of the analysis.

Impact Forces Produced in Accident (X8). Based on the Bureau of Motor Carrier Safety Data presented in Section 5.0, impact forces can be expected to be present in nearly all truck accidents. A probability of 1.0 was used for this event.

(X9) and (X10). Not used.

Sunshine Causes Tank Pressure to Exceed 1 psig (X11). Curves of gasoline vapor pressure as a function of temperature are presented in Appendix B. If the gasoline in the tank is assumed to be at an average ambient temperature of about $78^{\circ} \mathrm{F}$, a vapor pressure rise of 1 psi requires a temperature rise of about $6^{\circ} \mathrm{F}$ (see Figure B.1). Calculations in Appendix $D$ show that the maximum expected temperature rise from solar insolation is $3.8^{\circ} \mathrm{F}$ per hour. Thus, about 1 hour and 35 minutes would 
be required to produce a pressure rise that would open the small relief valve. The response of emergency assistance teams could be expected to alleviate this condition. The time between the ignition of a building fire and the arrival of fire-fighting forces has been used as a measure of the response time for emergency assistance personnel. In a study of 133 fires, 10 percent had a pre-burn time greater than 1 hour. (4) The probability that a large truck accident will occur between the hours of $8 \mathrm{a} . \mathrm{m}$. and 4 p.m. When insolation is significant can be extracted from BMCS data (5) as 0.54 . Assuming that $2 / 3$ of all days are not overcast gives a probability for this event of 0.04 . An analysis was performed to determine the sensitivity of the total release probability to the probability value used for this event. It was found that increasing this event probability by a factor of 10 raised the total release probability by less than 0.01 percent. This is well within the overall accuracy of the analysis.

Fire Duration Produces Pressure Rise Above 1 psig (X12). A temperature rise of about $6^{\circ} \mathrm{F}$ is required to raise the vapor pressure of gasoline 1 psi (see event $\times 11$ ). Extrapolation of the calculations in Appendix $D$ shows that a 3-minute fire is required to raise the gasoline temperature $6^{\circ} \mathrm{F}$. The probability that a fire in an accident will last longer than 3 minutes is given in Figure 5.1 as 0.85 .

Small Relief Valve Fails Closed From Normal Deterioration (X13). No data are available for this event. A survey of local trucking companies engaged in gasoline transportation indicated some question about the reliability of these devices. A probability of 0.05 was used for this event. An analysis was performed to determine the sensitivity of the total release probability to the probability value used for this event. It was found that increasing this event probability by a factor of 10 raised the total release probability by less than 0.01 percent. This is well within the overall accuracy of the analysis.

Small Relief Valve Fails Closed From Accident Forces (X14). No data are available for this event. The only method envisioned for the small relief valve to fail closed from accident conditions or by direct impact 
on the valve is by lodging debris on top of the valve. The valve is protected by the manway cover handle and by the protective top rails. Most accident forces would tend to open the valve. This event was assigned a probability of 0.01 . An analysis was performed to determine the sensitivity of the total release probability to the probability value used for this event. It was found that increasing this event probability by a factor of 10 raised the total release probability by less than $0.01 \%$. This is well within the overall accuracy of the analysis.

Small Relief Valve Fails Closed From Improper Installation (X15). A probability of $3 \times 10^{-3}$ was used for this event (see event $\times 2$ ).

Small Relief Valve Fails Closed From Manufacturing Defect $(X 16)$. A probability of 0.003 is used for this event (see event $\times 4$ ).

Smal1 Relief Valve Ball Check Closes When Tank Overturns (X17). The ball check is designed to close the valve when the tank overturns. The probability of overturn in a truck accident has been estimated to be 0.2 . A probability of 0.2 is used for this event. This value is conservative.

Puncture Probe Produced in Accident (X18). A description of the puncture environment to which a large container would be exposed in an accident is not available. Puncture accidents are lumped together in event A69. Individual puncture accidents are not analyzed (i.e., a probability of zero is used). Puncture events are included in the fault tree for completeness, so that the analysis could readily be changed if information on the puncture environment became available.

Puncture Probe Fails Manway Cover (X19). All puncture events were included in event A69. Therefore a value of zero was used for this event. (x20). Not used.

Manway Cover Exposed to Fire (X21). Overturn is required to expose the manway to fire. It is assumed that the fire will contact the manway cover of an overturned tank $75 \%$ of the time. Since overturn is also required for a release from the manway cover, a probability of 0.75 is used for this event. The probability of overturn is included in I204. 
Fire Duration Fails Manway Cover Gasket (X22). Gaskets are estimated to lose their liquid retention capability after a 20 -min exposure to an $1850^{\circ} \mathrm{F}$ fire (see Appendix D). The probability that a fire in an accident will last 20 min or longer is taken from Figure 5.1 as 0.2 .

Impact Forces Fail Manway Cover (X23). The manway cover was considered part of the tank walls for impact analysis. This event was not analyzed separately (i.e., a probability of zero was assigned).

Tank Remains Upright in Accident (X24). The probability of overturn in an accident is 0.2 (see event $\times 17$ ). This event is therefore assigned a probability of 0.8 .

Tank Overturns in Accident (X25). A probability of 0.2 was used for this event (see event $\times 17$ ).

Tank Over Half Fu11 When Accident Occurs (X26). A survey of local trucking companies engaged in gasoline transportation indicates that gasoline deliveries are made almost exclusively in truckload quantities (see Appendix A). A probability of 1.0 was used for this event.

Impact Forces Fail Assembly - Tank Mating Surface (X27). This area was considered part of the tank walls for impact analysis. A probability of zero was used for this event.

(X28). Not used.

Pressure Forces Fail Assembly - Tank Mating Surface (X29). This event requires a simultaneous failure of all three pressure relief devices and a pressure buildup in the tank from fire. The maximum probability that all three relief valves would fail simultaneously is less than $10^{-5}$ (see events $X 13$ through $X 17$ and $\times 105$ through $\times 108$ ). The probability that a fire will occur is 0.016 . The probability of this event is, therefore, less than $10^{-6}$. A value of $10^{-6}$ was used for the analysis.

Fire Duration Fails Valve Assembly - Tank Gasket (X30). A probability of 0.2 is used for gasket failure in a fire (see event $\times 22$ ). 
Puncture Probe Fails Assembly - Tank Mating Surface (X31). A11 puncture failures were included in event A69. A probability of zero is therefore used for this event.

(X32). Not used.

Crush Forces Fail Assembly - Tank Mating Surface (X33). Crush forces are not believed to be important in accidents involving large containers. This event was not analyzed (i.e., a probability of zero is used).

Crush Forces Fail External Valve (X34). Crush events were not analyzed (see event $\times 33$ ).

External Valve Experiences. Impact Forces (X35). The tank-trailer shipping configuration was conservatively used for this event. A side-on collision is required for the external valve to experience impact forces. The probability, given a collision, that a truck will be struck from the side by another vehicle is 0.139 (see Table 5.3). The outlet valve and manifold assembly occupies about $1 / 2$ the length of the tank trailer. The probability that the valve and manifold assembly will be struck when side-on impact occurs is therefore taken to be 0.5 . The probability used for this event is then 0.07 .

Impact Forces Sufficient to Fail Valve $(X 36)$. It is assumed that all side-on impacts striking the outlet valve or manifold assembly will fail them. A probability of 1.0 is used for this event.

(X37). Not used.

Fire Duration Produces Pressure That Fails External Valve (X38). It is assumed that the external valve will fail after a pressure increase of 5 psi. Assuming that the gasoline is initially at a temperature of $78^{\circ} \mathrm{F}$, Figure $\mathrm{B} .1$ shows that a temperature increase of $27^{\circ} \mathrm{F}$ is required to raise the vapor pressure 5 psi. The calculations in Appendix $D$ show that this requires a fire duration of at least $11 \mathrm{~min}$. The probability of a fire in an accident lasting longer than 11 min is given in Figure 5.1 as 0.5 . 
(X39). Not used.

Puncture Probe Fails External Valve (X40). Al1 puncture failures were included in event A69. A value of zero was therefore used for this event.

(X41). Not used.

Accident Forces Raise Internal Valve Handle (X42). The external portions of the internal valve assembly occupy less than $1 \%$ of the total length of the tank truck or trailer. The probability that a side-on impact will occur and strike the external valve handle is therefore taken to be 0.001 . To raise the valve handle without breaking the valve at the shear section, requires an impact of a very specific magnitude and direction. It was conservatively estimated that $1 \%$ of the accidents in which the valve assembly is struck will result in the valve handle being raised. Therefore, a probability of $1 \times 10^{-5}$ is used for this event. An analysis was performed to determine the sensitivity of the total release probability to the probability value used for this event. It was found that increasing this event probability by a factor of 10 raised the total release probability by less than $0.01 \%$. This is well within the overall accuracy of the analysis.

Accident Forces Break Outlet Valve Assembly at Shear Section (X43). The probability that the valve will be struck is 0.001 (event $\times 42$ ). It is conservatively assumed that the shear section will break for all impacts. A probability of 0.001 is used for this event.

Tank Overturns and Internal Valve Dislodged When External Valve Severed (X44). Breaking the outlet valve assembly at the shear section will sever the internal valve from the spring loaded handle that holds it closed. The internal valve will remain seated from liquid pressure in the tank but a tank rollover could dislodge the valve from its seated position. The probability of overturn is 0.2 (event $\times 25$ ). It is assumed that the interna 1 valve would be dislodged in $10 \%$ of these accidents. A probability of 0.02 is, therefore, used for this event. An analysis was performed to determine the sensitivity of the total release probability to the probability value used for this event. It was found that increasing this event probability by a factor of 10 raised the total release probability by less than $0.01 \%$. This is well within the overall accuracy of the analysis. 
Internal Valve Does Not Reseat From Liquid Pressure (X45). If the internal valve becomes dislodged the liquid pressure in the tank will tend to cause it to reseat. It is estimated that the valve would reseat $90 \%$ of the time. A probability of 0.1 is used for this event. An analysis was performed to determine the sensitivity of the total release probability to the probability value used for this event. It was found that increasing this event probability by a factor of 10 raised the total release probability by 1 ess than $0.01 \%$. This is well within the overall accuracy of the analysis.

Accident Forces Fail Internal Valve Seat (X46). No data are available for this event. The internal valve seat is located inside the tank and is protected from most accident forces. A probability of $10^{-3}$ was used for this event. An analysis was performed to determine the sensitivity of the total release probability to the probability value used for this event. It was found that increasing this event probability by a factor of 10 raised the total release probability by less than $0.1 \%$. This is well within the overall accuracy of the analysis.

Internal Valve Opened and Not Closed Manually (X47). A probability of 0.003 is used for human errors of omission (see event $\times 2$ ). Because the internal valve is spring-loaded, it would tend to seat from the truck motion during transit. A probability of $3.0 \times 10^{-4}$ is used for this event.

Internal Valve Seat Faulty From Normal Deterioration (X48). A probability of $10^{-3}$ was used for this event (see event $\times 3$ ). An analysis was performed to determine the sensitivity of the total release probability to the probability value used for this event. It was found that increasing this event probability by a factor of 10 raised the total release probability by less than $0.1 \%$. This is well within the overall accuracy of the analysis.

Internal Valve Seat Faulty From Manufacturing Defect (X49). A probability of 0.003 was used for this event (see event $X 4)$.

Internal Valve Seat Installed Improperly (X50). A probability of 0.003 was used for this event (see event X2). 
External Valve Packing Faulty From Normal Deterioration (X51). A probability of $10^{-3}$ was used for this event (see event $\times 3$ ). An analys is was performed to determine the sensitivity of the total release probability to the probability value used for this event. It was found that increasing this event probability by a factor of 10 raised the total release probability by less than $0.01 \%$. This is well within the overall accuracy of the analysis.

External Valve Packing Not Installed or Adjusted Properly (X52). A probability of 0.003 was used for this event (see event $X 2$ ).

External Valve Exposed to Fire (X53). A probability of 0.5 was used for this event. This is believed to be conservative.

Fire Duration Fails External Valve Packing (X54). A probability of 0.2 is used for gasket failure in a fire (see event $\times 22$ ). This probability is also used for this event.

External Valve Not Closed Properly (X55). A probability of 0.003 was used for this event (see event $X 2$ ).

External Valve Not Assembled Properly (X56). A probability of 0.003 was used for this event (see event X2).

External Valve Seat Faulty From Normal Deterioration (X57). A probability of $10^{-3}$ was used for this event (see event $\times 3$ ).

End Cap Does Not Seal Properly (X58). No data are available for this event. The end cap is a threaded pipe and cap. Damage which prevents a proper seal would also tend to make the end cap hard to install and remove and would be noticed and repaired. A probability of $10^{-5}$ was used for this event. An analysis was performed to determine the sensitivity of the total release probability to the probability value used for this event. It was found that increasing this event probability by a factor of 10 raised the total release probability by less than $0.01 \%$. This is well within the overall accuracy of the analysis. 
End Cap Not Properly Attached (X59). Previous studies have used a probability of 0.01 for a human error in omitting a step at the end of a procedure. ${ }^{(2)}$ The end cap will probably be the last item put in place when gasoline is unloaded, so a probability of 0.01 is used for this event.

Impact Forces Fail End Cap (X60). This event was not analyzed. The probability of failing the end cap by impact without failing the valve assembly at the weak link is believed to be low.

Crush Forces Fail End Cap (X61). Crash events were not analyzed (see event X33).

Pressure Forces Fail End Cap (X62). This event was assigned a probability of $10^{-6}$ (see event X29).

Puncture Probe Fails End Cap (X63). All puncture failures were included in event A69. A probability of zero was therefore used for this event.

Fire Duration Exceeds One Hour (X64). The calculations in Appendix D show that a l-hr fire is required to fail the tank walls by melting. The probability that a 1-hr fire will occur in an accident is given in Figure 5.1 as 0.01 . An analysis was performed to determine the sensitivity of the total release probability to the probability value used for this event. It was found that increasing this event probability by a factor of 10 raised the total release probability by less than $2.0 \%$. This is well within the overall accuracy of the analysis.

(X65). Not used.

Impact Forces Weaken Tank Walls (X66). It is assumed that a velocity change of at least $10 \mathrm{mph}$ is required to significantly weaken the tank walls in an impact accident. This value is believed to be conservative. The probability of a $10 \mathrm{mph}$ or greater velocity change in an impact accident is given in Figure 5.2 as 0.08 .

Impact Forces Sufficient to Fail Normal Tank Walls (X67). A velocity change of $30.6 \mathrm{mph}$ for the tank truck/tank trailer transport system and $23.6 \mathrm{mph}$ for the tractor/semitrailer shipping system is required to fail the tank in an end-on impact. A valve of $25 \mathrm{mph}$ will be conservatively 
assumed for the analysis. A velocity change of $18.7 \mathrm{mph}$ is required when the tank is struck from the side (see Appendix D). From Table 5.4, the probability that the tank will be accelerated or decelerated along its axis is 0.855 . This is taken as the probability of an end-on impact. The probability that the tank will be accelerated perpendicular to its axis is given in Table 5.4 as 0.145 . This is taken as the probability of a side-on impact. The probability of a velocity change of $25 \mathrm{mph}$ or greater in a collision accident is given in Figure 5.2 as 0.02 and the probability of an $18.7 \mathrm{mph}$ or greater velocity change is 0.04 . The total probability for this event is then 0.023 .

Tank Walls Defective (x68). A value of 0.003 is used for manufacturing defects (see event $\times 4$ ).

Impact Forces Sufficient to Fail Defective Walls (X69). It is assumed that defective walls would fail from impact twice as frequently as normal wal1s. A value of 0.046 (twice that of event $\times 67$ ) has been used for this event. An analysis was performed to determine the sensitivity of the total release probability to the probability value used for this event. It was found that increasing this event probability by a factor of 10 raised the total release probability by less than $2.0 \%$. This is well within the overall accuracy of the analysis.

Puncture Probe Fails Tank Walls (A69). A detailed description of the puncture environment that would be encountered by a gasoline tank truck in an accident was not available. Since the data that was available on puncture failure lacked sufficient detail to predict failure of individual components of the tank, all puncture failures are lumped together in this event. The probability that the tank will fail from puncture forces has been calculated in two ways. It is believed that these methods provide a reasonable range of values for this event. The DOT data on puncture accidents over a 5-year period are presented in Section 5.0. Table 5.8 shows a total of 358 puncture accidents over the 5-year period in tank trucks that could carry flammable liquids. It has been estimated that about $45 \%$ of the carriers involved in transportation of these commodities report to DOT. (7) This implies a total of 795 tank truck puncture accidents over the 5-year period or 159 punctures/yr. BMCS data for the period 1965-1967 show that 
gasoline was the commodity carried in $47 \%$ of the accidents involving tank trucks that could carry gasoline. ${ }^{(8)}$ This implies a total of 74 puncture accidents per year in gasoline tank trucks. For the shipping levels assumed for 1980 , a total of 75 puncture accidents/yr could be expected, or a probability of $5.5 \times 10^{-6} /$ shipment that the tank will fail from puncture forces. This implies a probability for this event of 0.044 .

The probability of this event has also been estimated from the probability that a truck carrying a hazardous liquid or gas will be involved in an accident that results in a lading loss. This value has been estimated as $2.7 \times 10^{-8} /$ mile. ${ }^{(9)}$ This gives a probability of $1.35 \times 10^{-6} /$ gasoline shipment. If $55 \%$ of these lading losses result from puncture forces (see Table 5.8), the probability of a lading loss from puncture is $7.4 \times 10^{-7}$ / shipment. This gives a probability for this event of $5.9 \times 10^{-3}$. The average of these two values 0.025 will be used for the initial stages of the analysis. $(x 70),(x 71)$, and $(X 72)$. Not used.

Fire Duration Produces Pressure That Fails Weakened Walls (X73). Appendix $D$ shows that a pressure rise of $30 \mathrm{psi}$ is required to overpressurize normal walls. It is assumed that weakened walls will fail at 15 psi. Extrapolation of the calculations in Appendix $D$ shows that a 25-min fire is required to produce a pressure rise of $15 \mathrm{psi}$ in the tank if the gasoline is originally at $78^{\circ} \mathrm{F}$. The probability of a 25 -min fire in an accident is given in Figure 5.1 as 0.1 . An analysis was performed to determine the sensitivity of the total release probability to the probability value used for this event. It was found that increasing this event probability by a factor of 10 raised the total release probability by less than $0.01 \%$. This is well within the overall accuracy of the analysis.

Puncture Probe Strikes Tank Wal1s (X74). A11 puncture failures are included in event A69. A probability of zero was therefore used for this event.

Puncture Probe Has Sufficient Energy to Fail Tank Walls (X75). All puncture failures are included in event A69. A probability of zero was therefore used for this event. 
Gas Released When Crush Forces Fail Tank Walls (X76). Crush events were not analyzed (see event $\times 33$ ).

Tank Overturns on Roadway $(x 77)$. The probability that the tank will overturn on the roadway in an accident is given in Table 5.1 as 0.028 .

Abrasion Fails Walls in Overturn Accident (X78). The fraction of various roadway surfaces used in the analys is is given in Table 5.5. For purposes of estimating abrasive failures, the road surfaces were grouped into two categories - asphalt, concrete and other surfaces (57\%) and bituminous surface treatment (BST) $(43 \%)$. Calculations in Appendix D indicate that a speed of $26 \mathrm{mph}$ is required for abrasive failure on asphalt or concrete surfaces and $20 \mathrm{mph}$ on BST surfaces. Because accident speed data are collected in 10-mph data blocks, it will be assumed that abrasive failure on concrete and asphalt surfaces will occur at a pre-accident speed of $30 \mathrm{mph}$. Table 5.6 gives the probability of a pre-accident speed of $30 \mathrm{mph}$ or greater as 0.307 and the probability that the pre-accident speed will exceed $20 \mathrm{mph}$ as 0.464 . The probability used for this event is then 0.37 .

Tank Does Not Overturn and Abrasion Fails Walls (X79). No data are available for this event. For abrasive failure against a vertical surface to occur a vertical abrasive surface must be present in an accident, the tank must slide along the surface, and the pre-accident speed must be sufficient for abrasive failure on the surface encountered. The probability that a vertical abrasive surface is present in an accident is assumed to be $10^{-3}$. The probability of vehicle overturn $(0.2)$ is used for the probability that the tank will slide along the vertical abrasive surface. It is assumed that all vertical abrasive surfaces are concrete. A speed of $26 \mathrm{mph}$ is required for abrasive failure on concrete surfaces (see Appendix D). A speed of $30 \mathrm{mph}$ is used here as the minimum pre-accident speed for failure on a concrete surface because accident speed data are collected in 10-mph data blocks. The probability of a pre-accident speed exceeding $30 \mathrm{mph}$ is 0.31 (see Table 5.6). The probability for this event is then $6.1 \times 10^{-5}$. An analysis was performed to determine the sensitivity of the total release probability to the probability value used for this event. It was found that 
increasing this event probability by a factor of 10 raised the total release probability by less than $3 \%$. This is we11 within the overa 11 accuracy of the analysis.

$(\mathrm{X} 81),(\mathrm{X} 82)$, and $(\mathrm{X} 83)$. Not used.

Abrasion Weakens Tank Wal1s (X84). It is assumed that the walls wil1 be weakened by abrasion of speeds between $10 \mathrm{mph}$ and $30 \mathrm{mph}$ for concrete or asphalt surfaces (53\% of a 11 roadways) and between 10 and $20 \mathrm{mph}$ for BST surfaces ( $47 \%$ of a11 roadways). The probability that an accident wil1 occur at a speed between 10 and $30 \mathrm{mph}$ is 0.313 . The probability that an accident will occur between 10 and $20 \mathrm{mph}$ is 0.157 (see Table 5.6). The probability of overturn on the road is 0.028 . This gives a probability for this event of 0.007 .

Fire Duration Produces Pressure That Fails Defective Wa11s (X85). Appendix $D$ shows that a pressure rise of $30 \mathrm{ps} i$ is required to fail normal wal1s. It is assumed that defective walls would fail at half that pressure. Extrapolation of the calculations in Appendix D shows that a 25-min fire would be required to produce this pressure rise. The probability of a 25-min fire can be taken from Figure 5.1 as 0.1 . An analysis was performed to determine the sensitivity of the total release probability to the probability value used for this event. It was found that increasing this event probability by a factor of 10 raised the total release probability by 1 ess than $0.01 \%$. This is we11 within the overa11 accuracy of the analysis.

$(\mathrm{X86}),(\mathrm{X87})$, and $(\mathrm{X88})$. Not used.

Fire Duration Produces Pressure That Fails Normal Walls (X89). Appendix $D$ shows that a 40-min fire is required to overpressurize a normal tank. The probability that a fire in an accident wi11 last 40-min or longer is given in Figure 5.1 as 0.03 .

(X90), (X91), and (X92). Not used.

Gas Released When Direct Impact Fails Relief Valves Open (X93). The manway cover and relief valves are considered part of the tank walls for impact analysis. A probability of zero is therefore used for this event. 
Gas Released When Puncture Fails Relief Valves Open (X94). This event was not analyzed (see event $\times 18$ ).

(X95), (X96), and (X97). Not used.

Relief Valve Open From Manufacturing Defect (X98). A probability of 0.003 is used for manufacturing defects (see event $\times 4$ ). Since there are two relief valves that could release material in an overturn accident, a probability of 0.006 was assigned to this event.

Relief Valve Open From Improper Installation or Maintenance (X99). A probability of 0.003 is used for installation or maintenance errors (see event $\times 2$ ). Since there are two relief valves, that could release material in an overturn. A probability of 0.006 was used for this event.

Rel ief Valve Open From Normal Deterioration (X100). A probability of 0.001 is used for deterioration of tank components. Since there are two relief valves that could release material in an overturn, a probability of 0.002 was used for this event.

(X101). Not used.

Sunshine Causes Tank Pressure To Exceed 9 psig $(\times 102)^{\prime}$. (see event $\times 11$ ). Approximately $10 \mathrm{hr}$ of exposure to direct sunlight is required to produce a tank pressure rise of 9 psi. No fire fighting response times greater than $3 \mathrm{hr}$ and $10 \mathrm{~min}$ were reported in Reference 4 . The probability of a 3-hr response time is 0.01 . The probability that the response time will exceed $10 \mathrm{hr}$ is conservatively estimated as $10^{-4}$. Using a probability of 0.54 that the accident will occur during daylight hours and 0.66 that the weather will not be overcast gives a probability for this event of $3.6 \times 10^{-5}$.

Fire Duration Causes Tank Pressure To Exceed 9 psig (X103). Assuming that the gasoline is originally at a temperature of $78^{\circ} \mathrm{F}$, Figure $\mathrm{B} .1$ shows that a temperature rise of $40^{\circ} \mathrm{F}$ is required to produce a pressure increase of $9 \mathrm{psi}$. Appendix $D$ shows that a fire duration of $16 \mathrm{~min}$ is required for a $40^{\circ} \mathrm{F}$ temperature rise in the tank. The probability of a 16-min fire in an accident is given in Figure 5.1 as 0.24 . 
Large Relief Valves Fail Closed From Normal Deterioration (X105). The probability used for a component failure from deterioration is 0.001 (see event $\times 3$ ). Failure of the largest relief valve requires simultaneous failure of two opposite springs. Since there could be some correlation between the failure of two large relief valve springs from deterioration a probability of $3.3 \times 10^{-4}$ is used for this event. The sum of the probability that the other large relief valve will fail from all causes is 0.017 . The probability that the largest relief valve will fail closed from deterioration while the other relief valve is failed closed is $5.6 \times 10^{-6}$.

Large Relief Valves Fail Closed From Manufacturing Defect (X106). A probability of 0.003 has been used for manufacturing defects (see event $\times 4)$. The probability that both valves will fail from the same defect is believed to be low. The sum of the probabilities that the other relief valve will fail for any cause is 0.017 . The probability that one relief valve will fail closed from a manufacturing defect while the other fails for any other reason is then $5.1 \times 10^{-5}$.

Large Relief Valves Fail Closed From Improper Installation (XI07). A probability of 0.003 is used for improper installation (see event $\times 2$ ). The probability that the other large relief valve will fail from all causes is 0.017. The probability that one relief valve will fail closed from improper installation while the other relief valve is closed from any other failure mode is then $5.1 \times 10^{-5}$.

Large Relief Valves Fail Closed From Accident Forces (X108). A probability of 0.01 is used for failure of a relief valve by accident forces (see event $\times 14$ ). The probability that one relief valve will fail from accident forces while the other fails for any reason is $1.7 \times 10^{-4}$.

Manway Cover Defective (X709). No data are available for this event. The probability that the manway cover will have a defect that weakens it structuraliy is taken to be the same as the probability of a manufacturing defect. A probability of 0.003 is used for this event (see event $\times 4$ ). 
Orientation After Accident Permits Release (From Manway Cover) (I204). The tank must overturn for a significant release to occur from the manway cover. The probability of overturn in an accident is 0.2 (see event $\times 25$ ).

Orientation After Accident Permits Release (Impact Fails Walls) (I260). Since the tanks are always shipped with a full load, it is assumed that gasoline will always be present at an impact site. A probability of 1.0 is used for this event.

Orientation After Accident Permits Release (Puncture Probe Fails Tank Walls) (1268). It is assumed that a release will always occur when puncture forces fail the tank. A probability of 1.0 is used for this event.

Orientation After Accident Permits Release (Abrasion Fails Tank Wal1s) (1270). It is assumed that a release will always occur when abrasion fails the tank walls. A probability of 1.0 is used for this event.

Orientation After Accident Permits Release (Pressure Fails Tank Wai1s) (1273). No data are available for this event. The failure point in an overpressurization is difficult to predict. It is conservatively assumed that all pressure failures result in a release. This event is assigned a probability of 1.0 .

Orientation After Accident Permits Release (Relief Valve Faulty) (I302). overturn is required for a significant release from a relief valve. A probability of 0.2 is used for this event (see event $\times 25$ ).

\subsection{RELEASE SEQUENCE PROBABILITIES}

The basic event probabilities presented in Section 8.1 provide the basis for evaluating the probability of each release sequence identified in the fault tree. The probability of the release sequences presented in Table 7.4 is shown in Table 8.1. On1y the release sequences with a frequency of occurrence greater than $10^{-12}$ per shipment are 1 isted in the table. All release sequences were retained in the actual risk calculation. The total probability per shipment that a release will occur is $8.9 \times 10^{-6}$. 
TABLE 8.1. Release Sequence Probabilities

\begin{tabular}{|c|c|c|c|c|c|c|c|c|c|}
\hline Probability Per Shipment & \multicolumn{9}{|c|}{ Release Sequence } \\
\hline $3.13 \mathrm{E}-6^{(\mathrm{a})}$ & $\times 1$ & $A G$ & & 1268 & & & & & \\
\hline $2.03 E-8$ & $\times 1$ & $x$ & 5 & $\times 64$ & & & & & \\
\hline $7.63 E-9$ & $\times 1$ & $x$ & 2 & I 204 & & & & & \\
\hline $2.54 \mathrm{E}-8$ & $x 1$ & $x$ & 3 & I 204 & & & & & \\
\hline $7.63 E-8$ & $\begin{array}{lll}x & 1\end{array}$ & $x$ & 4 & I 204 & & & & & \\
\hline $7.76 \mathrm{E}-9$ & $x 1$ & $x 7$ & 79 & I 270 & & & & & \\
\hline $1.53 \mathrm{E}-7$ & $x 1$ & $\times 9$ & 98 & I302 & & & & & \\
\hline $9.16 E-10$ & $\times 1$ & $\times 2$ & 25 & $x 102$ & & & & & \\
\hline $1.02 \mathrm{E}-10$ & $\times 1$ & $\times 2$ & 24 & $\times 29$ & & & & & \\
\hline $1.53 \mathrm{E}-7$ & $\times 1$ & $x$ & 99 & 1302 & & & & & \\
\hline $5.09 E-8$ & $\times 1$ & $\times 10$ & & 1302 & & & & & \\
\hline $4.07 \mathrm{E}-6$ & $\times 1$ & $x 1$ & 11 & $\times 24$ & & & & & \\
\hline $1.31 \mathrm{E}-6$ & $\times 1$ & $\times 7$ & 77 & $\times 78$ & 1270 & & & & \\
\hline $9.75 E-8$ & $\times 1$ & $x$ & 5 & $\times 25$ & $\times 103$ & & & & \\
\hline $2.54 \mathrm{E}-11$ & $\times 1$ & $\times 2$ & 25 & $\times 26$ & $\times 29$ & & & & \\
\hline $2.72 E-6$ & $\times 1$ & $x$ & 8 & $\times 67$ & I 260 & & & & \\
\hline $1.39 \mathrm{E}-6$ & $\times 1$ & $x$ & 5 & $\times 12$ & $\times 24$ & & & & \\
\hline $1.76 E-8$ & $\times 1$ & $x$ & 8 & $\times 68$ & $\times 69$ & 1260 & & & \\
\hline $1.63 \mathrm{E}-7$ & $\times 1$ & $x$ & 5 & $\times 24$ & $\times 30$ & $\times 53$ & & & \\
\hline $6.10 \mathrm{E}-8$ & $\times 1$ & $x$ & 5 & $\times 21$ & $\times 22$ & 1204 & & & \\
\hline $3.06 \mathrm{E}-12$ & $\times 1$ & $\times 2$ & 24 & $\times 46$ & $\times 56$ & $\times 59$ & & & \\
\hline $3.06 \mathrm{E}-12$ & $\times 1$ & $\times 2$ & 24 & $\times 46$ & $\times 55$ & $\times 59$ & & & \\
\hline $4.07 \mathrm{E}-8$ & $x \quad 1$ & $x$ & 5 & $\times 25$ & $\times 26$ & $\times 30$ & $\times 53$ & & \\
\hline $7.12 \mathrm{E}-9$ & $\times 1$ & $x$ & 8 & $\times 24$ & $\times 35$ & $\times 36$ & $\times 48$ & & \\
\hline $7.12 \mathrm{E}-9$ & $\times 1$ & $x$ & 8 & $\times 24$ & $\times 35$ & $\times 36$ & $\times 46$ & & \\
\hline $7.12 \mathrm{E}-11$ & $\times 1$ & $x$ & 8 & $\times 24$ & $\times 35$ & $\times 36$ & $\times 42$ & & \\
\hline $2.08 \mathrm{E}-12$ & $\times 1$ & $x$ & 5 & $\times 17$ & $\times 89$ & $\times 108$ & 1273 & & \\
\hline $1.63 \mathrm{E}-10$ & $x \quad 1$ & $x$ & 5 & $\times 24$ & $\times 48$ & $\times 53$ & $\times 54$ & & \\
\hline $1.63 \mathrm{E}-10$ & $\times 1$ & $x$ & 5 & $\times 24$ & $\times 46$ & $\times 53$ & $\times 54$ & & \\
\hline $1.63 \mathrm{E}-12$ & $\times 1$ & $x$ & 5 & $\times 24$ & $\times 42$ & $\times 53$ & $\times 54$ & & \\
\hline $2.27 \mathrm{E}-9$ & $\times 1$ & $x$ & 8 & $\times 24$ & $\times 35$ & $\times 36$ & $\times 47$ & & \\
\hline 2. $27 \mathrm{E}-8$ & $\times 1$ & $x$ & 8 & $\times 24$ & $\times 35$ & $\times 36$ & $\times 49$ & & \\
\hline $2.27 \mathrm{E}-8$ & $x 1$ & $x$ & 8 & $\times 24$ & $\times 35$ & $\times 36$ & $\times 50$ & & \\
\hline $4.89 \mathrm{E}-11$ & $\times 1$ & $x$ & 5 & $\times 24$ & $\times 47$ & $\times 53$ & $\times 54$ & & \\
\hline $4.89 E-10$ & $\times 1$ & $x$ & 5 & $\times 24$ & $\times 49$ & $\times 53$ & $\times 54$ & & \\
\hline $4.89 \mathrm{E}-10$ & $x \quad 1$ & $x$ & 5 & $\times 24$ & $\times 50$ & $\times 53$ & $\times 54$ & & \\
\hline $1.78 \mathrm{E}-9$ & $\begin{array}{ll}x & 1\end{array}$ & $x$ & 8 & $\times 25$ & $\times 26$ & $\times 35$ & $\times 36$ & $\times 48$ & \\
\hline $1.78 \mathrm{E}-9$ & $\times 1$ & $x$ & 8 & $\times 25$ & $\times 26$ & $\times 35$ & $\times 36$ & $\times 46$ & \\
\hline $1.78 \mathrm{E}-11$ & $\times 1$ & $x$ & 8 & $\times 25$ & $\times 26$ & $\times 35$ & $\times 36$ & $\times 42$ & \\
\hline $4.07 E-11$ & $x \quad 1$ & $x$ & 5 & $\times 25$ & $\times 26$ & $\times 48$ & $\times 53$ & $\times 54$ & \\
\hline $4.07 E-11$ & $x 1$ & $x$ & 5 & $\times 25$ & $\times 26$ & $\times 46$ & $\times 53$ & $\times 54$ & \\
\hline $5.34 E-10$ & $x \quad 1$ & $x$ & 8 & $\times 25$ & $\times 26$ & $\times 35$ & $\times 36$ & $\times 47$ & \\
\hline $5.34 \mathrm{E}-9$ & $\begin{array}{ll}x & 1\end{array}$ & $x$ & 8 & $\times 25$ & $\times 26$ & $\times 35$ & $\times 36$ & $\times 49$ & \\
\hline $5.35 E-9$ & $\times 1$ & $x$ & 8 & $\times 25$ & $\times 26$ & $\times 35$ & $\times 36$ & $\times 50$ & \\
\hline $1.21 E-10$ & $\times 1$ & $x$ & 5 & $\times 25$ & $\times 26$ & $\times 50$ & $\times 53$ & $\times 54$ & \\
\hline $1.43 \mathrm{E}-11$ & $\begin{array}{ll}x & 1\end{array}$ & $x$ & 8 & $\times 24$ & $\times 35$ & $\times 36$ & $\times 43$ & $\times 44$ & $\times 45$ \\
\hline
\end{tabular}

$\overline{\text { (a) Read } 3.13 \times 10^{-6}}$ 


\subsection{RELEASE FRACTIONS}

For the purposes of input into the environmental consequences model (Section 9), four release fractions have been selected:

- A release fraction of 1.0 , corresponding to the release of al 1 the contents of both the truck tank and trailer tank for the western shipping system or both compartments in the eastern shipping system. The nominal release size for this release fraction is $8,400 \mathrm{gal}$.

- A release fraction of 0.5 , corresponding to the release of a 11 the contents of either the truck tank or trailer tank of the western shipping system or one compartment of the eastern shipping system. The nominal release size for this release fraction is 4,200 gal.

- A release fraction of 0.35 , corresponding to the release of sliahtly more than half the contents of one tank of the western system or one compartment of the eastern system. The nominal release size for this release fraction is 3000 gal.

- A release fraction of 0.01 , for very small releases. These releases are assumed to have no consequences.

It was convenient to assign the release fractions by the portion of the tank from which the material was released, and either the accident force that caused the release or the orientation of the tank during the release. The release fractions used in the analysis are presented in Table 8.2. For conservatism, two release fractions were used for failure of the tank walls from impact. It was assumed that both tanks (or tank compartments) would fail in 50\% of all failures due to impact forces. It should be noted that these release fractions are valid only for the initial stages of the accident. If the release results in a gasoline fire, all of the truck contents would eventually burn. The material initially released is used to determine the pool size for the consequence model in Section 9. 
TABLE 8.2. Release Fractions for Gasoline Tank Truck Failures

\begin{tabular}{|c|c|c|}
\hline $\begin{array}{c}\text { Portion of Tank } \\
\text { Failing } \\
\end{array}$ & $\begin{array}{l}\text { Failure Cause } \\
\text { (Orientation) }\end{array}$ & Release Fraction \\
\hline Tank Walls & $\begin{array}{l}\text { Puncture } \\
\text { Pressure } \\
\text { Abrasion } \\
\text { Impact } \\
\text { Fire }\end{array}$ & $\begin{array}{c}0.5 \\
0.5 \\
1.0 \\
0.5(50 \%) 1.0(50 \%) \\
1.0\end{array}$ \\
\hline Relief Valve & $\begin{array}{l}\text { Faulty } \\
\text { (Overturn) } \\
\text { Pressure } \\
\text { (Upright) } \\
\text { (Overturn) }\end{array}$ & $\begin{array}{l}0.35 \\
0.01 \\
0.35\end{array}$ \\
\hline Outlet Valve & $\begin{array}{l}\text { Fire } \\
\text { A11 0ther Causes } \\
\text { (Upright) } \\
\text { (Overturn) }\end{array}$ & $\begin{array}{l}1.0 \\
0.5 \\
0.35\end{array}$ \\
\hline Manway Cover & $\begin{array}{l}\text { Fire } \\
\text { A11 0ther Causes } \\
\text { (Overturn) }\end{array}$ & $\begin{array}{l}1.0 \\
0.35\end{array}$ \\
\hline
\end{tabular}

\section{REFERENCES}

1. R. K. Clarke, J. T. Foley, W. F. Hartman and D. W. Larson, Severities of Transport Accidents - Vol IV - Motor Carriers. SLA-74-0001, Sandia Laboratories, Albuquerque, NM, July 1976.

2. Reactor Safety Study - An Assessment of the Accident Risks in U.S. Commercial Nuclear Power Plants. WASH-1400 (NUREG-75/014), p. III-81, U.S. Nuclear Regulatory Commission, Washington, DC, October 1975.

3. The Effect of Human Error and Static Component Failure on Engineered Safety System Reliability. HN-194, p. 1.32, Holmes and Narver, Inc., Los Angeles, CA, November 1967.

4. W. G. Labes, Fire Department Operations Analysis. IIT Research Institute, Chicago, IL, January, 1968.

5. R. E. Scott, et al., Statistical Analys is of Truck Accident Involvements. The University of Michigan Highway Research Institute, Ann Arbor, MI, December, 1971. 
6. T. I. McSweeney, R. J. Hall et al., An Assessment of the Risk of Transporting Plutonium Oxide and Liquid Plutonium Nitrate by Truck. BNWL-1846, Battelle, Pacific Northwest Laboratories, Richland, WA, August 1975.

7. L. M. Krasner et a1., Hazardous Materials Transportation Intrusion Protection for Hazardous Cargo Tanks. D0T HS-800 513, Factory Mutual Research Corp., Norwood, MA, June 1971.

8. L. M. Krasner, Motor Vehicle Standards for Hazardous Material Transportation. DOT HS-800 240, p. 18, Factory Mutual Research Corp., Norwood, MA, Jan. 1970.

9. A Modal Economic and Safety Study of the Transportation of Hazardous Substances in Bulk. COM-74-11271, p. 151, A. D. Little, Inc., Cambridge, MA, May 1974. 


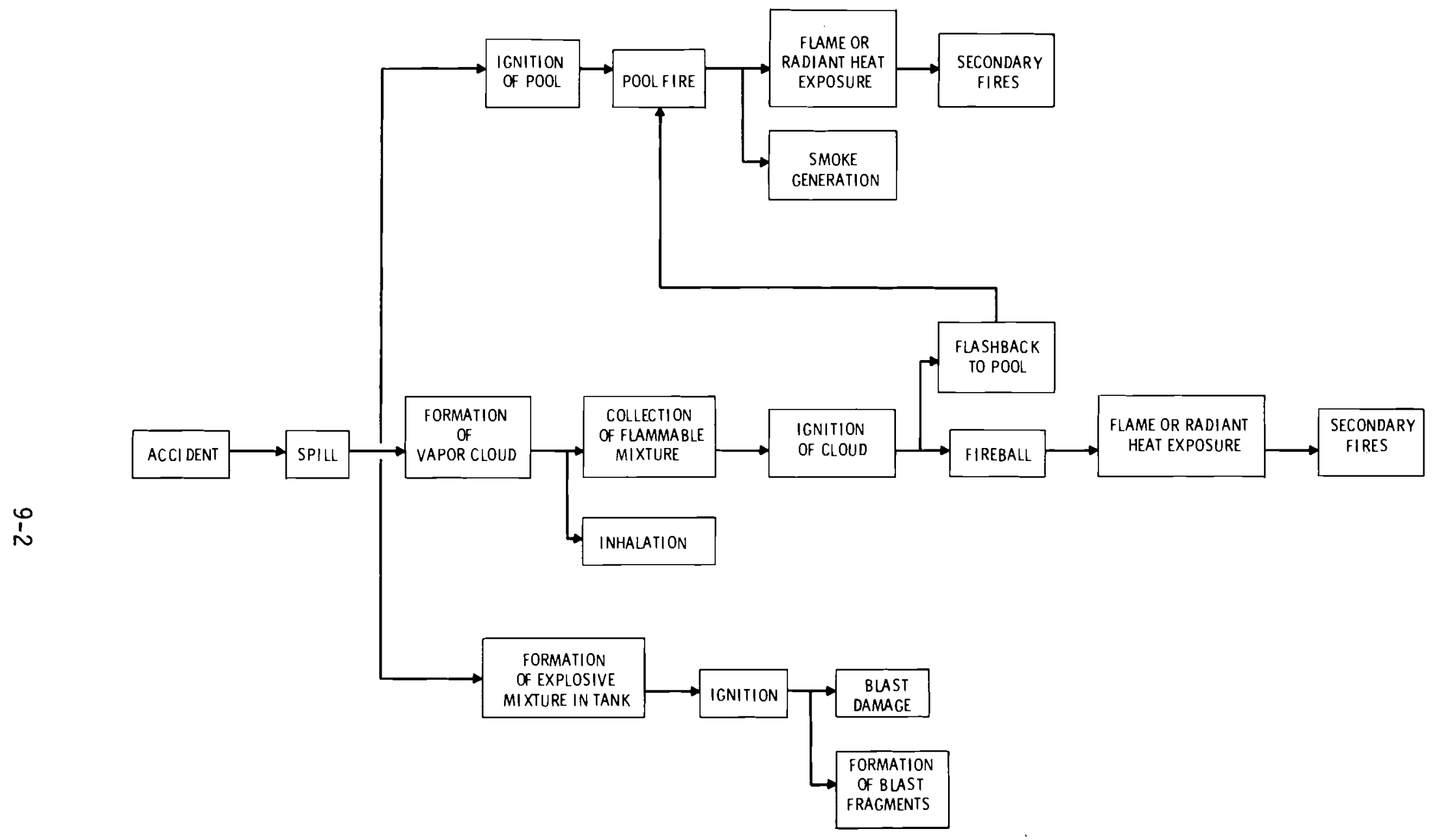

FIGURE 9.1. Gasoline Transportation Accident Consequence Model 


\subsection{EVALUATION OF THE CONSEQUENCES OF GASOLINE RELEASES}

Possible sequences of events that could result from a tank truck accident involving a gasoline spill are depicted in Figure 9.1. As shown on the figure, the consequences of a gasoline spill can be divided into three general areas--those resulting from: 1) gasoline pool fires, 2) the formation of vapor clouds, and 3) the explosion of vapors inside the tank.

\subsection{CONSEQUENCES OF GASOLINE POOL FIRES}

A gasoline spill will generally produce a large pool of liquid in the vicinity of the breached tank. The characteristics of gasoline pools in general are discussed in Appendix E. The pools are assumed to have an average depth of $0.5 \mathrm{in}$. Use of a shallower pool depth would increase the number of secondary fires initiated, but would have a small effect on the overall risk. The radius of a 4200-gal spi11, for example, is then about $77 \mathrm{ft}$. The assumed pool shape for spills on urban streets and freeways is presented in Appendix G.

It has been estimated ${ }^{(1)}$ that about $24 \%$ of spil1s from trucks carrying flammable liquids result in a fire. The consequences of a gasoline pool fire are dependent on the location of the accident. Three accident locations are considered in this study: 1) an unpopulated rural area, 2) an urban freeway and 3) a four-lane urban street. Data obtained from motor carrier accident reports submitted to the Bureau of Motor Carrier Safety in 1975 was analyzed to determine the location of accidents that resulted in a spillage of gasoline or other similar flanmable liquids. This data showed the following locations for spills from accidents involving flammable liquid tank trucks:

- $68.9 \%$ - rural highways

- $22.3 \%$ - business area

- $8.8 \%$ - residential area.

Data from truck accidents in the states of Texas and Washington were used to determine the fraction of the releases in business and residential areas that occur on city streets and on urban freeways. The Texas data ${ }^{(2)}$ indicate that $32.7 \%$ of tank truck accidents occur on city streets and $18.6 \%$ on urban freeways. 
Although $32.7 \%$ of a 11 tank truck accidents occur on city streets, it is not likely that an equal percentage of releases occur on city streets. It was necessary to establish the relative severity of accidents on city streets and on rural highways or urban freeways. It was assumed that the accident environment on an urban freeway would be adequately represented by the environment on a rural highway. Accident fatalities have been used as the measure of relative severity between accidents on city streets and rural highways (and urban freeways). According to information from the Washington State Patrol, (3) $2.08 \%$ of truck accidents on rural highways are fatal and $0.47 \%$ of truck accidents in urban areas are fatal. Therefore, the probability that a tank truck accident occurs on a city street $(p=0.327)$ and is fatal $(p=0.0047)$ is $1.54 \times 10^{-3}$, the probability that the accident occurs on a rural highway $(p=0.487)$ and is fatal $(p=0.0208)$ is $1.21 \times 10^{-2}$ and the probability that the accident occurs on an urban freeway $(p=0.186)$ and is fatal $(p=0.0208)$ is $3.87 \times 10^{-3}$. The total probability of a fatal accident is then $1.55 \times 10^{-2}$. The percentage of fatalities in each area is then:

- city streets $-9.9 \%$

- urban freeways - $24.9 \%$

- rural highways - $65.2 \%$

It is assumed that gasoline releases are divided between the three areas in the same proportions. Combining this information with the Bureau of Motor Carrier Safety data yields the following release locations that are used in this study:

- $68.9 \%$ - rura 1 highways

- $6.2 \%$ - business area on city street

- $16.4 \%$ - business area on urban freeway

- $2.5 \%$ - residential area on city street

- $6.3 \%$ - residential area on urban freeway

Fatalities from gasoline pool fires may result from direct exposure to the radiant energy from the fire or from secondary fires produced on adjoining buildings. It is assumed that no secondary fires are produced from an accident on a rural highway. Although large amounts of smoke are produced 
in a gasoline pool fire, it is assumed that no fatalities occur from smoke inhalation. The smoke plumes produced in the fire are very buoyant and are assumed to dilute to less than toxic levels before significant personnel exposure to the smoke occurs. (See Appendix E.)

Estimates of the number of secondary fires produced from a pool fire on a city street or an urban freeway are given in Appendix $G$ for each of the three spill sizes used in this study. Fatalities from these fires are estimated using data compiled by the National Fire Protection Association (NFPA). $(4,5)$ These data are summarized in Table 9.1.

TABLE 9.1. Summary of NFPA Data on Building Fire Deaths for 1974

\begin{tabular}{|c|c|c|}
\hline 0-2 Deaths/Fire & 3-10 Deaths/Fire & $\geq 10$ Deaths/Fire ${ }^{(a)}$ \\
\hline $1,270,000$ & 201 & 12 \\
\hline 10,763 & 766 & 171 \\
\hline 0.01 & 3.8 & 14.2 \\
\hline
\end{tabular}

(a)Combination of 1973 and 1974 data.

Using the data in Table 9.1, a probability distribution curve for deaths in building fires has been constructed. This curve is presented in Figure 9.2.

Using Figure 9.2 and the probability estimates on Tables G.3 through G.8, the probability can be estimated for various numbers of deaths from secondary fires when a gasoline spill occurs. It is first necessary to estimate the probability that a given number $(n)$ of deaths will occur when a given number $(j)$ of secondary fires are produced. The simplifying assumption is made that:

$$
P(n \text { deaths } \mid j \text { secondary fires })^{(a)}=j \cdot P(n \text { deaths } \mid 1 \text { secondary fire })
$$

This assumption slightly overestimates the term on the left. The values of $P(n$ deaths $/ 1$ secondary fire) are read from Figure 9.2. The results of these calculations are presented in Table 9.2.

(a)Read: "The probability of $n$ deaths occurring given that $j$ secondary fires have been started." 


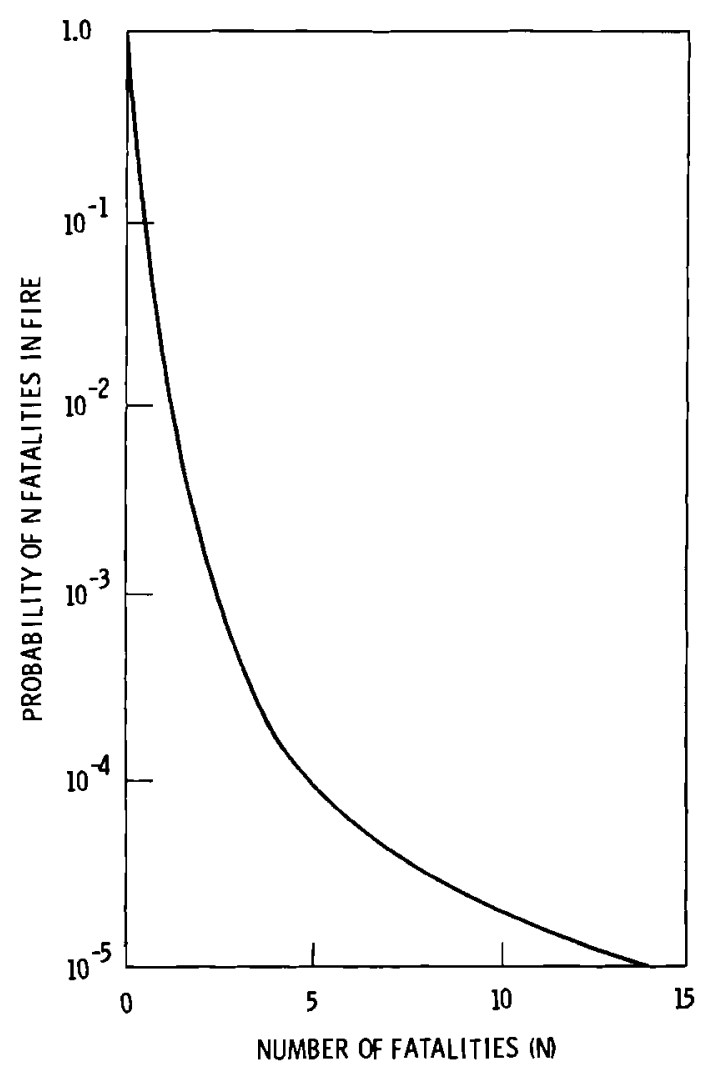

FIGURE 9.2. Probability Distribution for Fatalities in a Building Fire

TABLE 9.2. Estimated Probability of $n$ Deaths from $j$ Secondary Building Fires

\begin{tabular}{|c|c|c|c|c|c|c|c|c|}
\hline & \multicolumn{8}{|c|}{$P$ ( $n$ deaths $j$ fires $)$} \\
\hline$n$ & $j=0$ & 1 & 2 & 3 & 4 & 5 & 6 & 7 \\
\hline 0 & 1.0 & 0.99 & 0.98 & 0.97 & 0.96 & 0.95 & 0.94 & 0.93 \\
\hline 1 & 0.0 & 0.01 & 0.02 & 0.03 & 0.04 & 0.05 & 0.06 & 0.07 \\
\hline 2 & 0.0 & 0.0035 & 0.007 & 0.01 & 0.014 & 0.018 & 0.021 & 0.025 \\
\hline 3 & 0.0 & $3.0 \mathrm{E}-4(\mathrm{a})$ & $6.0 \mathrm{E}-4$ & $9.0 \mathrm{E}-4$ & $1.2 \mathrm{E}-3$ & $1.5 \mathrm{E}-3$ & $0.8 \mathrm{E}-3$ & $2.1 \mathrm{E}-3$ \\
\hline 4 & 0.0 & $1.5 \mathrm{E}-4$ & $3.0 \mathrm{E}-4$ & $4.5 \mathrm{E}-4$ & $6.0 \mathrm{E}-4$ & $7.5 E-4$ & $9.0 \mathrm{E}-4$ & $1.1 \mathrm{E}-3$ \\
\hline 5 & 0.0 & $1.0 \mathrm{E}-4$ & $2.0 \mathrm{E}-4$ & $3.0 \mathrm{E}-4$ & $4.0 \mathrm{E}-4$ & $5.0 \mathrm{E}-4$ & $6.0 \mathrm{E}-4$ & $7.0 \mathrm{E}-4$ \\
\hline 10 & 0.0 & $2.5 \mathrm{E}-5$ & $5.0 \mathrm{E}-5$ & $7.5 \mathrm{E}-5$ & $1.0 \mathrm{E}-4$ & $1.3 \mathrm{E}-4$ & $1.5 \mathrm{E}-4$ & $1.8 \mathrm{E}-4$ \\
\hline 15 & 0.0 & $8.0 \mathrm{E}-6$ & $1.6 \mathrm{E}-5$ & $2.4 \mathrm{E}-5$ & $3.2 \mathrm{E}-5$ & $4.0 \mathrm{E}-5$ & $4.8 \mathrm{E}-5$ & $5.6 \mathrm{E}-5$ \\
\hline
\end{tabular}

(a) Read $3.0 \times 10^{-4}$ 
The probability of $n$ deaths given a spill is then constructed for each spill size using the following equation:

$P(n \mid s p i 11)=P($ spill occurs on city street $)\left[P(\right.$ pool fire $\mid s p i 11) \cdot \sum_{j} P(j$ fires $\mid$ pool fire on city street $) \cdot P(n$ deaths $\mid j$ fires $)]+P$ (spill occurs on freeway) $\left[P\left(\right.\right.$ pool $\mid$ fire spi11) $\cdot \sum_{j} P(j$ fires $\mid$ pool fire on freeway $) \cdot P(n$ deaths $\mid j$ fires $]$

where

$P(n \mid s p i 11)=$ the probability that $n$ deaths occur from secondary fires given that a release occurs

$P($ spill on city street $)=$ the probability that the release will occur on a city street $=0.087$

$P($ pool fire|spill $)=$ the probability that a release will resuit in a pool fire $=0.24$

$P(j$ fires $\mid$ pool fire on city street $)=$ probability that $j$ secondary fires will occur given that a pool fire has occurred on a city street (See Table G.3, G.4 and G.5)

$P(n$ deaths $\mid j$ fires $)=$ probability that $j$ secondary fires result in $n$ fatalities (See Table 9.2)

$P($ spill occurs on freeway $)=$ probability that the release will occur on an urban freeway $=0.224$

$P(j$ fires $\mid$ spill on freeway $)=$ probability that $j$ secondary fires will occur given that a pool fire has occurred on an urban freeway (see Table G.6, G.7 and G.8).

The results of these calculations for the three spill sizes considered are presented in Table 9.3. 
TABLE 9.3. Estimated Probability of $n$ or more Deaths from Secondary Fires Given that a Gasoline Release Has Occurred

\begin{tabular}{|c|c|c|c|}
\hline \multirow{2}{*}{$\begin{array}{c}n \\
\text { deaths }\end{array}$} & \multicolumn{3}{|c|}{$\begin{array}{c}P(n \text { or more deaths|release }) \\
\text { Spill Size Gallons }\end{array}$} \\
\hline & 3000 & 4200 & 8400 \\
\hline 1 & $6.3 E-4$ & $9.4 \mathrm{E}-4$ & $1.8 \mathrm{E}-3$ \\
\hline 2 & $1.8 \mathrm{E}-4$ & $2.7 \mathrm{E}-4$ & $5.2 \mathrm{E}-4$ \\
\hline 3 & $2.7 E-5$ & $3.9 \mathrm{E}-5$ & $7.4 E-5$ \\
\hline 4 & 1. $3 E-5$ & $1.9 E-5$ & $3.6 \mathrm{E}-5$ \\
\hline 5 & $6.0 \mathrm{E}-6$ & $8.9 \mathrm{E}-6$ & $1.7 \mathrm{E}-5$ \\
\hline 10 & $1.5 \mathrm{E}-6$ & $2.2 \mathrm{E}-6$ & $4.2 E-6$ \\
\hline 15 & $3.6 E-7$ & $5.4 E-7$ & 1. $0 \mathrm{E}-6$ \\
\hline
\end{tabular}

Deaths by direct exposure to the radiant energy from a gasoline pool fire are assumed to be 1 imited to occupants of vehicles involved in the accident. Although other people in the vicinity of the accident could receive serious injuries, it is assumed that they could take evasive action to avoid fatal burns.

A spectrum of the number of vehicles involved in truck accidents has been estimated from data obtained from the University of Michigan Highway Safety Research Institute for heavy truck accidents in the state of Texas in 1974. The data are presented in Table 9.4.

TABLE 9.4. Distribution of Heavy Truck Accidents by Number of Vehicles Involved

\begin{tabular}{crc}
$\begin{array}{c}\text { Number of Vehicles } \\
\text { Involved }\end{array}$ & $\begin{array}{c}\text { Number of } \\
\text { Accidents }\end{array}$ & $\begin{array}{c}\text { Fraction of } \\
\text { Total }\end{array}$ \\
\cline { 1 - 1 } 1 & 7,234 & 0.232 \\
2 & 23,623 & 0.759 \\
3 & 234 & 0.008 \\
4 & 27 & 0.001 \\
5 & 7 & 0.0002 \\
6 & 2 & 0.00006 \\
8 & $\frac{1}{31,128}$ & 0.00003
\end{tabular}


The average number of occupants per vehicle is 1.13.(6) Using this figure and the data in Table 9.4, a distribution of the number of people involved in accidents can be obtained. This distribution is presented in Table 9.5 and plotted in Figure 9.3. Data from the Bureau of Motor Carriers for truck accidents in 1975 were analyzed to determine the probability that an occupant of a vehicle involved in a tank truck accident would be killed if a fire resulted. This value was determined to be 0.4 .

TABLE 9.5. Estimated Number of People Involved in Heavy Truck Accidents

Average Number of People Fraction of Total Accidents

$\begin{array}{ll}1.13 & 2.3 \mathrm{E}-1 \\ 2.26 & 7.6 \mathrm{E}-1 \\ 3.39 & 8.0 \mathrm{E}-3 \\ 4.52 & 1.0 \mathrm{E}-3 \\ 5.65 & 2.0 \mathrm{E}-4 \\ 6.78 & 6.0 \mathrm{E}-5 \\ 9.04 & 3.0 \mathrm{E}-5\end{array}$

Using this value and the information in Figure 9.3, an estimated probability distribution for the number of vehicle occupants killed from exposure to a gasoline pool fire, given a release, has been calculated. The results of these calculations are presented in Table 9.6. It is again assumed that $24 \%$ of all releases result in fire.

\subsection{CONSEQUENCES FROM THE FORMATION OF GASOLINE VAPOR CLOUDS}

If a pool of gasoline does not ignite within a few minutes of the spill, evaporation of the gasoline forms a vapor cloud that will drift downwind and diffuse. Diffusion of gasoline vapor clouds is discussed in Appendix $C$. There is a possibility of injury from inhalation of gasoline fumes. Exposure to air containing 500 ppm gasoline for periods of 30 min can result in unconsciousness and eventual suffocation. (7) The $500 \mathrm{ppm}$ limit can be detected by 


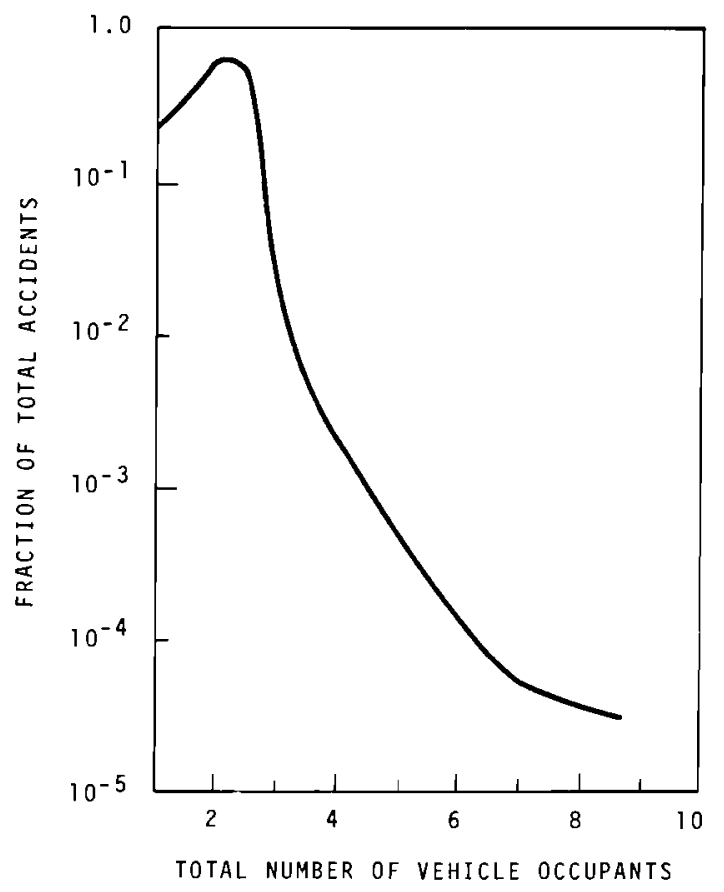

FIGURE 9.3. Estimated Total Number of Vehicle Occupants Involved in Heavy Truck Accidents Plotted as a Function of Accident Frequency

TABLE 9.6. Estimated Probability, Given a Release, of $n$ or More Deaths of Vehicle Occupants from Exposure to a Gasoline Pool Fire

Number of Fatalities $\quad \underline{P(n \text { of more fatalities|release) }}$

1

2

3

4

5

6

7

8

9
$1.9 \mathrm{E}-1$

3. $1 \mathrm{E}-2$

9.6E-4

1. $2 E-4$

$2.6 \mathrm{E}-5$

$5.0 \mathrm{E}-6$

$6.6 \mathrm{E}-7$

$6.3 \mathrm{E}-8$

$1.3 \mathrm{E}-8$

the human sense of sme11. It is expected that in a 30-min period, personnel would be able to move away from the danger area. Death by exposure to gasoline vapors is therefore discounted. 
The possibility exists of accumulation of flammable mixtures of gasoline downwind from the pool. During most weather conditions, the flammability hazard is confined to the immediate vicinity of the pool. Ignition of the vapor cloud under these circumstances constitutes a similar hazard to a pool fire. Under certain weather conditions, the instantaneous concentration of gasoline in portions of the vapor cloud can exceed the lower flammability limit at distances up to 280 meters from the edge of the pool (see Table C.4). The primary hazard from ignition of this cloud is the formation of a fire ball. Personnel in the path of the fire ball could be injured from direct exposure to the flames or, to a lesser extent from the radiant energy from the flame. The fire ball could also ignite secondary fires. It is expected that the fire ball would flash back to the pool, so that a pool fire would also result.

The probability of producing a large fire ball at large distances from the pool is believed to be low. Although detailed information on the consequences of formation of a fire ball in the vicinity of the pool and a flashback ignition of the pool was not available, it is believed to have consequences that are not significantly greater than those of a pool fire. For these reasons, the consequences of ignition of flammable portions of the vapor cloud have not been assessed separately from pool fires. Since the consequences of such an event would be similar to the consequences of a pool fire and the probability of occurrence is estimated to be low, it is believed that any fatalities that might result from these incidents would be accounted for in the conservatism of the gasoline pool fire consequence model. The results of the analysis show that omitting these events does not have a significant effect on the risk. It could, however, change the risk spectrum in the high consequence range.

\subsection{CONSEQUENCES OF TANK TRUCK EXPLOSIONS}

The damage that could be produced from a gasoline tank truck explosion has been estimated in Appendix F. Figure F.5 gives the maximum distances from the explosion site at which total destruction of buildings $(30 \mathrm{ft})$, serious structural damage $(75 \mathrm{ft})$ and missile damage $(300 \mathrm{ft})$ can be expected. The effects of these explosions on the occupants of the buildings were not 
determined. However, it was assumed that all occupants in buildings that are totally destroyed are killed, $10 \%$ of the occupants of buildings that suffer serious structural damage are killed, and $0.1 \%$ of the occupants of buildings within the range of missile damage are killed. The possibility of passersby outside the building being killed by the explosion was not included.

The urban model outlined in Appendix $G$ has also been used to estimate deaths from explosions. The number of occupants per building used to make these estimates is given in Table 9.7. The fraction of accidents in each development type was determined by combining the accident locations presented previously with the fraction of that development type in the urban area (see Table G.2). The number of occupants per residential building is based on data from the cities of San Jose, CA, Albuquerque, NM, and Detroit, MI. (8) The number of occupants in other buildings is based on a typical $150 \mathrm{ft}^{2}$ per person (information from Mr. McIntosh, Bechtel Corporation Office of Alterations and Office Space).

TABLE 9.7. Number of Occupants per Building and Accident Locations Used to Estimate Fatalities from Tank Truck Explosions in Urban Areas

\begin{tabular}{|c|c|c|}
\hline Development Type & $\begin{array}{c}\text { Fraction of } \\
\text { Accidents } \\
\end{array}$ & Occupants/Building \\
\hline Residential A & 0.12 & 3.5 \\
\hline Residential B & 0.16 & 3.5 \\
\hline Industrial & 0.52 & 11.2 \\
\hline Commercial & 0.02 & 8.6 \\
\hline Downtown & 0.01 & 16.0 \\
\hline Vacant & 0.17 & 0.0 \\
\hline
\end{tabular}

No data are available on the frequency of serious tank truck explosions in accidents that result in release. It has been estimated that one in a thousand releases will result in a serious explosion. This value is believed to be conservative (see discussion in Appendix $F$ on conditions required to produce an explosion). 
Some of the assumptions used previously to estimate fatalities from fires are used here to estimate the fatalities in adjacent buildings from explosions. These include:

- No fatalities from explosions in rural areas.

- $8.7 \%$ of explosions occur on urban streets, $22.4 \%$ on urban freeways and $68.9 \%$ on rural highways.

Other assumptions that have been made include:

- Explosions on city streets occur $25 \mathrm{ft}$ from the curb.

- Explosions on urban freeways occur at the edge of the freeway right-ofway (see Figure G.6).

The results of the estimates of the probability distribution for fatalities from explosions is given in Table 9.8 .

TABLE 9.8. Estimated Probability, Given a Release, That $\mathrm{n}$ or More Fatalities Will Occur in Adjacent Buildings from a Gasoline Tank Explosion

\section{Number of Fatalities}

1

2

3

4

5

10

15

20

25

30

35

40
$\underline{P(n \text { or more fatalities }}$ release)

4. $5 \mathrm{E}-4$

4. $2 \mathrm{E}-4$

4. $0 \mathrm{E}-4$

3.7E-4

$3.5 \mathrm{E}-4$

2. $5 \mathrm{E}-4$

1. $6 \mathrm{E}-4$

9. $2 \mathrm{E}-5$

4. $6 \mathrm{E}-5$

1. $6 \mathrm{E}-5$

4. $6 \mathrm{E}-6$

1. $.0 \mathrm{E}-6$ 
It is assumed that all the occupants of vehicles involved in the accident would be killed in an explosion. The estimated probability distribution of deaths of vehicle occupants from an explosion, given a release, is presented in Table 9.9. The distribution of vehicle occupants given in Figure 9.3 was used to make these estimates.

TABLE 9.9. Estimated Probability Distribution for Fatalities of Vehicle Occupants from Explosion, Given a Release

Number of Fatalities

1

2

3

4

5

6

7

8

9
Probability, Given a Release, of $n$ or More Fatalities from an Explosion

9. $9 \mathrm{E}-4$

$7.9 \mathrm{E}-4$

3.2E-5

2. $4 \mathrm{E}-6$

7.5E-7

2.5E-7

$1.2 \mathrm{E}-7$

$7.0 \mathrm{E}-8$

$3.0 \mathrm{E}-8$ 


\section{REFERENCES}

1. A Modal, Economic and Safety Analysis of the Transportation of Hazardous Substances in Bu1k. COM-74-11271, A. D. Little, Inc., Cambridge, MA, p. 160, May 1974.

2. R. E. Scott et al., Statistical. Analysis of Truck Accident Involvements. The University of Michigan Highway Research Institute, Ann Arbor, MI, December 1971.

3. Heavy Truck Accident Study: 1971. Washington State Patrol, Olympia, WA.

4. "Multiple-Death Fires, 1974." Fire Journal, pp. 9-11, July 1975.

5. "Fires and Fire Losses Classified, 1974." Fire Journal, pp. 43-45, September 1975.

6. Statistical Abstract of the United States: 1975. U.S. Department of Commerce Bureau of the Census, Washington, DC, 1975.

7. CHRIS-Hazardous Chemical Data. CG-446-2, U.S. Coast Guard, Department of Transportation, Washington, DC, January 1974.

8. A. N. Takata and F. Salzburg, Development and Application of a Complete Fire Spread Model. IIT Research Institute, Chicago, IL, June 1968. 


\subsection{THE RISK OF SHIPPING GASOLINE BY TRUCK}

In this section the risk of shipping gasoline by truck is calculated using the model described in Section 3.0. The probability that a release will occur during a shipment was presented in Section 8.0 and the consequences of the release were discussed in Section 9.0. The total risk of shipping gasoline in the Year 1980 is calculated in Section 10.1 using the industry characteristics presented in Section 4.0. Major contributors to the risk and the sensitivity of the assessment to the various parameters is presented in Section 10.2.

\subsection{RISK EVALUATION FOR GASOLINE SHIPMENTS}

The sum of the probabilities of the release sequences presented in Section 8.2 is $8.5 \times 10^{-6}$ /shipment. Based on a total of $1.37 \times 10^{7}$ shipments per year in 1980 (see Section 4.0), gasoline tank trucks would be expected to be involved in a total of 1,710 accidents, 110 of which would result in the release of a significant amount of gasoline. Using the release fraction information in Section 8.3 and assuming that the tanks are full when the accident occurs, 3 of these releases are expected to involve 3,000 gal of gasoline, 64 would release 4,200 gal of gasoline and 43 would result in a release of the total contents of the tank truck and trailer. Thirty-one of the releases are estimated to result in a fire.

The risk spectrum curve for all gasoline shipments in 1980 is shown in Figure 10.1. The risk spectrum is a plot of the expected frequency (in events/yr) of events versus the number of fatalities that are predicted from those events. For example, the curve shows that for the 1980's shipping levels used in the analysis, about 25 accidents resulting in 1 or more fatalities from the release of gasoline in an accident are predicted to occur each year. Accidents that produce 10 or more fatalities are estimated to occur at a rate of $2.2 \times 10^{-2}$ per year, or one accident in about 45 years. The risk curve shows that a number of events resulting in one or two deaths/ event can be expected each year from gasoline releases in transportation 


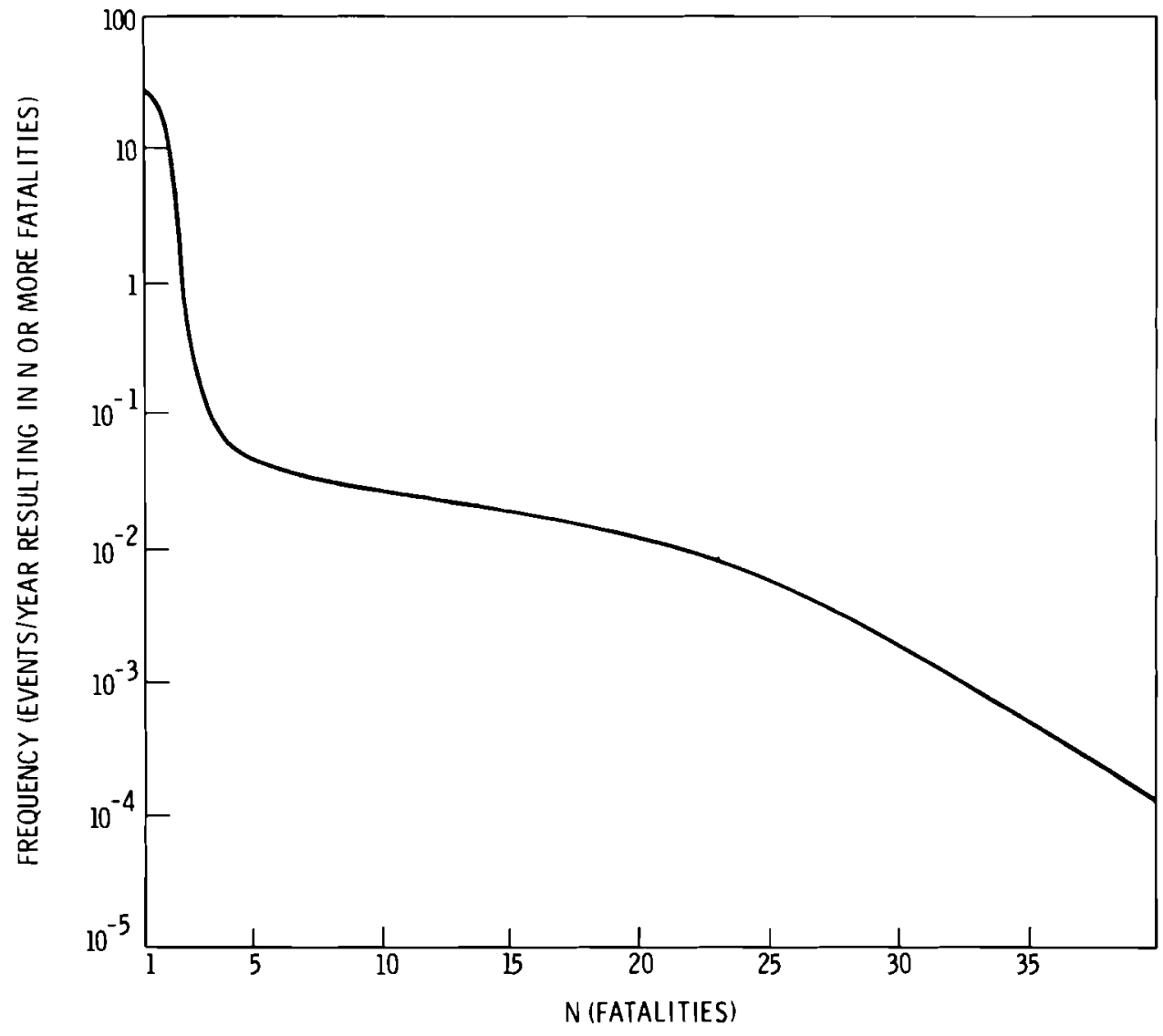

FIGURE 10.1. Risk Spectrum for Release of Gasol ine from Tank Truck Accidents in 1980

accidents. Events producing larger consequences occur relatively infrequently, however. There does not appear to be a significant potential for very large consequence events.

The risk curve was developed using the number of releases presented above and the consequence estimates presented in Section 9.0. Where necessary, the individual consequence probability distributions were extended to cover the full range ( 1 to 40 ) of number of fatalities considered in the assessment. It was not possible to determine the shape of the risk curve for events producing more than 40 fatalities. It is expected that an event such as an explosion near a crowded shopping area could produce more than 40 fatalities. Although it was not possible to determine the frequency of such an event using existing data, the probability of such an event is believed to be 
very low. A review of a summary of large consequence accidents for the period 1953-1973 showed no truck accidents involving hazardous materials that produced more than 13 fatalities. (1) (The accident resulting in 13 deaths did not involve gasoline).

The expected number of fatalities in 1980 from the risk spectrum presented in Figure 10.1 is 29 . It is estimated that 12 of these fatalities or $40 \%$ would be drivers of the gasoline tank trucks. The deaths are produced solely from the hazardous cargo carried in the tank truck. Figure 10.2 shows the effect on the risk spectrum of including the traffic deaths that can be expected from the 1,710 accidents in 1980 involving gasoline tank trucks. Twenty-six traffic fatalities would be expected in these accidents. The traffic fatality risk spectrum was developed from data for about 31,000 truck accidents in the state of Texas in 1974 (data obtained from J. C. Marsh, University of Michigan Highway Safety Research Institute, September 1976). These data are shown in Table 10.1.

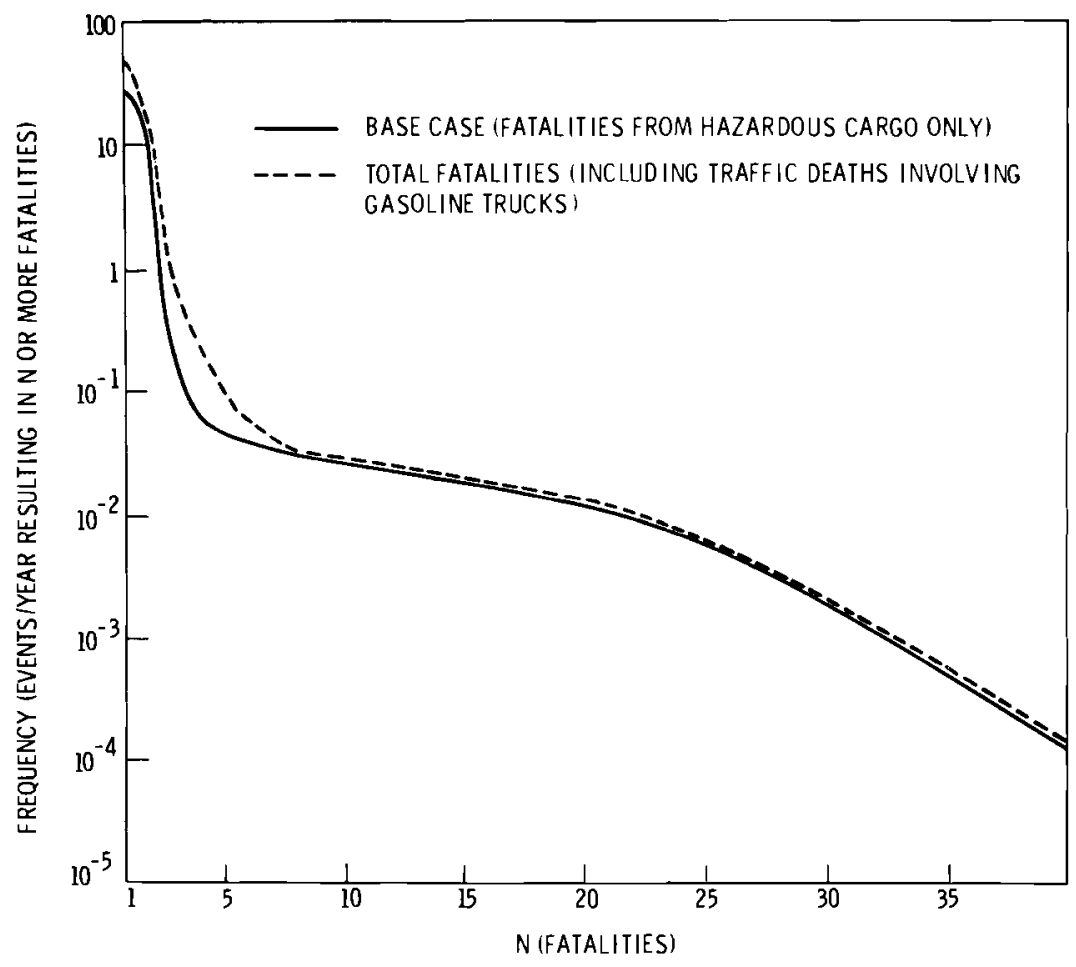

FIGURE 10.2. Accident Fatalities Not Associated with Hazardous Nature of Cargo 
TABLE 10.1. Traffic Fatalities in Heavy Truck Accidents

\begin{tabular}{|c|c|c|c|}
\hline$n$ (fatalities) & $\begin{array}{c}\text { Number of } \\
\text { Accidents Producing } \\
\text { n Fatalities } \\
\end{array}$ & $\begin{array}{c}\text { Fraction of } \\
\text { Total Accidents } \\
\end{array}$ & $\begin{array}{c}\text { Probability of } n \\
\text { Fatalities, Given } \\
\text { Accident Has Occ }\end{array}$ \\
\hline 0 & 30,731 & 0.987 & --- \\
\hline 1 & 342 & $1.10 \times 10^{-2}$ & $1.3 \times 10^{-2}$ \\
\hline 2 & 45 & $1.45 \times 10^{-3}$ & $1.8 \times 10^{-3}$ \\
\hline 3 & 7 & $2.25 \times 10^{-4}$ & $3.6 \times 10^{-4}$ \\
\hline 4 & 2 & $6.42 \times 10^{-5}$ & $1.4 \times 10^{-4}$ \\
\hline 5 & --- & $4.2 \times 10^{-5(a)}$ & $7.4 \times 10^{-5}$ \\
\hline 6 & 1 & $3.21 \times 10^{-5}$ & $3.2 \times 10^{-5}$ \\
\hline
\end{tabular}

(a)Extrapolated from other data

The risk from releases of gasoline in tank truck accidents in 1980 is compared to the risk from other kinds of accidents and natural disasters in Table 10.2. The table illustrates that the individual risk from gasoline transportation is comparable to the risk from lightning or tornadoes. The data in the table are from Reference 2 for the year 1973 except as otherwise indicated.

The results of the analysis have been compared to data obtained from the Bureau of Motor Carrier Safety. Interstate motor carriers are required to make accident reports to BMCS whenever an accident results in death, injury or greater than $\$ 2,000$ property damage. The accident reports include information on the accident location and time, accident type, condition of the driver, vehicle description, cargo, result of the accident, contributing causes and driving conditions. The BMCS has recently begun a program to codify this information for computer analysis. A copy of the computer data tape for 1975 was obtained and analyzed to determine the effects of accidents involving tank trucks carrying gasoline and similar flammable liquids. The results of this analysis are presented in Table 10.3. 
TABLE 10.2. Comparison of Gasoline Transportation Risks with Individual Risk from Various Accidents and Natural Disasters

Accident Type

Al1 Accidents

Motor Vehicle Accident

All Industrial Accidents $(a)$

Fal1s

Drowning

Fires

Poisoning

Airplane Crashes

Railway Accidents

Lightning (c)

Tornadoes $(d)$

Gasoline Tank Truck Accidents
Total Fatalities Individual Risk per Year

$\begin{array}{rl}115,821 & 1 \text { in } 2,000 \\ 55,511 & 1 \text { in } 4,000 \\ 14,100 & 1 \text { in } 6,000 \text { (b) } \\ 16,506 & 1 \text { in } 13,000 \\ 7,152 & 1 \text { in } 29,000 \\ 6,503 & 1 \text { in } 32,000 \\ 5,335 & 1 \text { in } 40,000 \\ 1,668 & 1 \text { in } 130,000 \\ 789 & 1 \text { in } 250,000 \\ 160 & 1 \text { in } 2,000,000 \\ 90 & 1 \text { in } 2,300,000 \\ 29 & 1 \text { in } 7,400,000\end{array}$

(a)Reference 3

(b) Only workers included in population at risk

(c) Reference 4

(d) Reference 3. Average value for several years

TABLE 10.3. Summary of Bureau of Motor Carrier Safety Data for 1975 on Accidents Involving Tank Trucks Carrying Gasoline and Similar Flammable Liquids

Accident Consequences Number of Accidents Fatalities Fatalities/Accident

No Spil1

Spill Without Fire 123

139

Spill with Fire
34
1

12

22
0.01

0.09

0.65 
This data would predict that the 1710 gasoline tank truck accidents (including 79 spills without fire and 31 spills with fire) estimated to occur by this study would result in 43 total fatalities - 20 from accidents involving fire and 23 from accidents that do not result in fire. The numbers obtained in the analysis are 55 total deaths, 29 from accidents involving fire. The analysis results are thus in substantial agreement with the BMCS data.

In addition to validating the results of the analysis, this comparison also illustrates the usefulness of the approach used in the study. The available data did not permit an overall determination of the gasoline shipping risks, because not all carriers of gasoline are required to report to BMCS, and many of the reports that are made do not specify that gasoline is the flammable liquid carried. The data would also not identify accidents that occur less frequently, but could result in much higher consequences. The analysis approach used in this study was able to extend the data available to predict the risk for the entire gasoline shipping system and also to construct a risk spectrum showing how accident severity varies with accident frequency.

\subsection{RISK SENSITIVITY EVALUATIONS}

Before discussing the sensitivity of the risk evaluation to the value of certain system parameters, it is important to point out a fundamental sensitivity of the risk evaluation. The calculated risk is a function of the sinipping assumptions. Use of a different type of truck, different shipping distances, changes in the predicted industry growth rate, etc., would result in a different risk. In general, reevaluation would be required to determine the risk under these conditions.

Risk sensitivity evaluations permit analysis of the importance of the various factors that contribute to the risk. They can be used: 1) to identify and quantify the effects of the major contributors to the risk; 2) to identify ways to decrease the uncertainty in the risk evaluation; and 3) to study the effects of possible design or regulatory changes on the risk. Most sensitivity studies are performed by repeating the risk calculation with a changed value 
for the parameter of interest. In general, the dependence of the risk on a particular parameter is complex. In some cases, however, the parameter enters simply and directly into the risk calculation and the sensitivity can be determined directly.

The results of the risk sensitivity studies for the shipment of gasoline in DOT specification MC-306 tank trucks are presented in Table 10.4 and Figures 10.3 through 10.6. Table 10.4 shows the sensitivity of the expected

TABLE 10.4. Sensitivity of the Expected Number of Fatalities from Gasoline Releases to the Value of Various System Parameters

\begin{tabular}{|c|c|c|}
\hline Description of Sensitivity Case & $\begin{array}{c}\text { Expected } \\
\text { Fatalities } \\
\end{array}$ & $\begin{array}{c}\text { Change from } \\
\text { Base Case }\end{array}$ \\
\hline $\begin{array}{l}\text { Base Case (puncture probability }= \\
0.025 / \text { accident) }\end{array}$ & 29 & -1 \\
\hline $\begin{array}{l}\text { Puncture Probability }= \\
0.044 / \text { accident }\end{array}$ & 36 & $+24 \%$ \\
\hline $\begin{array}{l}\text { Puncture Probability }= \\
0.006 / \text { accident }\end{array}$ & 22 & $-24 \%$ \\
\hline $\begin{array}{l}\text { Probability of Explosion }= \\
10^{-2} / \text { release }\end{array}$ & 36 & $+24 \%$ \\
\hline $\begin{array}{l}\text { Probability of Explosion }= \\
10^{-4} / \text { release }\end{array}$ & 28 & $-3 \%$ \\
\hline $\begin{array}{l}\text { All Vehicle Occupants Killed in } \\
\text { Fire }\end{array}$ & 55 & $+90 \%$ \\
\hline Al1 Release Fractions $=1.0$ & 29 & 0 \\
\hline Fire Suppression System on Truck & $<1$ & $-97 \%$ \\
\hline Tank Ten Times Stronger & 9 & $-70 \%$ \\
\hline
\end{tabular}

number of fatalities to the parameter being studied, while the figures illustrate the sensitivity of the shape of the risk spectrum curve to changes in these parameters. Most of the sensitivity studies were carried out to investigate the importance of assumptions that were made in basic event probabilities in Section 8.0 and in the consequence models in Section 9.0. These assumptions were generally necessary because data were not available for a more exact determination of the value of a parameter. In the base case, 


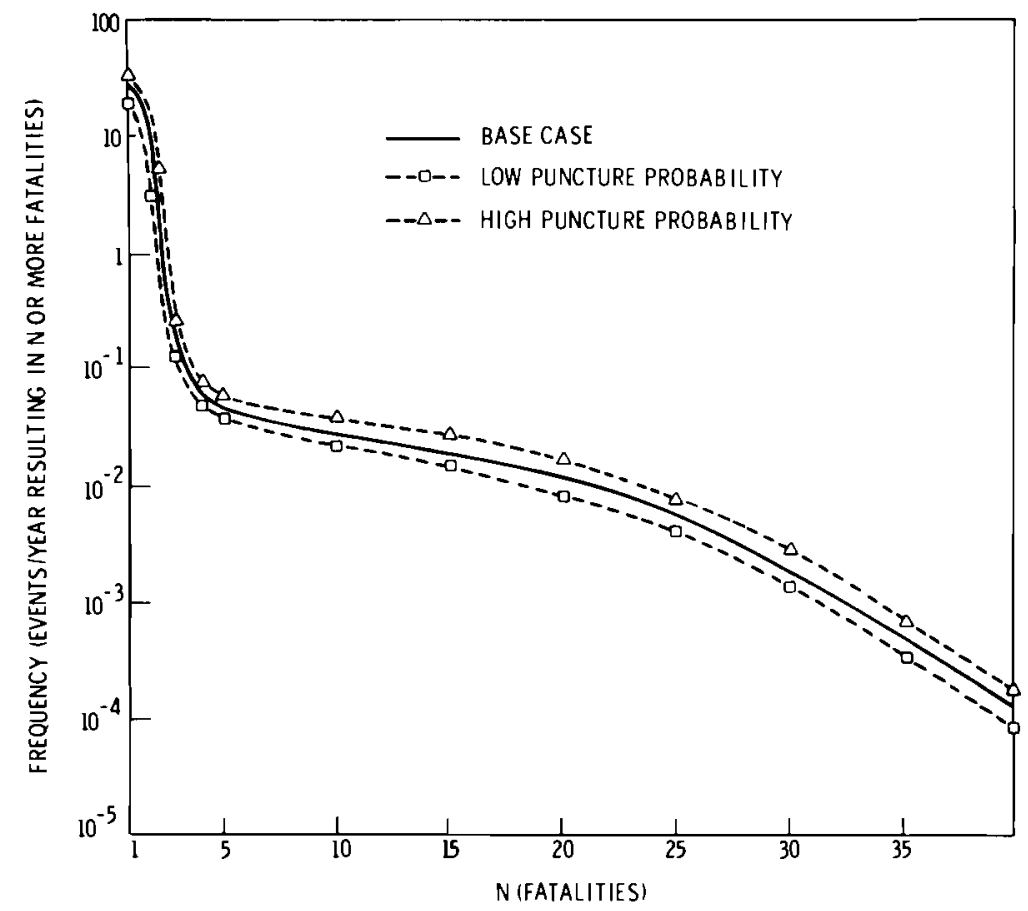

FIGURE 10.3. Sensitivity of Risk to Probability of Failure from Puncture Forces

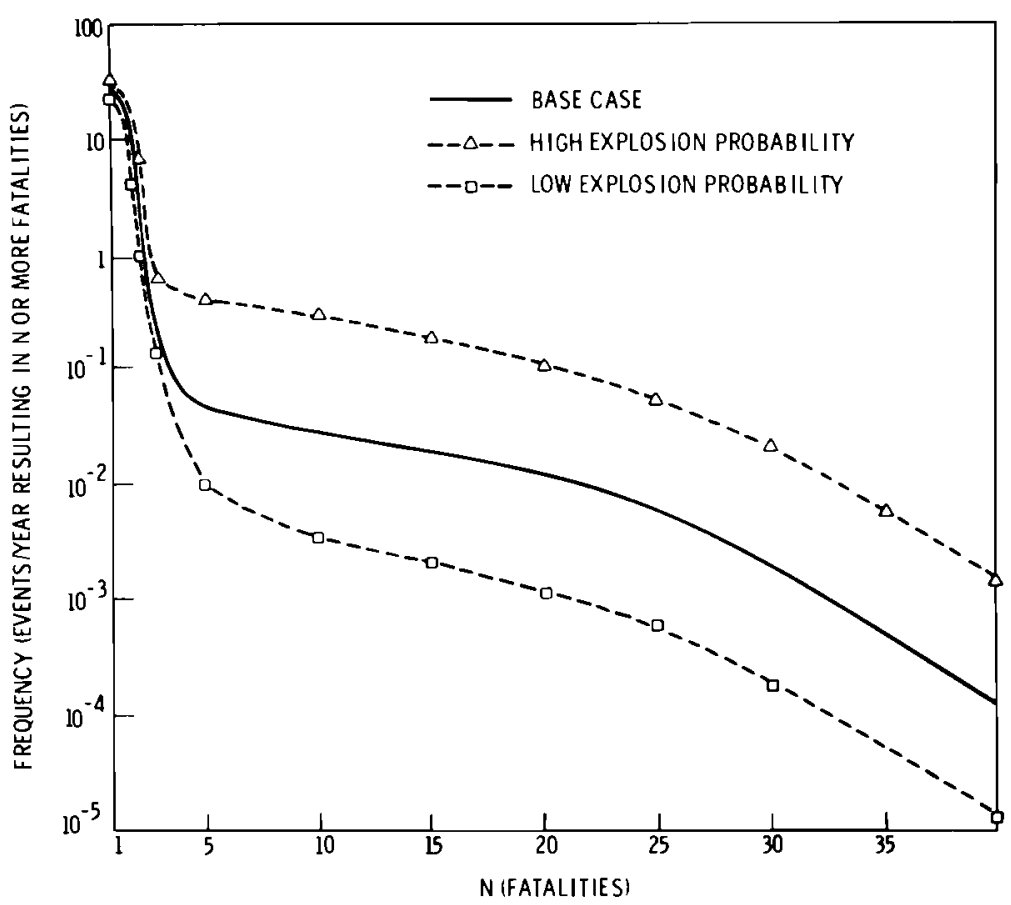

FIGURE 10.4. Sensitivity of Risk to Assumption of the Probability of an Explosion, Given a Release 


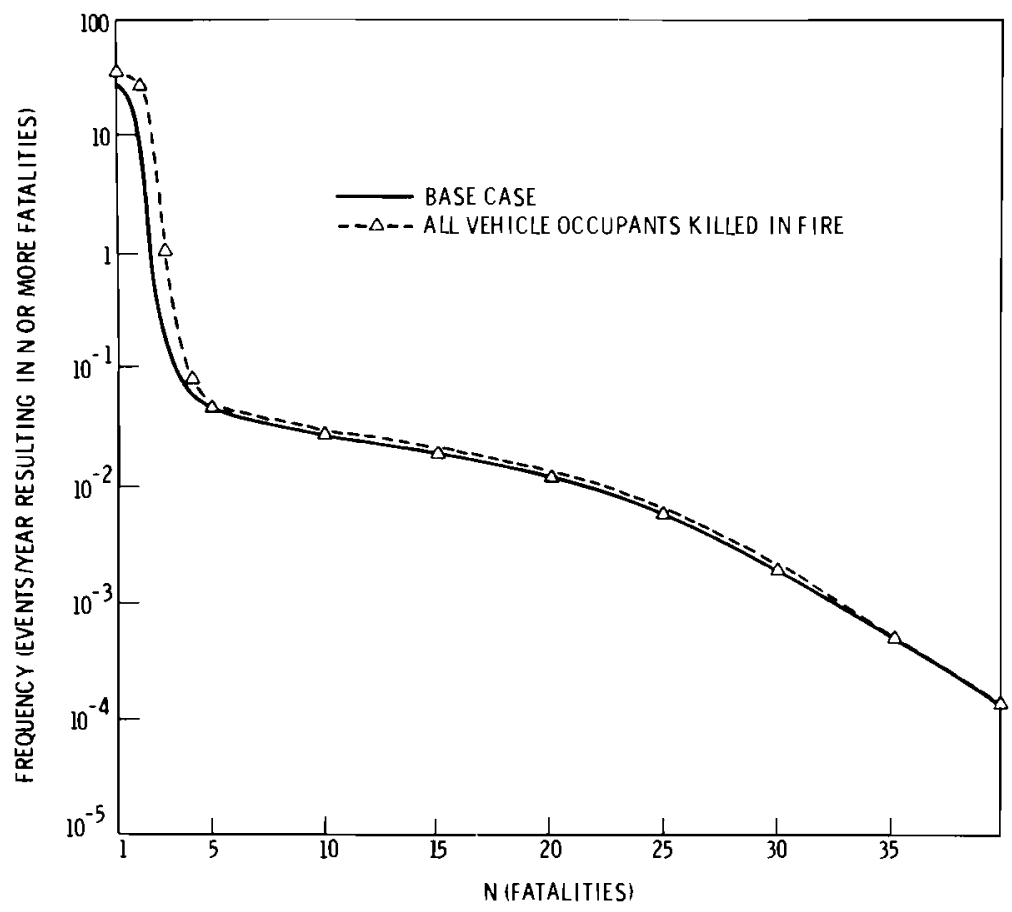

FIGURE 10.5. Sensitivity of Risk to Number of Vehicle 0ccupant Fatalities in a Fire

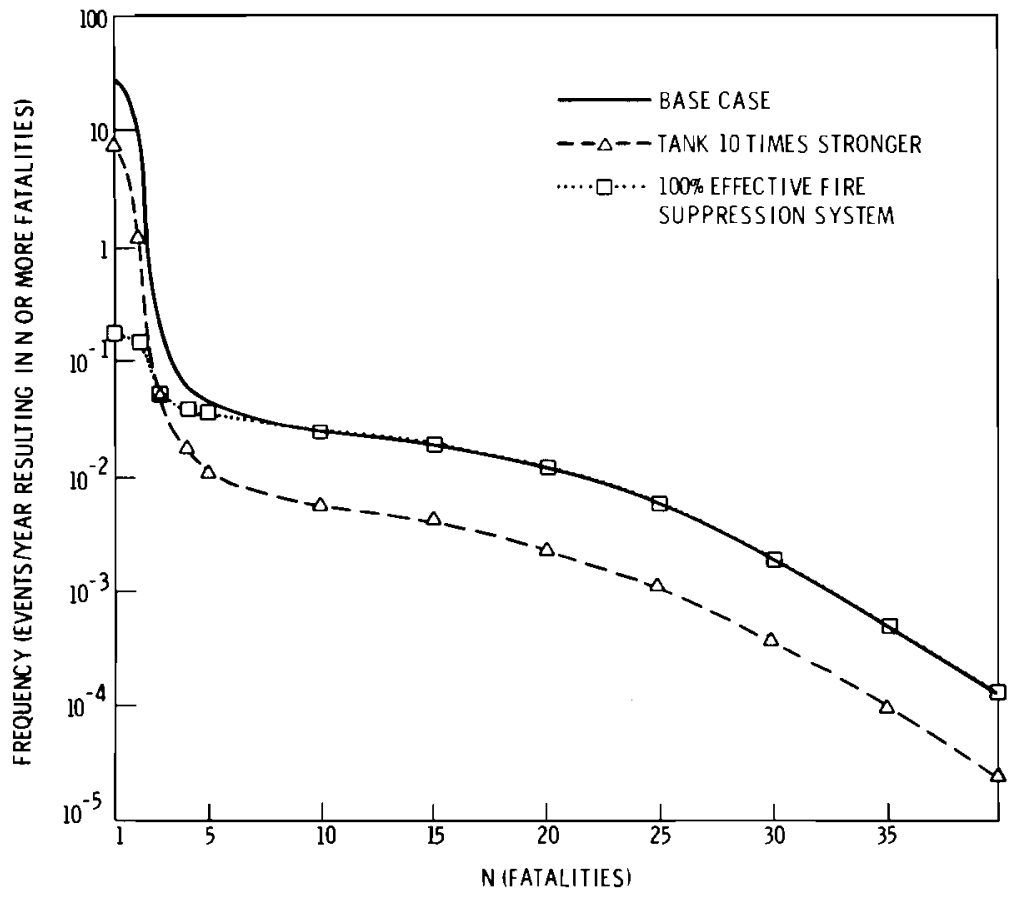

FIGURE 10.6. Effect on Risk of Strengthening Tank or Installing Fire Suppression System 
failure of the tank walls by puncture forces accounts for $39 \%$ of all releases, failure of the walls from impact forces for 39\% and failure of the walls by abrasion for $14 \%$ of the releases. Fires that do not initially involve the cargo contribute to about $5 \%$ of the releases. Changes in the value of the parameters making up these release sequences may have a significant effect on the total risk. Puncture failures have been selected to illustrate this point, since the greatest uncertainty exists in the prediction of the probability of a puncture failure.

Figure 10.3 shows the sensitivity of the risk to the value of event $A 69$. (Puncture Forces Fail Tank Walls.) The probability of this event was calculated in two independent ways (see Section 8.2). An average of these two calculations was used in the base case risk calculation. The sensitivity study shows the effect on the risk of using the high and low values calculated for this event.

It was necessary to assume a value for the probability of a gasoline tank truck explosion, given a release. A value of $10^{-3}$ was used in the base case. Figure 10.4 illustrates the effect on the risk spectrum of a two order of magnitude change in the explosion probability. The change affects the curve in the high consequence range, since most high consequence accidents are due to explosions. As shown in Table 10.4, however, the expected number of fatalities in 1980 is not affected significantly by the explosion probability.

The sensitivity of the risk to the release fractions used in the base case was also studied. Assuming that all release fractions $=1.0$ (that is, the entire contents of both truck and trailer are released in all accidents that produce a significant release) has a negligible effect on the risk spectrum and the expected number of fatalities. Figure 10.5 and Table 10.2 also show the sensitivity of the risk to change in the value of the probability that an occupant of a vehicle involved in the accident would be killed if a fire resulted from the release. In the base case, it was assumed that each vehicle occupant involved in the accident had a $40 \%$ chance of being killed in a fire. Changing this value by assuming that all the vehicle occupants are killed in a fire produces a corresponding increase of $97 \%$ in the expected number of fatalities. This shows that deaths of vehicle occupants in a fire account for nearly all of the expected fatalities. 
Two possible methods for reducing the risk from gasoline releases in tank truck accidents have been investigated. The first method involves shipping the gasoline in stronger tanks. Figure 10.6 shows the effect on the risk spectrum of making the tank 10 times more resistant to puncture, impact and abrasion forces. This has the effect of a substantial reduction in the number of releases and reduces the expected number of fatalities by about a factor of three. It has also been suggested ${ }^{(5)}$ that the instaliation of accidentactuated fire suppression systems on tank trucks might reduce the risk. Figure 10.6 also presents the results of assuming that a $100 \%$ effective fire suppression system is present in all tank truck accidents. The expected number of fatalities per year is reduced to less than one. Although a detailed cost benefit analysis would be required to determine which of these methods would be the most cost-effective, the installation of the fire suppression system would appear to merit the higher priority for further study if it is determined that the present risk is unacceptably high. Strengthening the tanks by an order of magnitude would probabiy require a change from aluminum to steel construction. This would have a significant impact on the cost of tank truck manufacture and would reduce the tank load because of added weight. The development of a reliable, lightweight fire suppression system at a reasonable cost appears to be feasible.

\section{REFERENCES}

1. The Consequences and Frequency of Selected Man-Originated Accident Events. CONSAD Research Corp., Pittsburgh, PA, August 1974.

2. U.S. Bureau of the Census, Statistical Abstract of the United States: 1975. U.S. Department of Commerce, Washington, DC, p. 66, 1975.

3. Accident Facts 1973. National Safety Council, Chicago, IL, 1974.

4. Reactor Safety Study, WASH-1400, U.S. Nuclear Regulatory Commission, Washington, DC, p. 3, October 1975.

5. L. M. Krasner, et a1., Hazardous Materials Transportation Intrusion Protection for Hazardous Cargo Tanks. DOT HS-800 513, Factory Mutua 1 Research Corporation, Norwood, MA, June 1971. 


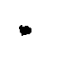


APPENDIX A

\section{GASOLINE TANK TRUCK DESCRIPTION AND OPERATING PROCEDURES}

\section{TRUCK DESCRIPTION}

Gasoline is classified as a hazardous substance by the Department of Transportation and must be transported in containers meeting DOT specifications. Several DOT specification tank trucks may be used to transport gasoline, but conversations with tank truck manufacturers and trucking companies that haul gasoline indicate that DOT specification MC-306 tank trucks are the most widely used for shipping gasoline. Two basic configurations of this shipping system are in current use. Shippers in the eastern U.S. generally use a tractor/semitrailer configuration while western operators use a tank truck/ tank trailer configuration.

A photograph of a typical rig used in the western U.S. is presented in Figure A.1. The truck tank has a capacity of about 4,600 gal and the trailer tank capacity is about 5,400 gal. The tanks are loaded through the dome lids in the top and unloaded by gravity through outlet valves in the back of the truck tank and in the front of the trailer tank. Tubes carrying hoses used to offload the tanks are welded to the outside of the tank. The truck tank is supported on the steel channels that form the truck frame, while, the trailer tank is the structural member of the trailer. The trailer is provided with a rear bumper capable of absorbing a "2g" deceleration of the loaded vehicle. The empty truck and trailer combination weighs about 23,000 lbs. The tanks are required to be shipped with an outage of at least $2 \%$, (i.e., less than $98 \%$ ful1), but typical loads are between 8,000 and 8,500 gallons, because of state vehicle gross weight restrictions.

The tanks have an eliptical cross section with a major diameter of 96 in. and a minor diameter of 60 in. The maximum radius of curvature of the shell is about $70 \mathrm{in}$. The ends of the tanks are dished outward about $4 \mathrm{in}$. at the center. Typical tank dimensions are given in Table A.1. 


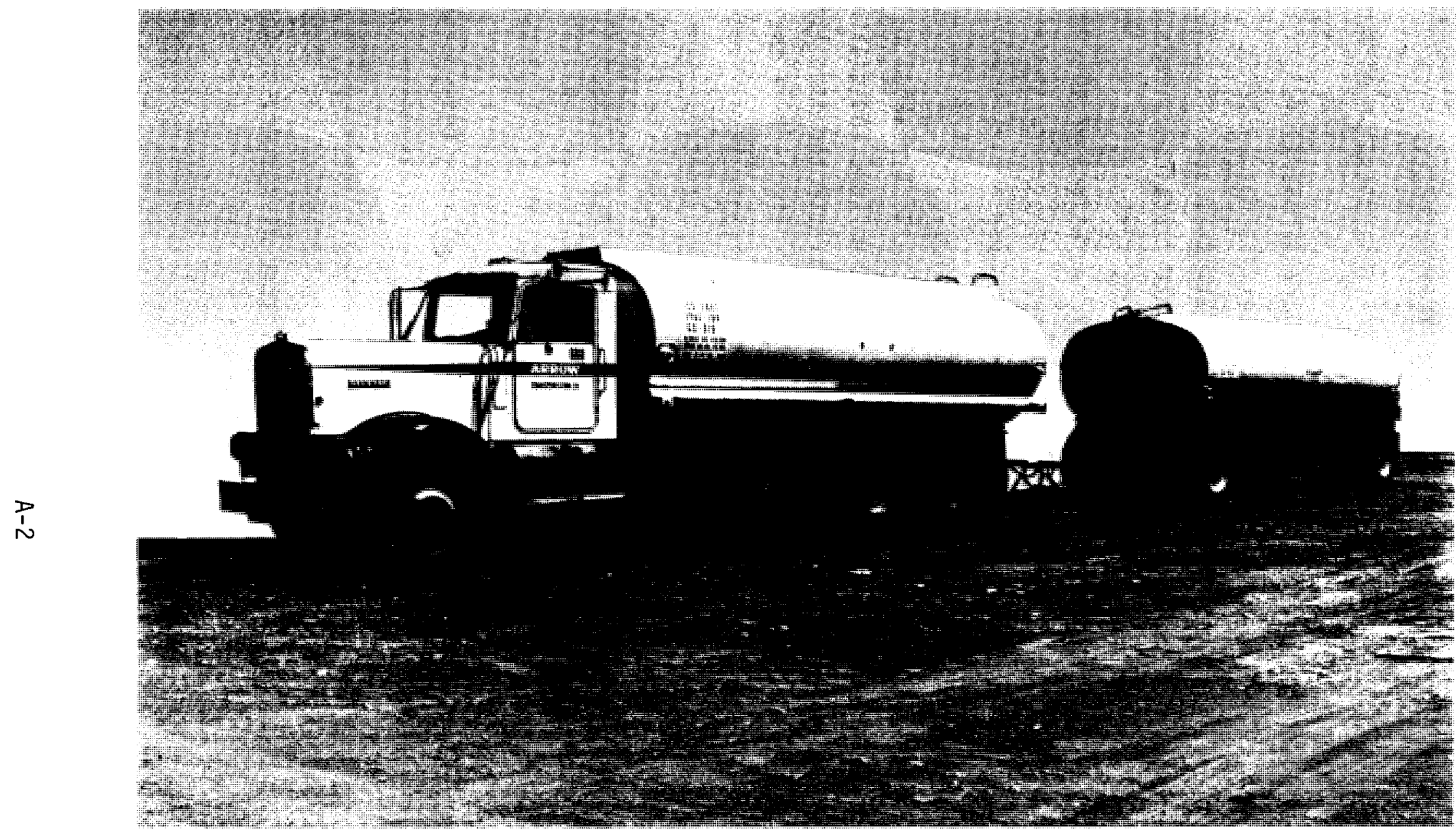

FIGURE A.1. DOT Specification MC-306 Tank Truck and Trailer Used for Gasoline Shipments in the Western U.S. 
TABLE A.1. Truck and Trailer Tank Dimensions for Western Shipping System

\begin{tabular}{|c|c|c|c|c|c|}
\hline & $\begin{array}{l}\text { Length } \\
\text { (in.) }\end{array}$ & $\begin{array}{l}\text { Width } \\
\text { (in.) }\end{array}$ & $\begin{array}{l}\text { Height } \\
\text { (in.) }\end{array}$ & $\begin{array}{c}\text { Cross } \\
\text { Section } \\
\text { Area } \\
\end{array}$ & $\begin{array}{l}\text { Volume } \\
\text { (Gallons) }\end{array}$ \\
\hline Truck Tank & 235 & 96 & 60 & 4524 & 4600 \\
\hline Trailer Tank & 276 & 96 & 60 & 4524 & 5400 \\
\hline
\end{tabular}

The tanks are provided with transverse baffles to stiffen the shell and to reduce liquid movement in transit. The baffles are spaced about 60 in. apart. Multiple compartment tanks may be used, but for purposes of this analysis it is assumed that the tanks have a single compartment. This is a conservative assumption. the tanks are constructed of aluminum. A typical alloy for the shell is ASTM B-209 Alloy 5454. The minimum shell thickness allowed by DOT regulations for a tank of this type is 0.151 in. The tanks are typically constructed with a she11 thickness of $0.188 \mathrm{in}$. on the bottom and side sheets and 0.154 in. on the top. The tank heads and baffles must also be at least 0.151 in. thick. They are typically manufactured from 0.188-in. thick material. The heads and baffles may be fabricated from material with 0 temper (annealed) or stronger tempers. Shell materials must have properties equivalent to $\mathrm{H} 32$ or $\mathrm{H} 34$ tempers. The tanks have a design pressure of 0 psig. They are tested at a pressure of 3 psig, primarily to ensure that welds are leak-tight.

The outlet valve assembly is shown in Figures A.2, A.3 and A.4. The valve consists of an internal valve, with its seat located inside the tank, an external gate valve and a threaded end cap. All three of these must be open before gasoline can flow out of the tank. The external portion of the valve body has a machined neck or "shear section" designed to be the area of fracture on impact. The internal valve will remain seated by 1 iquid pressure if the external valve is fractured at the shear section. The valve assembly is attached to the tank at a flanged outlet in the bottom of one of the tank heads. The assembly is held in place with 5 clips secured to 5/8-in. studs on the tank flange. A rubber gasket, usually of a nitrile butadiene substance 


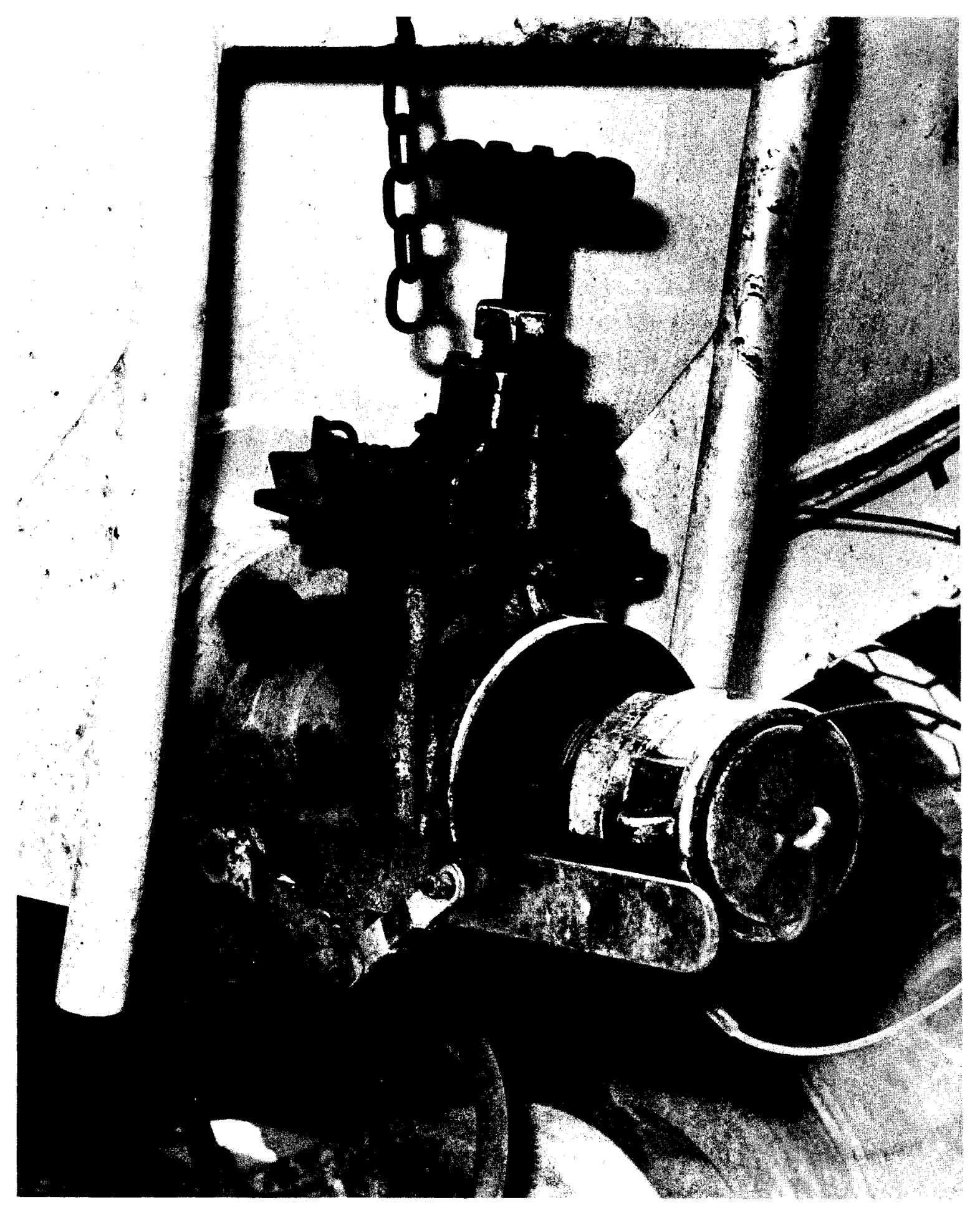

FIGURE A.2. Gasoline Trailer Tank Outlet Valve for Western Shipping System 


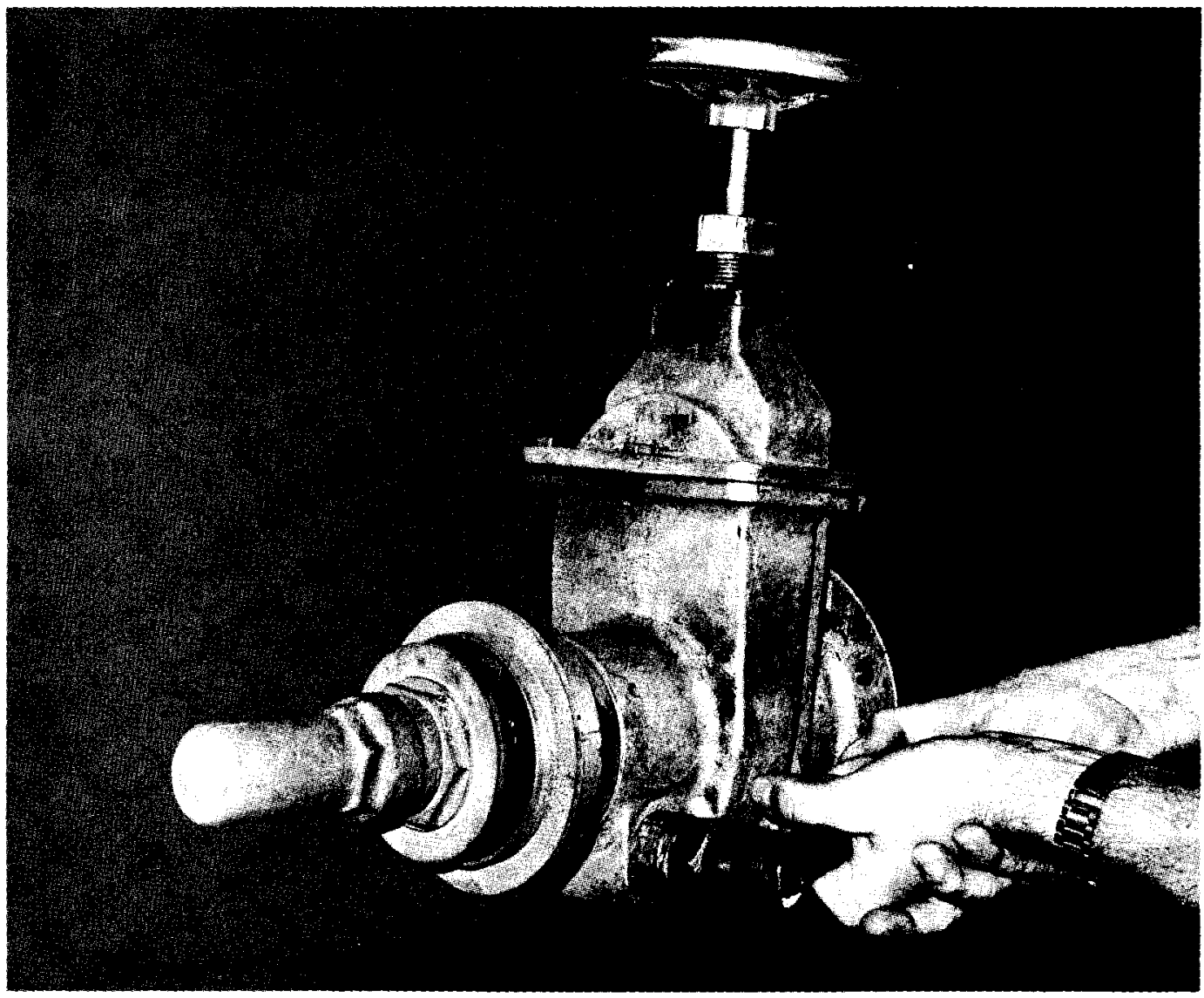

FIGURE A.3. Outlet Valve Showing Internal Valve Mechanism

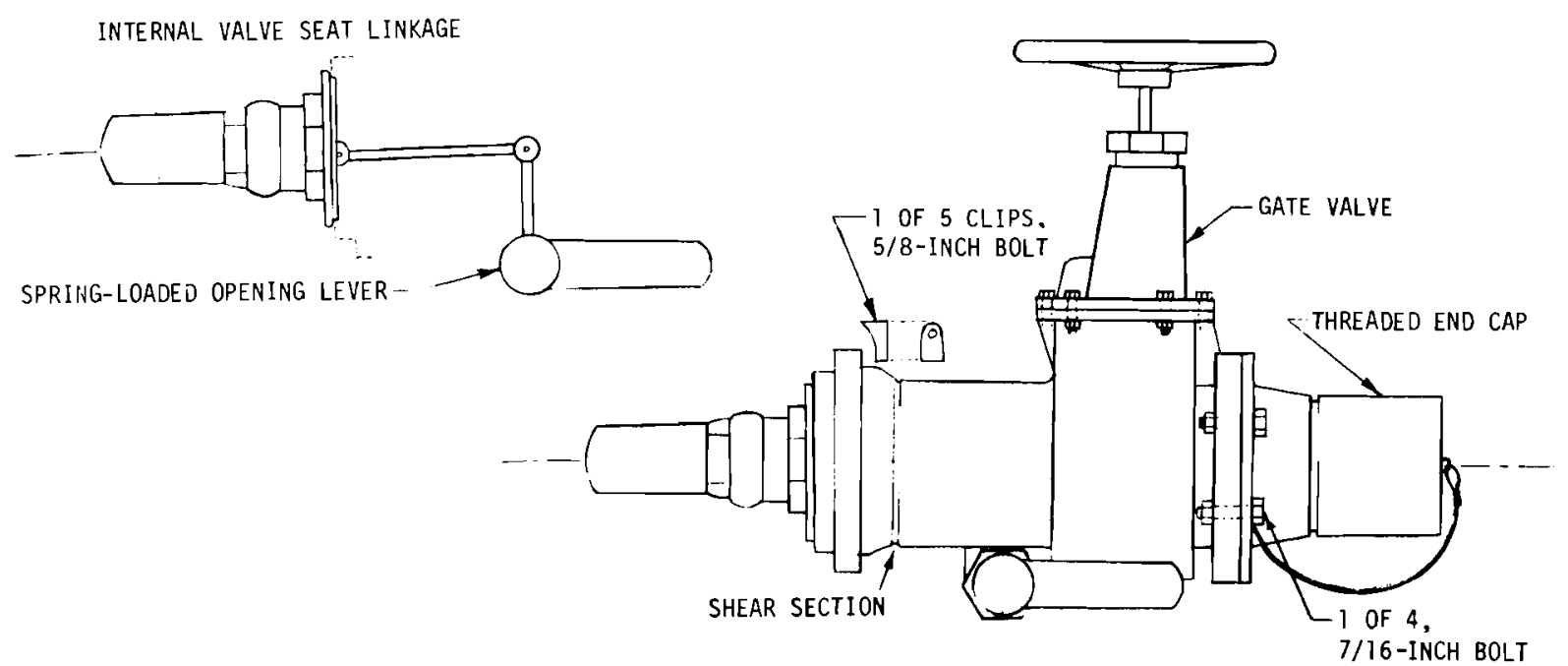

FIGURE A.4. Gasoline Tank Truck Outlet Valve Assembly 
such as BUNA-NR is placed between the valve and the flange. The outlet valve on the truck tank is protected by the two 10.5-in. by 3.75-in. steel channels that form the truck frame. No protection is provided for the outlet valve on the trailer tank.

Each tank is equipped with a manway cover that is used to fill the tank and that provides access to the inside of the tank for cleaning and maintenance. The manway cover is shown in Figures A.5 and A.6. The manway cover access hatch is held in place during transport by a cam-lock type safety catch. The hatch seals to an 0-ring gasket in the manway cover. The gasket is typically made of a nitrile butadiene polymer such as BUNA-NR. The manway cover is attached to the tank by four spring-loaded clips on 12-in. long studs. The clips secure the manway cover to a ring welded into the tank top. A cork gasket is installed between the manway cover and the welding ring in the tank top. The manway cover is protected from damage in a rollover by two rails running the length of the tank top on either side of the manway cover. The rails are approximately parabolic in shape. They are about 5 in. high, 1-1/2 in. wide at the top and 4 in. wide at the bottom. The rails are designed to support the entire weight of a loaded tank.

The manway cover contains the pressure and vacuum relief devices for the tank (Figure A.7). The tank has a single vacuum vent with a rated flow of $2775 \mathrm{ft}^{3}$ of air per hr at a pressure difference of 1 psig and is equipped with three pressure relief devices. The normal pressure relief device, located in the lid of the manway cover, has a venting capacity of $2960 \mathrm{ft}^{3}$ of air per hr at 3 psig. This device begins to open at about 1 psig and is equipped with a ball-check device that closes the valve if the tank is not upright. The second pressure relief device is the manway cover lid. The spring in the center of the lid will allow the lid to lift when the tank pressure exceeds about 9 psig. The entire manway cover forms the third pressure relief valve. The four spring-loaded clips that hold the manway cover in the tank allow the entire manway cover to lift and allow gas to escape along its circumference when the tank pressure reaches 9 psig. This relief device opens at a pressure slightly higher than the lid. It lifts its maximum of about $0.75 \mathrm{in}$. when the tank pressure is $5 \mathrm{psig}$. The rated flow at $5 \mathrm{psig}$ is $345,600 \mathrm{ft}^{3}$ of air per $\mathrm{hr}$. 


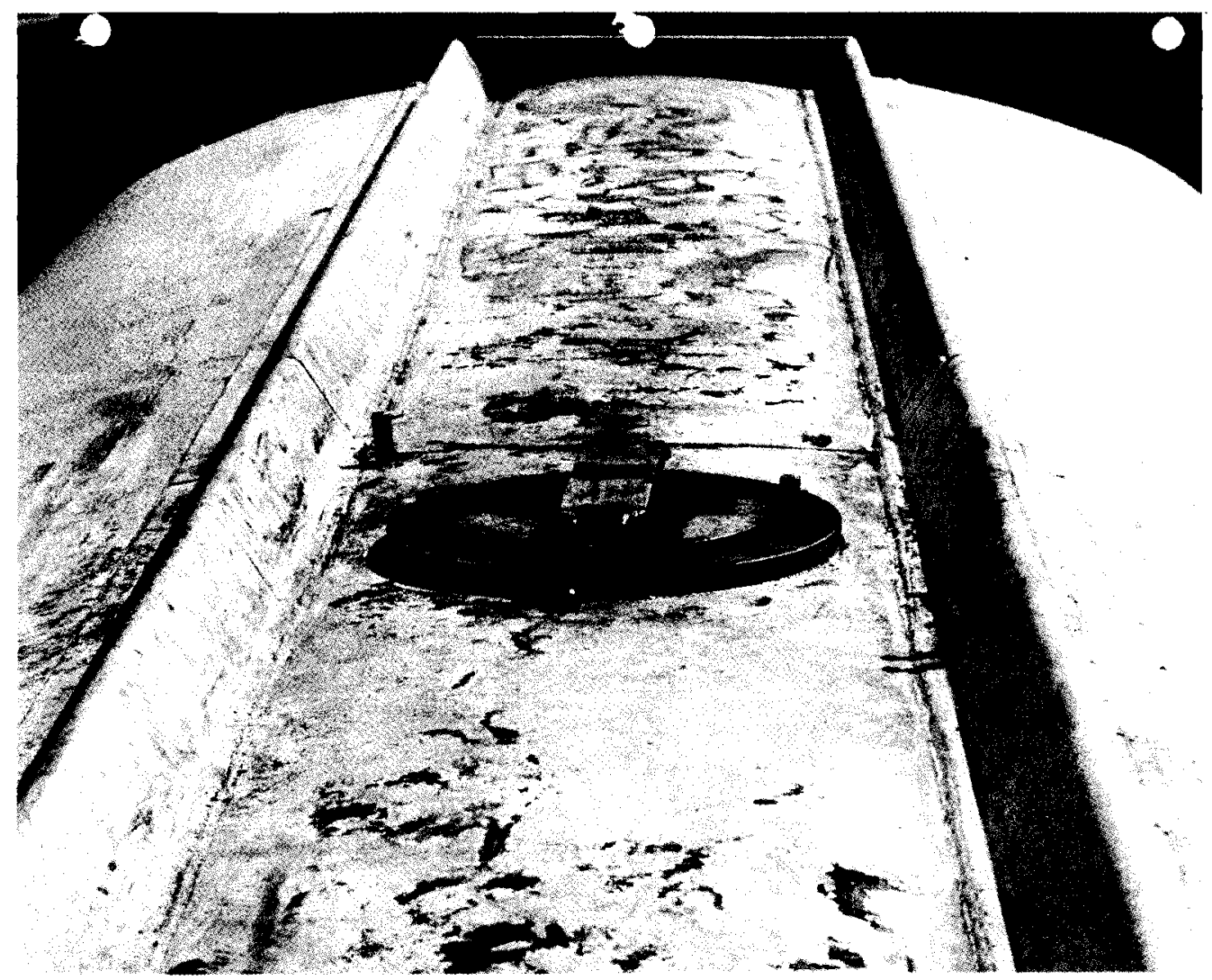

FIGURE A.5. Tank Top Showing Manway Cover and Protective Rails
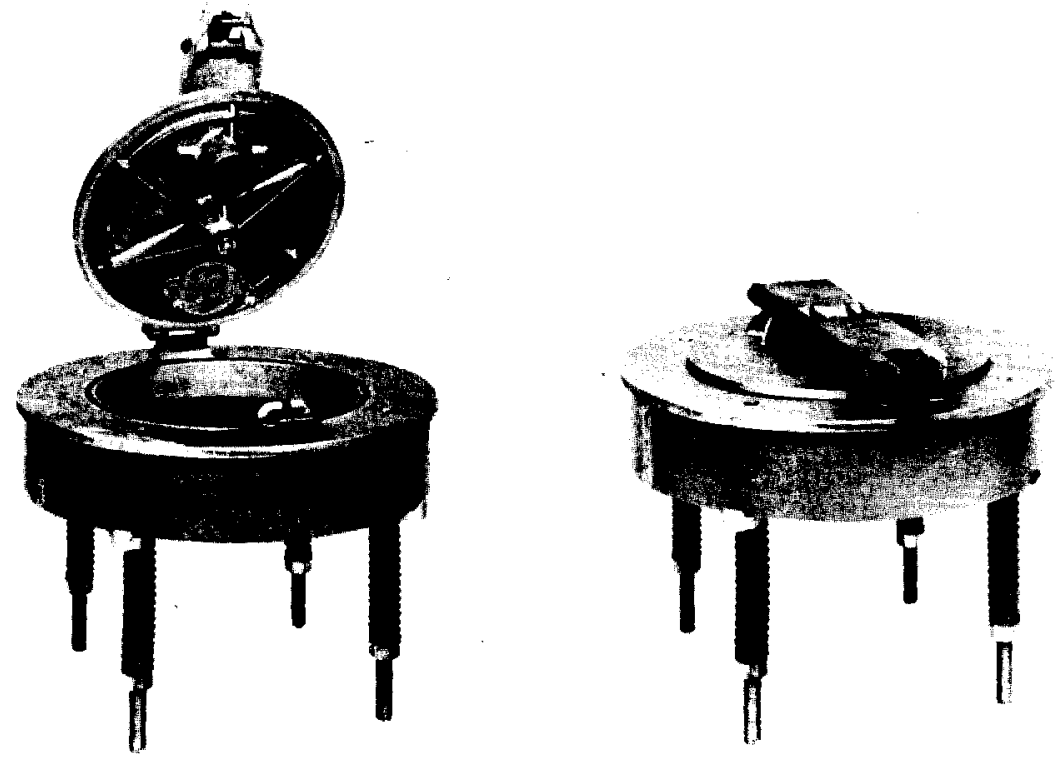

FIGURE A.6. Photograph of Manway Cover

(C-B Equipment, Inc. Lynwood, CA, 1976) 


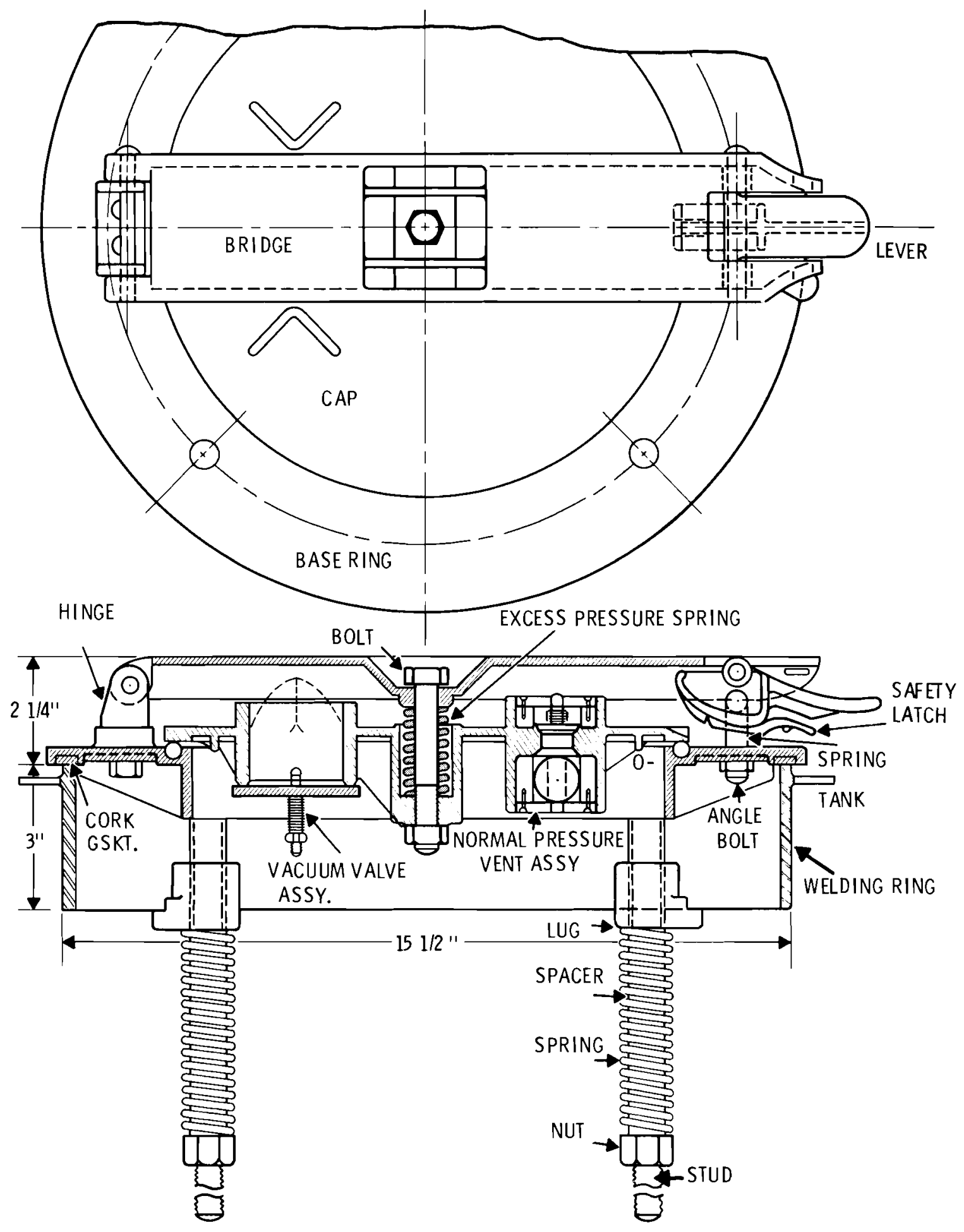

FIGURE A.7. Schematic Drawing of Manway Cover Showing Pressure and Vacuum Relief Devices 
The eastern half of the United States uses a tractor tank trailer configuration. A typical 4-compartment tank trailer is shown in Figure A.8. A tank truck manufacturer indicates that these tank trailers are built $5 \%$ with 3 compartments, $80 \%$ with 4 compartments and 15\% with 5 compartments. The tank trailer is constructed of aluminum with tank wall thicknesses of 0.250 in. on the belly and $0.188 \mathrm{in}$. on the walls and top, reflect the greater volume of the tank.

The typical 4-compartment tank trailer has the 1iquid flow from all compartments brought to a central manifold as shown in Figure A.9. The piping and gate valve have a diameter of $3 \mathrm{in}$. and are made of aluminum. Each compartment has an outlet valve that is cable actuated from a cabinet apart from the discharge area. In the case of any type of emergency, a front remote trip can be actuated that will stop the flow from a11 compartments. For the purposes of this study, other details of the tractor tank-trailer will be considered to be the same as the truck tank and 4-wheeler trailer combination.

\section{OPERATING PROCEDURES}

To determine typical gasoline truck operating procedures, an informal survey was conducted of common carriers in southeastern Washington engaged in

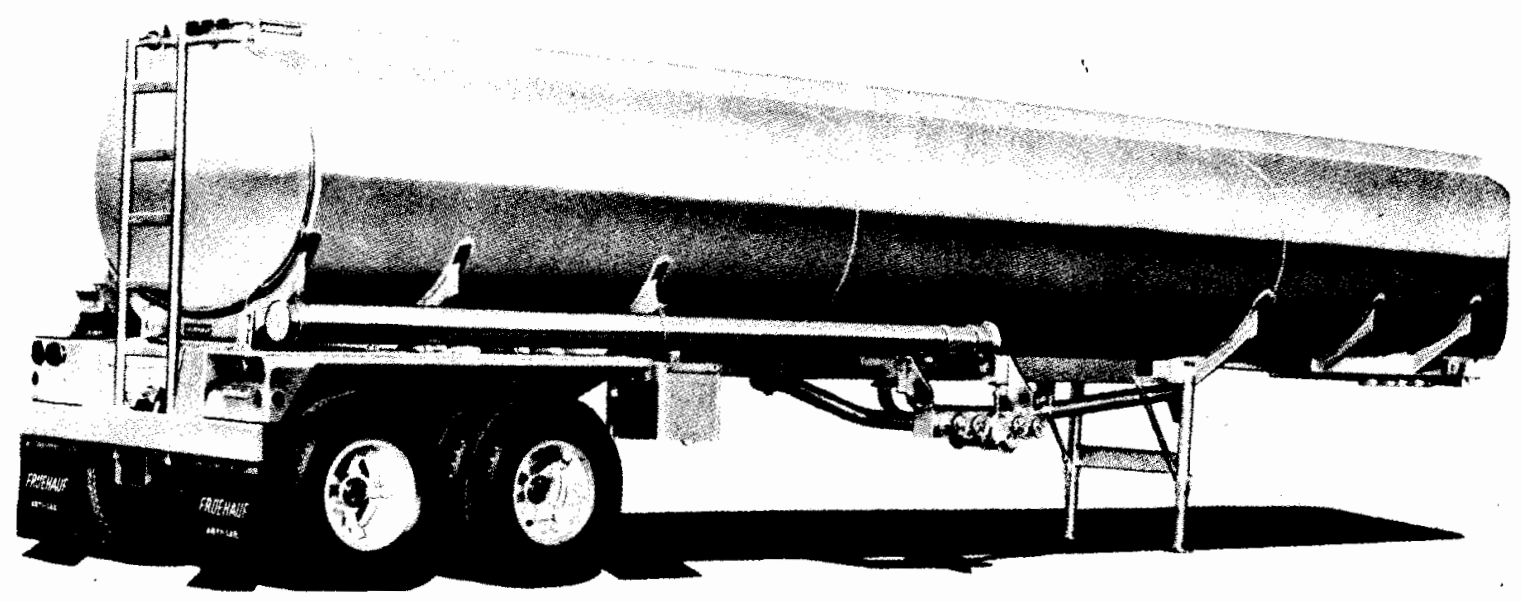

FIGURE A.8. MC-306 Semitrailer Used for Gasoline Shipments in the Eastern U.S. 


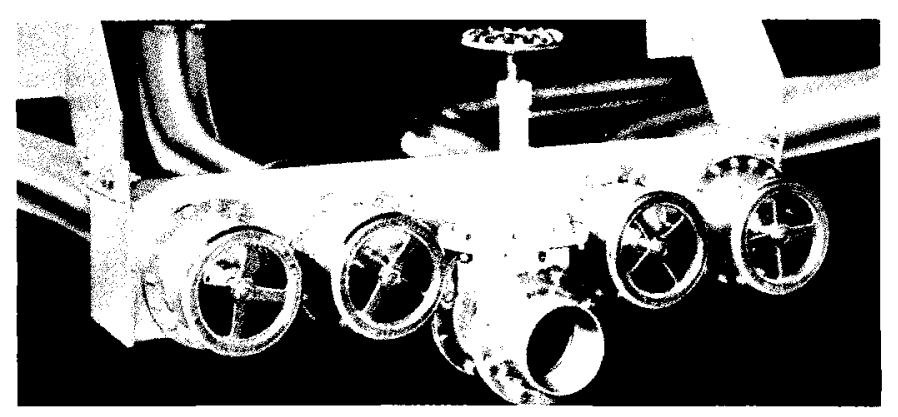

FIGURE A.9. Outlet Valve Assembly for 4-Compartment Semitrailer

gasoline transportation. The results of this survey are summarized here. Gasoline tank trucks are loaded at the bulk distribution terminal to the maximum gross weight allowed by state highway regulations without overweight permits. The maximum gross weight in most states is 73,280 1bs. This gives a full load of about 8,200 gal of gasoline, leaving more than the $2 \%$ minimum tank outage required by DOT. The trucking companies indicated that overfilling of the tanks occurred very infrequently. The trucks are loaded by volume through an accurate metering device. This metering device is used to bill the retailer for the gasoline and to assess transportation changes so mistakes in filling are rare.

Deliveries are generally made to the retail outlet in truckload quantities. Less than truckload deliveries are seldom made because a surcharge is added for this service. The tanks are, therefore, full on the run from the distribution terminal to the retail outlet and empty on the return trip.

The tanks are loaded through the manway cover on top of the truck and unloaded through the outlet valve assembly be gravity feed. The manway cover is opened during offloading to provide an air vent for the tank.

The companies indicated that maintenance of the trucks was routine when they were being used for hauling gasoline. The maintenance items were those associated with the operation of any large truck rig, rather than any necessitated by the nature of the cargo. 


\section{PHYSICAL PROPERTIES OF GASOLINE}

Gasoline is a light end product of the petroleum refining process. It is produced both by direct distillation and by cracking or reforming longer molecules. The chemical composition of gasoline varies with grade, but it is made up generally of hydrocarbons with from 5 to 10 carbon atoms per molecule. Most of the molecules are in the heavier range with 8 to 10 carbons per molecule. The hydrocarbons are a combination of paraffins (saturated hydrocarbons), olefins (unsaturated hydrocarbons) and aromatic and naphthenic rings. Small amounts of tetraethyl lead and other additives are also present.

The chemical makeup and physical properties of gasoline depend on the type of crude oil used as feedstock and also vary with the method used to produce the gasoline. Some physical properties of gasoline are listed in Table B.1. Ranges are given for most of the properties to reflect the variety of gasolines produced.

\section{TABLE B.1. Physical Properties of Gasoline}

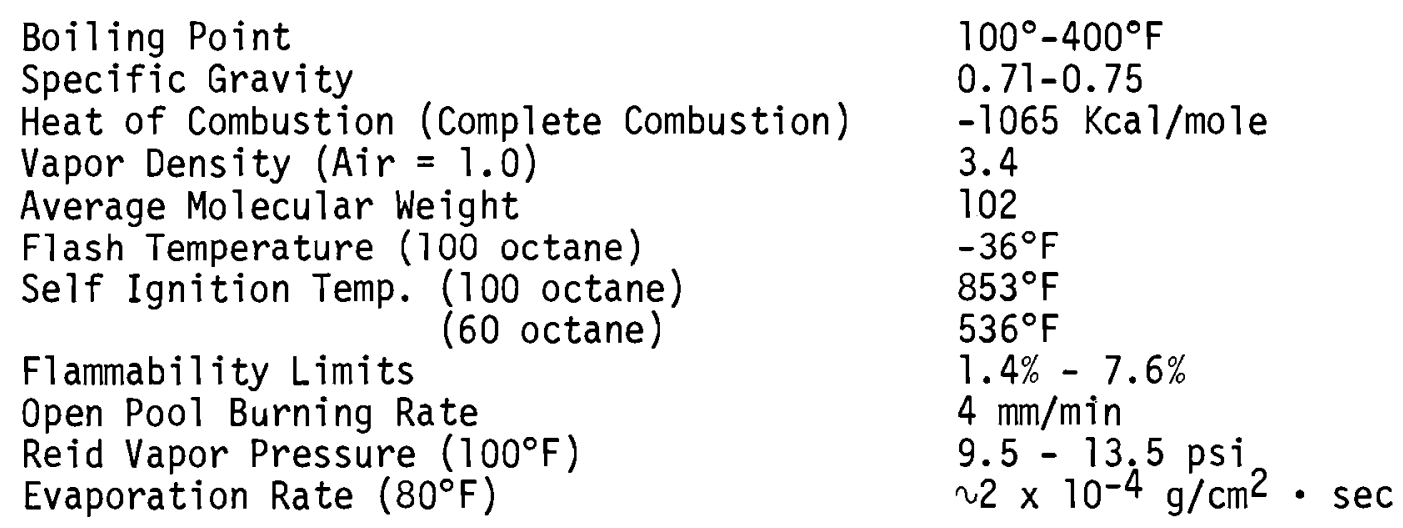

The heat of combustion presented in the table is for ideal complete combustion with carbon dioxide and water vapor as the only combustion 
products. A burning pool of gasoline in open air, such as might be encountered in a transportation accident, would be expected to produce significantly less heat because of incomplete combustion.

The evaporation rate listed in the table is an approximation. The evaporation rate varies with the type of surface on which the spill occurs, the temperature, wind velocity, insolation and other factors. The value listed is what might be expected on a warm sunny day with a moderate wind. It would, therefore, tend to be a maximum value.

The Reid vapor pressure at $100^{\circ} \mathrm{F}$ is 1 isted in the table. The actual vapor pressure at a given temperature can be determined from the nomograph in Figure B.1.
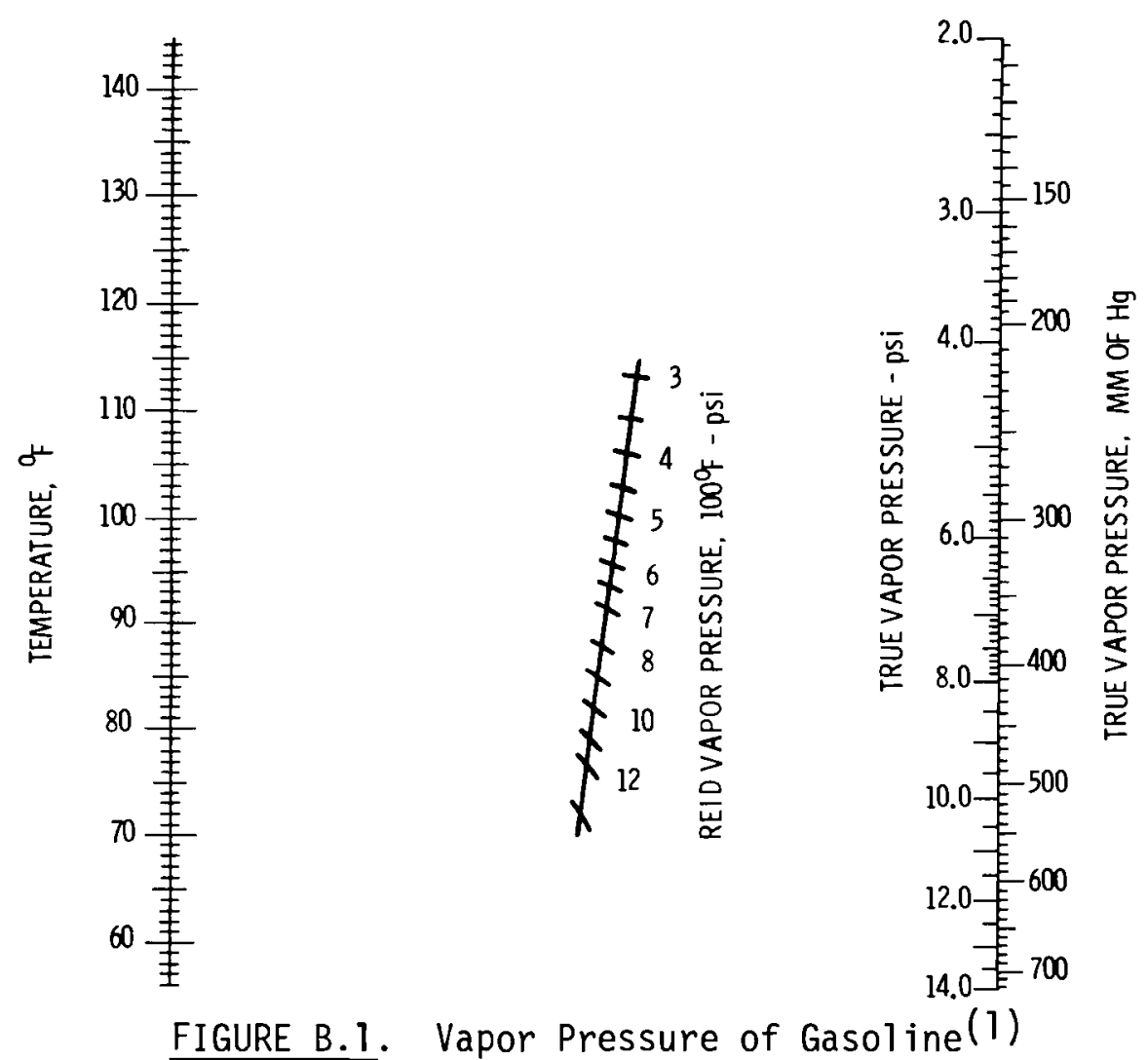

\section{REFERENCE}

1. J. B. Maxwe11, Data Book on Hydrocarbons. Standard 011 Development Company, 1950. 
The atmospheric diffusion of vapors from an evaporating pool of gasoline has been calculated in order to estimate the downwind areas subject to health and flammability hazards. The diffusion has been modeled by the standard Gaussian plume. (1)

$$
c=\frac{\dot{Q}}{u \pi \sigma_{y} \sigma_{z}} \exp \left[-y^{2} / 2 \sigma_{y}{ }^{2}-z^{2} / 2 \sigma_{z}{ }^{2}\right]
$$

where $C$ is the air concentration (quantity per $\mathrm{m}^{3}$ ), $\dot{Q}$ is the source strength (quantity per sec) and $u$ is the windspeed $(\mathrm{m} / \mathrm{sec}) . \sigma_{y}$ and $\sigma_{z}$ are the standard deviations of the plume in the crosswind $(y)$ and vertical directions $(z)$ and are a function of downwind distance $(x)$ and atmospheric stability. The formulas of Briggs ${ }^{(2)}$, shown in Table C.1, were used to determine the atmospheric stability categories and the diffusion parameters. Calculations were made for each stability category using the mean windspeed for that category as determined by one year (1970) of data from the Hanford Meteorology Tower ${ }^{(3)}$. These mean winds are also shown in Table C.1. An additional calculation was also made for the extreme case of Pasquill $F$ and a mean wind of $0.5 \mathrm{~m} / \mathrm{sec}$.

The greatest concentration of gasoline vapors will be found at the downwind edge of the pool. This maximum concentration can be calculated by assuming that the pool has an infinite extent in the crosswind direction. The concentration is given by:

$$
C=\int_{0}^{2 R} \frac{2 E}{\sqrt{2 \pi} u \sigma_{z}} e^{-z^{2} / 2 \sigma_{z}^{2}} d x
$$


TABLE C.1. Formulas for the Determination of $\sigma_{z}$ and $\sigma_{y}$

\section{Stability Categories}

Windspeed
mph

Day

Night

A

$13 \&$

greater

\section{Stability \\ Class}

$\begin{array}{lll}\text { A } & & 0.20 x \\ \text { B } & & 0.12 x \\ C & & 0.08 x(1+.0002 x)^{-1 / 2} \\ D & & 0.06 x(1+.0015 x)^{-1 / 2} \\ \text { E } & & 0.03 x(1+.0003 x)^{-1} \\ \text { F } & & 0.02 x(1+.0003 x)^{-1}\end{array}$

\begin{tabular}{|c|c|}
\hline$\sigma_{y}$ & $\begin{array}{c}\mathrm{u} \\
(\mathrm{mph})\end{array}$ \\
\hline $0.22 x\left(1+10^{-4} x\right)^{-1 / 2}$ & 2.0 \\
\hline $0.16 x\left(1+10^{-4} x\right)^{-1 / 2}$ & 5.3 \\
\hline $0.11 \times\left(1+10^{-4} x\right)^{-1 / 2}$ & 9.7 \\
\hline $0.08 \times\left(1+10^{-4} x\right)^{-1 / 2}$ & 14.1 \\
\hline $0.06 x\left(1+10^{-4} x\right)^{-1 / 2}$ & 5.5 \\
\hline $0.04 x\left(1+10^{-4} x\right)^{-1 / 2}$ & 1.7 \\
\hline
\end{tabular}

where $R$ is the pool radius and $E$ is the evaporation rate (quantity per $\mathrm{m}^{2}$ per sec). Since diffusion plumes are quite narrow in the crosswind direction, this will overestimate $C$ at the center of the downwind edge of the pool by only a few percent. Calculations were made using the physical properties of gasoline listed in Appendix B. The results of these calculations for heights above the pool $1 \mathrm{~m}$ and $10 \mathrm{~cm}$ are presented in Table C.2. Since gasoline vapor is 3.4 times heavier than air, the percentage of vapor is large enough for the gasoline to resist to some extent the vertical mixing of the atmospheric turbulence. To approximately account for this, subsequent calculations were made assuming that the vertical mixing is always similar to that present under stable atmospheric conditions (Pasquill $\mathrm{F}$ stability), while the lateral mixing is controlled by the existing meteorology.

Equation (1) applies to the diffusion from a point source of material. It can be used to calculate the diffusion from a horizontal area source by placing an equivalent point source $\dot{Q}=\pi R^{2} E$, upwind of the pool a distance $x_{0}$ such that:

$$
3 \sigma_{y}\left(x_{0}\right)=R
$$


TABLE C.2. Volume Fraction at Downwind Pool Edge

\begin{tabular}{ccccc} 
Stability & $\begin{array}{c}\text { Mean Wind } \\
(\mathrm{m} / \mathrm{sec})\end{array}$ & \multicolumn{2}{c}{$\begin{array}{c}\text { Volume Fraction } \\
\text { at } 1 \mathrm{~m} \text { (percent) }\end{array}$} & $\begin{array}{c}\text { at } 10 \mathrm{~cm} \\
\text { (percent) }\end{array}$ \\
\cline { 1 - 2 } A & 0.9 & & 0.42 & 0.91 \\
B & 2.4 & 0.20 & 0.51 \\
C & 4.3 & 0.12 & 0.37 \\
D & 6.3 & 0.08 & 0.31 \\
E & 2.5 & 0.15 & 1.2 \\
F & 0.8 & 0.12 & 5.6 \\
F & 0.5 & 0.17 & 8.4
\end{tabular}

This accounts approximately for the initial crosswind extent of the vapor cloud. Using this model, the area subject to a health hazard $(0.05 \%$ and higher) and the maximum downwind distance to this concentration were calculated. The results are presented in Table C.3.

TABLE C.3. Health Hazard (0.05\%)

\begin{tabular}{|c|c|c|c|}
\hline Stability & $\begin{array}{l}\text { Mean Wind } \\
(\mathrm{m} / \mathrm{sec})\end{array}$ & $\begin{array}{c}\text { Downwind } \\
\text { Distance } \\
(\mathrm{m}) \\
\end{array}$ & $\begin{array}{l}\text { Area } \\
\left(\mathrm{m}^{2}\right)\end{array}$ \\
\hline A & 0.9 & 290 & $2.6 \times 10^{4}$ \\
\hline B & 2.4 & 190 & $9.1 \times 10^{3}$ \\
\hline C & 4.3 & 150 & $4.5 \times 10^{3}$ \\
\hline D & 6.3 & 120 & $2.7 \times 10^{3}$ \\
\hline$E$ & 2.5 & 270 & $8.3 \times 10^{3}$ \\
\hline $\mathrm{F}$ & 0.8 & 720 & $3.3 \times 10^{4}$ \\
\hline $\mathrm{F}$ & 0.5 & 960 & $5.3 \times 10^{4}$ \\
\hline
\end{tabular}

The results of the calculations presented in Table C.2 show that the maximum vapor concentrations at the edge of the pool rarely exceed the upper flammability limit (7.6\%) and are usually below the lower flammability limit $(1.4 \%)$. This would imply that the flammable portion of the vapor cloud is 
confined to the immediate vicinity of the pool. There is another consideration, however. The diffusion parameters of Table C.l are applicable to calculation of air concentrations which are time averages over periods on the order of 20 minutes. While this is the proper period for consideration of the health hazard, the flammability problem requires knowledge of the instantaneous concentration. Along the centerline of the diffusion plume, slade ${ }^{(4)}$ and Ramsde11 ${ }^{(5)}$ indicate that the instantaneous vapor concentration may be greater than the average concentration by a factor of 5 to 2 . Using the higher value, the average volume fraction must be less than $0.28 \%$ to assure that the instantaneous fraction is below the lower flammability limit of $1.4 \%$. Table C.4 gives the results of calculations with the model of Equations (C-1) and (C-3) for a concentration of $0.28 \%$.

TABLE C.4. Instantaneous Flammability Hazard (0.28\%)

\begin{tabular}{|c|c|c|c|}
\hline Stability & $\begin{array}{l}\text { Mean Wind } \\
(\mathrm{m} / \mathrm{sec})\end{array}$ & $\begin{array}{c}\text { Downwind } \\
\text { Distance } \\
(\mathrm{m})\end{array}$ & $\begin{array}{l}\text { Area } \\
\left(m^{2}\right)\end{array}$ \\
\hline A & 0.9 & 100 & $4.1 \times 10^{3}$ \\
\hline B & 2.4 & 56 & $1.2 \times 10^{3}$ \\
\hline C & 4.3 & 29 & 350 \\
\hline D & 6.3 & 8 & 39 \\
\hline$E$ & 2.5 & 53 & 620 \\
\hline $\mathrm{F}$ & 0.8 & 200 & $3.7 \times 10^{3}$ \\
\hline $\mathrm{F}$ & 0.5 & 280 & $6.6 \times 10^{3}$ \\
\hline
\end{tabular}

Using Pasquill $\mathrm{F}$ conditions for the vertical dispersion regardless of the meteorological situation is only an approximate attempt to account for the large specific gravity of the gasoline vapors. An even more conservative approach would be to confine the vertical mixing to some small layer next to the ground. Table C.5 shows the downwind distances and areas for the most conservative meteorological situation, Pasquill $\mathrm{F}$ and a mean wind of $0.5 \mathrm{~m} / \mathrm{sec}$, and for layers assumed to be $10 \mathrm{~cm}$ and $1 \mathrm{~m}$ deep. Part of the 
TABLE C.5. Vertical Mixing Confined to a Shallow Layer

\begin{tabular}{|c|c|c|c|c|}
\hline \multirow[b]{2}{*}{$\begin{array}{l}\text { Vapor } \\
\text { Fraction } \\
\text { (percent) }\end{array}$} & \multicolumn{4}{|c|}{ (Lateral Diffusion $=$ Pasquill $\mathrm{F}, \mathrm{u}=0.5 \mathrm{~m} / \mathrm{s}$ ) } \\
\hline & $\begin{array}{l}\text { Distance } \\
(\mathrm{m}) \\
\end{array}$ & $\begin{array}{l}\text { Area } \\
\left(\mathrm{m}^{2}\right)\end{array}$ & $\begin{array}{c}\text { Distance } \\
(\mathrm{m}) \\
\end{array}$ & $\begin{array}{l}\text { Area } \\
\left(\mathrm{m}^{2}\right)\end{array}$ \\
\hline 1.4 & 500 & $1.3 \times 10^{4}$ & $8.3 \times 10^{3}$ & $1.9 \times 10^{7}$ \\
\hline 0.28 & $3.5 \times 10^{3}$ & $4.1 \times 10^{6}$ & $1.1 \times 10^{5}$ & $1.3 \times 10^{8}$ \\
\hline
\end{tabular}

instantaneous concentration fluctuations are contained in the action of the vertical eddies, which have been supplanted in the current assumption, and hence the instantaneous lower flammability limit of $1.4 \%$ is achieved when the average vapor fraction is somewhere between $0.28 \%$ and $1.4 \%$. Table $\mathbf{C . 5}$ shows results for both of these values.

\section{REFERENCES}

1. F. Pasquil1, Atmospheric Diffusion. Halsted Press, New York, p. 352, 1974.

2. G. A. Briggs, Diffusion Estimation for Small Emissions. ATDL Contribution 79, Air Resources Atmospheric Turbulence and Diffusion Laboratory, Oak Ridge, TN, 1973.

3. T. W. Horst, The Resuspension of Material Dispersed by Atmospheric Diffusion from a Point Source. BNWL-1964, Battelle, Pacific Northwest Laboratories, Richland, WA, 1975.

4. D. H. Slade, (ed.), Meteorology and Atomic Energy 1968. U.S. Atomic Energy Commission, Division of Technical Information, Washington, D.C., 1968.

5. J. V. Ramsdell, Jr., and W. T. Hinds, "Concentration Fluctuations and Peak-to-Mean Concentration Ratios in Plumes from a Ground-Leve 1 Continuous Point Source," Atmospheric Environment. 몬 483-495, 1971. 
APPENDIX D

\section{CALCULATION OF GASOLINE TANK TRUCK FAILURE THRESHOLDS}

Failure thresholds were summarized in Section 6.0. This appendix describes the analytical approach and calculations used to derive the failure thresholds. The types of stresses evolving from the accident environment identified as most significant to gasoline tanker failure are:

- impact

- puncture

- abrasion

- thermal

The response of gasoline tanker to each of these stresses is presented below. Failure threshold calculations were performed for both transport systems considered in the study. The tank truck/tank trailer system is used as the reference system to demonstrate the calculational procedures used. In cases where different results are obtained for the tractor/semitrailer system, the results of similar calculations for that system are presented.

\section{1 IMPACT}

Some of the typical surfaces which constitute the impact environment in a tank truck accident include: the roadway; other vehicles; large rocks or structures near the roadway (such as bridge abutments or overpass supports); roadway guardrails; highway signs; and power, lighting or telephone poles. The relatively thin and unprotected skin of the tanks inherently make the tankers vulnerable to failure by impact at moderate relative velocities.

No attempt is made to analyze the response of the tanks under impact conditions to a wide range of impact surface sizes and configurations. Rather, the failure threshold is estimated for impact against a flat surface when the relative velocity between the tank and the object is parallel to the longitudinal axis of the tank or perpendicular to it. 
For the case of direct impact against a flat surface when the relative velocity is in the direction of the longitudinal axis of the tank, it is assumed that the tank is $90 \%$ full and strikes the barrier in an upright position. No allowance has been made for the energy absorbed by the truck cab. The elliptical heads project approximately four inches beyond the shell in the longitudinal direction. The impact initially flattens the elliptical head so that the shell of the tank can be approximated by a long cylinder with a radius of 42 in. and a wall thickness of $0.172 \mathrm{in}$.

Tests at Oak Ridge National Laboratory and Battelle-Columbus Laboratories $(1,2)$ show that thin-walled cylinders compressed between a moving plate and a fixed plate tend to compress (buckle) in a manner similar to the pleats of an accordion. The tests further indicate that the force required to buckle the tube is essentially constant over the entire distance of compression. The "accordion" effect begins at the end where the moving load is applied and continues axially down the shell to a point well past one half of the length, as shown schematically in Figure D. 1 .

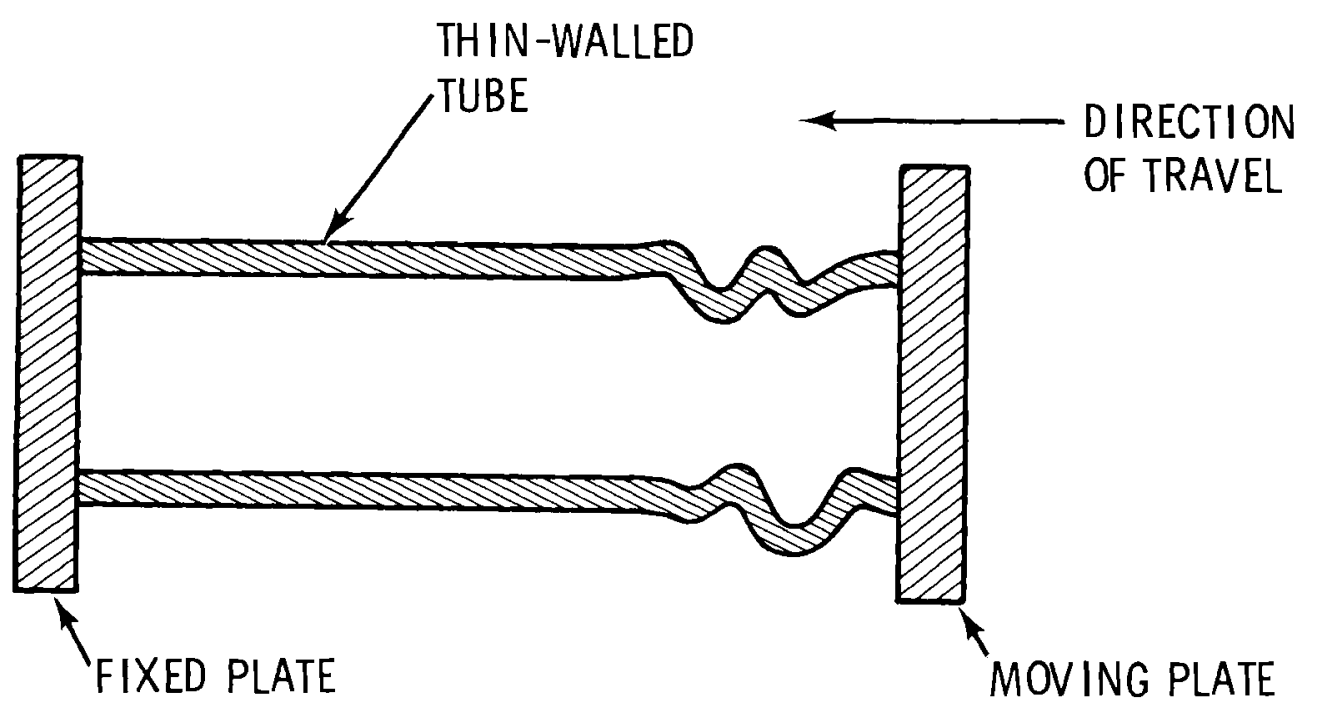

FIGURE D.1. Buckling Mechanism of a Thin-walled Tube Under Axial Compression 
It is assumed that the shell of the tank will buckle in a similar mode when impacting under inertial loading against a flat surface. Observation of gasoline tank vehicles that have been in overturn accidents indicates that the aluminum skin can undergo gross deformation similar to the "accordion" effect without failure. Failure is assumed to occur when the tank volume has been reduced by $10 \%$. At this point, the air and gasoline vapor in the tank will have been expelled through the pressure relief devices and the tank will contain only liquid gasoline. Relief of liquid gasoline through the vents will not keep up with the continued reduction in volume due to buckling of the tank and the ensuing rapid pressure rise will rupture the tank.

The energy associated with buckling the shell of the tank is derived below, using the tank truck/tank trailer as a reference system. Results of the analysis for the tractor/semitrailer system are presented at the end of the analysis. For a thin-walled cylinder under uniform longitudinal compression. (3)

$$
S^{\prime}=\frac{1}{\sqrt{3}} \frac{E}{\sqrt{1-\mu^{2}}} \frac{t}{r}
$$

where:

$$
\begin{aligned}
& S^{\prime}=\text { unit compressive stress } \\
& E=\text { Modulus of Elasticity }=10.3 \times 10^{6} \text { psi } \\
& \mu=\text { Poisson's Ratio }=0.33 \\
& t=\text { thickness }=0.172 \mathrm{in} . \\
& r=\text { radius }=42 \mathrm{in} .
\end{aligned}
$$

The unit compressive stress is found to be 25,800 psi (yield strength $229,000 \mathrm{psi}$ ). Experimental results have shown that the actual stress is only about $40 \%$ of the theoretical value. ${ }^{(3)}$ A stress of 10,300 psi will, therefore, be assumed. The force in the shell is equal to the stress multiplied by the cross sectional area of the shell, or

$$
F=10,300 \pi(84)(0.172)=468,0001 \mathrm{~b}
$$


This force (assumed to be constant) acts through approximately 24 in. to reduce the volume of the tank by 10\% (neglecting the flattening of the elliptical head). The energy to produce a $10 \%$ reduction is the constant force of 468,000 lb acting through $24 \mathrm{in.}$, or $0.937 \times 10^{6} \mathrm{ft}-1 \mathrm{~b}$.

Equating the initial kinetic energy of the tank as the truck is moving to the energy required for $10 \%$ compression:

$$
\begin{aligned}
1 / 2 \mathrm{mv}^{2} & =0.937 \times 10^{6} \mathrm{ft}-1 \mathrm{~b} \\
\mathrm{~m} & =\text { mass of tank plus contents }=\frac{30,000 \mathrm{lb}}{32.2 \mathrm{ft} / \mathrm{sec}^{2}} \\
v & =\text { velocity }(\mathrm{ft} / \mathrm{sec})
\end{aligned}
$$

substituting

$$
v=44.85 \mathrm{ft} / \mathrm{sec} \text { or } 30.6 \mathrm{mph}
$$

A similar analysis for the semitrailer transport configuration (wall thickness $=0.188 \mathrm{in}$, weight $=60,000 \mathrm{lb}$ ) yields a minimum impact failure velocity of $23.6 \mathrm{mph}$.

Impact against flat surfaces perpendicular to the longitudinal axis can occur when the tank vehicle overturns and impacts the roadway or when the trailer "jackknifes" and remains upright and slides into the impacting surface. Nieasurements of a trailer tank that overturned and impacted a flat road surface indicate a reduction of volume of approximately $3 \%$ (see Figure D.2). The energy dissipated during the overturn can be approximated by the distance that the center of mass of the tank drops. This distance is estimated to be $31 / 2 \mathrm{ft}$. Therefore, the energy dissipated is the weight of the tank plus the contents multiplied by the drop distance $(30,000 \mathrm{lb} \times 3.5 \mathrm{ft})$ or $105,000 \mathrm{ft}-1 \mathrm{~b}$.

If it is assumed that an overturn involving 105,000 $\mathrm{ft}-\mathrm{lb}$ of energy causes a reduction in volume of $3 \%$, then approximately $350,000 \mathrm{ft}-1 \mathrm{~b}$ would be required to reduce the volume $10 \%$. Equating the potential energy required for deformation to the kinetic energy of the tank vehicle: 


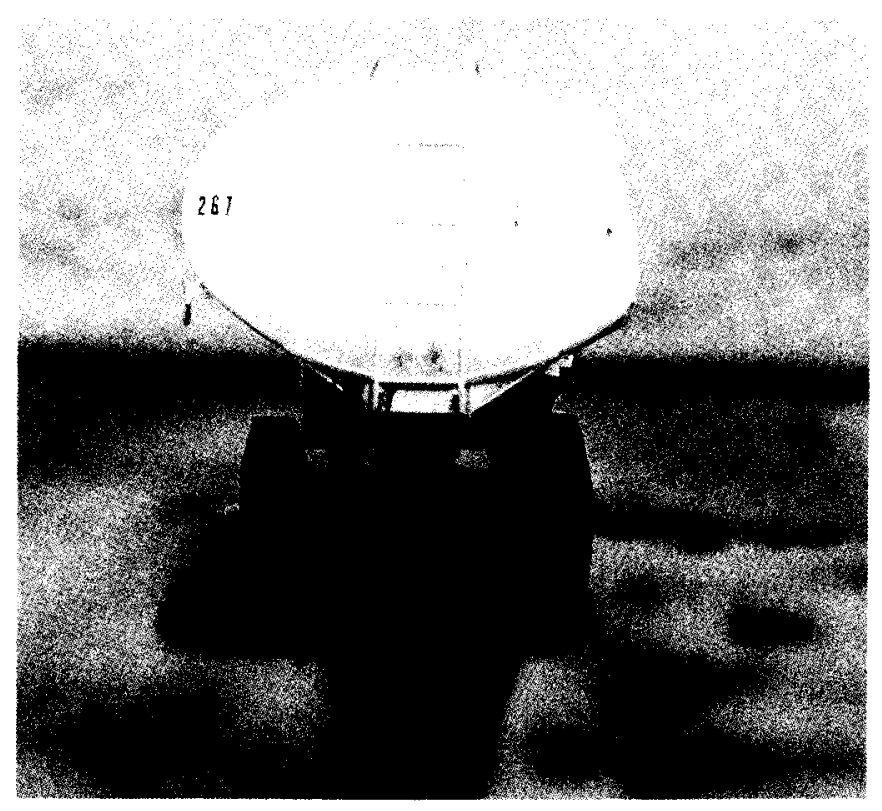

FIGURE D.2. End View of Tank Truck After Overturn Accident

$$
\begin{aligned}
1 / 2 \mathrm{mV}^{2} & =350,000 \mathrm{ft}-1 \mathrm{~b} \\
\mathrm{~V} & =27.4 \mathrm{ft} / \mathrm{sec} \text { or } 18.7 \mathrm{mph} .
\end{aligned}
$$

It was observed that tank vehicles frequently overturn without loss of lading if the forward velocity is low enough to prevent failure by abrasion. The equivalent velocity of the center of mass of the trailer falling through $31 / 2 \mathrm{ft}$ is determined from the expression

$$
V=\sqrt{2 g h}
$$

where:

$$
\begin{aligned}
& V=\text { final velocity }(\mathrm{ft} / \mathrm{sec}) \\
& g=\text { gravitational force }=32.2 \mathrm{ft} / \mathrm{sec}^{2} \\
& \mathrm{~h}=\text { drop height in feet } \\
& V=15.01 \mathrm{ft} / \mathrm{sec} \text { or } 10.2 \mathrm{mph}
\end{aligned}
$$

The failure threshold of the tank overturning and subsequently skidding against a barrier would be relatively lower than a similar situation for an upright tank because the gasoline vapors and air in the headspace would not 
vent. (The headspace would have rotated $90^{\circ}$ with respect to the vents). Compression of the air might produce earlier failure by overpressurization. The reduction in velocity to produce failure was not calculated for the nonventing case. The question is somewhat academic because other factors such as abrasion during the skid would lead to earlier failure.

\section{D.2 PUNCTURE}

Puncture of the relatively thin $(<1 / 4-i n$.$) and unprotected skin of a$ gasoline tank can be expected whenever a fixed probe more than a few inches long contacts the tank during an accident. The approach used to determine the energy required to puncture the skin of the tank is to assume that all probes up to approximately one foot equivalent diameter deflect or dent the skin approximately 6 in. without failure and subsequently fail the skin material surrounding the head of the probe from sheer stresses. The puncture analysis presented below is for a tank truck/tank trailer combination vehicle. The conclusions are virtually the same for the tractor/semitrailer transport system.

The initial force associated with denting the tank skin 6 in. is determined from the expression below, ${ }^{(3)}$ developed for plates of any size or shape, any type of edge support, and a concentrated load at any point:

$$
W_{u}=S_{y}\left(1 / 2 \pi t^{2}\right)
$$

where

$$
\begin{aligned}
W_{u}= & \text { total load in pounds required to collapse plate } \\
t= & \text { thickness of plate }=0.172 \mathrm{in} . \\
\text { Sy }= & \text { yield point of the material }(29,000 \text { psi for tempered } \\
& 500-\text { series aluminum })
\end{aligned}
$$

substituting

$$
W_{u}=29,000(1 / 2 \pi) 0.71^{2}=13321 \mathrm{~b}
$$


The error in using this equation can be up to $30 \%$, ${ }^{(3)}$ so the force to collapse the plate is assumed to be 932 1b. Any probe or projectile contacting the skin of the tank must be capable of exerting a 932-1b force constantly for a distance of 6 in. before the tank skin fails from shear stresses. The energy associated with the denting is $466 \mathrm{ft}-1 \mathrm{~b}$. It is further assumed that any probe impinging against the skin at an angle greater than $45^{\circ}$ with respect to the skin (see Figure 0.3 below) will ultimately puncture the tank if sufficient energy is available.

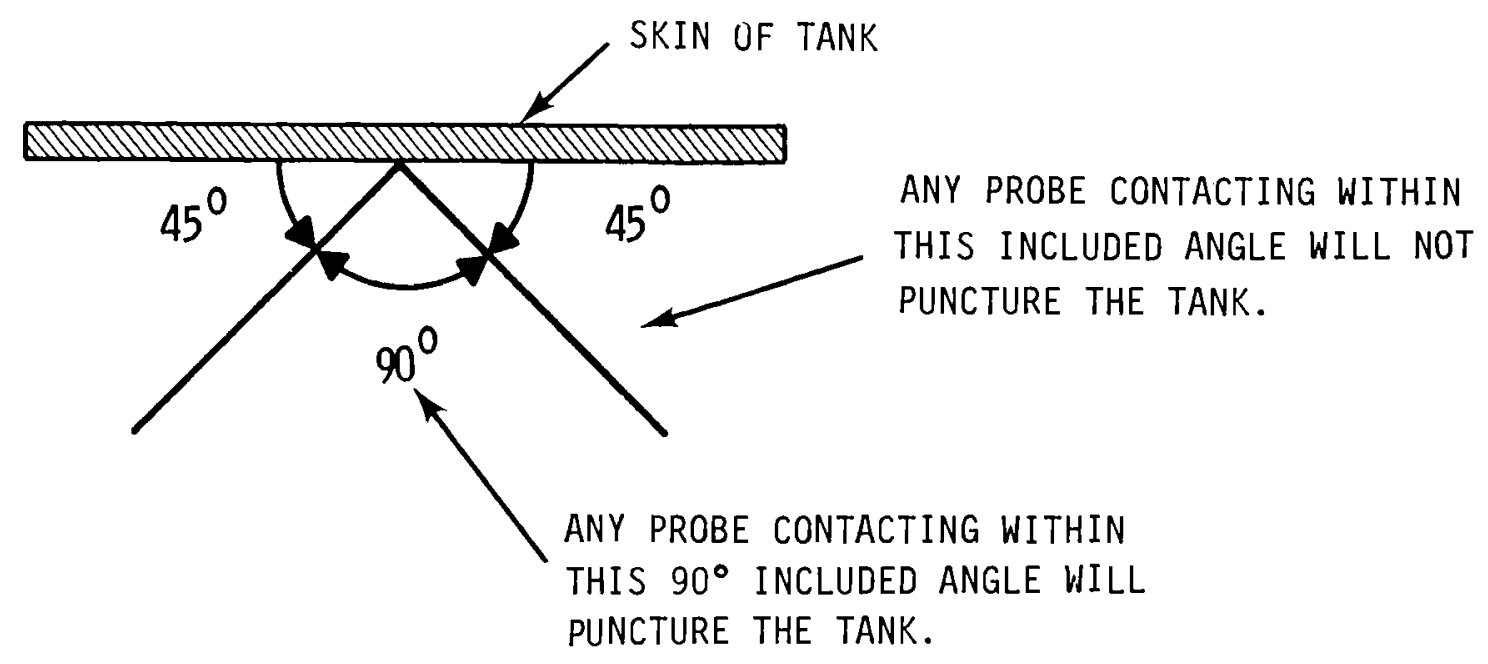

FIGURE D.3. Relative Angle of Contact Required for Puncture

The force required to shear through the tank skin is equal to the perimeter of the probe head multiplied by the thickness of the shell and the shear strength of the aluminum skin (assuming that the strength of the probe material is greater than that of the aluminum skin). For round probes, the shear force required for puncture is:

$$
F=\pi D t S_{S}
$$

where

$$
\begin{aligned}
D & =\text { probe diameter } \\
t & =\text { skin thickness }=0.172 \mathrm{in} . \\
S_{S} & =\text { shear strength of } \text { skin }=17,000 \text { psi }
\end{aligned}
$$


substituting

$$
F=\pi D(0.172) 17,000=9,186 D
$$

A plot of shearing force versus probe diameter is shown in Figure D.4.

The average distance that a probe must travel to effectively shear the material has been found to be approximately $1 / 3$ of the material thickness. (4)

The energy required to shear through the skin of the tank can be expressed as the puncture force acting through a distance of $1 / 3$ of the skin thickness, or,

$$
E=9,1860 \frac{0.172}{3(12)}=440(f t-1 b)
$$

Figure 0.5 shows the shearing energy as a function of probe diameter.

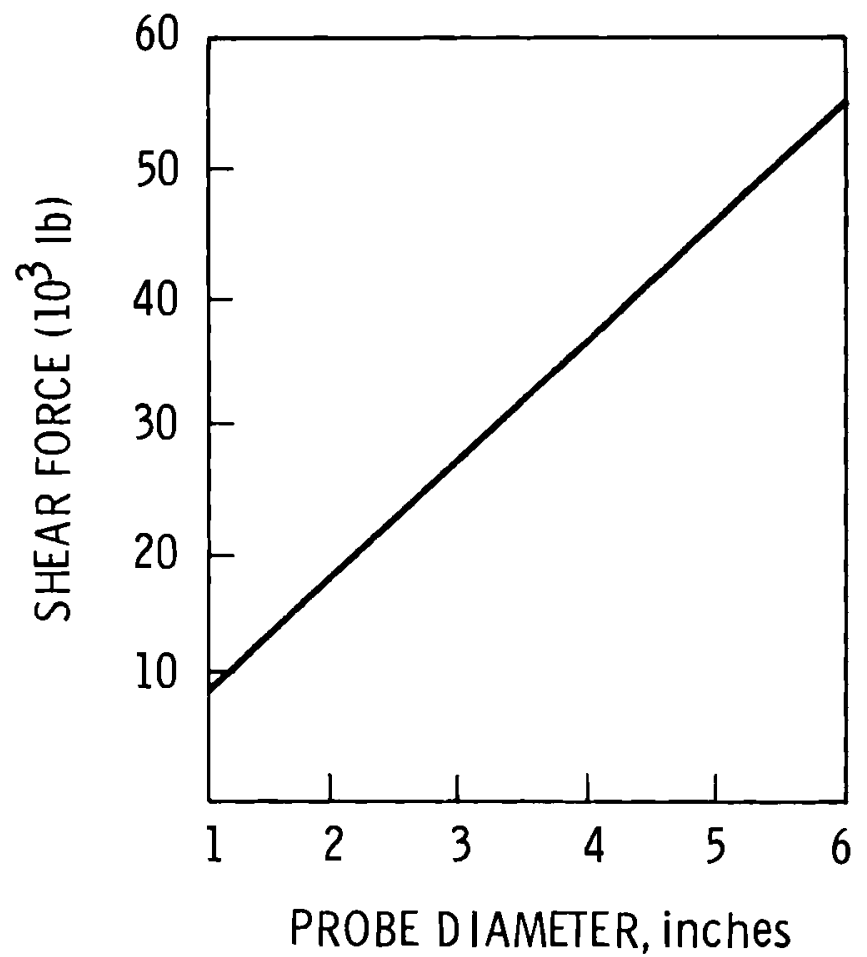

FIGURE D.4. Shear Force Required to Puncture Tank as a Function of Probe Diameter 


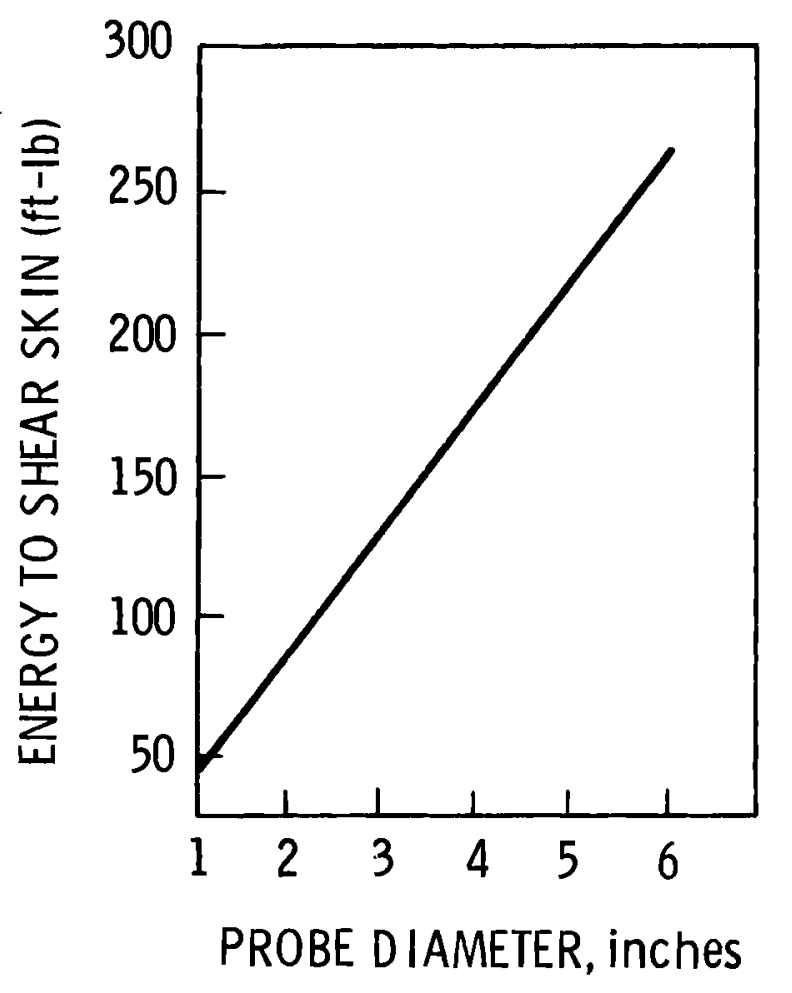

FIGURE D.5. Energy to Shear Tank Skin as a Function of Probe Diameter

The total energy associated with puncture includes the initial denting of the skin and the shearing or

$$
E=[466+44 D] \mathrm{ft}-1 \mathrm{~b}
$$

Figure D.6 shows the total puncture energy as a function of probe diameter.

The minimum energy of $466 \mathrm{ft}-1 \mathrm{~b}$ can be equated to the kinetic energy of the moving tank during transport to determine the minimum velocity for puncture:

$$
\begin{gathered}
1 / 2 \mathrm{mv}^{2}=466 \mathrm{ft}-1 \mathrm{~b} \\
m=\text { mass of tank }=\frac{30,000 \mathrm{lb}}{32.2 \mathrm{ft} / \mathrm{sec}^{2}}
\end{gathered}
$$




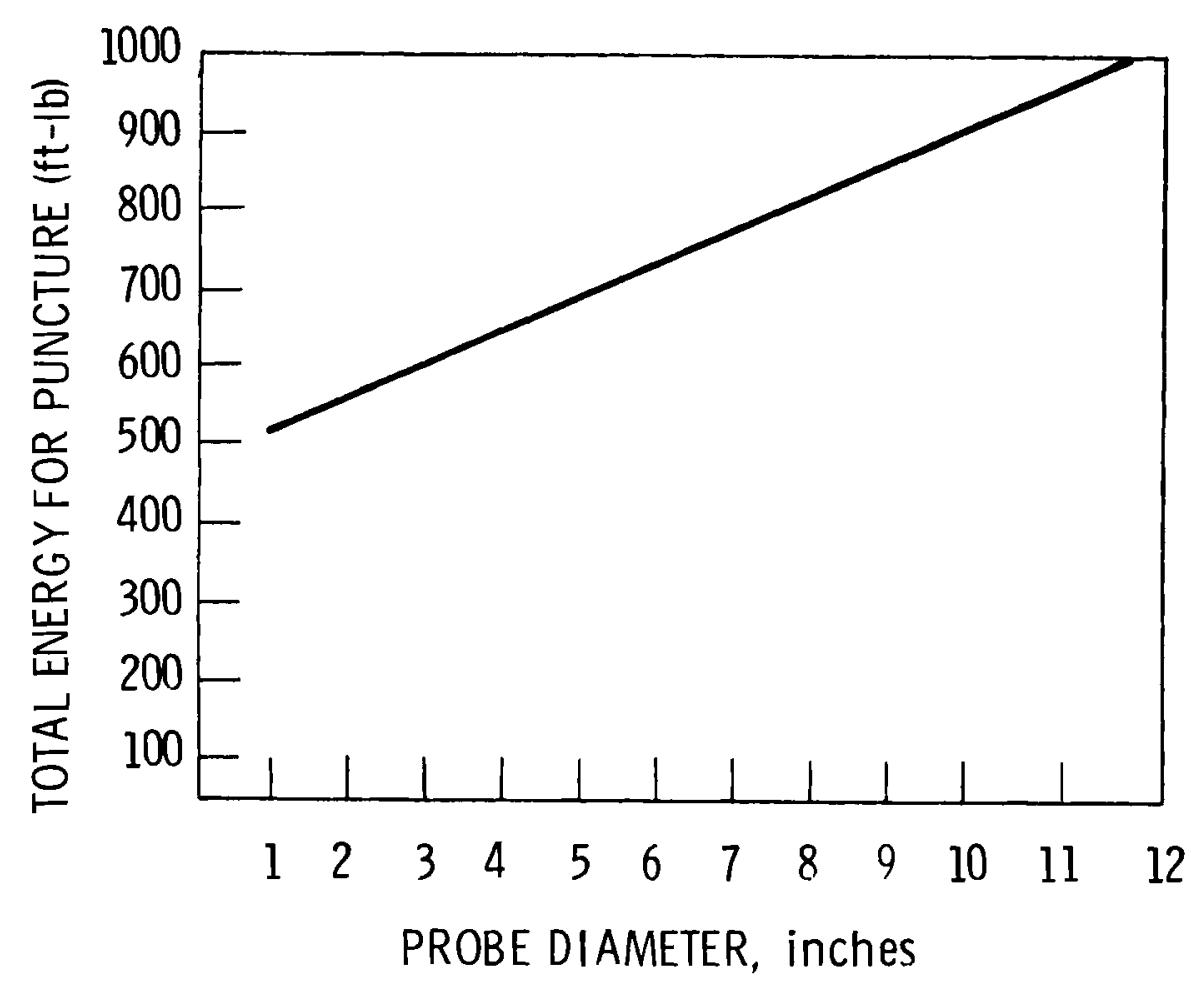

FIGURE D.6. Total Energy for Puncture as a Function of Probe Diameter

$$
v=\operatorname{velocity}(\mathrm{ft} / \mathrm{sec})
$$

substituting

$$
v=1 \mathrm{ft} / \mathrm{sec} \text {, or less than } 1 \mathrm{mph}
$$

Thus, any probe can potentially puncture the tank if its length exceeds 6 in. and the diameter is sufficient to prevent buckling during the process of denting the tank.

The minimum probe diameter can be determined assuming a 6-in. minimum length and circular cross-section. The equation for buckling of a rigidly fixed column is: ${ }^{(5)}$

$$
P_{\text {crit }}=C \frac{E I}{L^{2}}
$$


where

$$
\begin{aligned}
P_{\text {crit }} & =\text { buckling force (minimum) } \\
& =9321 \mathrm{~b} \\
C & =\text { a constant based on configuration } \\
& =2.47 \\
E & =\text { Modulus of Elasticity }=10.3 \times 10^{6} \mathrm{psi} \\
I & =\text { Moment of Inertia }=\frac{\pi d^{4}}{64}\left(\mathrm{in.}^{4}\right) \\
L & =\text { Length }=6 \mathrm{in} .
\end{aligned}
$$

substituting

$$
\mathrm{d}=0.40 \mathrm{in} \text {. }
$$

\section{3 ABRASION}

The predicted failure threshold by pure abrasion of the skin of a gasoline tank was derived from the results of analytical and experimental studies of abrasion rates of snow plow skids on roadways and observations of a tank that had overturned and failed by abrasion. The analysis assumes that the gasoline tanker overturns onto a flat surface. The elliptical tank cross section is typically flattened as shown in Figure D.2. The skin of the tank and baffles are deformed as shown in Figure D.7 and D.8. Primary wear areas in the skin occur at the ends of the tank and at the baffles as indicated in Figure D.7. The primary wear areas support most of the weight of the tank and its contents during skid along the roadway.

Observations of the primary wear areas on a tanker that had overturned indicated that primary wear occurs over an area of approximately $165 \mathrm{in.}{ }^{2}$ in a tank with four baffles (22.5 in. ${ }^{2}$ at each baffle and 37.5 in. ${ }^{2}$ at each end).

The sequential mode of failure by abrasion is assumed to be as follows: 1) the overturned tank is pressurized due to flattening of the shell upon contact with the roadway, and 2) the skin is abraded away during skidding to a thickness where the pressure causes the stress in the skin to rise above the yield stress. 


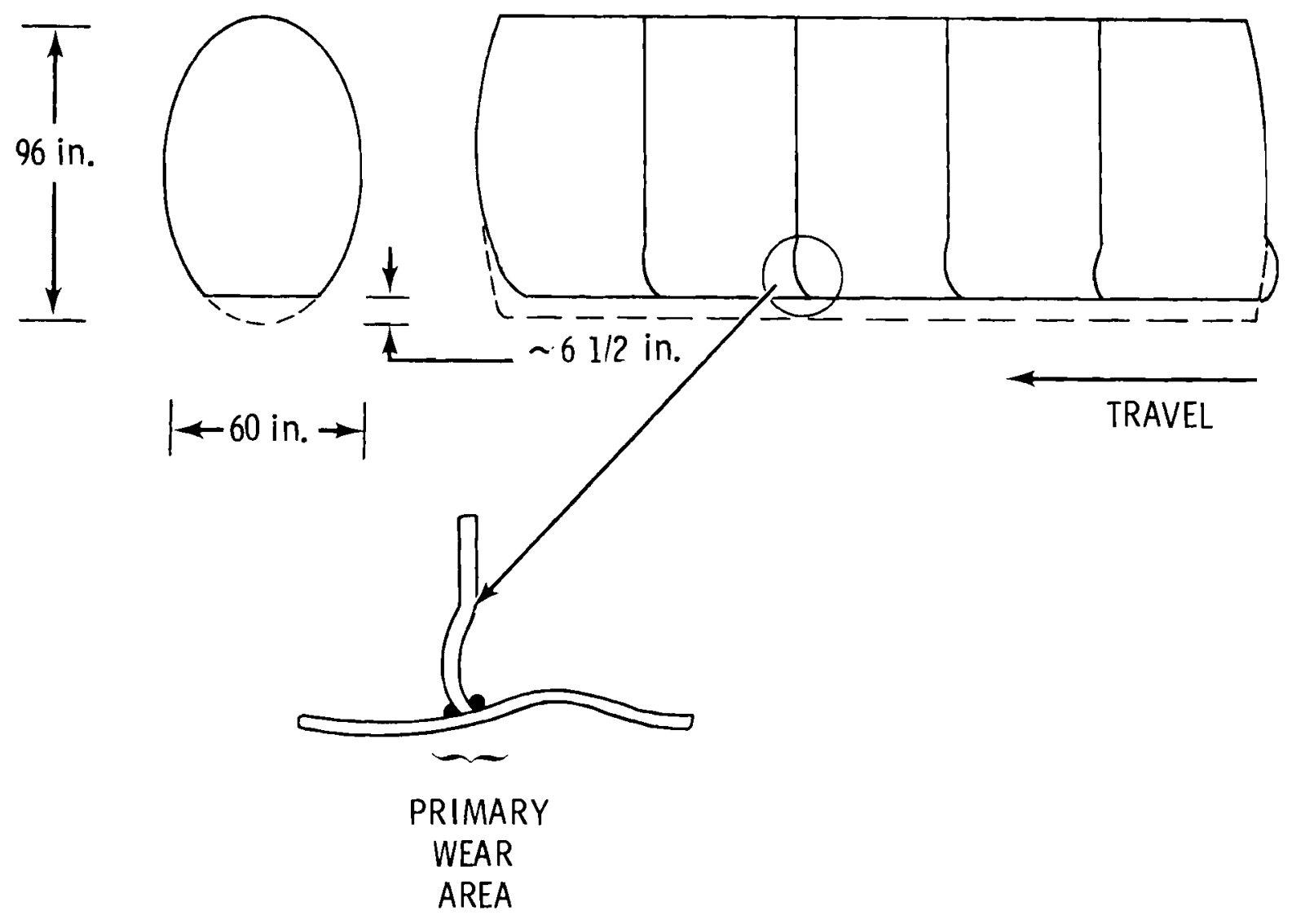

FIGURE D.7. Deformed Configuration of a Tank Overturning with Forward Velocity Showing Primary Wear Areas

Measurement of a tank that had overturned in a highway accident (Figure D.2) showed a reduction in tank volume of approximately $3 \%$. Assuming $10 \%$ of the tank volume is head space and the gasoline is incompressible, the $3 \%$ reduction in overall tank volume would reduce the head space volume by $30 \%$. The increased pressure due to the volume reduction is assumed to remain constant as long as the tank is skidding because the pressure relief devices along the top of the tank have rotated $90^{\circ}$ and are covered with liquid gasoline. Using the relationship $P_{1} V_{1}=P_{2} V_{2}$, where $P$ and $V$ are the headspace pressure and volume, the pressure rise is found to be 6.3 psi due to flattening of the tank. This is well below the manhole cover relief valve setting of $9 \mathrm{psi}$. 


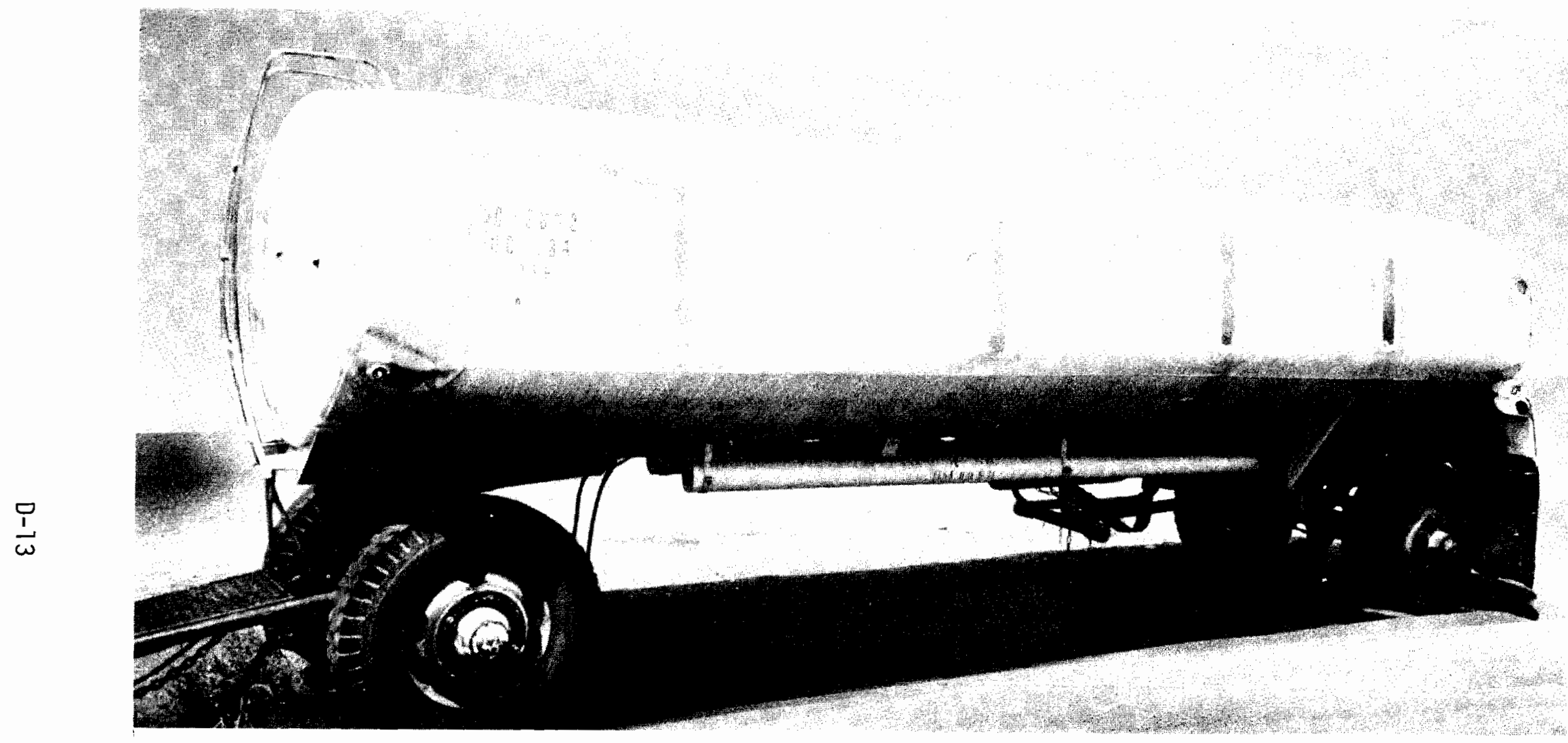

FIGURE D.8. Side View of Tank Truck After Overturn Accident (Note: Failed Sections Around Baffles Have Been Repaired) 
The cross section of the tank is elliptical (96-in. major axis diameter, 60-in. minor axis diameter) and the tank heads are ellipsoidal. Measurement of a tank indicated that the radius at the center of the ellipsoidal head is equal to the diameter of the major axis of the cross section along the longitudinal axis (96 inches). The shell and head are thus designed to fail at the same pressure. The stress in the shell is calculated using the relationship: (3)

$$
\sigma=P \frac{r}{t}
$$

where:

$$
\begin{aligned}
& \sigma=\text { stress, psi } \\
& p=\text { pressure, psi } \\
& r=\text { radius, inches } \\
& t=\text { shell thickness }(0.172 \text { in.) }
\end{aligned}
$$

The longitudinal cross section is assumed to be a circle with a diameter equivalent to the major diameter of the ellipse. The stress in the head is calculated using the relationship: ${ }^{(3)}$

$$
\sigma=P \frac{r}{2 t}
$$

The point of highest stress is assumed to be in the center of the head. The formula is based on the assumption that the head can be treated as a sphere with a radius equivalent to the radius at the center point (96 in.).

The thickness at which the yield stress $(29,000 \mathrm{ps} i)$ in the heads or shell is reached due to the pressure of 6.3 psi caused by overturn is found to be 0.0104 in., using either of the above equations. It is estimated that many factors such as stress risers due to the baffles, local heating and uneven loading will increase this failure thickness by a factor of four. Thus, when the shell or head thickness is reduced to 0.042 in. by abrasion, gross failure results. A total of $0.172-0.042=0.130 \mathrm{in}$. must be abraded away to produce failure. Removal of the skin material by abrasion is based 
on data derived from the wear rates of snow plow skid plates. The volume of material abraded from snow plow skid plates fabricated of steel is estimated to be $232.5 \mathrm{in}^{3}{ }^{3}$ of steel on a $60-\mathrm{in} .{ }^{2}$ contact plate $(1 / 2-\mathrm{in}$. thick by $10-\mathrm{ft}$ long) used on a dry or lightly snow-covered highway. (Information from

G. Thompson, State of Washington Department of Highways, Pasco, WA, June 1976.)

Estimates of wear are based on the parameters shown in Table D.1.

TABLE D. 1. Snow Plow Skid Plate Wear Data

Plow Weight

(1b)

Miles Traveled Before Removal of 232.5 in. of Steel

(3-7/8 in. Thickness)

$\begin{array}{ccc} & & \begin{array}{c}\text { Bituminous } \\ \text { Surface }\end{array} \\ \text { Treatment } & \text { Asphalt-Concrete } & \text { Trea } \\ 2,000 & 150 & 100 \\ 1,000 & 300 & 200\end{array}$

(a) 1/4- to 1.2-in. rock

Converting to a wear rate:

$\frac{\text { Surface }}{\text { Asphalt-Concrete }}$

Asphalt-Concrete

Bituminous Surface Treatment
Wear Rate (inches of wear per foot of travel per pound of contact pressure)

$1.468 \times 10^{-7}$

$2.202 \times 10^{-7}$

Experiments are currently underway at Battelle-Columbus Laboratories to develop methods to predict the wear rate of snow plow skids. On a wear-rate fixture, it was determined that mild steel wears at a rate of $1 \times 10^{-7}$ in. per foot per psi of contact pressure. Aluminum was found to wear at a corresponding rate of $15 \times 10^{-6}$. The test fixture presses the materials against an 80-grit belt moving at approximately $50 \mathrm{mph}$ (information from W. Glaeser, Battelle-Columbus Laboratories, June 1976). Relatively soft aluminum alloys (3003) and harder alloys (6061-T6) were found to wear at essentially 
the same rate. The Battelle-Columbus experimental wear rate data can be correlated to observed snow plow steel skid plate wear rates by using the ratio of wear rates:

$\frac{\text { experimental aluminum wear rate }}{\text { experimental steel wear rate }}=\frac{15 \times 10^{-6}}{1 \times 10^{-7}}=150$

Applying this rate, the predicted wear rate for aluminum used for snow plow skids on road surfaces is:

$\begin{array}{lc}\frac{\text { Surface }}{\text { Asphalt-concrete (A-C) }} & \frac{\text { Wear Rate Range (in./ft-psi) }}{2.202 \times 10^{-5}} \\ \begin{array}{l}\text { Bituminous Surface } \\ \text { Treatment (BST) }\end{array} & 3.303 \times 10^{-5}\end{array}$

The contact pressure on the primary wear areas of a tank with four baffles can be determined by dividing the total normal force (weight of tank plus lading) by the area derived earlier for the primary wear areas (165 in. ${ }^{2}$ ). A loaded tank weighs approximately 30,000 1b. The contact pressure is, therefore, 30,000 1b/165 in. $^{2}$, or $181.8 \mathrm{psi}$.

To determine skid distance to remove the previously determined 0.134 in. skin thickness, the skin thickness is divided by the appropriate wear rate multiplied by the contact pressure (181.8 psi). The following skid distances result:

\section{Surface Skid Distance Range (ft)}

\begin{tabular}{ll}
\hline Asphalt-concrete & 35.4 \\
$\begin{array}{l}\text { Bituminous Surface } \\
\text { Treatment }\end{array}$ & 21.6
\end{tabular}

The initial velocity, $V_{0}$ that will produce a given skid distance (assuming constant deceleration) is determined by the following relationship: (4)

$$
v_{0}=\sqrt{f^{2}-2 a S}
$$


where

$$
\begin{aligned}
V_{f} & =\text { final velocity }=0 \\
a & =\text { deceleration }=\frac{F}{M}
\end{aligned}
$$

where

$$
\begin{aligned}
F & =\text { retarding force }=\mathrm{fW} \\
f & =\text { coefficient of friction }=0.45 \\
W & =\text { lading and tank weight }=30,000 \mathrm{lb} \\
F & =(0.45)(30,000) \\
& =13,5001 \mathrm{~b} \\
M & =\text { Mass }=\mathrm{W} / \mathrm{g} \\
& =\frac{30,000 \mathrm{lb}}{32.2 \mathrm{ft} / \mathrm{sec}^{2}}=932 \mathrm{slugs} \\
& =932.841 \mathrm{~b} \mathrm{sec} / \mathrm{ft} \\
a & =\frac{13,5001 \mathrm{~b}}{932.841 \mathrm{~b} \mathrm{sec} 2 / \mathrm{ft}}=-14.5 \mathrm{ft} / \mathrm{sec}^{2}
\end{aligned}
$$

Substituting into the above relationships yields:

$$
v_{0}=5.4 \sqrt{5}
$$

Substituting the previously determined skid distance to wear through a 0.134-in. thick skin, the initial velocities are as follows:

Surface

Initial Velocity Range to Wear

$\frac{\text { Surface }}{\text { Asphalt-concrete }}$
Through 0.134 Skin Thickness

BST

$32 \mathrm{mph}$

$25 \mathrm{mph}$

Nonuniform deformation (buckling) of the skin in the primary wear area plus the hydrostatic pressure of the loading and transient forces not accounted for will tend to aggrevate wear and reduce the skid distance ranges by an estimated $20 \%$.

Corresponding initial velocities become: 


\section{Surface}

Asphalt-concrete

Bituminous Surface

Treatment
Initial Velocity Range to Wear

Through $0.108 \mathrm{in.}$ Skin Thickness

$26 \mathrm{mph}$

$20 \mathrm{mph}$

Velocity ranges for failure by abrasion on softer dirt and loose gravel surfaces normally encountered on the shoulders of roadways were determined to be greater than the maximum speeds encountered in truck accidents. Abrasive failure velocities for the tractor/semitrailer transport system are essentially the same. The thicker tank skin tends to increase the velocity, while the greater tank weight decreases the initial velocity required for failure. These two effects are approximately equal in magnitude.

\section{D.4 THERMAL}

Gasoline tanks can and do burn violently, but the violent burning is normally restricted to cases where the source of fuel initially comes from the tank itself after failure by other modes such as puncture. An intact gasoline tanker would normally be expected to survive an extended external fire (calculated below) if the tank starts in a near full condition and the pressure relief devices are functioning.

The primary means of thermal failure identified is the case where the gasoline level is lowered within the tank, permitting the high temperature external heat source to impinge directly on portions of the tank not backed up by liquid gasoline. The situation is similar to that of an aluminum pan on a stove overheating. The aluminum pan is prevented from overheating as long as the bottom has a water covering. Once the water has vaporized, the pan rapidly overheats.

The calculations presented below are for the truck tank/tank trailer transport system. Similar results are obtained for the tractor/semitrailer system. The calculations are based on the assumption that failure occurs when $1 / 2$ of the tank contents have vaporized. The following additional assumptions are made: 
1. Latent heat of vaporization of gasoline is $133-145 \mathrm{Btu} / 1 \mathrm{~b}^{(6)}$ at one atmosphere.

2. The tank contains 4,500 gal (28,000 1bs) of gasoline.

3. The thermal input from an external hydrocarbon fire is $17,000 \mathrm{Btu} / \mathrm{hr}^{-} \mathrm{ft}^{2}$. (7)

4. The surface area of the tank exposed to the fire is about $120 \mathrm{ft}^{2}$. The thermal input is:

$$
120 \mathrm{ft}^{2}\left(17,000 \frac{\mathrm{Btu}}{\mathrm{hr}-\mathrm{ft}^{2}}\right)=204 \times 10^{6} \mathrm{Btu} / \mathrm{hr}
$$

One half of the 28,000 1b of gasoline must vaporize and be released out the vent before failure. Multiplying the weight of gasoline vaporized by the latent heat of vaporization:

$$
14,0001 \mathrm{~b}\left(139 \frac{\mathrm{Btu}}{1 \mathrm{~b}}\right)=1.96 \times 10^{6} \mathrm{Btu}
$$

The time to failure can be found by dividing the total therma 1 input required by the rate of thermal input:

$$
\frac{1.96 \times 10^{6} \mathrm{Btu}}{2.04 \times 10^{6} \mathrm{Btu} / \mathrm{hr}}=0.96 \mathrm{hr}
$$

Exposure of a greater tank surface area would, of course, result in a shorter time to failure. In most cases, it would be expected that less surface area would be exposed to the fire. The melting point of aluminum is approximately $1220^{\circ} \mathrm{F}$. Very rapid failure of the tank (within a few minutes) would be expected if a source of external heat above $\sim 7500^{\circ} \mathrm{F}$ were to impinge directly against a portion of the tank not backed up with gasoline.

An unlikely, but conceivable, mode of failure due to thermal input would occur if all three pressure relief devices failed simultaneously. The burst 
pressure can be approximated by considering the tank as a cylindrical shell with a diameter of $96 \mathrm{in.}$ and wall thickness of $0.172 \mathrm{in}$. The burst pressure can be found from the expression: ${ }^{(3)}$

$$
P u=2 S u \frac{b-a}{b+a}
$$

where

$$
\begin{aligned}
P u & =\text { burst pressure } \\
\text { Su } & =\text { ultimate strength } \approx 38,000 \text { psi } \\
b & =\text { outer radius }=48 \mathrm{in} . \\
a & =\text { inner radius }=47.83 \mathrm{in} .
\end{aligned}
$$

substituting

$$
\mathrm{Pu}=136.4 \mathrm{psi}
$$

The ellipsoidal heads on the tank do not behave as a sphere, and the tank baffles tend to concentrate stress in the shel1. The burst pressure has been reduced by an estimated factor of 3 to account for this fact. The tank would then be assumed to burst at $45 \mathrm{psi}$. A further lowering of the assumed burst pressure to $30 \mathrm{psi}$ is included to account for reduced material strength due to elevated temperature.

To find time to failure, the thermal input calculated earlier is used $\left(2.04 \times 10^{6} \mathrm{Btu} / \mathrm{hr}\right)$. The tank will fail when the vapor pressure reaches $30 \mathrm{psi}$. The temperature that produces a vapor pressure rise of $30 \mathrm{psi}$ is estimated from Figure B. 1 as $178^{\circ} \mathrm{F}$.

Gasoline has a specific heat of approximately $0.5 \mathrm{Btu} / 1 \mathrm{~b}^{\circ} \mathrm{F}$. The thermal input to raise the temperature of the 28,000 lbs of gasoline to $178^{\circ} \mathrm{F}$ is

$$
(28,000 \mathrm{1b})\left(0.5 \frac{\mathrm{Btu}}{1 \mathrm{~b}^{\circ} \mathrm{F}}\right)=14,000 \mathrm{Btu} /{ }^{\circ} \mathrm{F}
$$

If the gasoline is assumed to start at a temperature of $78^{\circ} \mathrm{F}$, the heat energy required to reach $178^{\circ} \mathrm{F}$ will be $1.395 \times 10^{6} \mathrm{Btu}$. 
Dividing the total heat required by the heat flux

$$
\frac{1.395 \times 10^{6} \mathrm{Btu}}{2.04 \times 10^{6} \mathrm{Btu} / \mathrm{hr}}=0.68 \mathrm{hr} \text { to burst }
$$

Thermal failure of the gasket material on the tank manway cover or outlet valve in a fire is also a potential release mechanism. The gasket materials used on the tank are either cork or elastomer ("0"-ring types). A study of thermal degradation of cork gaskets in a fire indicates that the material maintains its sealing properties for a relatively long period of time. The failure mechanism is slow, but progressive charring when the cork is exposed to surfaces heated to about $800^{\circ} \mathrm{C}$. Based on the information in Reference 8 , it is estimated that cork and "0"-ring gaskets will lose their liquid retention properties after a 20 -min exposure to an $1850^{\circ} \mathrm{F}$ heat source.

Releases from the tank can also occur when the tank overturns and solar insolation causes a pressure rise that opens the relief valves. The maximum solar input to the tank area 12-ft wide by $20-\mathrm{ft}$ long is absorbing this solar energy, the thermal input to the tank is about $52,800 \mathrm{Btu} / \mathrm{hr}$.

Using the relationship

$$
q=C_{p} \Delta T
$$

where

$$
\begin{aligned}
\mathrm{q} & =\text { thermal input }=52,800 \mathrm{Btu} / \mathrm{hr} \\
\mathrm{C}_{\mathrm{p}} & =\text { specific heat of gasoline }=0.5 \mathrm{Btu} / 1 \mathrm{~b} \\
\Delta \mathrm{T} & =\text { temperature } \text { rise in }{ }^{\circ} \mathrm{F} / \mathrm{hr} \\
\Delta T & =\frac{\mathrm{q}}{\mathrm{C}_{\mathrm{p}}}=105,600^{\circ} \mathrm{Flb} / \mathrm{hr} \div 28,0001 \mathrm{~b} \text { gasol ine } / \text { tank } \\
\Delta \mathrm{T} & =3.77^{\circ} \mathrm{F} / \mathrm{hr} .
\end{aligned}
$$




\section{REFERENCES}

1. J. H. Evans, "Experimental Study of the Stress-Strain Properties of Cask Materials Under Specified Inpact Conditions" in Proceedings of the Fourth International Symposium on Packaging and Transportation of Radioactive Materials. CONF-740901, Miami Beach, FL, pp. 232-243, September 1974.

2. E. C. Lusk and R. F. Burian, "Impact Protection for Radioactive Material Shipping Containers" in Proceedings of the Fourth International Symposium on Packaging and Transportation of Radioactive Materials. CONF-740901, Miami Beach, FL, pp. 438-448, September 1974.

3. R. J. Roark, Formulas for Stress and Strain. McGraw-Hi11, New York, NY, 1965.

4. E. Oberg, F. Jones and H. Horton, Machinery's Handbook, 20th Edition. Industrial Press, Inc., New York, NY, 1975.

5. S. H. Crandall and N. C. Dah1, ed, An Introduction to the Mechanics of Solids. McGraw-Hill, New York, 1959.

6. T. Baumeister and L. S. Marks, ed, Standard Handbook for Mechanical Engineers 7th Edition. McGraw-Hil1, New York, NY, 1967.

7. F. E. Adcock, ATMX-600 Railcars for Radioactive Waste Shipments. RFP-1411, The Dow Chemical Company, Rocky Flats Division, Golden, C0, p. 31 , January 1979.

8. F. E. Dixon, "A New Thermal Shield for (Type B) Transportation Packages." Reprinted from Engineering Review, September 1967. 


\section{APPENDIX E}

\section{CHARACTERISTICS OF GASOLINE FIRES}

Fire is the most important mechanism which produces property damage or personal injuries following a release of gasoline from a tank truck accident. Property damage is not assessed in this report. Injuries and deaths may be produced by direct exposure to the radiant energy from the gasoline fire, by secondary fires started in buildings near the spill site or by inhalation of smoke from either of these fires. These mechanisms have been modeled using techniques available in the literature.

For purposes of the fire model, the spilled gasoline is assumed to collect in a pool 1/2-in. in depth. This is an average value for land surfaces. (1) Pool depths on asphalt or concrete would probably be less than this value, while depths in soil would be greater. For an assumed spill volume of 3000 gal, this produces a pool with a radius of about $55 \mathrm{ft}$.

It has been estimated from available accident statistics that $24 \%$ of spills from tank trucks carrying flammable liquids result in fires. ${ }^{(2)}$ The properties of gasoline fires are not well known. The energy radiated from the fire is the most important characteristic for predicting injuries and deaths or the possibility of igniting secondary fires. The radiant heat flux is dependent on the size of the pool, the substrate on which the spil1 occurred, the height above the pool, the distance from the pool and the direction of windspeed. A conservative estimate of the safe separation distance as a function of pool size and flame angle is shown in Figure E.l. Flame angle can be predicted from windspeed using Figure E.2. Molecular weight divided by boiling temperature $\left(M / T_{b}\right)$ for gasoline is about 0.25 . The safe separation distance is based on a radiant flux of $10,000 \mathrm{Btu} / \mathrm{hr} / \mathrm{ft}^{2}$ $\left(0.75 \mathrm{cal} / \mathrm{cm}^{2} / \mathrm{sec}\right)$. As shown in Figure E.3, exposure to this heat flux for longer than about $25 \mathrm{sec}$. will cause third degree burns on uncovered skin. This figure assumes no attempts by the exposed individual to avoid the intense heat. If an individual simply turns to ward off the effects of the heat, the effective irradiance could be reduced by a factor of $1 / \pi .{ }^{(3)}$ The time required to produce severe burns is increased substantially under these conditions. 

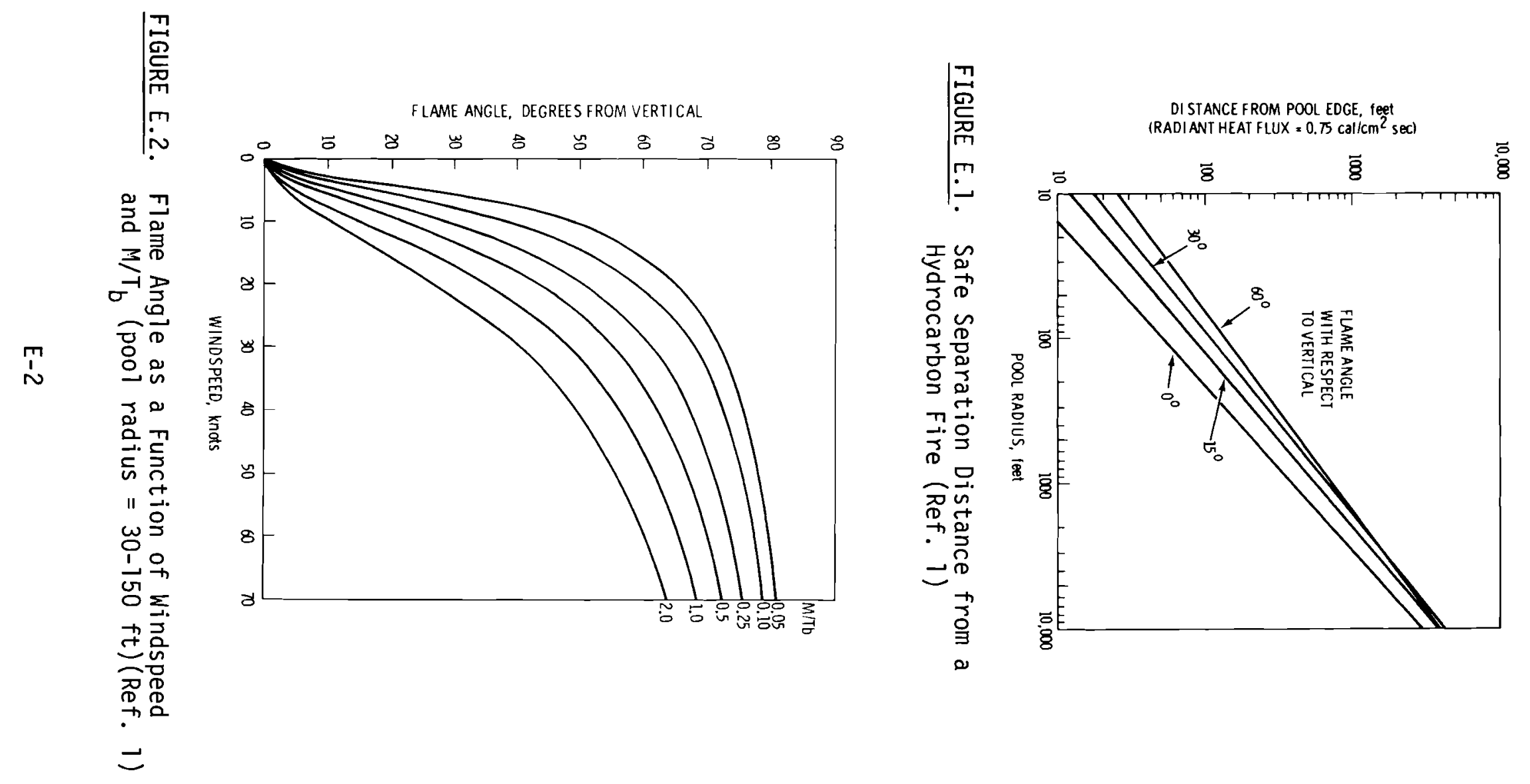


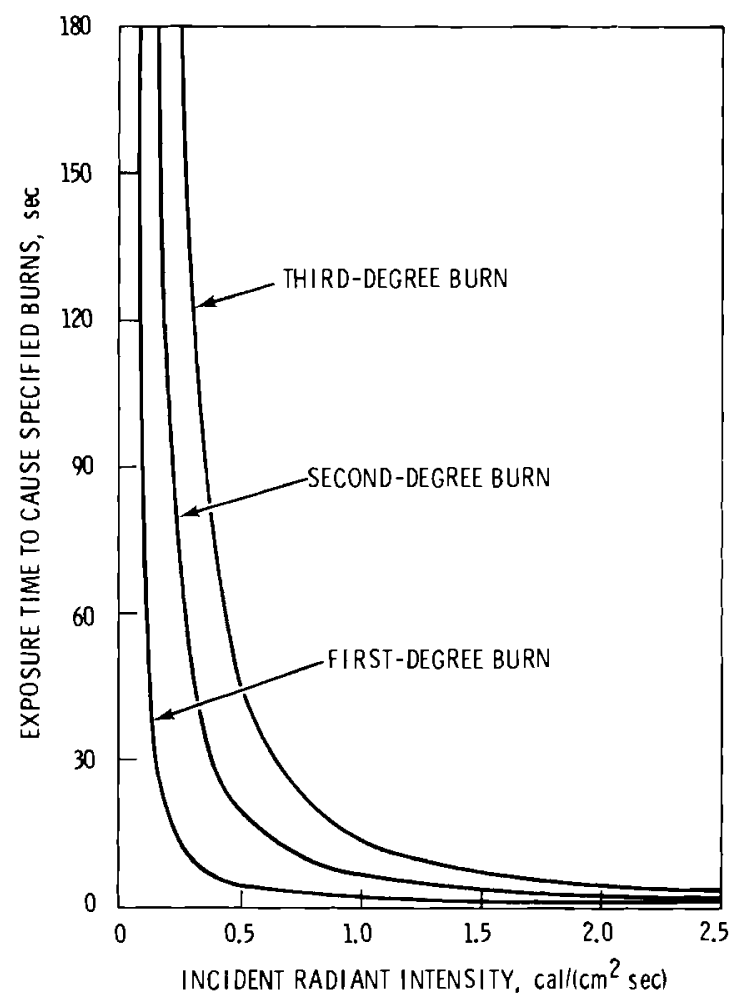

FIGURE E.3. Radiant Exposures to Cause Various Flesh Burns (Ref. 3)

At a windspeed of 10 knots, Figure E.1 predicts a safe separation distance of about $55 \mathrm{ft}$ from the downward edge of a burning pool of gasoline $110 \mathrm{ft}$ in diameter. This value may be conservative because Figure E.l was derived assuming a clean flame. In actuality, heavy hydrocarbons like gasoline result in very smokey fires. The presence of smoke in the fire reduces the emissivity of the flame, resulting in smaller radiant heat fluxes. Actual measurements of heat fluxes from gasoline fires are not available, but measurements have been made for JP5 fires. ${ }^{(4)}$ JP5 is a heavy hydrocarbon with combustion properties similar to those of gasoline. The results of a representative set of measurements are presented in Figure E.4. The radiant heat fluxes were measured $10 \mathrm{ft}$ from the crosswind edge of a flaming $10-\mathrm{ft}$ diameter pool of JP5 on a water substrate. The heat flux measured $5 \mathrm{ft}$ above the ground was about $3600 \mathrm{Btu} / \mathrm{hr} / \mathrm{ft}^{2}$. This can be compared with the no wind case in Figure E.1, which can be extrapolated to give a safe separation distance $\left(10,000 \mathrm{Btu} / \mathrm{hr} / \mathrm{ft}^{2}\right)$ of about $2 \mathrm{ft}$ for a $10 \mathrm{ft}$. diameter pool. Figure E.5 

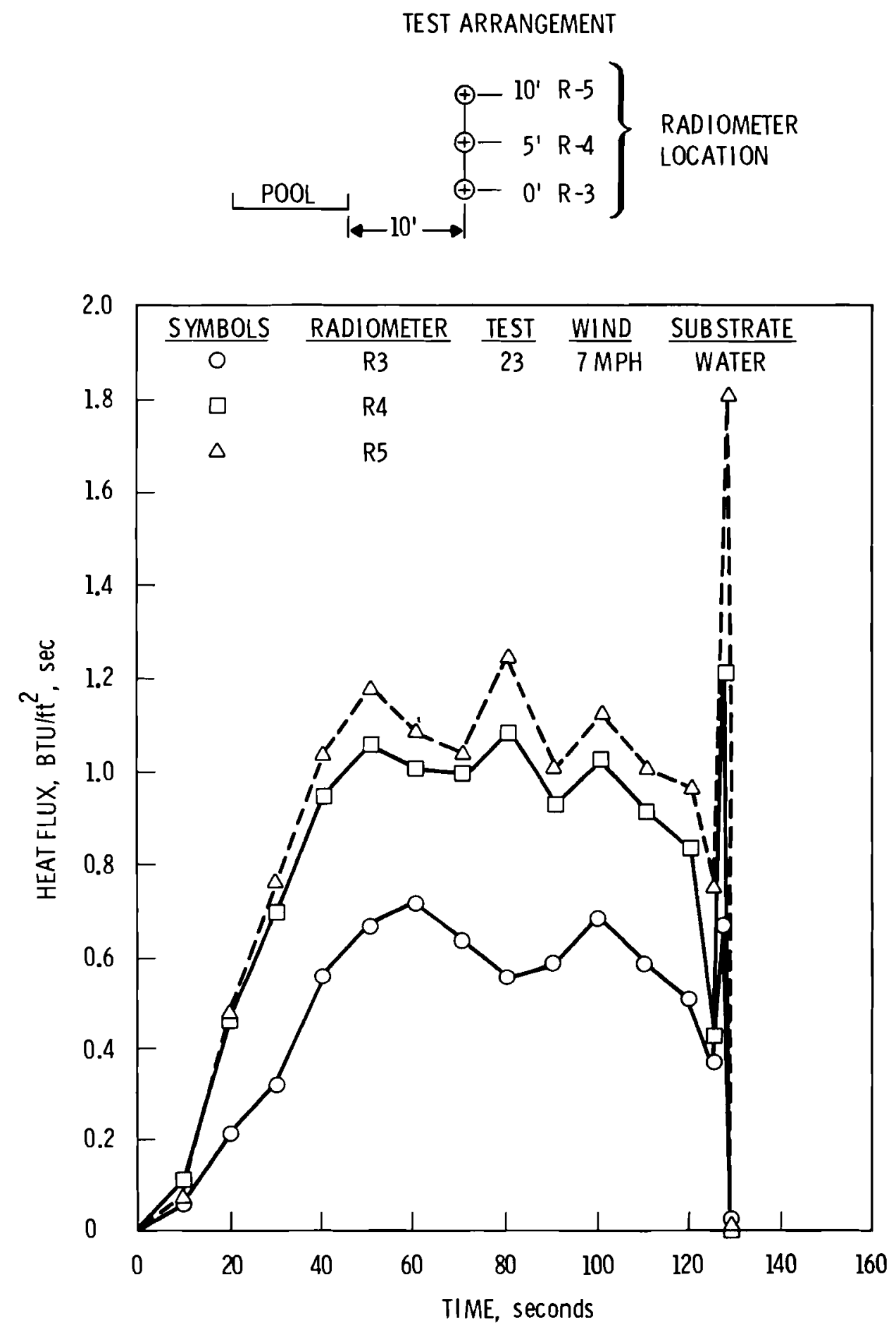

FIGURE E.4. Radiation from 10-ft Diameter JP5 Fires versus Radiometer Level Above Ground (Ref. 4) 


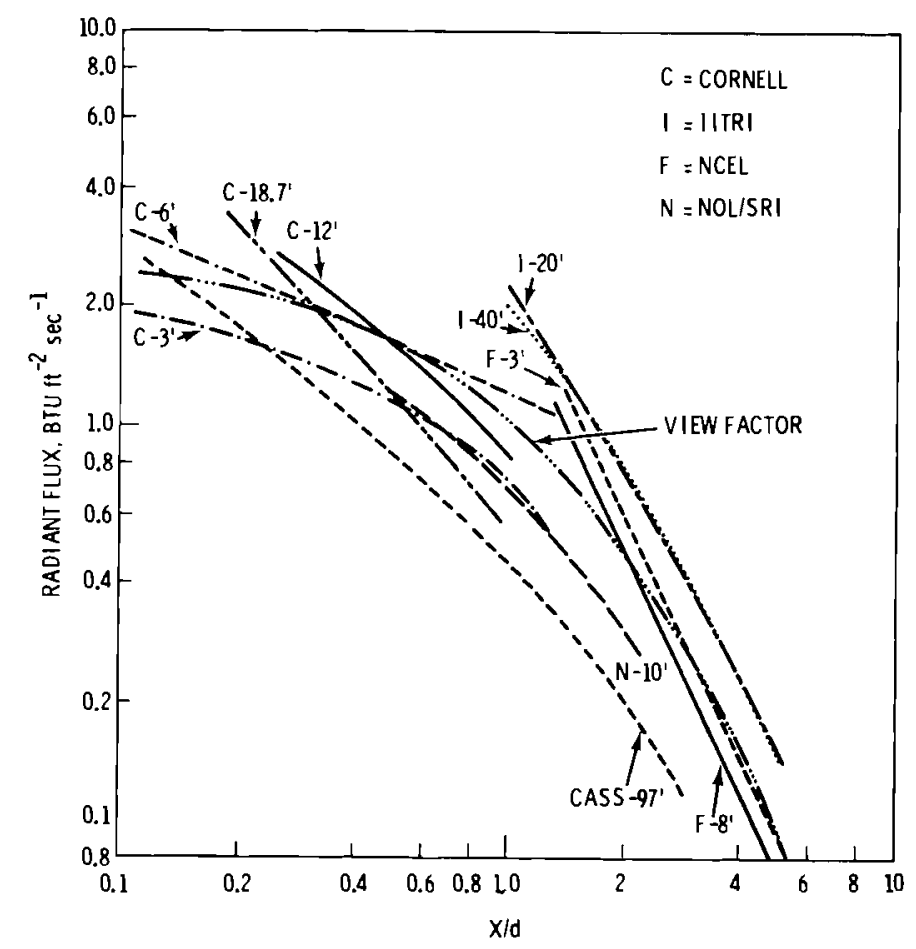

FIGURE E.5. Radiant Flux as a Function of Distance from JP5 Fire (Ref. 4)

shows that the radiant heat flux varies by about a factor of two in going from $2 \mathrm{ft}$ to $10 \mathrm{ft}$ from the edge of the fire. There is this reasonable agreement between the JP5 experiments and the calculations represented in Figure E.1. The results presented in Figure E.1 are believed to be conservative and will be used as the gasoline fire model.

The variation of the radiant heat flux from a gasoline fire with distance for various windspeeds may be estimated by assuming that the heat flux varies in the same way as the JP5 heat flux plotted in Figure E.5. The curve labeled "view factor" in Figure $E .5$ has been used as representative of the experimental measurements on JP5 fires. It is assumed that the ratio of the JP5 heat flux of the safe separation distance to the heat flux at a particular distance is the same as the ratio of the gasoline heat flux at the safe separation distance $\left(0.75 \mathrm{cal} / \mathrm{cm}^{2} \mathrm{sec}\right)$ to the heat flux at the distance of interest, i.e.,

$$
\phi_{\mathrm{JP5}}(\mathrm{SSD}) / \phi_{\mathrm{JP} 5}(\mathrm{x})=\phi_{\mathrm{GAS}}(\mathrm{SSD}) / \phi_{\mathrm{GAS}}(\mathrm{x})
$$


The values for JP5 are taken from Figure E.5 and the value of the heat flux from the gasoline fire at that distance is calculated. The results for a fire on a $55-\mathrm{ft}$ radius pool are plotted in Figure E.6.

Figure E.7 shows the irradiance as a function of time required to ignite various materials. Whitewood can be used to represent the flammable exteriors of buildings. (3) The "safe separation distance" heat flux of $0.75 \mathrm{cal} / \mathrm{cm}^{2} \mathrm{sec}$ can be seen to be capable of igniting secondary fires after an exposure time of about $1 \mathrm{~min}$.

As stated previously, gasoline pool fires produce large amounts of smoke since the atmosphere directly above the pool becomes oxygen deficient. If inhaled, the sooty smoke could induce coughing and sneezing and possibly produce respiratory damage. Inhalation of large concentrations of the smoke for a sufficient length of time can be fatal. Smoke inhalation is not believed to be a significant health hazard in gasoline fires, because the smoke plumes are strongly buoyant. It is assumed that the smoke will be carried high into the air and be diluted by the atmosphere to below toxic concentrations before they descend to ground level.

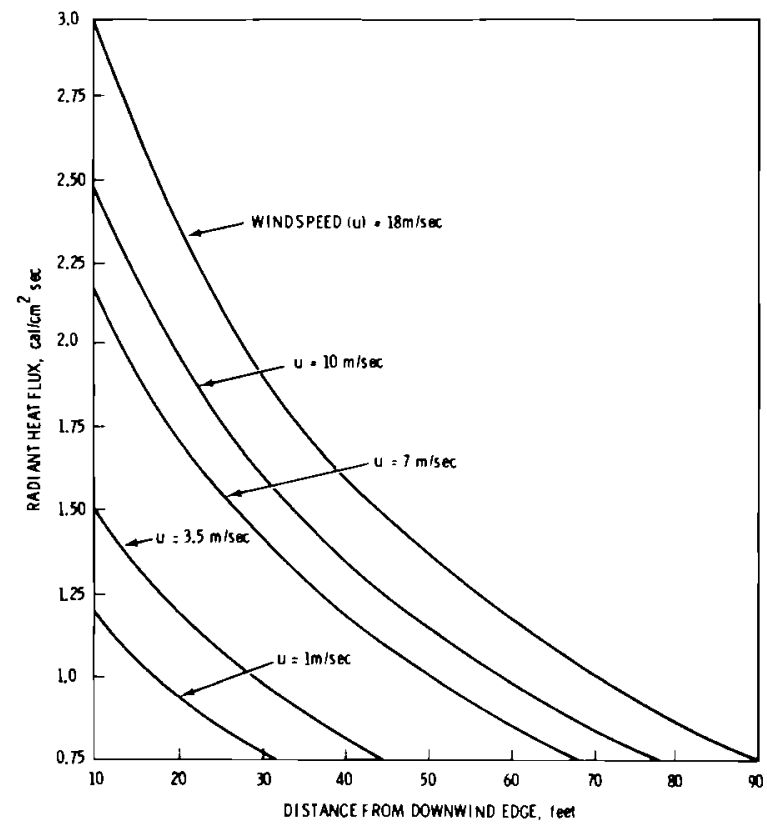

FIGURE E.6. Variation of Radiant Heat Flux with Downwind Distance from a 55-ft Radius Gasoline Pool Fire 


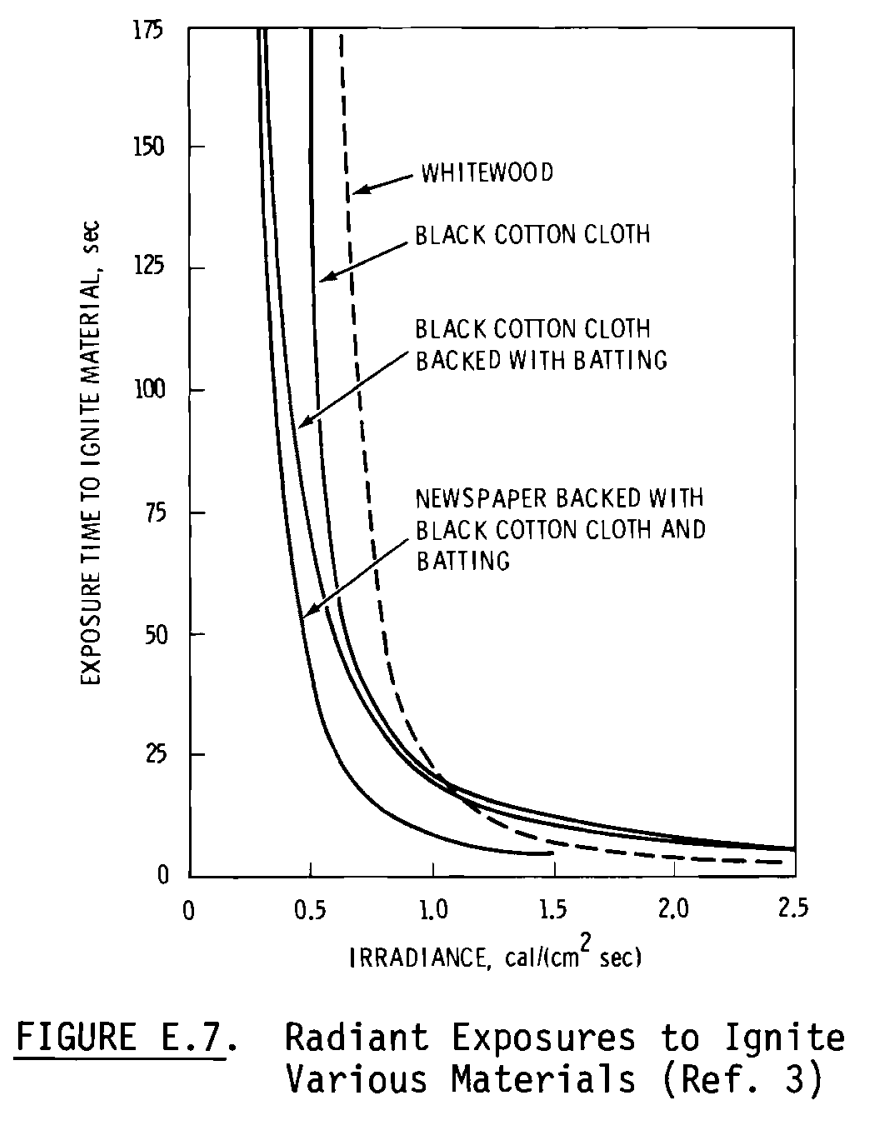

\section{REFERENCES}

1. A Modal Economic and Safety Analys is of the Transportation of Hazardous Substances in Bu7k. COM-74-11271, A. D. Litt7e, Inc., Cambridge, MA, p. 226, May 1974.

2. Ibid, p. 160 .

3. A. N. Takata, Review of Fire Hazard Distances. IIT Research Institute, Chicago, IL, Apri1 1970.

4. E. L. Capner and R. S. Alger, "Characterization and Suppression of Aircraft Fuel Fires." WSCI 72-26 presented at Western States Section/The Combustion Institute 1972 Fal1 Meeting, Monterey, CA, October 1972. 
APPENDIX F

ESTIMATE OF DAMAGE FROM GASOL.INE

TANK TRUCK EXPLOSIONS

The volatility of gasoline leads to the possibility of an explosion following an accident involving a gasoline tank truck. These explosions are basically of two types--deflagrations in vapor clouds and detonations inside the tank.

Appendix $C$ shows that explosive concentrations of gasoline vapor in air can be encountered as the vapor cloud drifts away from a gasoline spill. Ignition of this mixture produces a deflagration. A deflagration is characterized by a subsonic flame front velocity and small pressure changes (typically a maximum of 1.5 psi.) (1) Although these pressures can cause window breakage and exterior building damage, the possibility of producing deaths from such blast waves is believed small.

The type of explosion that is of major interest from a damage standpoint is the detonation of an explosive mixture inside the tank. A detonation is characterized by a flame front with supersonic velocity. The detonation of gasoline vapors in a confined area can produce blast waves that have a significant potential for causing damage.

Brasie and Simpson ${ }^{(2)}$ have developed a method for estimating the damage resulting from a chemical explosion. The first step in their procedure is to estimate the weight of TNT that will produce a blast equivalent to the chemical explosion as a function of the standard heat of combustion of the confined vapor and the amount of vapor in the confined area. Damage produced at various distances is then determined from the equivalent TNT weight of the explosion.

The TNT equivalent yield of a hydrocarbon explosion can be estimated from the following expression: 


$$
W=\frac{\alpha \cdot{ }^{\Delta H_{c}} \cdot m}{2,000 \text { Btu/1b TNT }}
$$

where $W$ is the mass in pounds of TNT with a yield equivalent to the hydrocarbon explosion, $\Delta \mathrm{H}_{\mathrm{c}}$ is the standard heat of combustion in Btu/unit mass and $\mathrm{m}$ is the mass of vapor in the confined area. $\alpha$ is an empirical factor developed from experimental observations. It accounts for the inefficiencies in explosions, since $\Delta \mathrm{H}_{\mathrm{C}}$ is the yield for complete combustion.

No experimental data are available for gasoline explosions, so that $\alpha$ cannot be evaluated directly. As an alternate approach, an effective heat of combustion was calculated to replace $\left(\alpha \cdot \Delta H_{C}\right)$ in Equation $F-1$. These calculations are based on experimental measurements by Stecher ${ }^{(3)}$ of the gasoline explosion pressure over the entire range of flammable mixtures of air and gasoline. Stecher's data are plotted in Figure F.1.

Several assumptions were made in calculating the equivalent heats of combustion. The explosion pressures are assumed to be the final static pressure after combustion in a closed, constant volume container. The reaction is assumed to be adiabatic (the change in the total energy of the system is zero) and no work is done on the surroundings. This implies that the change in internal energy $(\Delta U)$ of the system is also zero.

The burning process is assumed to proceed in two steps--a combustion step at constant temperature and a pressurization step. The process is depicted in Figure F.2. If the process proceeds as shown in Figure F.2, we have:

$$
\Delta \mathrm{U}=\Delta \mathrm{U}_{\mathrm{C}}+\Delta \mathrm{U}_{\mathrm{P}}=0
$$

The relationship of $\Delta U$ to enthalpy $(\Delta H)$ is given by:

$$
\Delta U=\Delta H-V \Delta P-P \Delta V
$$

or since $\Delta V=0$ (constant volume container):

$$
\Delta U=\Delta H-\Delta(V P)
$$




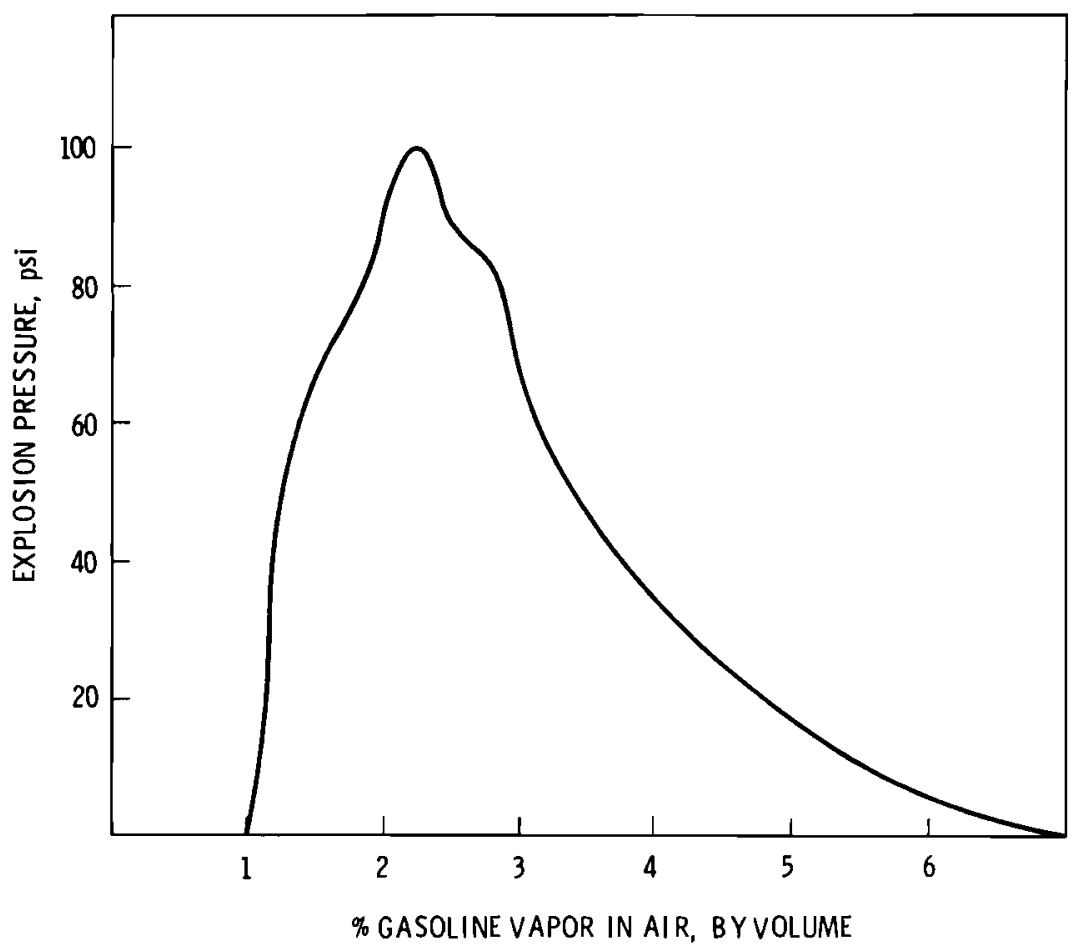

FIGURE F.1. Explosion Pressures over the Explosive Range of Gasoline (Ref. 3)

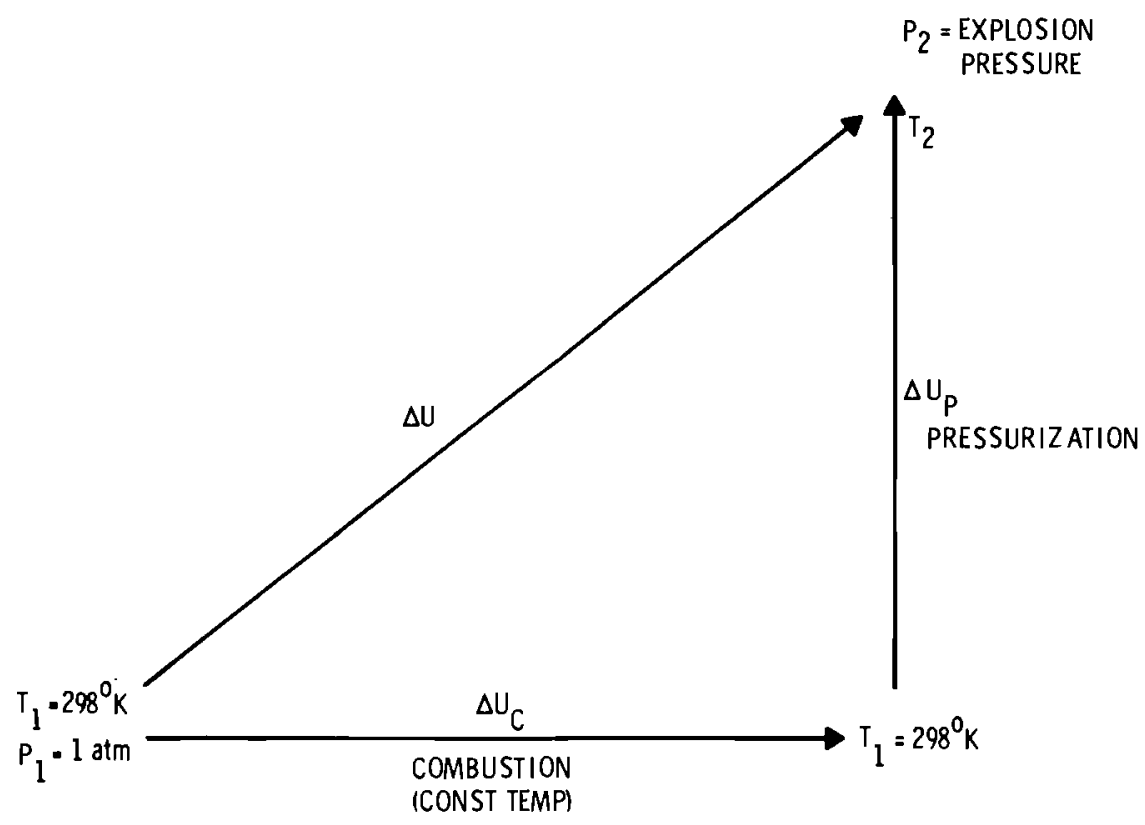

FIGURE F.2. Assumed Burning Process for Calculation of Equivalent Heat of Combustion of Gasoline 
The enthalpy change in each step of the combustion process can be calculated separately, so that:

$$
\begin{aligned}
& \Delta U_{c}=\Delta H_{c}-\Delta(V P)_{c} \\
& \Delta U_{p}=\Delta H_{p}-\Delta(V P)_{p}
\end{aligned}
$$

If the gas in the enclosed volume is assumed to be ideal, so that $\Delta(V P)=$ $R \Delta(n T)$, then for the combustion step $\Delta(V P)_{C}=R T \Delta n$ and for the pressurization step $(\Delta V P)_{p}=R n \Delta T$. Applying these relationships and adding Equations F-5 and F-6 together gives:

$$
\Delta U=\Delta U_{c}+\Delta U_{p}=0=\Delta H_{c}+\Delta H_{p}-R \Delta(n T)
$$

Equation $\mathrm{F}-7$ is solved for $\Delta \mathrm{H}_{\mathrm{C}}$ in the following way:

- For the gasoline-air mixture of interest, calculate the total number of moles initially present $\left(n_{1}\right)$, assuming that $1 \mathrm{~g}$-mole of gasoline is present.

- Calculate the number of moles present after combustion $\left(n_{2}\right)$ by assuming that the combustion products are $\mathrm{N}_{2}, \mathrm{CO}_{2}, \mathrm{H}_{2} \mathrm{O}$ and excess $\mathrm{O}_{2}$ or unburned gasoline.

- Read the final pressure $\left(P_{2}\right)$ from Figure F.1.

- Calculate $T_{2}$ from the ideal gas law at constant volume

$$
T_{2}=\frac{n_{1}}{n_{2}} \cdot \frac{P_{2}}{P_{1}} \cdot T_{1}
$$

- Estimate $\Delta H_{p}$ from the relationship

$$
\Delta H_{p}=\Delta T \sum_{i} n_{i} C_{p}^{*}(i)
$$

where the summation is over all the combustion products $\left(\mathrm{N}_{2}, \mathrm{CO}_{2}\right.$, $\mathrm{H}_{2} \mathrm{O}$ and $\left.\mathrm{O}_{2}\right)$ and $\mathrm{C}_{\mathrm{p}}^{*}(\mathrm{i})$ is the mean specific heat of each substance. $A$ sample calculation of $\Delta H_{C}$ is given in Attachment $A$. 
Figure F. 3 contains a plot of the effective heats of combustion for various gasoline-air mixtures. Equation F-l can then be used to calculate the equivalent TNT yield. The mass of gasoline in the tank is calculated for the particular gasoline-air mixture assuming that the volume of the tank is $4,500 \mathrm{gal}$ and that the ambient temperature before the explosion is $77^{\circ} \mathrm{F}$.

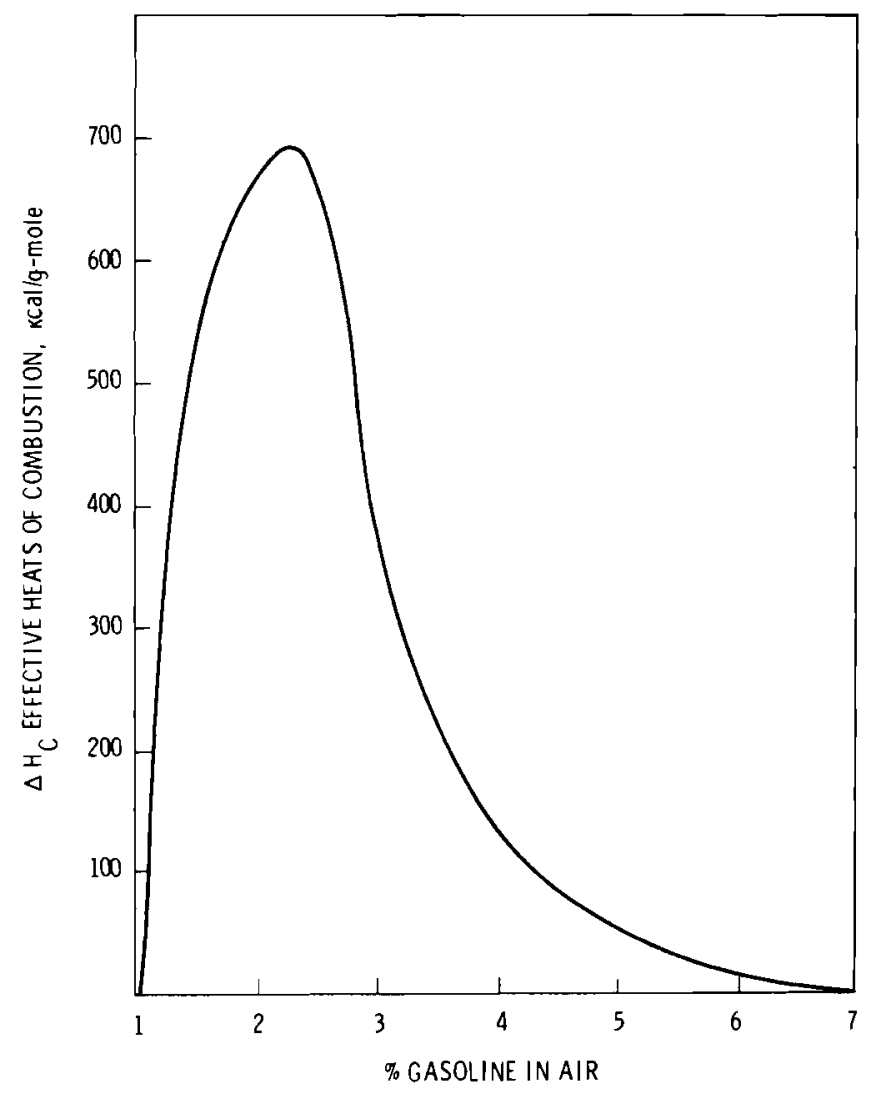

FIGURE F.3. Effective Heats of Combustion of Gasoline

When the equivalent TNT yield has been found, the damage limits can be estimated from Figure F.4. The scaled range for serious damage given in Figure $F .4$ is $27 \mathrm{ft} / 1 b^{1 / 3}$. The serious damage limit for the explosion of interest is determined by multiplying the scaled range by the cube root of the TNT equivalent yield. A plot of the probable total destruction, serious structural damage and missile damage limits for various gasoline and air mixtures is given in Figure F.5. A sample calculation of the TNT equivalent yield and damage limits is given in Attachment $B$. 


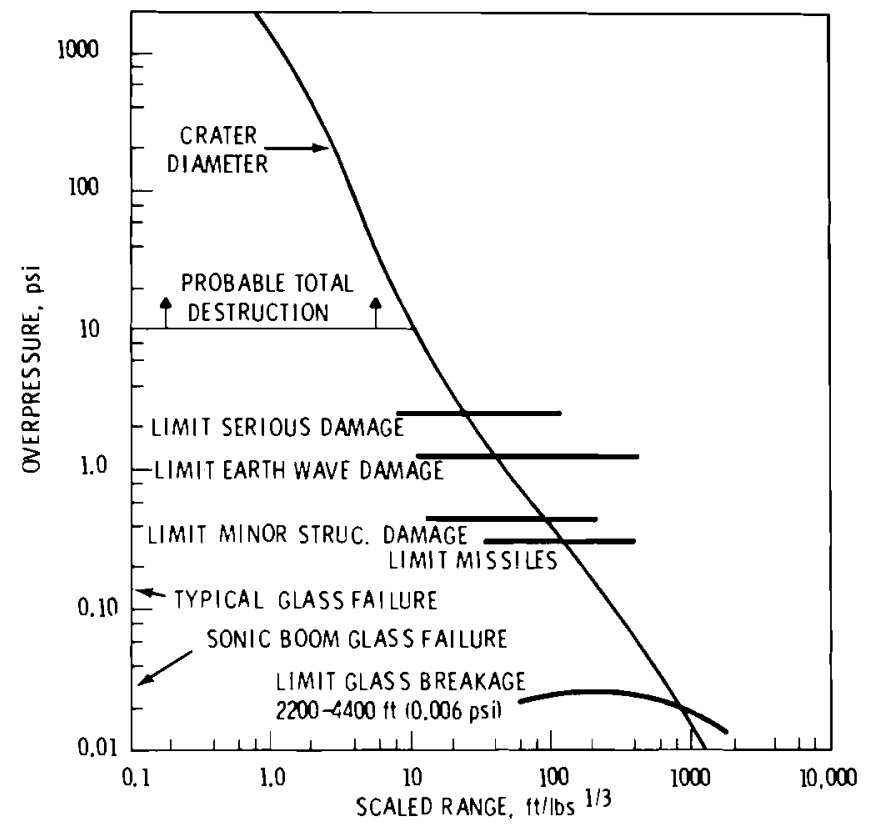

FIGURE F.4. Explosion Damage Limits versus Scaled Range ${ }^{(1)}$

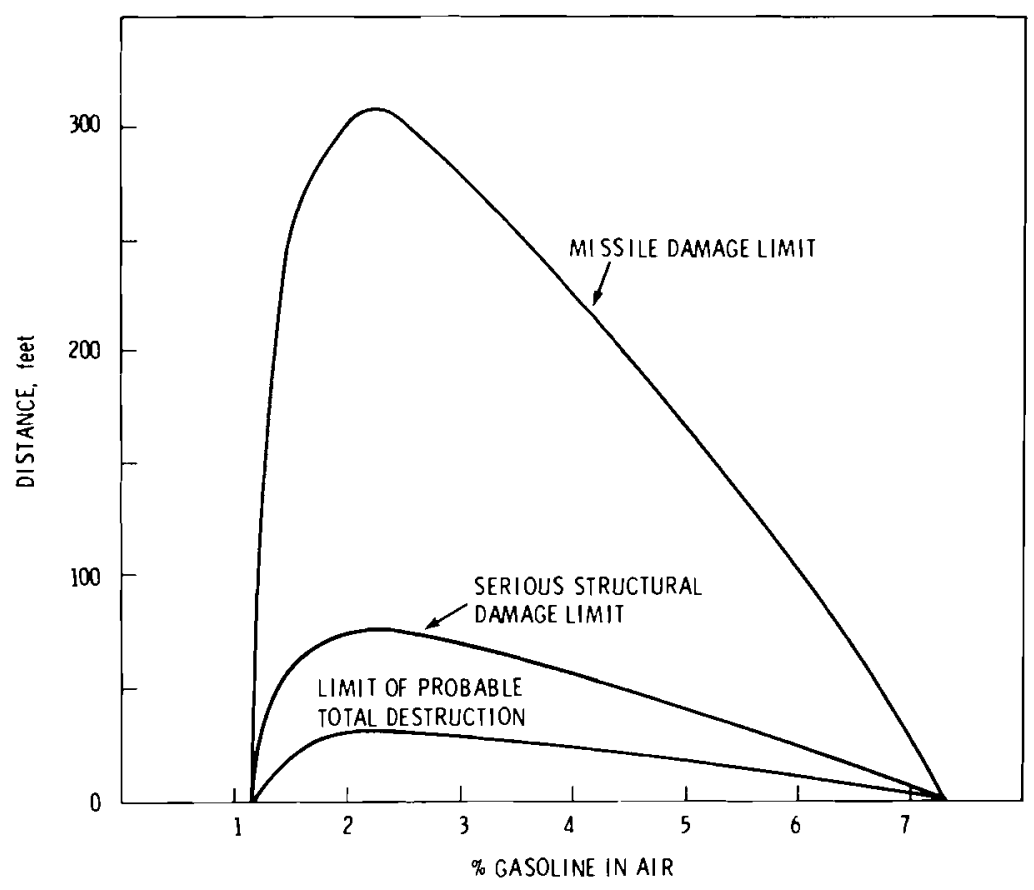

FIGURE F.5. Probable Total Destruction, Serious Structural Damage and Missile Damage Limits for Gasoline and Air Mixtures 
The conditions required to produce an explosive concentration of vapors in the gaoline tank should also be considered. At $70^{\circ} \mathrm{F}$, the vapor pressure of gasoline is about 7.5 psi (see Appendix B). If the vapor is in equilibrium with the liquid in the tank, the vapor will be about $51 \%$ gasoline by volume. Even for a temperature of $20^{\circ} \mathrm{F}$, the air-gasoline mixture is $19 \%$ gasoline by volume. If complete mixing is assumed, an explosion in a gasoline tank that is partially filled with liquid is impossible. Because the gasoline vapors are 3.4 times heavier than air, it is possible that concentration gradients could be present in the vapor space, so that some portions of the vapor could be within the flammable limits. However, an ignition source must still contact the flammable region for an explosion to occur, and the explosive yield would be much smaller than those predicted above for an explosive mixture that completely fills the tank. The most likely configuration to produce a serious explosion would be an empty tank that is somehow open to the atmosphere. For an explosion to occur, an ignition source would be required when the mixture in the tank was diluted to within flammable limits. 


\section{ATTACHMENT A}

\section{SAMPLE CALCULATION OF EFFECTIVE HEAT}

OF COMBUSTION OF GASOLINE

This sample calculation will be carried out for a mixture that is $1.5 \%$ gasoline by volume. The explosion pressure for this mixture is taken from Figure F.1 as 65 psig. Assuming the mixture contains 1 g-mole of gasoline the number of g-moles of air $n_{1}=\frac{1}{0.015}=66.7 \mathrm{~g}$-moles. Using an average chemical formula for gasoline of $\mathrm{C}_{7.3} \mathrm{H}_{14.6}$, and assuming complete combustion to $\mathrm{N}_{2}, \mathrm{CO}_{2}$ and $\mathrm{H}_{2} \mathrm{O}$ in excess oxygen, the number of moles of combustion products $\mathrm{n}_{2}=51.9 \mathrm{~N}_{2}+7.3 \mathrm{CO}_{2}+7.3 \mathrm{H}_{2} \mathrm{O}+2.84 \mathrm{O}_{2}=69.3 \mathrm{~g}$-moles. Assuming ideal gas behavior, the final temperature of the combustion products:

$$
\begin{aligned}
& T_{2}=\frac{n_{1}}{n_{2}} \cdot \frac{P_{2}}{P_{1}} \cdot T_{1}=\frac{(66.7 \mathrm{~g} \text {-moles })}{(69.3 \mathrm{~g} \text {-moles })} \cdot \frac{(79.7 \mathrm{psia})}{(14.7 \mathrm{psia})} \cdot\left(298^{\circ} \mathrm{K}\right) \\
& T_{2}=1553^{\circ} \mathrm{K}=2336^{\circ} \mathrm{F}
\end{aligned}
$$

Next calculate $\Delta H_{p}$ from $\Delta H_{p}=\Delta T \sum_{i} n_{i} C_{p}^{*}(i)$ using the following mean values for specific heats. (4)

$$
\begin{aligned}
& C_{\mathrm{p}}^{*}\left(\mathrm{CO}_{2}\right)=12.3 \mathrm{kcal} / \mathrm{g}-\mathrm{mole}{ }^{\circ} \mathrm{K} \\
& \mathrm{C}_{\mathrm{p}}^{*}\left(\mathrm{H}_{2} \mathrm{O}\right)=9.6 \mathrm{kcal} / \mathrm{g}-\mathrm{mole}{ }^{\circ} \mathrm{K} \\
& C_{\mathrm{p}}^{*}\left(\mathrm{~N}_{2}\right)=7.7 \mathrm{kcal} / \mathrm{g}-\mathrm{mole}{ }^{\circ} \mathrm{K} \\
& C_{\mathrm{p}}^{*}\left(\mathrm{O}_{2}\right)=8.1 \mathrm{kcal} / \mathrm{g}-\mathrm{mole}{ }^{\circ} \mathrm{K} \\
& \text { Then, } \Delta \mathrm{H}_{\mathrm{p}}=\left(1553^{\circ} \mathrm{K}-298^{\circ} \mathrm{K}\right)[51.9(7.7)+(7.3)(12.3)+7.3(9.6)+ \\
&(2.8)(8.1)] \mathrm{CO}_{2} \\
& 0_{2}
\end{aligned}
$$




$$
\Delta H_{p}=731 \mathrm{kcal}
$$

and

$$
\begin{aligned}
\Delta H_{c} & =R \Delta(n T)-\Delta H_{p} \\
\Delta H_{c} & =1.99 \times 10^{-3} \mathrm{kcal} / \mathrm{g}-m o l e{ }^{\circ} \mathrm{K}[69.3(1553)-66.7(298)]-731 \\
\Delta H_{c} & =-557 \mathrm{kcal} / \mathrm{g} \text {-mole gasoline }
\end{aligned}
$$


ATTACHMENT B

\section{SAMPLE CALCULATION OF TNT EQUIVALENT}

This calculation is performed for an air-gasoline mixture that is $2.25 \%$ gasoline by volume. Assume that the tank volume is 4,500 gal, the ambient temperature is $77^{\circ} \mathrm{F}$ and that the gasoline air mixture behaves as a perfect gas. The number of moles of gasoline in the tank is calculated from the ideal gas law:

$$
\begin{aligned}
& n=\frac{P V}{R T}=\frac{(14.7 \mathrm{psia})(2.25 \% \mathrm{gasoline})(4,500 \mathrm{gal})\left(0.13 \mathrm{ft}^{3} / \mathrm{gal}^{\prime}\right)}{\left(10.73 \frac{\mathrm{ft}^{3} \mathrm{psia}}{1 \mathrm{~b}-\mathrm{mole}^{\circ} \mathrm{R}}\right)\left(537^{\circ} \mathrm{R}\right)} \\
& n=0.034 \text { 1b-moles gasoline }
\end{aligned}
$$

The mass of gasoline in the tank

$$
\begin{aligned}
& \mathrm{m}=(0.034) 1 \mathrm{~b} \text {-moles } \times 1021 \mathrm{~b} / 1 \mathrm{~b} \text {-mole } \\
& \mathrm{m}=3.51 \mathrm{~b} \text { gasoline }
\end{aligned}
$$

To find the equivalent yield, read $\Delta H_{C}$ from Figure $F .3$.

$$
\Delta H_{C}=-696 \frac{\mathrm{kcal}}{\mathrm{g}-\mathrm{mole}}=-12,300 \mathrm{Btu} / 1 \mathrm{~b} \text { gasoline }
$$

The equivalent yield is then

$$
\begin{aligned}
& W=\frac{\left(\Delta \mathrm{H}_{\mathrm{C}}\right)(\mathrm{m})}{2000}=\frac{(-12,300 \mathrm{Btu} / 1 \mathrm{~b})(3.52 \mathrm{lb})}{2000 \mathrm{Btu} / 1 \mathrm{~b} \text { TNT }} \\
& W=21.6 \mathrm{lb} \mathrm{TNT}
\end{aligned}
$$

To find the limit of serious structural damage, read the scaled range from Figure F.4 $(27 \mathrm{ft})$ and multiply by $w^{1 / 3}$. The 1 imit of serious structural damage is then

$$
L=(21.6)^{1 / 3}(27)=75 \mathrm{ft} .
$$




\section{REFERENCES}

1. W. Geiger, "Generation and Propagation of Pressure Waves Due to Unconfined Chemical Explosions and Their Impact on Nuclear Power Plant Structures." Nuclear Engineering and Design 27:189-198, 1974.

2. W. C. Brasie and D. W. Simpson, "Guidelines for Estimating Damage Explosion." Loss Prevention 2, 1968.

3. G. E. Stecher, Fire Prevention and Protection Fundamentals. Chilton Co., 1953.

4. J. M. Smith and H. C. Van Ness, Introduction to Chemical Engineering Thermodynamics. McGraw-Hi11, 1959 . 
APPENDIX G

\section{ESTIMATE OF SECONDARY FIRES INITIATED BY GASOLINE POOL FIRES}

This appendix describes the method used to estimate the number of secondary building fires that would be produced if a tank truck accident initiated a gasoline pool fire on a city street or freeway. For the purposes of this analysis, three spill sizes are considered--3,000 gal., 4,200 gal. and $8,400 \mathrm{gal}$. The analysis is based on an assumed "typical" urban area developed from the work of Takata and Salzberg. (1) The model includes suburban areas surrounding a typical city. Very densely populated areas such as might be found in the business districts of very large cities are excluded from the analysis. (It is assumed that the large tank trucks used to carry gasoline would avoid traveling in these areas whenever possible.)

The analysis is based on the pool fire model described in Appendix E. However, on a city street the gasoline pool would not be expected to assume a circular shape. City streets are usually sloped from the center toward the curbs to facilitate runoff. This will generally confine the pool to one side of the street. The curbs will also limit the spread of the pool. The pool shape assumed for this analysis is shown in Figure G.1(a). The pool G.1(a) is assumed to be confined to an area 40-ft wide (about one half the width of a typical four lane street) and as long as the diameter predicted by the pool model. The safe separation distance from the fire is estimated using the pool model (see Figure E.1). The flame angle and safe separation distance for the three pool sizes as a function of distance is presented in Table G.1. The safe separation distance for several windspeeds and directions is illustrated in Figure G.1 ( $b$ and $c$ ).

It is theoretically possible that flammable concentrations of gasoline vapors could accumulate in sewer systems following a spill on a city street. It is believed that such events would make a minimal contribution to the overall risk, so they were not analyzed in detail. 

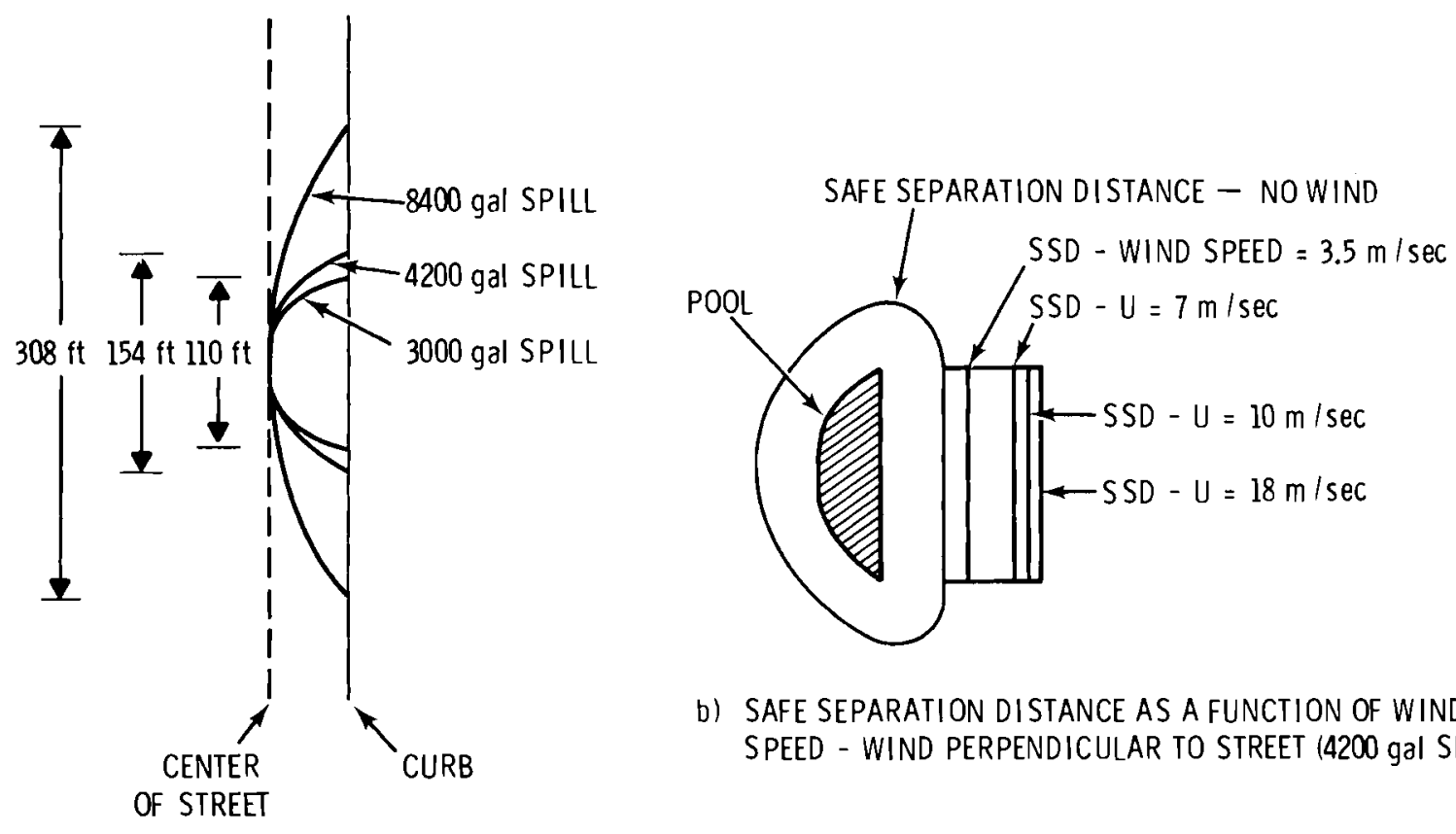

b) SAFE SEPARATION DISTANCE AS A FUNCTION OF WIND SPEED - WIND PERPENDICULAR TO STREET $(4200 \mathrm{gal}$ SPILL)

a) POOL SHAPE

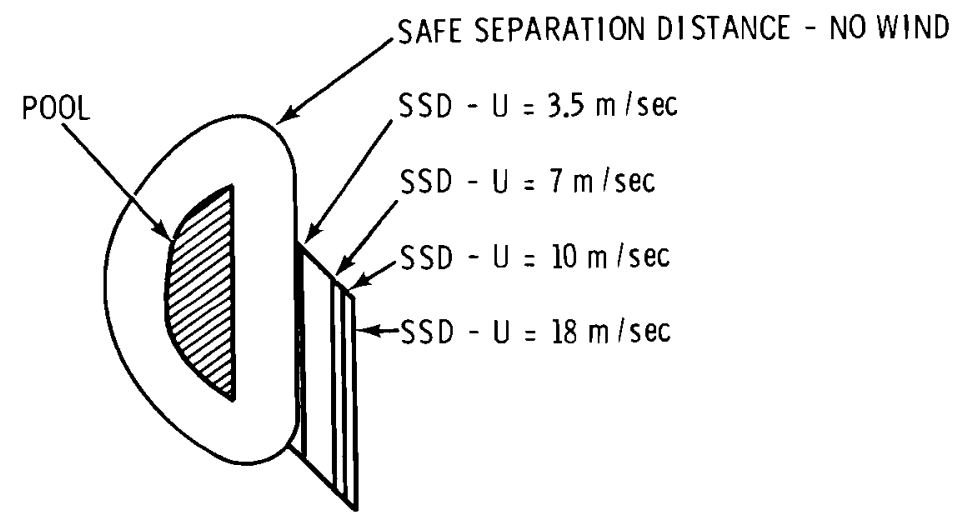

c) SAFE SEPARATION DISTANCE FOR SEVERAL WIND SPEEDS WIND AT $45^{\circ}$ ANGLE TO STREET (4200 gal SPILL)

FIGURE G.1. Assumed Gasoline Pool Shapes and Safe Separation Distance for Various Windspeeds for a Gasoline Pool Fire on a City Street 
TABLE G.1. Flame Angle and Safe Separation Distance as a Function of Windspeed for Gasoline Pool Fires

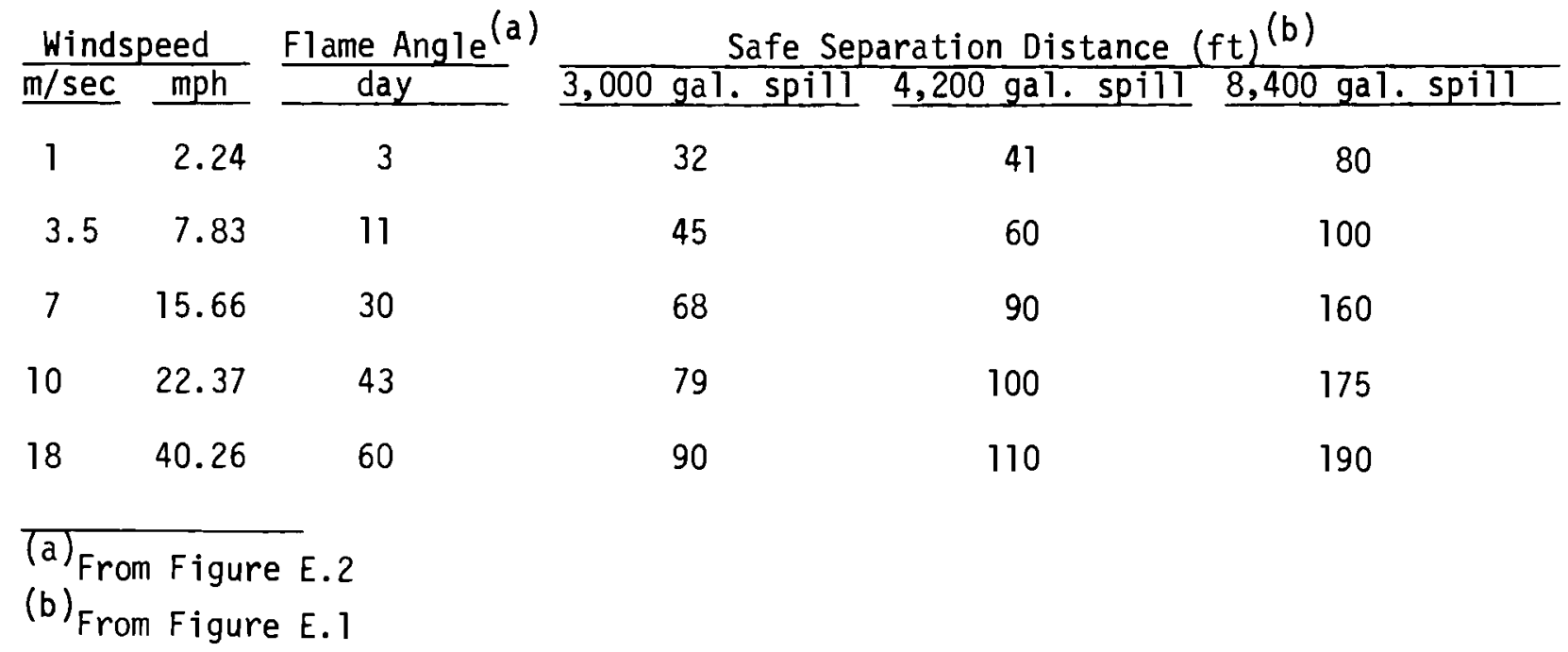

A model urban area was developed to determine the probability of initiating secondary building fires from gasoline pool fires of the three assumed spill sizes. Previous attempts ${ }^{(1)}$ to model urban areas have classified the land development into as many as 23 types of residential areas, several types of industrial areas, schools, commercial areas and downtown districts. For the purposes of this study, these have been condensed into six types of areas. The basic characteristics of the land development types and the percentage of each in the model urban area are listed in Table G.2.

Each type of land development is depicted graphically in Figures G.2 through G.5. A city block is assumed to be $380 \mathrm{ft}$ long and $210 \mathrm{ft}$ wide with a 15-ft wide alley running lengthwise through the center of the block. Building sizes and lot sizes are averages based on figures for Detroit, Michigan; Albuquerque, New Mexico, and San Jose, California. The gasoline pool fire is assumed to occur on a four lane street that is $60 \mathrm{ft}$ wide. All other streets are $40 \mathrm{ft}$ wide. The buildings in the residential areas are assumed to be $25 \mathrm{ft}$ from the curb because of zoning restrictions. Commercial buildings are assumed to sit in the center of the lot. Industrial buildings are assumed to be separated from the street by a 6 - $\mathrm{ft}$ wide sidewalk and downtown buildings by a 10-ft wide sidewalk. 
TABLE G.2. Model Urban Area Land Development

\begin{tabular}{|c|c|c|c|}
\hline Development Type & Building Size (ft) & Lot Size $(f t)$ & $\begin{array}{c}\text { Percentage of Total } \\
\text { Land Area }\end{array}$ \\
\hline Residential A & $38 \times 22 W$ & $63.3 \mathrm{~W} \times 97.5 \mathrm{D}$ & 31.2 \\
\hline Residential $\mathrm{B}^{(\mathrm{a})}$ & $62 \mathrm{~L} \times 24 \mathrm{~W}$ & $95 \mathrm{~W} \times 97.5 \mathrm{D}$ & 43.4 \\
\hline Industrial & $56 \mathrm{~L} \times 30 \mathrm{~W}$ & $76 W \times 97.5 \mathrm{D}$ & 18.4 \\
\hline Commercial & $36 \mathrm{~L} \times 36 \mathrm{~W}$ & $76 \mathrm{~W} \times 97.5 \mathrm{D}$ & 0.6 \\
\hline Downtown & $50 \mathrm{~L} \times 50 \mathrm{~W}$ & $51 \mathrm{~W} \times 97.5 \mathrm{D}$ & 0.4 \\
\hline Vacant \& Schools & -- & -- & 6.0 \\
\hline
\end{tabular}

(a) $42 \mathrm{ft} \times 24 \mathrm{ft}$ house with attached garage $20 \mathrm{ft} \times 24 \mathrm{ft}$.

The following simplifying assumptions have been made to estimate the secondary fires from a gasoline spill on a city street:

- The spill can occur with equal probability at any position along a four lane street.

- All buildings have flammability characteristics of wooden structures.

- The wind is equally likely to blow from any direction.

- The probability of various windspeeds is that given in Table G.3.

- The probability of an accident occurring on a city street is independent of the type of land development in which the accident occurs.

TABLE G.3. Probability of Various Windspeeds ${ }^{(2)}$

\begin{tabular}{|c|c|}
\hline Windspeed $(\mathrm{m} / \mathrm{sec})$ & Probability \\
\hline $0-1$ & 0.255 \\
\hline $1-3.5$ & 0.508 \\
\hline $3.5-7$ & 0.161 \\
\hline $7-10$ & 0.052 \\
\hline $10-18$ & 0.024 \\
\hline
\end{tabular}


RESIDENTIAL A
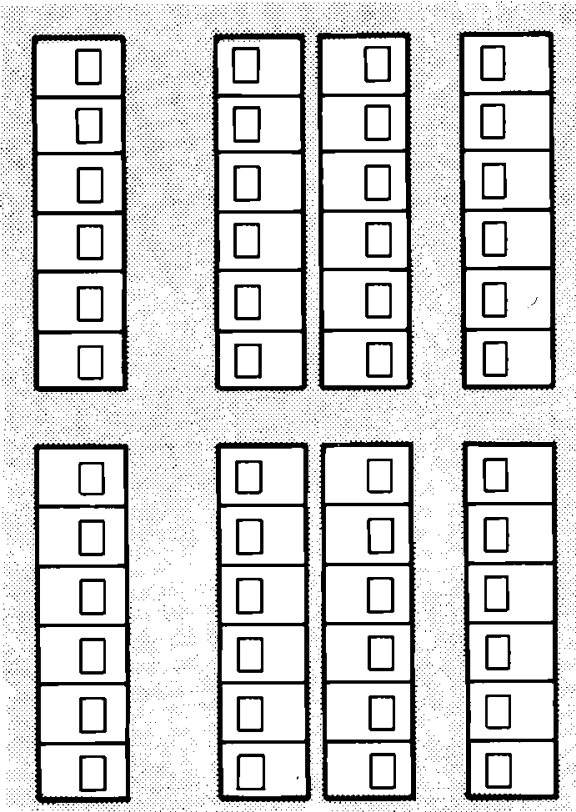

FIGURE G.2. Residential Area Models Used to Estimate Secondary Fires from Gasoline Spills

INDUSTRIAL
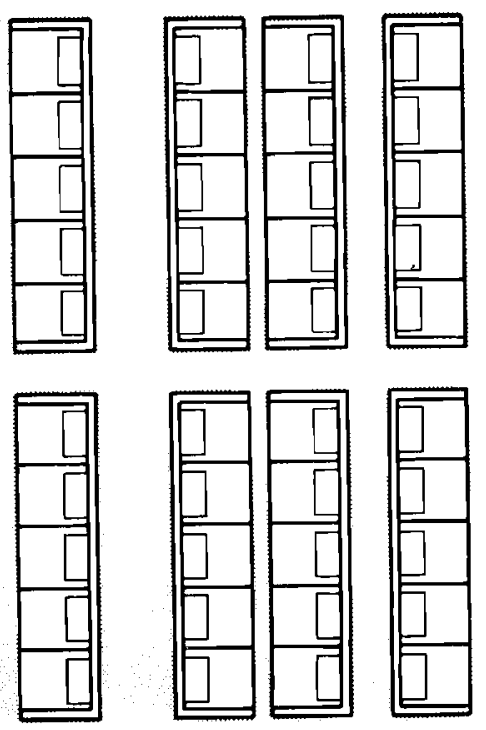

FIGURE G.3. Industrial Area Model Used to Estimate Secondary Fires from Gasoline Spills 
COMMERCIAL

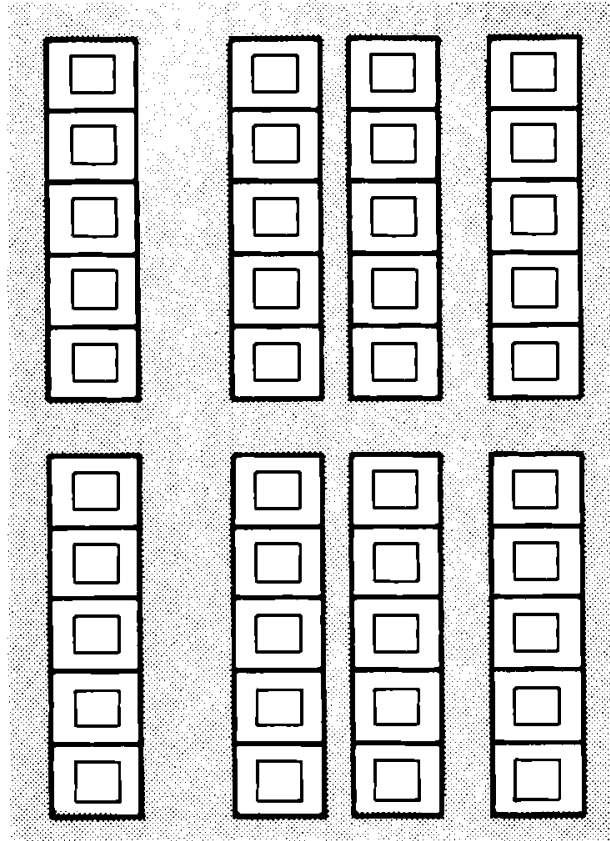

FIGURE G.4. Commercial Area Model Used to Estimate Secondary Fires from Gasoline Spills

DOWNTOWN
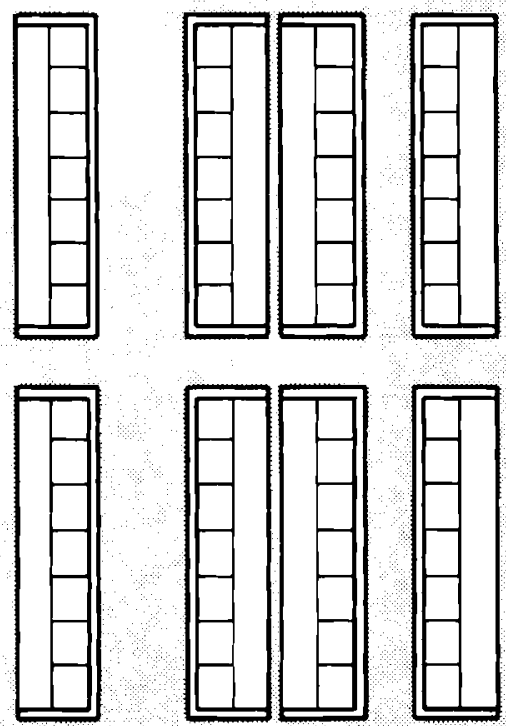

FIGURE G.5. Downtown Area Model Used to Estimate Secondary Fires from Gasoline Spills 
Using the urban model, gasoline pool shape and the other assumptions discussed above, the probability of initiating secondary fires from a gasoline spill on a city street has been estimated for each land development type for the three spill sizes. The results are presented in Tables G.4 through G.6.

TABLE G.4. Probability of Secondary Building Fires from a Gasoline Pool Fire on a City Street - 3000-gal Spi11

Development Type

Probability of Number of Fires Indicated

\begin{tabular}{lccccccccc}
\hline Residential A & & -- & & -- & 0.400 & 0.585 & 0.010 & 0.005 & -- \\
Residential B & -- & 0.247 & 0.625 & 0.125 & 0.003 & 0.005 & -- \\
Industrial & -- & -- & 0.327 & 0.665 & 0.003 & 0.004 & 0.001 \\
Commercial & -- & & -- & 0.120 & 0.530 & 0.350 & -- & -- \\
Downtown & -- & & -- & 0.160 & 0.310 & 0.530 & -- & -- \\
Vacant \& Schools & 1.0 & & -- & -- & -- & -- & -- & --
\end{tabular}

TABLE G.5. Probability of Secondary Building Fires from a Gasoline Pool Fire on a City Street - 4200-gal Spil1

Development Type

Probability of Number of Fires Indicated

$\begin{array}{lcccccccc}\text { Residential A } & -- & -- & 0.155 & 0.505 & 0.310 & 0.015 & 0.015 & 0.005 \\ \text { Residential B } & -- & -- & 0.640 & 0.320 & 0.020 & 0.010 & -- & -- \\ \text { Industrial } & -- & -- & 0.080 & 0.605 & 0.280 & 0.015 & 0.015 & 0.004 \\ \text { Commercial } & -- & -- & 0.330 & 0.540 & 0.130 & -- & -- & -- \\ \text { Downtown } & -- & -- & -- & 0.050 & 0.520 & 0.430 & -- & -- \\ \text { Vacant \& Schools } & 1.0 & -- & -- & -- & -- & -- & -- & --\end{array}$


TABLE G.6. Probability of Secondary Building Fires from a Gasoline Pool Fire on a City Street - 8400-gal Spill

\begin{tabular}{|c|c|c|c|c|c|c|c|c|}
\hline \multirow[b]{2}{*}{ Development Type } & \multicolumn{8}{|c|}{ Probability of Number of Fires Indicated } \\
\hline & 0 & 1 & 2 & 3 & 4 & 5 & 6 & 7 \\
\hline Residential A & -- & -- & -- & -- & -- & -- & 1.0 & -- \\
\hline Residential B & -- & -- & -- & -- & 1.0 & -- & -- & - \\
\hline Industrial & -- & -- & -- & -- & -- & 1.0 & -- & -- \\
\hline Commercial & -- & -- & -- & -- & -- & 1.0 & -- & -- \\
\hline Downtown & -- & -- & -- & -- & -- & -- & -- & 1.0 \\
\hline Vacant \& Schools & 1.0 & -- & -- & -- & -- & -- & -- & -- \\
\hline
\end{tabular}

To estimate the probability of initiating secondary fires from a gasoline tank truck fire on an urban freeway, a model freeway was developed. The model freeway is shown in Figure G.6. The freeway is assumed to have six lanes with a total fenced right of way of $200 \mathrm{ft}$. Each lane is assumed to be $12 \mathrm{ft}$ wide and the shoulders are $10 \mathrm{ft}$ wide. A 10- $\mathrm{ft}$ median separates the two traffic flows. A two lane street is assumed to run along the fence with the mixture of the development types discussed previously located along the street.

The model gasoline pool used to estimate the secondary fires from a gasoline spill on an urban freeway is shown in Figure G.7. The freeway is assumed to be graded toward the outside shoulders for runoff, so that the spill forms a pool from the center lane to the edge of the right of way (about $75 \mathrm{ft}$ ). The pool length is taken to be the diameter predicted by the pool model in Appendix E. The assumptions on wind direction and speed and building flammability characteristics outlined previously for a spill on a city street are made here also. The values of safe separation distance given in Table G.l were again used. The results are presented in Tables G.7 through G.9. 

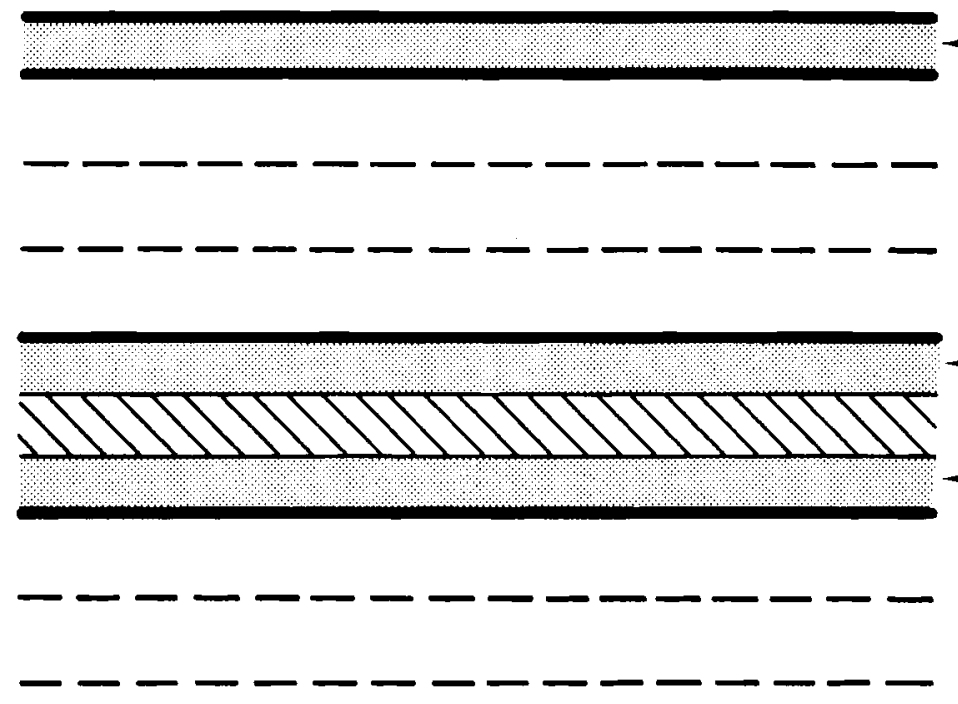

$-\cdots--\cdots--\cdots-\cdots-\cdots$

$\longleftarrow$ SHOULDER

LANE 1

LANE 2

LANE 3

$\longleftarrow$ SHOULDER

MEDIAN

$\longleftarrow$ SHOULDER

LANE 4

LANE 5

LANE 6

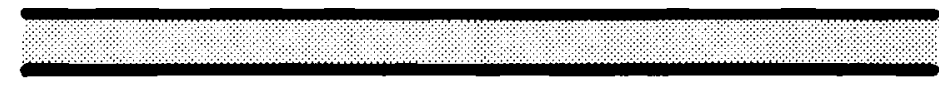

SHOULDER

RIGHT OF WAY

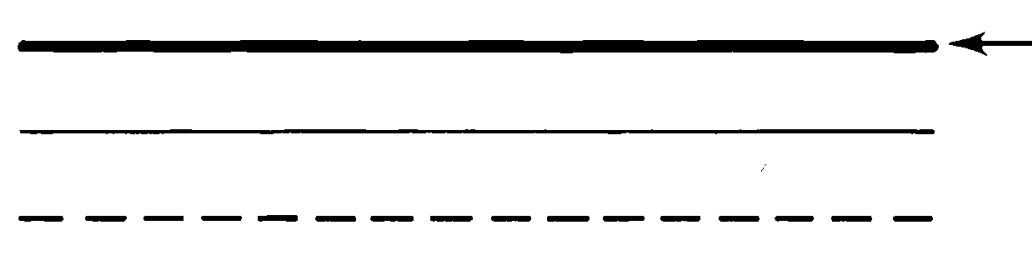

FENCE

PARKING

LANE 1

LANE 2

PARKING
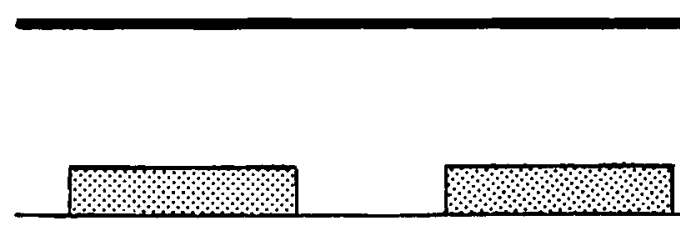

FIGURE G.6. Model Urban Freeway Used to Estimate Secondary Building Fires Initiated by a Gasoline Pool Fire 


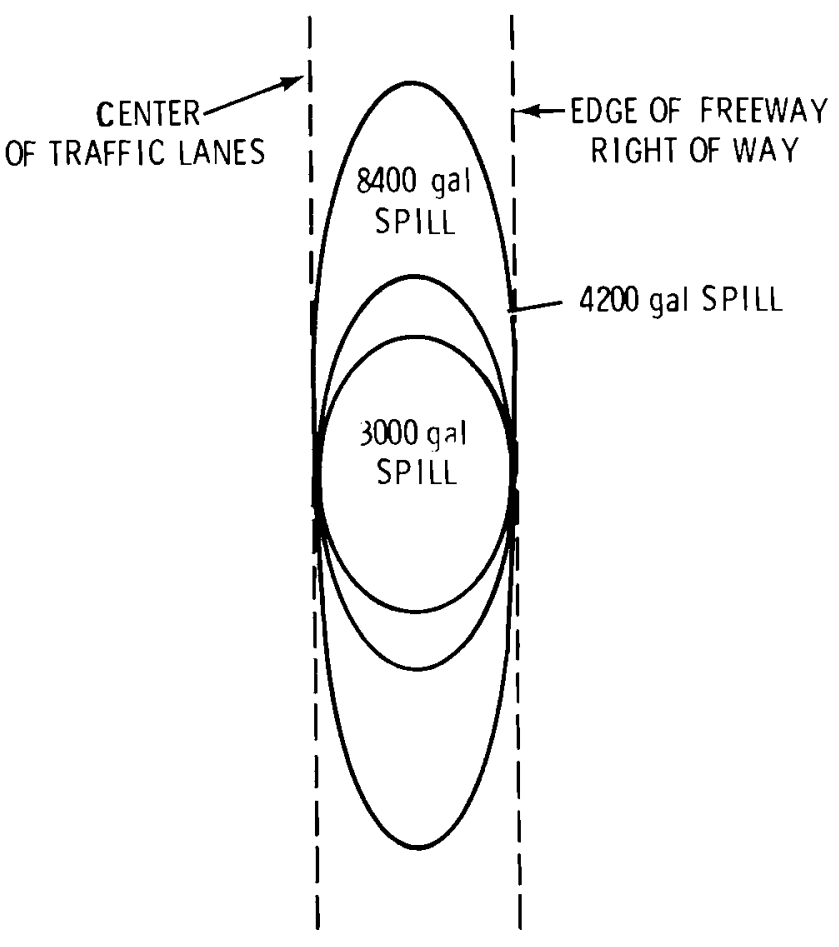

FIGURE G.7. Assumed Gasoline Pool Shape for a Spil1 on an Urban Freeway

TABLE G.7. Probability of Secondary Building Fires Initiated by a Gasoline Pool Fire on an Urban Freeway - 3000-gal Spil1

Development Type

\begin{tabular}{ccc} 
Probability of Number of Fires & Indicated \\
\hline 0 & 1 & 2
\end{tabular}

Residential A

$$
0.997
$$

0.997

0.002

0.001

Residential B

0.990

0.002

0.001

Industrial

0.997

0.002

0.008

Commercial

0.990

0.002

0.001

Downtown

Vacant \& Schools $\quad 1.0$

0.001

0.003

0.006 
TABLE G.8. Probability of Secondary Building Fires Initiated by a Gasoline Pool Fire on an Urban Freeway - 4200-gal Spill

Development Type

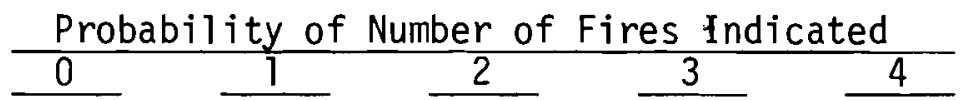
Residential A 0.876 0.008

0.051

0.072

Residential B

0.870

0.022

0.100

0.008

Industrial

0.868

0.009

0.079

0.043

Commercial

0.870

0.017

0.074

0.039

Downtown

0.867

0.002

0.031

0.053

0.047

Vacant \& Schools

1.0

TABLE G.9. Probability of Secondary Building Fires Initiated by a Gasoline Pool Fire on an Urban Freeway - 8400-gal Spill

Development Type

$\begin{array}{r}\text { Pro } \\ 0 \\ \hline\end{array}$

Residential A

$$
0.74 \quad--0.031
$$

0.072

--

--

Residential B

0.074

-- 0.092

0.123

-- 0.702

0.195

$\begin{array}{ll}-- & 0.048 \\ 0.136 & 0.156\end{array}$

0.123

0.074

0.448

$\frac{4}{4} \frac{5}{5}$

Commercial

$--\quad 0.136$

0.156

0.085

0.065

0.007

0.044

$\begin{array}{ll}0.092 & 0.01\end{array}$

Downtown

Vacant \& Schools 1.0

\section{REFERENCES}

1. A. N. Takata and F. Slazburg, Development and Application of a Complete Fire Spread Model Volumes I and IV. IIT Research Institute, Chicago, IL, June 1968.

2. T. I. McSweeney, R. J. Hall et al., An Assessment of the Risk of Transporting Plutonium 0xide and Liquid Plutonium Nitrate by Truck. p. 10-12, BNWL-1846, Batte11e, Pacific Northwest Laboratories, Richland, WA, August 1975. 


\section{DISTRIBUTION}

No. of

Copies

OFFSITE

A. A. Churm

Chicago Patent Group

DOE Chicago Operations Office

9800 South Cass Avenue

Argonne, IL 60439

171 DOE Technical Information Center

K. A. Trickett

Division of Reactor Development and Demonstration

Department of Energy

Germantown, MD 20014

J. Counts

Transportation Branch

Division of Environmenta1

Control Technology

Department of Energy

Washington, DC 20545

R. F. Garrison

Transportation Branch

Division of Environmental

Control Technology

Department of Energy

Washington, DC 20545

25 J. A. Sisler

Transportation Branch

Division of Environmenta 1 Control Technology

Department of Energy

Washington, DC 20545

R. B. Chitwood

Division of Fuel Storage and Transfer

Department of Energy

Washington, DC 20545
No. of

Copies
E. C. Hardin, Jr.

Office of the Assistant

Secretary for Energy Technology

Department of Energy

Washington, DC 20545

R. M. Moser

DOE Chicago Operations office

9800 South Cass Avenue

Argonne, IL 60439

W. G. O'Quinn

DOE Savannah River Operations Office

P.0. Box A

Aiken, SC 29801

N. Stetson

DOE Savannah River Operations Office

P.0. Box A

Aiken, SC, 29801

L. L. Turner

DOE Savannah River Operations Office

P.0. Box A

Aiken, SC 29801

D. Davis

DOE ATbuquerque Operations Office

P.0. Box 5400

A1buquerque, NM 87115

Susan Metzler

Systems Communications

N. E. Utilities

P.0. Box 270

Hartford, CT 06101 
No. of

Copies

J. Wolfson

DOT/TSC 533

Kendal1 Square

Cambridge, MA 02142

P. H. Zabel

Southwest Research Institute

6220 Culebra Road

P.0. Drawer 28510

San Antonio, TX 78284

N. J. McCormack

Department of Nuclear Engineering

Benson $\mathrm{Hall}$

University of Washington

Seattle, WA 98195

L. Blalock

DOE Oak Ridge Operations

Office

P.0. Box E

Oak Ridge TN 37830

J. L. Russel 1

Office of Radiation Programs

AW-459, EPA

401 M. St. S.W.

Washington, DCC 20460

R. L. Ferguson

Director, Nuclear Energy Programs

Department of Energy

Washington, DC 20545

T. K. Keenan

University of California

Los Alamos Scientific Laboratory

P.0. Box 1663

Los Alamos, NM 87545

T. A. Butler

University of California

Los Alamos Scientific Laboratory

P.0. Box 1663

Los Alamos, NM 87545
No. of

Copies

\author{
L. Benner \\ National Transportation \\ Safety Board \\ Department of Transportation \\ Washington, DC 20594
}

E. J. Wilson

Department of Transport

Dangerous Goods Branch

2 Marsham St.

London SW 1

ENGLAND

Ichiro Yabe

Nuclear Safety Research

Association

Room 1037, National Press

Building

14th and F St. N.W.

Washington, DC 20004

A. L. Schmeig

National Transporation

Safety Board

Department of Transportation

Washington, DC 20594

P. J. Eicker

Sandia Laboratories, Livermore

Livermore, CA 94550

J. W. Langhaar

E. I. Dupont de Nemours \& Company

Savannah River Plant

Aiken, SC 29801

L. D. Santman

Materials Transportation Bureau

Department of Transportation

2100 Second St. S.W.

Washington, DC 20590

Dr. H. C. Thompson

Battelle Memorial Institute

Washington Operations

20301 M St. N.W.

Washington, DC 20036 
No. of

Copies

W. Rowe

Environmental Protection Agency 401 M St.

Washington, DC 20460

A. J. Nertney

Aerojet Nuclear Company

550 2nd St.

Idaho Fa11s, ID 83401

C. Starr

Electrical Power Research Inst.

P.0. Box 10412

Palo Alto, CA 94304

C. Comar

Electric Power Research Inst.

P.0. 10412

Palo Alto, CA 94304

E. Zebrowski

Electrical Power Research Inst.

P.0. Box 10412

Palo Alto, CA 94304

R. Williams

Electrical Power Research Inst.

P.0. Box 10412

Palo Alto, CA 94304

Prof. Norman C. Rasmussen

Massachusetts Institute of Technology

Cambridge, MA 02139

J. T. Foley

Sandia Laboratories

P.0. Box 5800

Albuquerque, NM 87115

W. F. Hartmann

Sandia Laboratories

P.0. Box 5800

Albuquerque, NM 87115

R. M. Jefferson

Sandia Laboratories

P.0. Box 5800

Albuquerque, NM 87115
No. of

Copies

R. Luna

Sandia Laboratories

P.0. Box 5800

A1buquerque, NM 87115

T. G. Priddy

Sandia Laboratories

P.0. Box 5800

A1buquerque, NM 87115

R. F. Barker

Nuclear Regulatory Commission

Washington, DC 20555

C. B. Bartlett

Nuclear Regulatory Commission

Washington, DC 20555

S. H. Hanauer

Nuclear Regulatory Commission

Washington, DC 20555

S. Levine

Nuclear Regulatory Commission

Washington, DC 20555

R. B. Minogue

Nuclear Regulatory Commission

Washington, DC 20555

C. McDonald

Nuclear Regulatory Commission Washington, DC 20555

W. E. Vesely

Nuclear Regulatory Commission

Washington, DC 20555

I. Wa11

Nuclear Regulatory Commission

Washington, DC 20555

M. J. Steindler

Argonne National Laboratory

9800 South Cass Aveue

Argonne, IL 60439 
No. of

Copies

A. L. Kaplan

General Electric Co.

Nuclear Fuel Division

P.0. Box 780

Wilmington, NC 28401

L. Shappert

Union Carbide Corporation

Oak Ridge National Laboratories

P.0. Box $X$

Oak'Ridge, TN 37830

H. G. Shealy

Bureau of Radiological Health

South Carolina Department of

Health and Environmental Control

Columbia, SC 29405

J. S. Corbett

ChemNuclear Systerıs, Inc.

P.0. Box 1866

Bellevue, WA 98009

J. A. Hebert

Battelle Seattle Research Center

P.0. Box 5395

Seattle, WA 98105

D. Okrent

Department of Engineering and Applied Science

University of California

Los Angeles, CA 90024

J. Walker

California Energy Resources Conservation and Development Commission

1111 Howe Avenue

Sacramento, CA 95825

B. Jost

Mail Stop 18

Cal ifornia Energy Commission

1111 Howe Avenue

Sacramento, CA 95825
No. of

Copies

R. H. Jones

Transportation Systems

Nuclear Energy Programs

Division

General Electric Company

175 Curtner Avenue

San Jose, CA 95125

M. Gordon

Atomic Industrial Forum

7101 Wiscons in Avenue

Washington, DC 20014

A. L. Babb

Department of Nuclear Engineering

Benson Hall

University of Washington

Seattle, WA 98195

W. S. Fellows

Southern Interstate Nuclear Board

One Exchange Place, Suite 1230

Atlanta, GA 30341

S. Hartwig

Battelle Institute, e.v.

Am Romerhof 35

600 Frankfurt Main 90

GERMANY

J. L. Ridihalgh

Ridihalgh, Eggers \& Associates

2112 Iuka Avenue

Columbus, $\mathrm{OH} 43201$

S. C. Cohn

Teknekron

4701 Sangamore Rd.

Washington, DC 20016

K. R. Shuttz

Atomic Energy Control Board

P.0.B. 1046

Ottawa KIP $5 S 9$

CANADA 
No. of

Copies

W. R. Taylor

Atomic Energy of Canada Ltd. Chalk River Laboratories

Chalk River, Ontario KOJIJO

CANADA

H. F. McDonald

CEGB

Berkeley Nuclear Labs

Berkeley

Gloucestershire GL139PB

UNITED KINGDOM

G. D. Bell

United Kingdom Atomic Energy Authority

Safety and Reliability

Directorate

Warrington WA3 4NE

UNITED KINGDOM

M. Tomlinson

White Shell Nuclear Research Establishment

Pinewa, Manitoba ROE ILO

CANADA

S. A. Mayman

Fuel Recycle Waste Management Program

Whiteshell Nuclear Research Establishment

Pinewa, Manitoba ROE ILO CANADA

A. Jansson

Library, Reports Section

Whiteshel1 Nuclear Research Establishment

Pinewa, Manitoba ROE ILO

CANADA

R. W. Peterson

Battelle Memorial Institute

Office of Nuclear Waste Isolation

505 King Avenue

Columbus, $\mathrm{OH} 43201$
No. of

Copies

A. Carson

General Electric Company

175 Curtner Avenue

San Jose, CA 95125

R. A. Koynenburg

University of California

Lawrence Livermore Laboratories

P.0. Box 808

Livermore, CA 94551

R. E. Best

Nuclear Assurance Corporation

24 Executive Park West

Atlanta, GA 30329

M. Pollock

Oregon Department of Energy

Salem, OR 97301

W. M. Rogers

Western Interstate Nuclear

Board

1300 Carr

Denver, CO 80226

G. P. Jones

University of Southern

California

University Park

Los Angeles, CA 90007

E. A. Straker

Science Applications, Inc.

P.0. Box 2351

La Jolla, CA 92038

R. C. Erdman

Science Applications, Inc.

2680 Hanover St.

Palo Alto, CA 94304

N. C. Harris

Imperial Chemical Industries, Ltd.

Mond Division

P.0. Box No. 47 Brunner House

Winnington Northwich

Cheshire CW8 40J

ENGLAND 
No. of

Copies

G. Waymire

Exxon Nuclear Company, Inc.

P.0. Box 3990

MS 8A-68

Seattle, WA 98124

W. R. Rhyne

Science Applications Inc.

P.0. Box 843

Oak Ridge, TN 37830

Hubert Baker

E. I. Dupont de Nemours \& Co.

Savannah River Laboratory

Aiken, SC 29801

C. A. Mayer

Tri-State Motor Transit Co., Inc.

P.0. Box 113

Jopl in, MO 64801

J. Edlow

Edlow International

1100 17th Street N.W.

Washington, DC

W. F. Black

Hazardous Materials Branch

Federal Railroad Administration

Department of Transportation

Washington, DC

Dr. C. Furber

Research and Test Department

Association of American Railroads

1920 L. Street N.W.

Washington, DC 20036

R. R. Rawt

Materials Transportation Bureau

U.S. Department of Transportation

Washington, DC 20545

J. Nal evanko

Materials Transportation Bureau

U.S. Department of Transportation

2100 2nd Street S.W.

Washington, DC 20590
No. of

Copies

C. S. Wexler

Federal Highway Administration

Bureau of Motor Carrier Safety

U.S. Department of Transportation

Washington, DC 20590

A. D. Morris

Morris and Ward Consulting

Engineers

P.0. Box 5937

Washington, DC 20014

C. Cunningham

I11inois Department of Transportation

Division of Traffic Safety

2300 S. Dirksen Pkwy

Springfield, IL 62764

Dr. D. Price

Department of IEOR

Virginia Polytechnic Institute

302 Whittlemore

B1acksburg, VA 24061

C. Halverson

National Tank Truck Carriers

As sociation

1616 P St. N.W.

Washington, DC 20036

W. Johns

American Trucking Association

1616 P St. N.W.

Washington, DC 20036

Dr. R. E. Scott

University of Michigan

Highway Safety Research Institute

Huron Pkwy and Baxter Rd.

Ann Arbor, MI 48105

W. Miller

Transportation Division

American Petroleum Institute

1801 K St. N.W.

Washington, DC 20006 
No. of

Copies

T. B. Mattox

C/O W. Miller

Transportation Division

American Petroleum Institute

1801 K Street N.W.

Washington, DC 20006

J. E. Cunming

C/o W. Miller

Transportation Division

American Petroleum Institute

1801 K St. N.W.

Washington, DC 20006

E. J. Gavin

C/o W. Miller

Transportation Division

American Petroleum Institute

1801 K St. N.W.

Washington, DC 20006

H. B. Uhlig

c/o W. Miller

Transportation Division

American Petroleum Institute

1801 K St. N.W.

Washington, DC 20006

W. J. Myers

C/o W. Miller

Transportation Division

American Petroleum Institute 1801 K St. N.W.

Washington, DC 20006

R. D. Solsrud

C/O W. Miller

Transportation Division

American Petroleum Institute

1801 K St. N.W.

Washington, DC 20006

J. W. Hamilton

c/o W. Miller

Transportation Division

American Petroleum Institute 1801 K St. N.W.

Washington, DC 20006
No. of

Copies

A. J. Moorhead

c/o W. Miller

Transportation Division

American Petroleum Institute

1801 K St. N.W.

Washington, DC 20006

B. J. Webb

C/o W. Miller

Transportation Division

American Petroleum Institute

1801 K St. N.W.

Washington, DC 20006

D. A. Beldon

C/o W. Miller

Transportation Division

American Petroleum Institute

1801 K St. N. W.

Washington, DC 20006

N. Darmstader

American Trucking Association

1616 P St. N.W.

Washington, DC 20036

R. A. Kaye

Director Bureau of Motor

Carrier Safety

Federal Highway Administration

U.S. Department of Transportation

Washington, DC 20590

H. Latham

Oregon Emergency Services

Division

Rm. 43 State Capitol Bldg.

Salem, OR 97310

Mrs. Berit Jansson

Studsvik Energiteknik

ABS-61182

NYKÖPING, SWEDEN

R. Carlson

Group Q-10, Mai1 Stop 264

Los Alamos Scientific Laboratory

Los Alamos, NM 87545 
No. of

Copies

E. F. Edeskuty

Los Alamos Scientific Laboratory MS-764

P.0. Box 1663

Los Alamos, NM 87545

\section{ONSITE}

7. DOE Richland Operations Office

T. A. Bauman

R. B. Goranson

P. E. Lamont

J. M. Peterson

H. E. Ransom

J. J. Schreiber

D. J. Squires

3 Rockwell Hanford Company

W. G. Bevan

W. M. Harty

D. D. Woodrich

3 UNC Nuclear Industries

J. A. Adams

P. A. Crosetti

T. E. Dabrowski

2 Washington Public Power Supply System

G. F. Bailey

J. B. Vetrano

3 Exxon Nuclear Company, Inc.

E. Mays

R. Nilsen

R. K. Robinson

Hanford Engineering Deve lopment Laboratory

A. W. DeMerschman
No. of

Copies

58 Pacific Northwest Laboratory

W. B. Andrews

W. J. Bair

C. L. Brown

J. L. Buelt

N. M. Burleigh (25)

S. H. Bush

J. G. DeSteese

G. W. Dawson

H. K. Elder

A. L. Franklin

J. Friley

C. A. Geffen

R. J. Hall

H. Harty

S. W. Heaberlin

H. L. Henry

T. Horst

W. S. Kelley

S. N. Liu

R. McCann

T. I. McSweeney

J. Mishima

E. S. Murphy

P. L. Peterson

R. E. Rhoads

B. A. Ross

J. W. Voss

E. C. Watson

R. D. Widrig

L. D. Williams

W. K. Winegardner

Technical Information (5)

Publishing Coordination (2)

Ma 